Universidade de São Paulo

Escola Politécnica

Alex Ander Javarotti Zumalde

AVALIAÇÃO COMPARATIVA ENTRE TÉCNICAS DE PROGRAMAÇÃO DEFENSIVA APLICADAS A UM SISTEMA CRÍTICO SIMULADO 
Alex Ander Javarotti Zumalde

Universidade de São Paulo

Escola Politécnica

\section{AVALIAÇÃO COMPARATIVA ENTRE TÉCNICAS DE PROGRAMAÇÃO DEFENSIVA APLICADAS A UM SISTEMA CRÍTICO SIMULADO}

Dissertação apresentada à Escola Politécnica da Universidade de São Paulo como parte dos requisitos para obtenção do grau de Mestre em Engenharia.

Áreas de concentração: Engenharia Elétrica

Orientador Professor Livre-Docente João Batista Camargo Júnior 
Este exemplar foi revisado e alterado em relação à versão original, sob responsabilidade única do autor com anuência de seu orientador.

São Paulo, 30 de junho de 2011.

Assinatura do autor:

Assinatura do orientador:

FICHA CATALOGRÁFICA

Zumalde, Alex Ander Javarotti.

Avaliação comparativa entre técnicas de programação defensiva aplicadas a um sistema crítico simulado / A.A.J. Zumalde. -- ed. rev. -- São Paulo, 2011.

184 p.

Dissertação (Mestrado) - Escola Politécnica da Universidade de São Paulo. Departamento de Engenharia Elétrica. Área de concentração Sistemas Digitais.

1. Segurança de software. 2. Sistemas embutidos. 3. Confiabilidade de software. 4. Erro (Falhas computacionais). 5. Sistemas integrados em larga escala. I. Universidade de São Paulo. Departamento de Engenharia Elétrica. II. T. 


\section{DEDICATÓRIA}

A minha mãe, irmão e esposa cuja compreensão e apoio proporcionaram o pleno desenvolvimento do trabalho que dedico, nesse momento, a eles.

Ao meu pai que sempre será para mim um motivo de inspiração e admiração. 


\section{AGRADECIMENTOS}

Ao Prof. Dr. João Batista Camargo Junior, meu orientador, pela atenção, apoio e compreensão, principlamente nos momentos de maior dificuldade.

A Fausto Almeida pelo apoio incondicional expresso desde os primeiros dias que iniciei essa jornada.

A Jorge Secall pelo apoio e atenção dedicados.

Aos colegas do GAS (Grupo de Análise de Segurança) pela atenção e pelas valiosas idéias compartilhadas durante toda a nossa convivência. 


\section{RESUMO}

A introdução de software em sistemas de aplicações críticas traz consigo questões relacionadas à segurança (safety) que, durante muito tempo recaíram predominantemente sobre o desenvolvimento do hardware que compunha tais sistemas. Atualmente, padrões relacionados à segurança de software avaliam qualitativamente o impacto do seu uso sobre sistemas suscetíveis a falhas de natureza randômica. A pesquisa aqui desenvolvida visa, em complemento a outras investigações já realizadas, avaliar quantitativamente diversas técnicas de programação defensiva em função de sua representatividade no quesito segurança de sistemas de aplicação crítica tolerantes a erros.

Como objetivo essencial, buscou-se avaliar o comportamento adquirido por um sistema tolerante a erros quando submetido a um processo de injeção de falhas por software. A tolerância a erros do sistema de aplicação crítica em estudo é alcançada, através de técnicas de programação defensiva aplicadas ao software original. Foram aplicadas diversas técnicas de programação defensiva e diversas combinações entre elas, de modo que foi possível avaliar quantitativamente e identificar possíveis padrões de níveis de segurança adquiridos em cada caso.

Palavras-chave: 1. Segurança de software. 2. Sistemas embutidos. 3. Confiabilidade de software. 4. Erro (Falhas computacionais). 5. Sistemas integrados em larga escala 


\begin{abstract}
The introduction of software systems for critical applications raises safety issues that have long fell predominantly on the development of the hardware composing such systems. Currently, standards related to safety software qualitatively assess the impact of their use on systems sensitive to random errors. The research developed here seeks, in addition to other previous investigations, to quantitatively evaluate different techniques of defensive programming in function of their safety level in fault-tolerant safety critical systems.

As a key objective, we sought to evaluate the behavior acquired by a faulttolerant system when subjected to a software fault injection process. The faulttolerance system, in a typical critical application under study, is achieved through the application of defensive programming techniques over the original software. Many defensive programming techniques and various combinations among them were applied, hence making it possible to quantitatively assess and identify possible patterns of safety levels acquired in each case.
\end{abstract}

Keywords: 1. Software safety. 2. Embedded systems. 3. Software reliability. 4. Error (Commputer failures). 5. Large-scale integrated systems 


\section{LISTA DE ILUSTRAÇÕES}

Figura 1 - Período de vida de uma variável: "Vulnerabilidade" .............................................................. 23

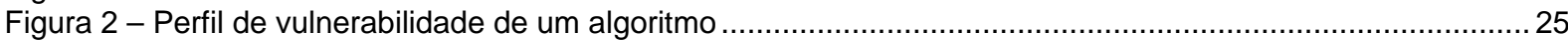

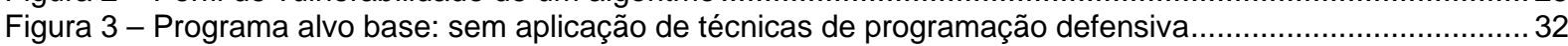

Figura 4 - Perfil de vulnerabilidade do programa alvo ............................................................................ 34

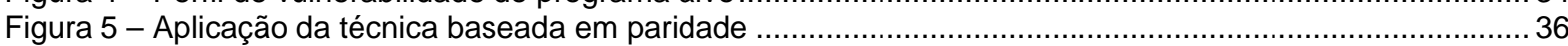

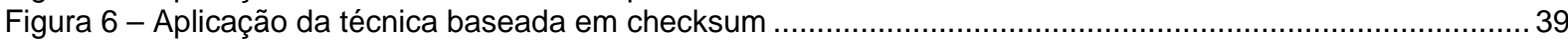

Figura 7 - Aplicação da técnicas baseada em BCH ............................................................................... 41

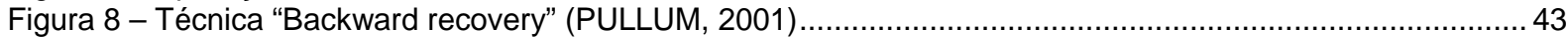

Figura 9 - Aplicação da técnica baseada em backward recovery ............................................................4

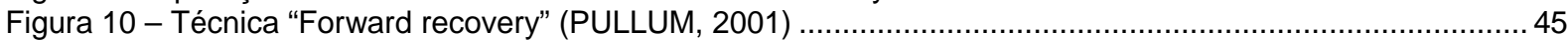

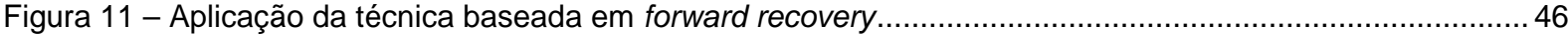

Figura 12 - Aplicação da técnica baseada em duplicação de variáveis ..................................................... 48

Figura 13 - Aplicação da técnica baseada em diversidade ....................................................................49

Figura 14 - Aplicação das técnicas backward recovery e checksum combinadas ..........................................5 53

Figura 15 - Aplicação das técnicas backward recovery e diversidade combinadas ..........................................54

Figura 16 - Aplicação das técnicas backward recovery e paridade combinadas ...........................................55

Figura 17 - Aplicação das técnicas duplicação de variáveis e backward recovery combinadas ..........................56

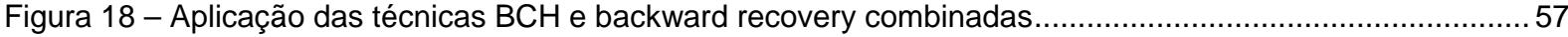

Figura 19 - Aplicação das técnicas BCH e Checksum combinadas ......................................................... 59

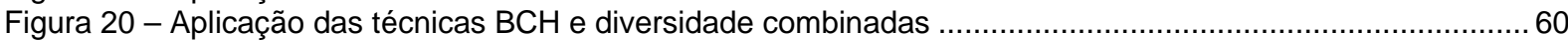

Figura 21 - Aplicação das técnicas BCH e forward recovery combinadas .................................................61

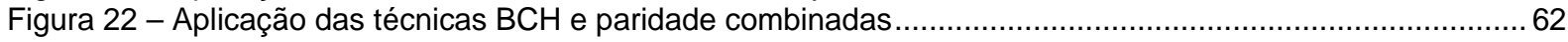

Figura 23 - Aplicação das técnicas de variáveis duplicadas e $\mathrm{BCH}$ combinadas...........................................63

Figura 24 - Aplicação das técnicas de checksum e diversidade combinadas ..............................................6. 64

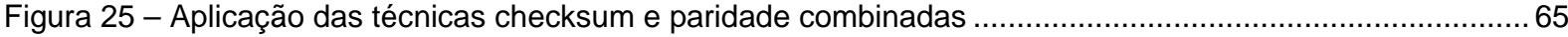

Figura 26 - Aplicação das técnicas de duplicação de variáveis e checksum combinadas .....................................66

Figura 27 - Aplicação das técnicas de duplicação de variáveis e diversidade combinadas ..............................67

Figura 28 - Aplicação das técnicas forward recovery e backward recovery combinadas.................................69

Figura 29 - Aplicação das técnicas de paridade e diversidade combinadas ................................................ 70

Figura 30 - Aplicação das técnicas de duplicação de variáveis e paridade combinadas ................................... 71

Figura 31 - Injeção de erros entre camadas .................................................................................. 81

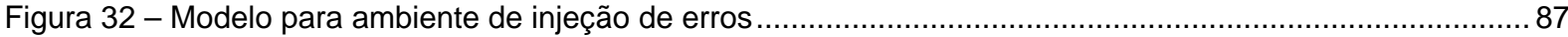

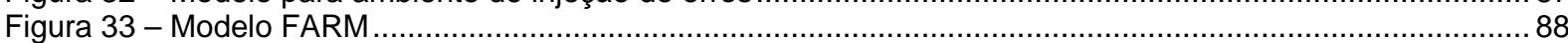

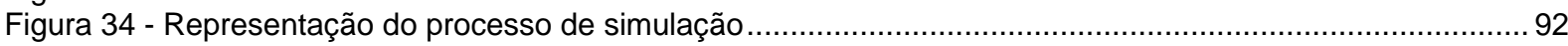

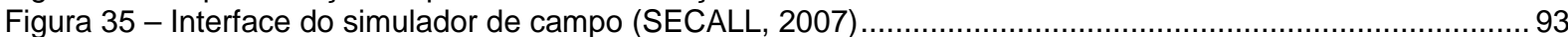

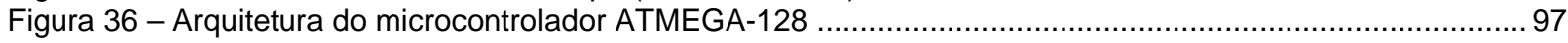

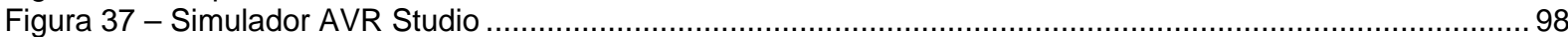

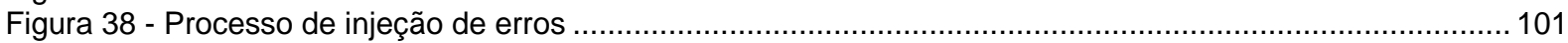

Figura 39 - Distribuição típica obtida através de simulação.................................................................. 106

Figura 40 - Média de tempos para falha insegura e parâmetros Weibull ...................................................... 110

Figura 41 - Tempo de processamento dedicado a técnica e ao programa ............................................... 112

Figura 42 - Taxas de falhas inseguras (Técnicas BCH e duplicação de variáveis) ....................................... 115

Figura 43 - Taxa de falhas inseguras (Técnicas BCH e paridade) ....................................................... 116

Figura 44 - Taxa de falhas inseguras (Técnicas BCH e Cheksum) .......................................................... 117

Figura 45 - Taxa de falhas inseguras (Técnicas duplicação de variáveis e paridade) ................................... 118

Figura 46 - Taxa de falhas inseguras (Técnicas diversidade e $\mathrm{BCH}$ ) ...................................................... 119

Figura 47 - Taxa de falhas inseguras (Técnicas Checksum e duplicação de variáveis) ..................................120

Figura 48 - Taxa de falhas inseguras (Técnicas duplicação de variáveis e diversidade)..................................121

Figura 49 - Taxa de falhas inseguras (Técnicas diversidade e paridade) ..................................................... 122

Figura 50 - Taxa de falhas inseguras (Técnicas diversidade e checksum) ............................................... 123

Figura 51 - Taxa de falhas inseguras (Técnicas backward recovery e forward recovery) ...............................124

Figura 52- Taxa de falhas inseguras (Técnicas checksum e paridade) ....................................................... 126

Figura 53 - Comparação entre resultados obtidos através injeção de falhas por software e por radio frequência

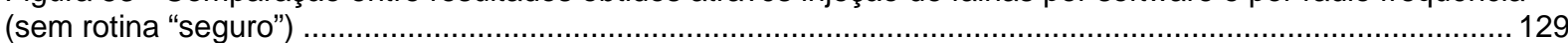

Figura 54 - Comparação entre resultados obtidos através injeção de falhas por software e por radio frequência (aplicação de rotina "seguro") ........................................................................................................... 130

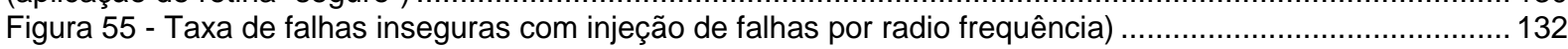

Figura 56 - Padrão "A" para taxa de falhas inseguras identificado em combinações de técnicas de programação

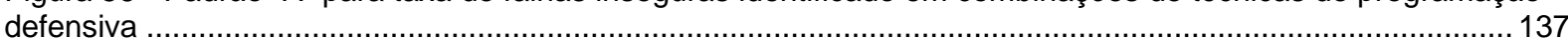

Figura 57 - Padrão "B" para taxa de falhas inseguras identificado em combinações de técnicas de programação

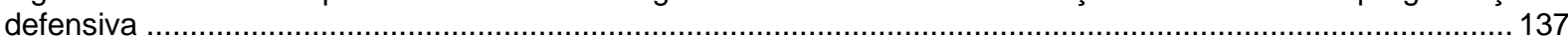

Figura 58 - Função de densidade de probabilidade para falhas inseguras: técnica de programação defensiva backward

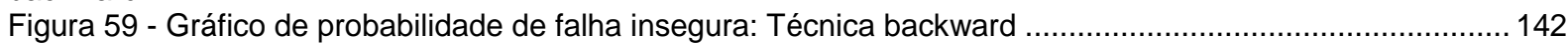


Figura 60 - Função de densidade de probabilidade para falhas inseguras: técnica de programação defensiva

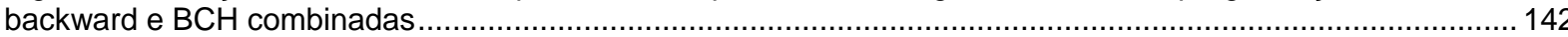

Figura 61 - Gráfico de probabilidade de falha insegura: Técnica backward e BCH combinadas...................... 143 Figura 62 - Função de densidade de probabilidade para falhas inseguras: técnica de programação defensiva backward e forward combinadas ......................................................................................................... 143

Figura 63 - Gráfico de probabilidade de falha insegura: Técnica backward e forward combinadas .................. 144 Figura 64 - Função de densidade de probabilidade para falhas inseguras: técnica de programação defensiva $\mathrm{BCH}$

Figura 65 - Gráfico de probabilidade de falha insegura: Técnica $\mathrm{BCH}$

Figura 66 - Função de densidade de probabilidade para falhas inseguras: técnica de programação................. Checksum

Figura 67 - Gráfico de probabilidade de falha insegura: Técnica Checksum ............................................ 146

Figura 68 - Função de densidade de probabilidade para falhas inseguras: técnica de programação defensiva checksum e backward combinadas ........................................................................................ 146

Figura 69 - Gráfico de probabilidade de falha insegura: Técnica checksum e backward combinadas ............... 147 Figura 70 - Função de densidade de probabilidade para falhas inseguras: técnica de programação defensiva checksum e BCH combinadas....

Figura 71 - Gráfico de probabilidade de falha insegura: Técnica checkusm e BCH combinadas

Figura 72 - Função de densidade de probabilidade para falhas inseguras: técnica de programação defensiva checksum e forward combinadas.

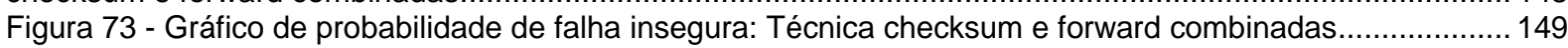

Figura 74 - Função de densidade de probabilidade para falhas inseguras: técnica de programação defensiva diversidade

Figura 75 - Gráfico de probabilidade de falha insegura: Técnica diversidade .............................................. 150 Figura 76 - Função de densidade de probabilidade para falhas inseguras: técnica de programação defensiva

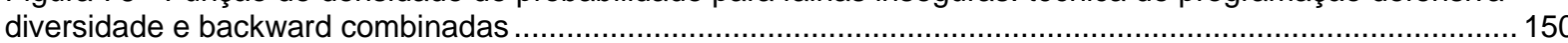

Figura 77 - Gráfico de probabilidade de falha insegura: Técnica diversidade e backward combinadas ............. 151 Figura 78 - Função de densidade de probabilidade para falhas inseguras: técnica de programação defensiva diversidade e $\mathrm{BCH}$ combinadas

Figura 79 - Gráfico de probabilidade de falha insegura: Técnica diversidade e BCH combinadas

Figura 80 - Função de densidade de probabilidade para falhas inseguras: técnica de programação defensiva diversidade e checksum combinadas

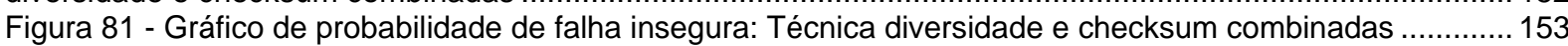

Figura 82 - Função de densidade de probabilidade para falhas inseguras: técnica de programação defensiva

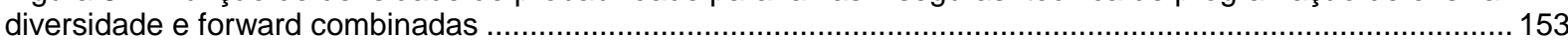

Figura 83 - Gráfico de probabilidade de falha insegura: Técnica diversidade e forward combinadas ................ 154 Figura 84 - Função de densidade de probabilidade para falhas inseguras: técnica de programação defensiva duplicação de variáveis

Figura 85 - Gráfico de probabilidade de falha insegura: Técnica duplicação de variáveis.....

Figura 86 - Função de densidade de probabilidade para falhas inseguras: técnica de programação defensiva duplicação de variáveis e backward combinadas....

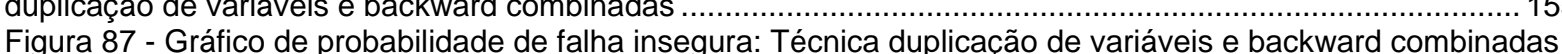

Figura 88 - Função de densidade de probabilidade para falhas inseguras: técnica de programação defensiva duplicação de variáveis e BCH combinadas ............................................................................................ 156 Figura 89 - Gráfico de probabilidade de falha insegura: Técnica duplicação de variáveis e BCH combinadas... 157 Figura 90 - Função de densidade de probabilidade para falhas inseguras: técnica de programação defensiva duplicação de variáveis e checksum combinadas Figura 91 - Gráfico de probabilidade de falha insegura: Técnica duplicação de variáveis e checksum combinadas

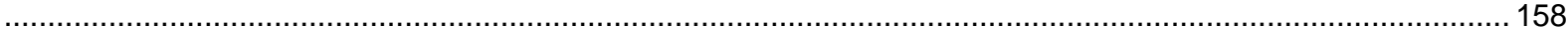
Figura 92 - Função de densidade de probabilidade para falhas inseguras: técnica de programação defensiva duplicação de variáveis e diversidade combinadas ................................................................................. 158 Figura 93 - Gráfico de probabilidade de falha insegura: Técnica duplicação de variáveis e diversidade combinadas

Figura 94 - Função de densidade de probabilidade para falhas inseguras: técnica de programação defensiva duplicação de variáveis e forward combinadas................................................................................ 159 Figura 95 - Gráfico de probabilidade de falha insegura: Técnica duplicação de variáveis e forward combinadas

Figura 96 - Função de densidade de probabilidade para falhas inseguras: técnica de programação defensiva duplicação de variáveis e paridade combinadas...................................................................................... 160 Figura 97 - Gráfico de probabilidade de falha insegura: Técnica duplicação de variáveis e paridade combinadas

Figura 98 - Função de densidade de probabilidade para falhas inseguras: técnica de programação defensiva forward

Figura 99 - Gráfico de probabilidade de falha insegura: Técnica forward 
Figura 101 - Gráfico de probabilidade de falha insegura: Técnica forward e BCH combinadas

Figura 102 - Função de densidade de probabilidade para falhas inseguras: técnica de programação defensiva paridade

Figura 103 - Gráfico de probabilidade de falha insegura: Técnica paridade.

Figura 104 - Função de densidade de probabilidade para falhas inseguras: técnica de programação defensiva paridade e backward combinadas

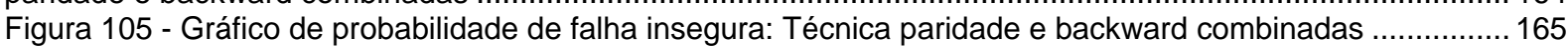

Figura 106 - Função de densidade de probabilidade para falhas inseguras: técnica de programação defensiva paridade e $\mathrm{BCH}$ combinadas

Figura 107 - Gráfico de probabilidade de falha insegura: Técnica paridade e BCH combinadas ....................... 166 Figura 108 - Função de densidade de probabilidade para falhas inseguras: técnica de programação defensiva paridade e checksum combinadas.....

Figura 109 - Gráfico de probabilidade de falha insegura: Técnica paridade e checksum combinadas.....

Figura 110 - Função de densidade de probabilidade para falhas inseguras: técnica de programação defensiva paridade e diversidade combinadas

Figura 111 - Gráfico de probabilidade de falha insegura: Técnica paridade e diversidade combinadas ............. 168 Figura 112 - Função de densidade de probabilidade para falhas inseguras: técnica de programação defensiva paridade e forward combinadas.

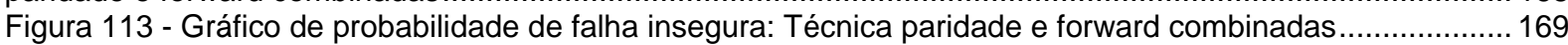
Figura 114 - Função de densidade de probabilidade para falhas inseguras : programa alvo (ausência de técnicas de programação defensiva)

Figura 115 - Gráfico de probabilidade de falha insegura: programa alvo (ausência de técnicas de programação defensiva)

Figura 116 - Aplicação das técnicas forward recovery e paridade combinadas............................................ 171

Figura 117 - Aplicação das técnicas forward recovery e duplicação de variáveis combinadas ...........................172

Figura 118 - Aplicação das técnicas forward recovery e diversidade combinadas .............................................172

Figura 119 - Aplicação das técnicas forward recovery e checksum combinadas .........................................173 


\section{LISTA DE TABELAS}

Tabela 1 - Classificação de métodos de injeção de erros: Hardware e Software ........................................... 85

Tabela 2 - Média de tempos para falha insegura e parâmetros Weibull .................................................... 109

Tabela 3 - Seleção de combinações para análise .................................................................................. 114

Tabela 4 - Valores de tempo para falha insegura do programa alvo e das técnicas de programação defensiva: paridade, checksum e diversidade.

Tabela 5 - Valores de tempo para falha insegura das técnicas de programação defensiva: duplicação de variáveis, backward e forward, checksum e backward, diversidade e backward.

Tabela 6 - Valores de tempo para falha insegura das técnicas de programação defensiva: diversidade e checksum, paridade e backward, paridade e checksum, paridade e diversidade

Tabela 7 - Valores de tempo para falha insegura das técnicas de programação defensiva: duplicação de variáveis e backward, duplicação de variáveis e checksum, duplicação de variáveis e diversidade, duplicação de variáveis e paridade

Tabela 8 - Valores de tempo para falha insegura das técnicas de programação defensiva: backward e $\mathrm{BCH}$, checksum e $\mathrm{BCH}$, diversidade e $\mathrm{BCH}$, forward e $\mathrm{BCH}$

Tabela 9 - Valores de tempo para falha insegura das técnicas de programação defensiva: paridade e $\mathrm{BCH}$, duplicação e $\mathrm{BCH}$, backward, $\mathrm{BCH}$

Tabela 10 - Valores de tempo para falha insegura das técnicas de programação defensiva: checksum e forward, diversidade e forward, forward, paridade e forward, duplicação de variáveis e forward 


\section{LISTA DE ABREVIATURAS E SIGLAS}

LAAS-CNRS Laboratoire d'Analyse et d'Architecture des Systèmes - Centre National de la Recherche Scientifique (França)

(Laboratório de Análise e Arquitetura de Sistemas - Centro Nacional de Pesquisa Científica - França)

TMR Triple Modular Redundancy

(Redundância Modular Tripla)

SEE Single Event Effect

(Efeito de Evento Único)

SEU Single Event Upset

(Pertubação de Evento Único)

REE Remote Exploration and Experimentation

(Exploração e Experimentação Remota)

VHDL VHSIC - Hardware Description Language

(VHSIC - Linguagem Descritiva de Hardware)

VHSIC Very High Speedy Integrated Circuits

(Circuitos Integrados de Altíssima Velocidade)

EDA Electronic Device Automation

(Automação de Dispositivo Eletrônico)

PLD $\quad$ Programmable Logical Devices

(Dispositivos Lógicos Programáveis)

VLSI Very Large Scale Intregation

(Integração em Alta Escala)

EDAC Error Detection and Correction

(Correção e Detecção de Erro)

SEC-DEC Single-Error-Correcting and Double-Error-Detection Code (Código de Correção Simples de Erro e Detecção Dupla de Erro) 


\section{SUMÁRIO}

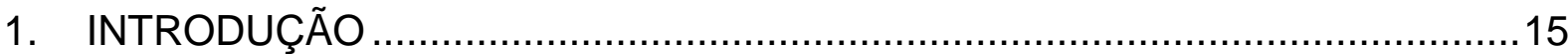

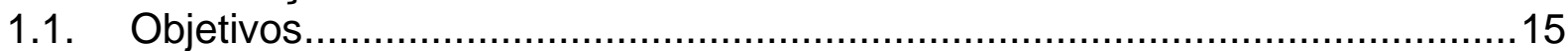

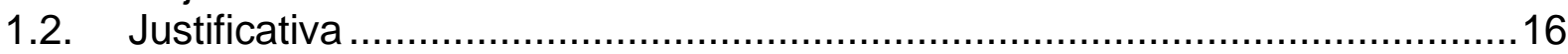

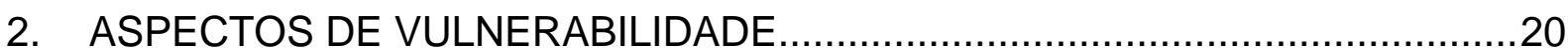

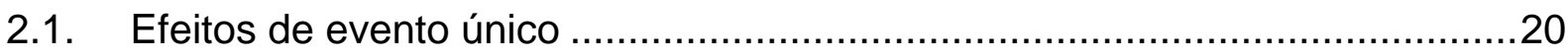

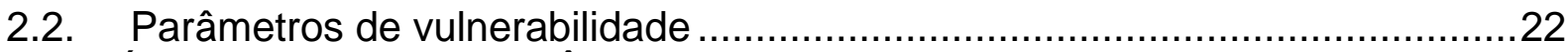

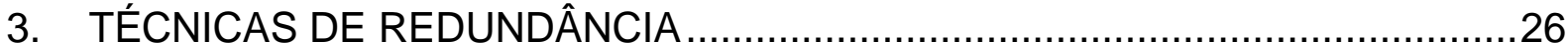

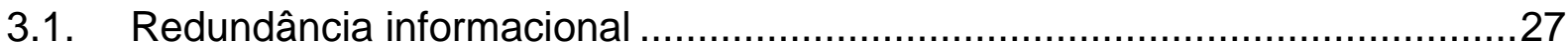

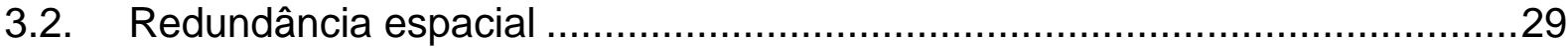

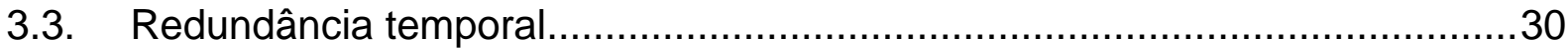

3.4. Técnicas de programação defensiva ................................................ 31

4. APLICAÇÃO DAS TÉCNICAS DE PROGRAMAÇÃO DEFENSIVA .................32

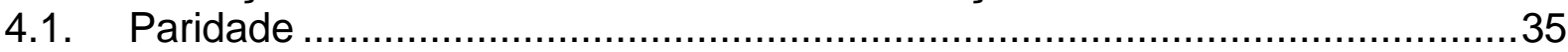

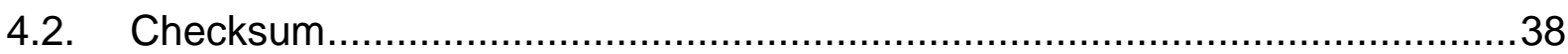

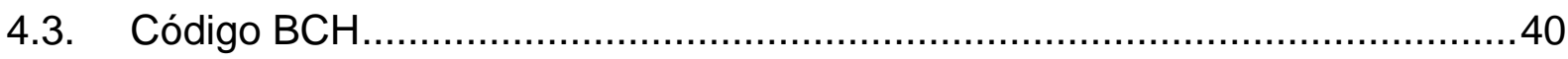

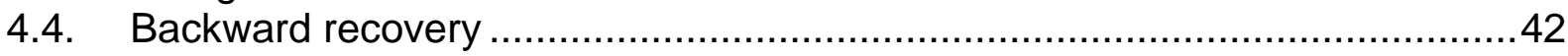

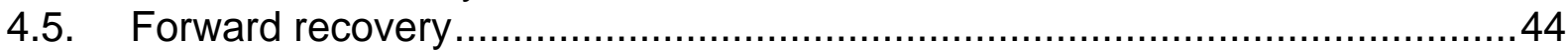

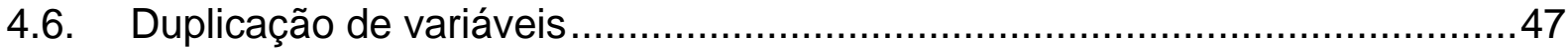

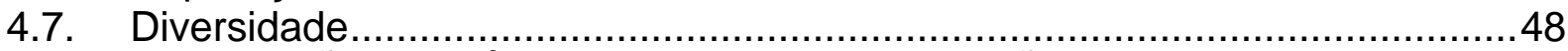

5. COMBINAÇÃO DE TÉCNICAS DE PROGRAMAÇÃO DEFENSIVA ................51

5.1. Combinação da técnica forward recovery e demais técnicas .......................52

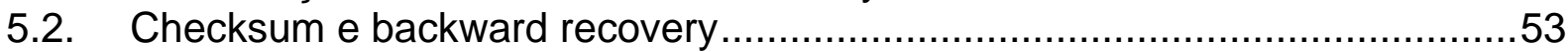

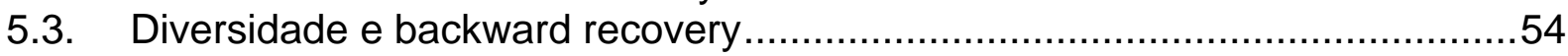

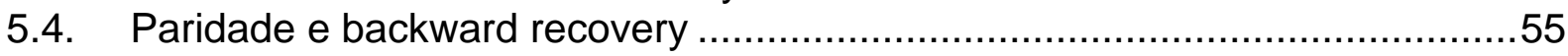

5.5. Duplicação de variáveis e backward recovery ......................................56

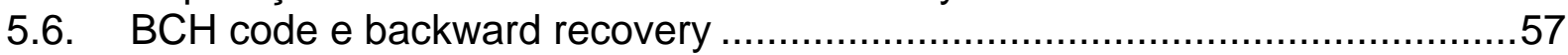

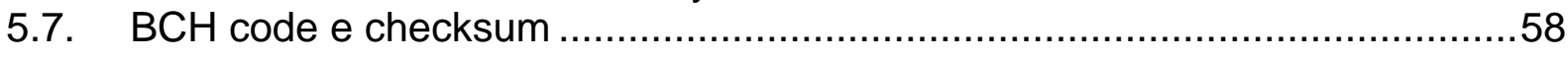

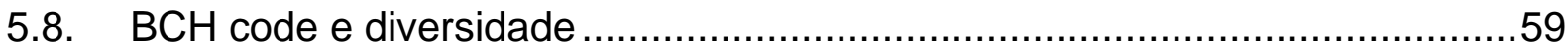

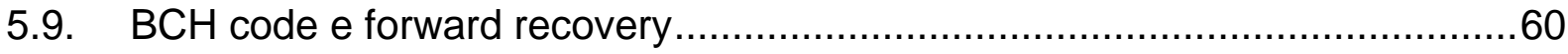

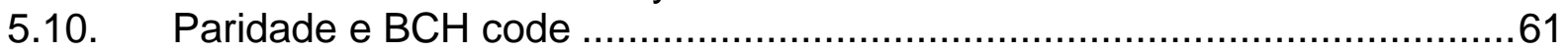

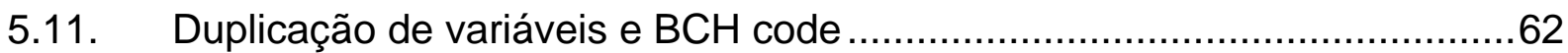

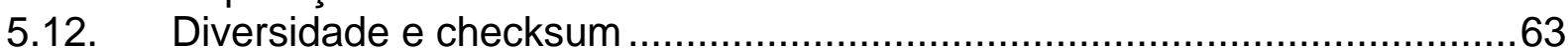

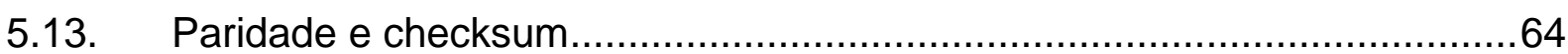

5.14. Duplicação de variáveis e checksum ...............................................65

5.15. Diversidade e duplicação de variáveis ............................................67

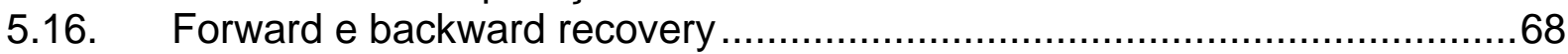

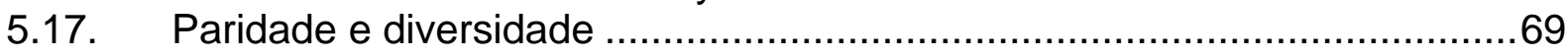

5.18. Duplicação de variáveis e paridade ....................................................... 70

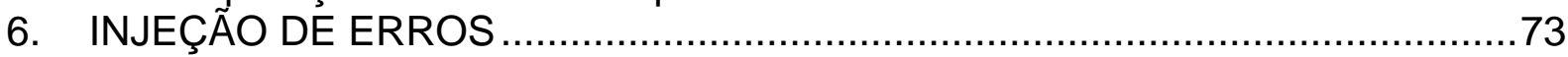

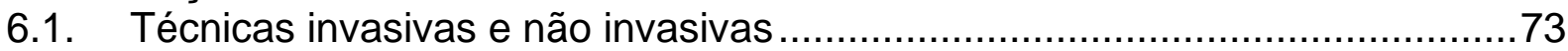

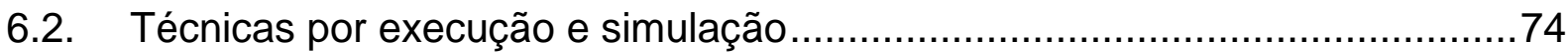

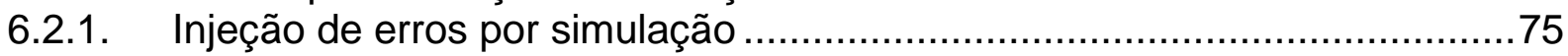

6.3. Técnicas aplicadas por hardware e por software ................................. 77

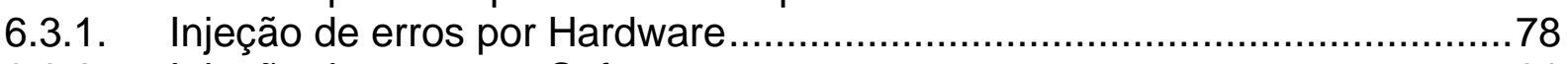

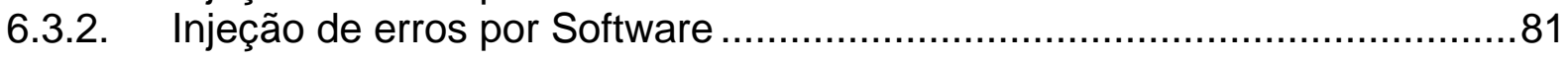

6.4. Modelo para ambiente de injeção de erros........................................... 86

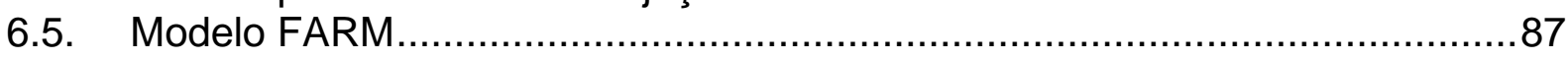

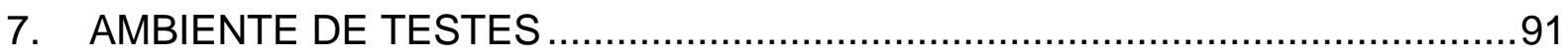




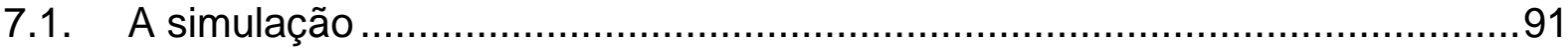

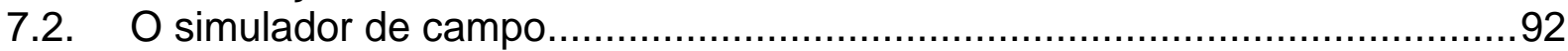

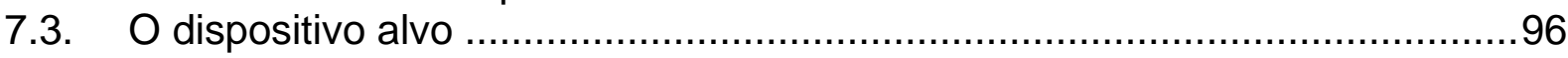

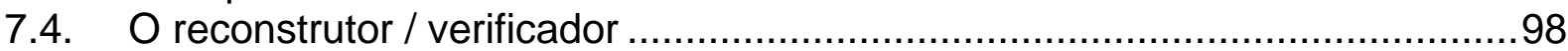

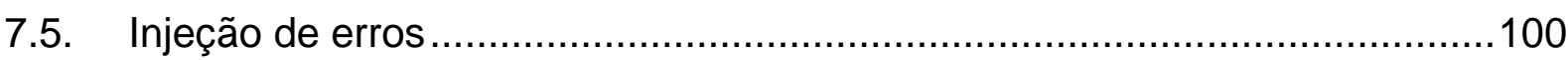

7.6. Considerações quanto à injeção de erros ………..................................101

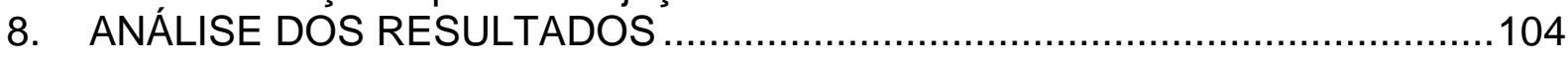

8.1. A distribuição de Weibull ................................................................107

8.2. Tempo de processamento dedicado …………..................................111

8.3. Análise de combinações entre técnicas de programação defensiva .............113

8.4. Comparação de resultados para métodos de injeção de falhas distintos .....126

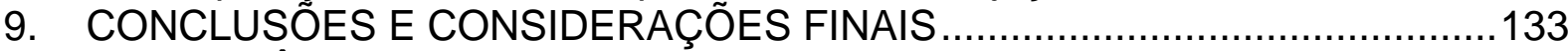

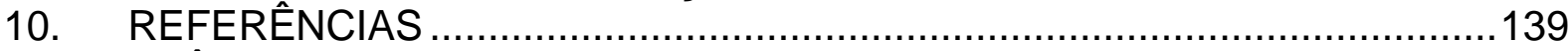

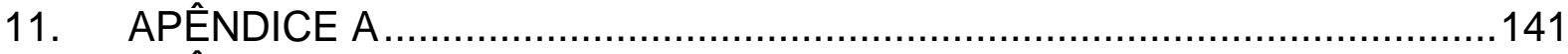

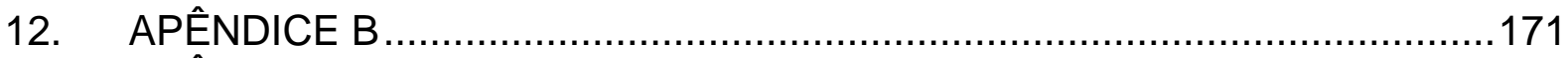

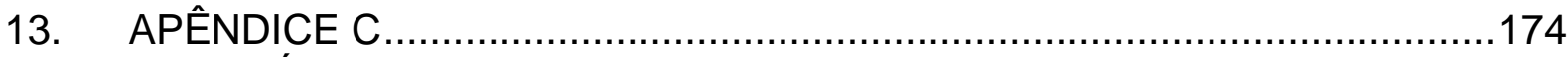

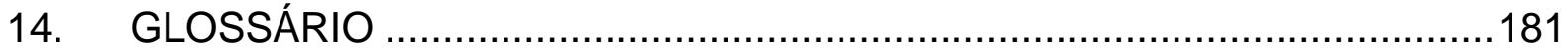




\section{INTRODUÇÃO}

Sistemas microprocessados assumiram nos últimos anos um papel relevante em aplicações que exigem altos níveis de dependabilidade, em especial nas áreas de aviação, espacial e ferroviária. A possibilidade de ocorrência de falhas nesses sistemas tem importância vital, sobretudo caso o ambiente em que o sistema é inserido, deixa de ser controlado e passa a ser palco de fenômenos físicos agressivos, tais como descargas elétricas de alta potência.

Somando esse aspecto ao surgimento de efeitos parasitas internos (e.g. diafonia induzida) como conseqüência do contínuo desenvolvimento de circuitos integrados de densidades e velocidades de operação crescentes, é possível identificar uma vasta variedade de falhas. Dessa forma, o software pode vir a assumir parte do papel antes desempenhado quase que exclusivamente pelo hardware com objetivo de diminuir riscos inerentes à construção de sistemas de alta dependabilidade.

Com esse propósito, técnicas de programação defensiva podem ser aplicadas a sistemas dessa natureza. Porém, elaborar critérios que levem a escolha de uma determinada técnica em função do tipo de sistema e sua aplicação, ainda é objeto de inúmeras pesquisas, tais como em (SECALL, 2007).

\subsection{Objetivos}

A proposta desta dissertação é avaliar comparativamente diversas técnicas de programação defensiva quando submetidas a um processo de injeção de erros por software. Tal avaliação se concentra em aspectos associados à segurança 
(safety) de um sistema crítico simulado após a aplicação isolada e combinada destas técnicas.

Para alcançar tal objetivo emprega-se, dentre diversos elementos, um conjunto de técnicas de programação defensiva e, com base nos registros produzidos pela simulação, são elaboradas análises que identificam maior ou menor eficácia, com relação à segurança, de uma técnica em relação às demais, com foco no aspecto de segurança.

A aplicação das técnicas de programação defensiva foi fortemente orientada no sentido de permitir a combinação entre elas. Isso se deve ao fato de que as técnicas exploradas nesse trabalho podem ser aplicadas de forma complementar parte das técnicas tem a função de detectar erros e outras a função de detectar e/ou corrigi-los.

Com base nos resultados das simulações e a produção dos resultados, pôdese desenvolver análises que possibilitaram a identificação de similaridades e padrões capazes de evidenciar uma ou mais técnicas em relação às demais, quanto à eficácia no aspecto de segurança.

\subsection{Justificativa}

O trabalho desenvolvido em (SECALL, 2007) coloca em evidência a importância de, nas palavras do próprio autor, "se desenvolver um método capaz de avaliar quantitativamente o impacto de técnicas de programação defensiva na segurança dos sistemas de aplicação crítica quando expostos a falhas aleatórias". Os resultados obtidos a partir desse trabalho demonstram não só a validade do método, como a criação de uma plataforma que abre espaço para a investigação 
experimental de diversos aspectos relacionados ao estudo da segurança em sistemas de aplicação crítica.

Dentro do contexto desta pesquisa, serão usados alguns termos comuns da área de dependabilidade. Entende-se por dependabilidade como a habilidade para evitar falhas que são mais frequentes e severas do que um nível aceitável (AVIZIENIS, 2004). Neste sentido, os desvios das funcionalidades internas ao sistema sendo avaliado serão tratados como "erro", enquanto que a exteriorização destes desvios para o universo externo será tratado como "falha".

O desenvolvimento desta pesquisa permitiu, até o presente momento, avaliar o atual estado da arte tanto sobre técnicas de injeção de erros como técnicas que produzam, em vários níveis, tolerância a erros. Um aspecto que se tornou visível durante a pesquisa, trata em diversos casos, da difícil tarefa de equilibrar os benefícios alcançados e os efeitos colaterais produzidos. Em diversos casos, a aplicação de técnicas baseadas em software produz um aumento real da segurança, mas traz consigo efeitos não desejáveis tais como a redução do desempenho e aumento da quantidade de memória necessária. Em outros casos, onde são aplicadas técnicas baseadas em hardware, como o uso de TMR - Triple Modular Redundancy - em células de memória, pode-se observar de forma similar um aumento no tamanho do circuito integrado que compõe a memória e uma degradação do desempenho.

Esses custos adicionais podem ter um forte impacto em sistemas embarcados, por exemplo, onde tamanho e consumo de energia são limitados. Além disso, deve-se considerar o impacto sobre o próprio ganho de confiabilidade e segurança atingidos, uma vez que tais soluções trazem consigo o aumento da complexidade, o aumento da quantidade de dados, que passam a ser vulneráveis a 
perturbações de eventos únicos e o acréscimo no tempo de processamento dedicado aos processos de tolerância a erros.

O conflito de benefícios gerados em função desses aspectos leva a um ponto onde a escolha pela técnica de programação defensiva, ou a combinação de técnicas que produzam certo grau de tolerância a erros em um sistema de aplicação crítica, é de vital importância para sua a concepção e dependabilidade pretendida.

Nos capítulos seguintes são abordados os conceitos que permitem fundamentar os objetivos e justificativas do estudo aqui apresentado. Em um primeiro momento são explorados os conceitos de vulnerabilidade - capítulo 2 - e redundância - capítulo 3. O termo vulnerabilidade trata, neste estudo, da susceptibilidade atribuída a dispositivos programáveis, segundo os efeitos que produzem erro nos resultados por eles produzidos. Já o termo redundância, não só representa o conceito base que permite a tais dispositivos, adquirir a característica de tolerância a erros, como também produzir as técnicas de programação defensiva exploradas neste estudo.

No capítulo 4 é descrita a aplicação de cada uma das técnicas de programação defensiva, assim como combinações entre elas, sobre o sistema de aplicação crítica usado por este estudo. Neste capítulo, também são descritos diversos casos de estudo que exploram a influência de uma determinada técnica de programação defensiva, sobre um sistema em particular.

Como parte essencial de estudos que visam avaliar diversos aspectos relacionados à dependabilidade de sistemas de aplicação crítica, são descritas, no capítulo 5, diferentes técnicas usadas no processo de injeção de erros sobre tais sistemas. 
E por fim, o capítulo 6 descreve em detalhes o ambiente de testes desenvolvido com a finalidade de trazer ao campo experimental por simulação, todos os aspectos abordados nos capítulos anteriores e dessa forma permitir a análise dos resultados sob a ótica da segurança de sistemas - capítulo 7. 


\section{ASPECTOS DE VULNERABILIDADE}

O capítulo a seguir descreve a interferência dos efeitos de evento único (SEE - Single Event Effect) sobre o funcionamento de dispositivos eletrônicos. Em seguida, são descritos alguns aspectos relacionados à vulnerabilidade de programas embarcados em dispositivos susceptíveis a tais eventos.

\subsection{Efeitos de evento único}

Um dos efeitos que recebe especial atenção de pesquisadores e projetistas de sistemas tolerantes a erros é o Efeito de Evento Único SEE (Single Event Efect).

Os efeitos de evento único podem ser caracterizados pela perturbação produzida sobre um microcircuito, que podem produzir danos irreversíveis ou apenas perturbações sobre sua funcionalidade. Perturbações de evento único conhecidas como SEU (Single Event Upset) são alvo de pesquisas voltadas à operação confiável de aeronaves e especialmente espaçonaves, em função da existência de fenômenos - e.g. radiações eletromagnéticas - que podem ser encontrados com significativa intensidade em regiões acima da atmosfera terrestre.

O SEU que ocorre na superfície terrestre pode ter como causa a incidência de raios cósmicos que, em choque com átomos da atmosfera, produzem a emissão de prótons e nêutrons que interagem com circuitos eletrônicos.

Em um primeiro momento, a análise da vulnerabilidade de um software pode conter uma importante parcela de aleatoriedade, e de fato o contém. Porém, alguns estudos têm sido desenvolvidos com o objetivo de se criar análises que destacam 
algumas das características e aspectos de algoritmos suscetíveis a essa natureza de fenômeno.

Dentre as pesquisas voltadas para esse tipo de fenômeno destaca-se a análise de (SPRINGER, 2001) que se baseia em um experimento desenvolvido por meio do projeto REE (Remote Exploration and Experimentation). O projeto REE, da NASA, propôs o embarque de um supercomputador em uma espaçonave para favorecer análises a bordo de dados originados em instrumentos de altíssima taxa de aquisição de dados, tais como radares de abertura sintética, que monitoram clima, oceanos, florestas, perda de ozônio e aquecimento global.

Segundo o modelo de confiabilidade do projeto REE, descrito por (DUNPHY; ROGSTAD, 2001) a maioria das falhas previstas em ambientes, tais como no espaço, se deve a presença de rajadas de radiação transitória que causam SEU. A maioria desses eventos não provoca erros de memória em função dos mecanismos de proteção existentes. Porém, não se pode deixar de lado que algumas memórias cache e os próprios registradores não possuem esse tipo de proteção e podem levar a conseqüências difíceis de prever. Dentre as possibilidades destacam-se:

- A parada completa da aplicação

- A aplicação terminará com um resultado falho

- A aplicação terminará com um resultado correto, porém em um tempo maior. Um dos aspectos que pode auxiliar na identificação de características de um algoritmo que influenciam em sua suscetibilidade a efeitos de evento único baseiase no estudo da vulnerabilidade (HWANG; CHOI, 2000). 


\subsection{Parâmetros de vulnerabilidade}

Uma das formas de se tentar tornar mais claro o quanto um programa é vulnerável a um SEU pode ser encontrado em (SPRINGER, 2001). Segundo alguns estudos desenvolvidos nesse sentido, quando um programa é submetido de forma randômica, aos bit-flips, simulando assim os efeitos de um SEU, grande parte deles pode não resultar em erro. Dentre as diversas explicações, (BENSO; REBAUDENGO; IMPAGLIAZZO; MARMO, 1998) definem o termo "período de vida" de uma variável, como sendo a medida pela qual se pode chegar a um valor de vulnerabilidade de um programa e assim, propiciar a comparação entre diversos algoritmos quanto à vulnerabilidade e ainda, promover análise sobre a composição do algoritmo de forma a mitigar os efeitos de um SEU.

Para a explanação a seguir, será considerado um ambiente no qual o nível de radiação é relativamente constante. Assim, a frequência com que os SEU's afetariam o programa é proporcional ao montante de memória RAM empregada. Para quantificar a vulnerabilidade do algoritmo serão usados bytes-segundos.

Segundo (SPRINGER, 2001), existem diversas razões para esse efeito. Quando olhamos para alterações dos dados armazenados na memória RAM, podemos destacar três situações:

- O erro ocorre em uma região da memória que nunca é acessada.

- O local de armazenamento que sofreu um bit-flip pode ter sido usado apenas em um instante anterior à ocorrência do erro.

- O local que sofreu o bit-flip pode ter sido corrigido após ter recebido nova informação. 
A idéia de "período de vida de uma variável" pode ser melhor compreendida a partir do exemplo a seguir (Figura 1).

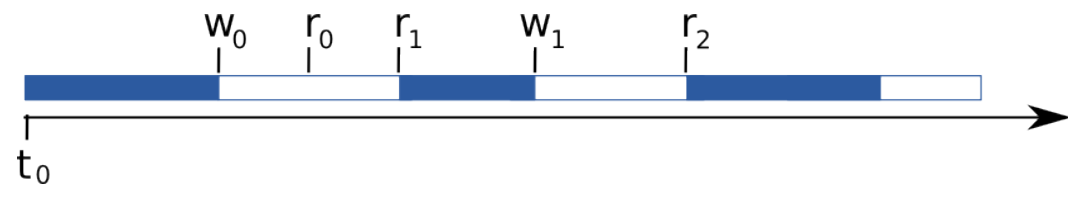

Figura 1 - Período de vida de uma variável: "Vulnerabilidade" (Adaptado: SPRINGER, 2001)

A seta vista na parte inferior da figura 1 representa a faixa de tempo em que é feita a análise sobre as operações de uma variável qualquer, onde $t_{0}$ é o instante inicial. As operações sobre a variável são representadas pelas letras W - escrita - e $\mathrm{R}$ - leitura - acrescidas de um número que representa a seqüência das operações.

Em $w_{0}$ a variável recebe um valor e a partir desse momento passa para o estado "vulnerável". Tal variável permanece nesse estado até a segunda leitura $\left(r_{1}\right)$ quando o seu valor deixa de ser útil ao sistema, passando assim para um estado "não vulnerável". Em w $w_{1}$ a variável recebe um novo valor que é lido pelo sistema em $r_{2}$. Nesse período a variável passou a ser novamente vulnerável, deixando de ser logo em seguida (após $r_{2}$ ), e permanecendo assim até que o sistema volte a usá-la. Ao final da faixa de tempo considerada no exemplo, a vulnerabilidade da variável pode ser medida pelo espaço em bits que ela ocupa e pelo tempo total em que ela permanece vulnerável.

É importante observar o termo "variável" tem aqui uma forte conotação física, ou seja, admite-se neste exemplo que uma vez que a variável ganha um local (endereço) de memória, este permanece o mesmo, indefinidamente. É muito comum em linguagens de alto nível, que uma mesma variável seja alocada em diferentes endereços ao longo de seu período de vida, o que não é o caso do exemplo anterior. 
Pode-se, portanto dizer que um byte de memória é vulnerável em faixas de tempo nas quais a ocorrência de um SEU produz erro e que tal erro se manifestará no instante de leitura do byte pelo processador. Dito de outra forma, um byte é vulnerável apenas durante o seu "período de vida". O tempo de vulnerabilidade de um Byte $\vee_{B}$ (byte vulnerability) permite o cálculo da vulnerabilidade de dados de um algoritmo completo. A vulnerabilidade de dados $V_{D}$ (data vulnerability) é o montante de todos os bytes empregados para o armazenamento de informações, e que são efetivamente usados durante o processamento. $V_{D}$ pode ser medido em bytessegundos, o que representa o total de memória vulnerável durante o tempo total de exposição. Como exemplo, pode-se considerar que uma faixa de memória de 2Kbytes, que permanece vulnerável durante 5 segundos resulta em um $V_{D}$ de 10Kbytes-segundos.

Além dos dados de trabalho, um programa possui vulnerabilidade de código $V_{C}$, que pode ser calculada de forma similar. Uma instrução, quando carregada em memória, permanece vulnerável até a sua última leitura pelo processador. A diferença em relação à vulnerabilidade de dados está apenas no fato de que para a maioria das aplicações as instruções têm natureza estática, ou seja, não sofrem escrita durante tempo de execução.

Para exemplificar será considerado um algoritmo que ocupe $1000 \mathrm{~K}$ bytes de espaço em memória, execute a maior parte do seu código seqüencialmente e permaneça em ciclo fazendo uso de apenas 3K bytes em 95\% do tempo restante de execução. Para esse caso pode-se chegar ao $\mathrm{V}_{\mathrm{C}}$ simplesmente calculando a integral da função representada na figura 2; aproximadamente 2,79M Bytes-seg. 


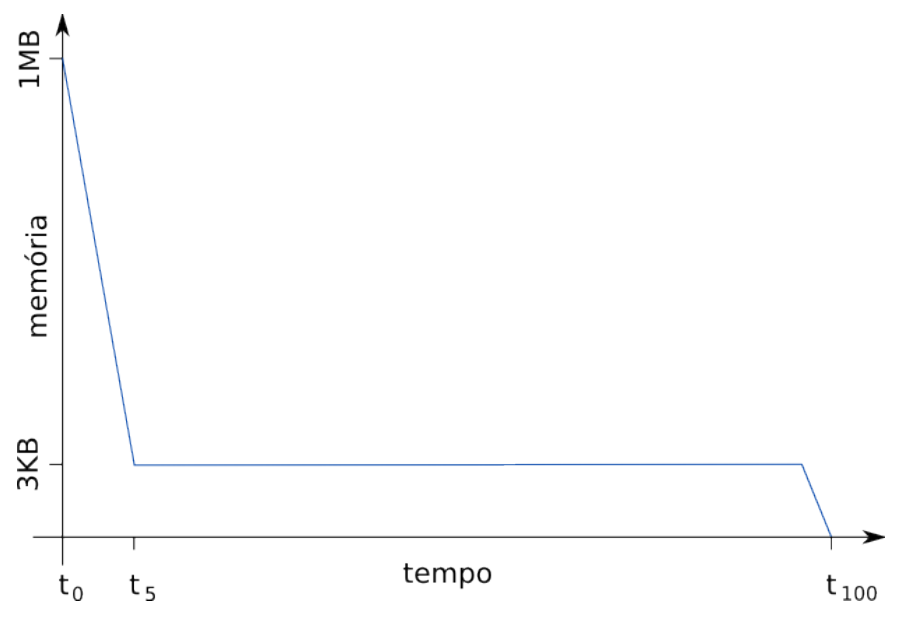

Figura 2 - Perfil de vulnerabilidade de um algoritmo

Em função da vulnerabilidade presente em sistemas baseados em microprocessamento, algumas técnicas, baseadas no conceito de redundância, permitem a redução dos efeitos que produzam inclusive, perda de confiabilidade e segurança em tais sistemas. O capítulo 3 explora o conceito de redundância e algumas técnicas baseadas neste conceito. 


\section{TÉCNICAS DE REDUNDÂNCIA}

Um dos conceitos chave atribuídos a sistemas tolerantes a erros é redundância. A redundância é uma forma de se acrescentar recursos adicionais ao sistema que possibilitem o tratamento de erros em um de seus elementos, com a intenção de manter o sistema em operação. Em virtude do custo que a implementação de redundância representa, diversos tipos de redundância podem ser usados em razão dos requisitos exigidos pela aplicação.

As técnicas usadas na aplicação de redundância, assim como mascaramento de erros, são redundância informacional (estruturas de dados redundantes e software redundante), redundância espacial (hardware redundante) e redundância temporal (operações sequenciais redundantes). A simplicidade ou complexidade exigida por essa técnicas dependem da natureza das funções realizadas por cada uma das estruturas presentes no sistema (INIEWSKI, 2010).

A redundância temporal faz uso de tempo adicional para realizar as tarefas relacionadas ao processo de tolerância à falhas. Essencialmente, esse tipo de redundância executa repetidas vezes tarefas que usam como recursos, o mesmo hardware e mesmo software. A aplicação desse tipo de redundância pode ser muito vantajosa em aplicações que não possuam restrições muito exigentes quanto ao tempo de resposta, tal como programas de interação humana. Já em sistemas de tempo real com restrições exigentes quanto ao tempo de resposta, esse tipo de redundância pode ser usado de forma a não comprometer os tempos máximos exigidos pela aplicação.

A redundância de informação faz uso de formas distintas de representação e processamento da informação com a intenção de promover tolerância a erros. 
Exemplos desse tipo de redundância incluem detecção de erro (error-detection) e códigos de correção de erro (error-correcting codes).

Por exemplo, em relação ao custo de hardware exigido pela aplicação de redundância, quando aplicada sob a forma de redundância informacional, é tipicamente menor quando comparada à redundância espacial. A aplicação de redundância espacial acrescenta ao hardware tamanho, peso, consumo de energia e custo. Além disso, os componentes acrescentados, não só geraram maior interconectividade, como também afetam indiretamente a confiabilidade global do sistema (SCHRIMPF; FLEETWOOD, 2004).

\subsection{Redundância informacional}

Redundância informacional e mecanismos de codificação são projetadas de tal forma que, na presença de erros, ou seja, informação interna inconsistente, permitem a detecção e correção de erros (EDAC - Error Detection And Correction). A teoria de detecção e correção de erros é um recurso comumente usado no desenvolvimento de sistemas digitais com o objetivo de promover dependabilidade (ZARAGOZA, 2006). A detecção e correção de erros podem variar em sua capacidade, eficiência e complexidade. Redundância por verificação cíclica, demais códigos cíclicos e mecanismos convolucionais de codificação são usados para detectar, por exemplo, erros em interfaces de transferência serial de dados e mídias de armazenamento.

Códigos de Hamming são a primeira classe de códigos de blocos lineares que foram concebidos para correção de erros. Esses códigos e suas derivações têm sido usados freqüentemente em comunicação digital e sistemas de armazenamento de 
dados. O código de Hamming denominado SEC-DEC - single-error-correcting and double-error-correcting - é um código de bloco muito usado em sistemas de memória. Essa versão é capaz de detectar e corrigir códigos de 64 bits de informação, usando 8 bits de verificação. Códigos ainda mais poderosos podem ser construídos usando geração de polinômios apropriados (HORIGUCHI; ITOH, 2011).

O aprimoramento desse tipo de mecanismo corretor produziu os códigos de Hamming curtos, que foram criados através da remoção de colunas da matrix geradora, produzindo conjuntos de códigos com capacidade de deteç̧ão e correção reduzidas. Para que um código seja utilizável em aplicações com memórias de alto desempenho, sua estrutura deve permitir codificação paralela e operações de decodificação eficientes. (HSIAO; TOU, 1969) desenvolveu códigos SEC-DEC através da análise das propriedades de códigos de Hamming curtos para identificar códigos específicos que permitissem processos rápidos de codificação e decodificação. Já Bose, Chaudhuri e Hocquenghem (CARRASCO; JOHNSTON, 2008), elaboraram o código $\mathrm{BCH}$, que forma uma numerosa classe de poderosos códigos cíclicos de correção de erros randômicos. Códigos cíclicos são uma importante subclasse de códigos lineares que se tornaram bastante atrativos devido a estrutura algébrica inerente e que permitem implementações de codificação e decodificação rápidas e eficientes. $\mathrm{O}$ código $\mathrm{BCH}$ é a generalização de códigos de Hamming e permitem a correção de múltiplos erros. Dentre os códigos $\mathrm{BCH}$ não binários, a subclasse mais importante são os códigos Reed-Solomon (RED). 


\subsection{Redundância espacial}

A forma mais comum de redundância espacial (ou redundância modular) é a redundância modular tripla (TMR - Triple Modular Redundancy). Esse tipo de redundância faz uso de três módulos e um votador majoritário. Em caso de erro em um dos módulos, esse é corrigido pela ação do votador através de consenso majoritário, ou regra de votação dois de três (LAPLANTE, 2004). Os módulos por sua vez, realizam funções baseadas em elementos de memória, D-Flip Flops ou Latches, máquinas de estados e funções lógicas complexas; incluindo funções baseadas em módulos de processamento ou até mesmo subsistemas inteiros.

O conceito de redundância modular pode ser expandido a fim de permitir a implementação de sistemas que possuam redundância n-modular, além de associar melhorias a capacidade de tolerância a erros. Nesse sentido, a aplicação de redundância modular quádrupla, por exemplo, fornece a capacidade de tolerar erros em até dois módulos, caso o votador tenha a capacidade de discernir sobre as características ou sinais de erro. Para isso o votador deve ser capaz de responder ao erro inicial, removendo o direito de participação na votação do módulo defeituoso e impondo regras de votação majoritária aos demais. Assim, um erro em um segundo módulo pode ser tolerado pela estrutura TMR remanescente. Essa capacidade de alterar o mecanismo de votação durante a operação do sistema é chamada de redundância dinâmica. É possível identificar três ações associadas a esse tipo de redundância: detecção do erro, localização do erro e reconfiguração da estrutura para que seja aplicado ao sistema o processo mais adequado de recuperação de erros. 


\subsection{Redundância temporal}

Uma alternativa à redundância espacial é a redundância temporal, na qual os mesmos elementos de hardware e software são usados em operações consecutivas, usando diversidade em tempo para produzir resultados que devem ser comparados por meio de comparadores/detectores e técnicas de correção similares aos usados em redundância espacial.

Em tecnologias anteriores as atuais, pulsos transientes de eventos simples teriam pouca probabilidade de se propagar através dos circuitos lógicos combinacionais de menor complexidade e sistemas de frequências reduzidas e assim produzir um estado lógico incoerente durante a presença do erro. Porém, o advento de larguras de banda maiores presentes em tecnologias mais avançadas, favorece a propagação de certos tipos de pulsos, e altas frequências de clock produzem uma abundante oportunidade para o aparecimento de erros de amostragem em elementos de memória (SCHRIMPF; FLEETWOOD, 2004).

Uma proposta promissora para o desenvolvimento de dispositivos de alta confiabilidade faz uso de redundância espacial estática aplicada a um sistema, com o objetivo de torná-lo tolerante a erros em elementos de memória, juntamente com a aplicação de redundância temporal que produza mitigação contra eventos transientes sobre a lógica combinacional de tais dispositivos. A aplicação dessas duas tecnologias de forma integrada ocorre primeiramente através de amostragem feita sobre os resultados da lógica combinacional e da persistência desses resultados em elementos Latch distintos, concluindo o processo através de uma votação majoritária. Usualmente, utiliza-se a duração estimada de um erro transiente de forma que a amostragem sobre a lógica combinacional ultrapasse a duração do 
erro, tornando improvável que a corrupção de dados atinja mais de um elemento Latch que pertença ao conjunto de votação. Já a aplicação de redundância espacial, procura assegurar que a atualização de elementos de memória também seja produzida através de votação majoritária.

\subsection{Técnicas de programação defensiva}

Tendo como base o conceito de redundância, algumas técnicas de programação defensiva foram eleitas como objeto de estudo. São elas as técnicas de paridade, checksum, $\mathrm{BCH}$ code - acrônimo das iniciais de seus criadores Bose, Chaudhuri e Hocquenghem, Forward Recovery, Backward Recovery, duplicação de variáveis e diversidade.

No capítulo 4, são descritas cada uma das técnicas mencionadas, assim como a aplicação destas, sobre um programa denominado "programa alvo", também descrito a seguir. 


\section{APLICAÇÃO DAS TÉCNICAS DE PROGRAMAÇÃO DEFENSIVA}

Este capítulo descreve como as técnicas de programação defensiva são aplicadas ao programa original, chamado neste estudo de programa alvo.

Primeiramente será descrito o programa alvo a partir da figura 3 que representa a abordagem adotada para implementação de um programa, cuja função básica é a de executar uma série de regras de um sistema de tráfego metroferroviário por meio de um conjunto de equações booleanas. Tal sistema será descrito com mais detalhes nos tópicos seguintes.

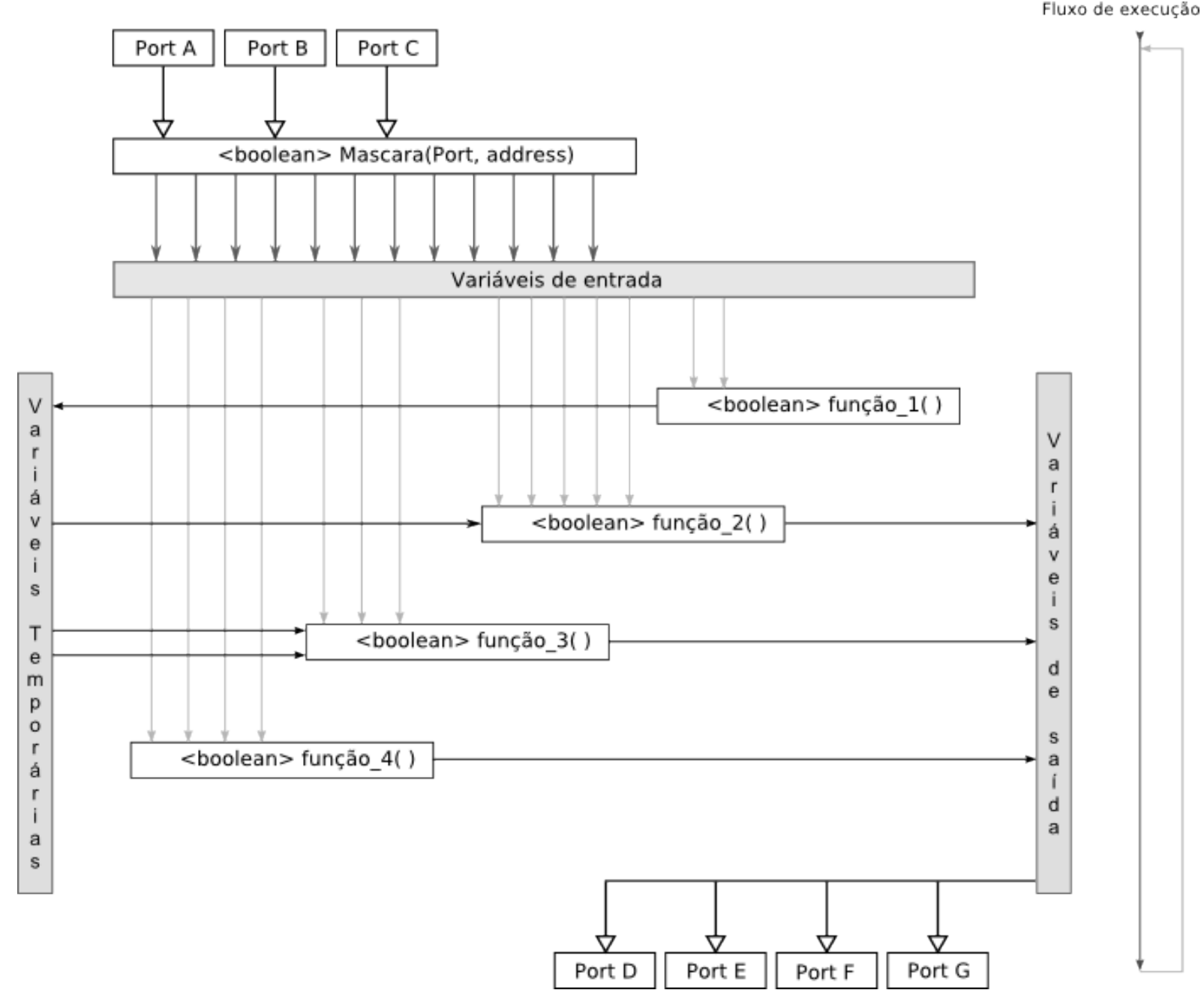

Figura 3 - Programa alvo base: sem aplicação de técnicas de programação defensiva 
O fluxo de execução desse programa é representado pelo loop na borda direita da figura 3. Assim, após o seu início, o programa é executado indefinidas vezes, sempre obtendo no seu início, os dados de entrada, representados pelos elementos Port A, Port B e Port $C$, denominados portas de entrada. A execução do programa segue em diante processando as funções booleanas, representadas aqui pelos elementos <boolean> função_n. Por fim, os resultados geram os dados de saída, representados pelos elementos Port D, Port E, Port F e Port G, denominados portas de saída. Como será visto adiante, esse padrão será alterado apenas pela inclusão de elementos adicionais cuja função será a de aplicar a técnica de programação defensiva sobre o programa alvo.

As portas de entrada produzem as variáveis de entrada, transformando os dados obtidos do simulador de campo em informação usada pelas equações booleanas. Essa informação fica disponível durante todo o ciclo de processamento. Porém, nessa etapa da discussão deve-se atentar para a natureza da vulnerabilidade do algoritmo em questão. $\quad \mathrm{Na}$ figura 4 foi elaborada uma representação do perfil de vulnerabilidade próxima a real, que permite a análise de alguns aspectos importantes.

Primeiramente, pode-se identificar no gráfico a reta de vulnerabilidade de código $\mathrm{V}_{c}$, cujo o valor máximo de 17 Kbytes é alcançado assim que inicia-se o ciclo de execução. Esse valor corresponde ao total de bytes do código compilado. A reta, por sua vez, representa a vulnerabilidade do programa, durante sua execução no tempo de um ciclo $T_{\mathrm{c}}$. A medida que o código é executado, a parcela de código já executada deixa de ser vulnerável desde que nossa análise, para efeito de simplificação, seja restrita a um único ciclo. 
As demais curvas, se somadas, representam a vulnerabilidade de dados $V_{d}$. Ao observar cada uma das curvas, identifica-se a entrada de dados pelas três portas (A,B e C) que permanecem vulneráveis apenas no início do ciclo, uma vez que a informação contida nelas passa para as variáveis de entrada ao final da leitura. A curva correspondente as variáveis de entrada tem sua vulnerabilidade decrescida a cada booleana executada, uma vez que os dados deixam de ser usados pelo programa a medida que ele é executado. O raciocínio inverso pode ser aplicado às variáveis de saída. Por fim, a curva das variáveis temporárias adquire um aspecto aleatório em função da reutilização de algumas delas pelo programa.

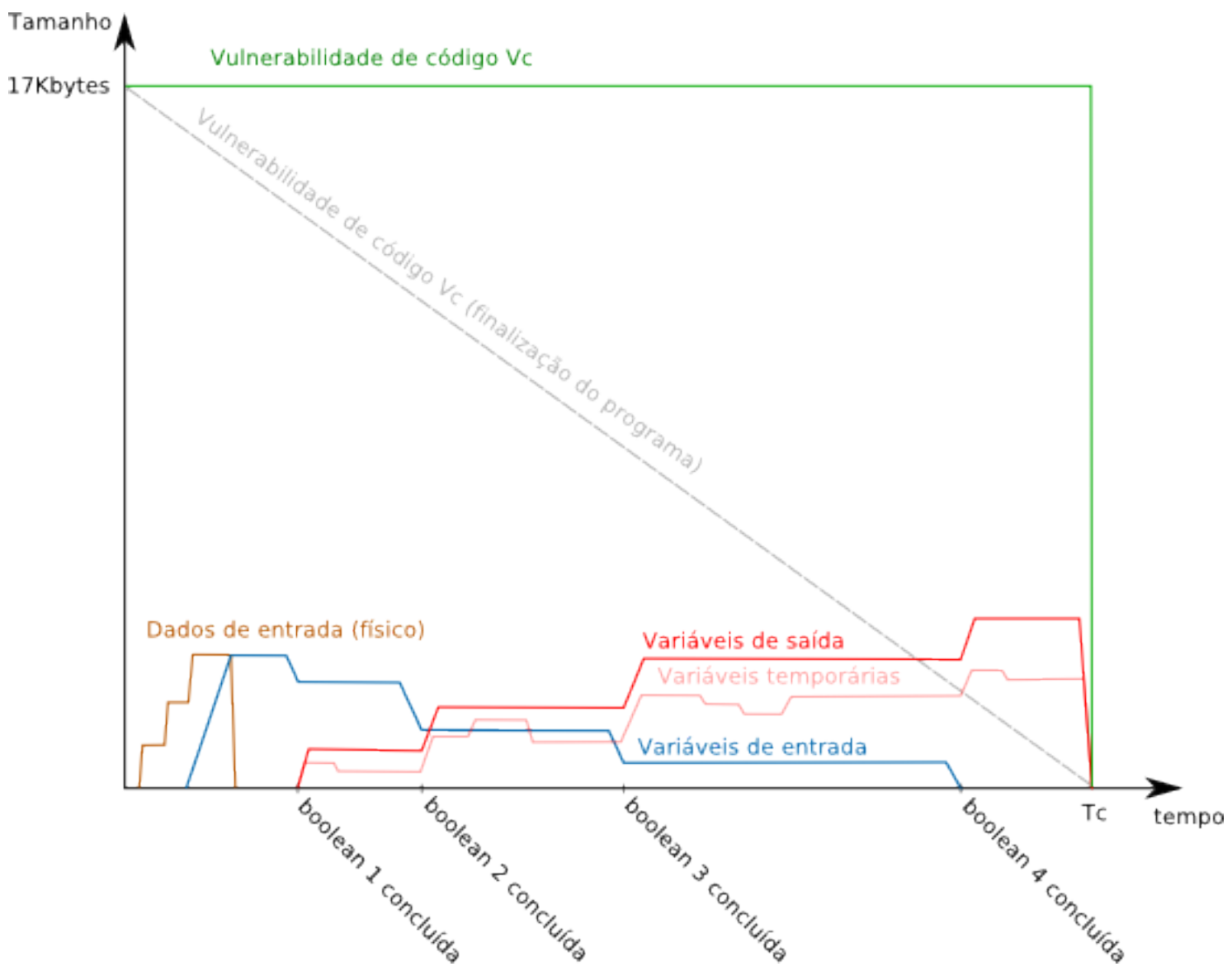

Figura 4 - Perfil de vulnerabilidade do programa alvo 
Em razão da forma como é implementado o programa, existe uma significativa diferença entre as integrais de $V_{c}$ e $V_{d}$. Esta investigação, como será visto nos próximos tópicos, é voltada ao estudo dos resultados obtidos através de simulação de erros sobre os dados do programa, ou seja, erros sobre $V_{d}$.

\subsection{Paridade}

A verificação de código por paridade simples é o mais popular tipo de detector de erro. Ele requer um bit de verificação independente do tamanho do dado. Quando uma paridade é requerida, o bit de verificação associado é produzido a partir da quantidade de bits 1 presentes na palavra de código. Um código com paridade pode detectar qualquer erro simples ou múltiplos erros em quantidade impar.

Em nosso caso, a técnica de paridade é aplicada sobre os valores obtidos através das portas de entrada, atribuindo-se essa informação aos 8 bits que compõem cada uma. Esse processo é repetido no início de cada ciclo, renovando o valor da paridade a cada leitura das portas de entrada.

A verificação do valor de paridade é feita toda vez que se faz necessária a leitura de uma variável de entrada. Assim, antes que o processo de execução de uma equação booleana seja iniciado, a técnica se encarrega de verificar a consistência dos dados para que em seguida, caso não seja identificado um erro, o processo seja desencadeado.

Em caso de erro, ocorrerá um desvio do fluxo normal do programa. Esse desvio provoca a interrupção do processo e volta ao ponto inicial, deixando, portanto de atualizar as variáveis de saída. No ponto inicial, as portas de entrada são lidas, o valor de paridade é recalculado e o conjunto de booleanas é novamente processado. 
Para descrever o processo de tolerância a erros, mencionado anteriormente, foram acrescentados alguns elementos gráficos sobre a representação do programa alvo da figura 3. Primeiramente, os processos que se iniciam pela leitura das portas de entradas e aplicam sobre seus valores algum tipo de redundância (e.g. redundância de informação), são representados de forma detalhada na parte superior da figura e de forma simplificada através de retângulos que se sobrepõem às equações booleanas (e.g. <boolean> função_1()).

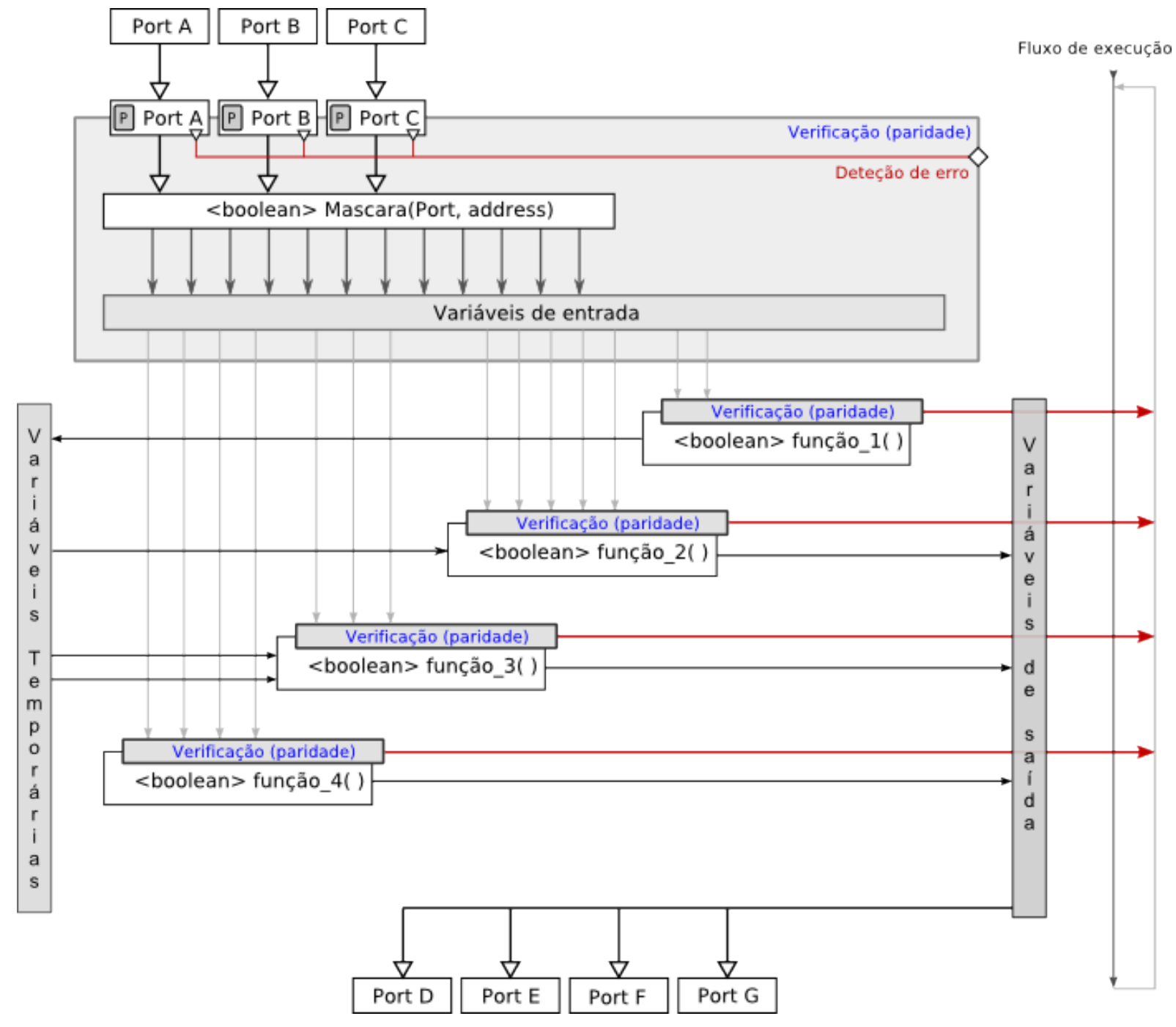

Figura 5 - Aplicação da técnica baseada em paridade 
Dessa forma, a detecção de um erro é representada pelas setas em vermelho que indicam em diversos casos, o retorno para o início do processo. Tal padrão se repete em todas as figuras que representam a aplicação das técnicas de programação defensiva, nos tópicos a seguir. A figura 5 descreve a técnica baseada em paridade.

A técnica de paridade se caracteriza por não possuir uma capacidade de detecção de erros múltiplos muito abrangente, porém ela adiciona pouca carga de trabalho ao programa alvo.

De fato, a técnica de paridade é frequentemente usada em conjunto com outras técnicas para se alcançar níveis de confiabilidade desejáveis. Em um estudo desenvolvido em (SRIDHARAN; ASADI; TAHOORI; KAELI, 2006), com o objetivo de reduzir a susceptibilidade de memórias cache, tal aspecto fica evidente. Segundo o estudo, para se reduzir a vulnerabilidade limitando o impacto sobre o consumo de energia e desempenho, pode-se investigar como combinar refetch seletivo e paridade como um substituto a técnicas ECC (Error-Correcting Code). De fato, em algumas situações, SEC-DEC ECC (o qual detecta e corrige 100\% dos erros de único-bit) pode ser pouco atrativo devido ao seu impacto sobre o consumo de energia e espaço. Os resultados do estudo mostram que a combinação de refetch seletivo e paridade detecta $100 \%$ dos erros e corrige $85 \%$ dos erros de bit-único e conclui que em aplicações onde o consumo de espaço e energia representam um aspecto relevante em comparação ao DUE (Detected Unrecovered Error) desejável, essa solução deve ser considerada. 


\subsection{Checksum}

Checksum é usado em uma grande variedade de sistemas de codificação, tais como códigos de barras ISBN - International Standard Book Numbers. Estes são códigos autoverificáveis e indicam se os dados precedentes foram mal interpretados. O CRC - cyclic redundancy check - é um tipo de checksum usado principalmente em comunicação de dados que determina se um erro ocorreu em um grande conjunto de bits. Checksum's e CRC's são um tipo de mecanismo de detecção de erro sistemático, o que significa que os bit's de verificação são acrescentados ao byte de informação original. O grupo de bit's de verificação leva o nome de syndrome e o byte de informação original não sofre qualquer alteração em função da aplicação desse tipo de método (NULL; LOBUR, 2006).

A técnica Checksum é aplicada sobre o programa alvo de forma similar a técnica de paridade. Porém, essa técnica produz uma resultante de soma binária syndrome - sobre os valores obtidos através de todas as portas de entrada.

A técnica Checksum faz a verificação do valor de soma toda vez que se faz necessária a leitura de uma variável de entrada. Tal como na aplicação da técnica de paridade, antes que o processo de execução de uma equação booleana seja iniciado, a técnica se encarrega de verificar a consistência dos dados para que, em seguida, caso não seja identificado um erro, o processo seja desencadeado. Em caso de erro, ocorrerá um desvio do fluxo normal do programa e este volta ao ponto inicial. O retorno ao início do ciclo provoca a releitura das entradas e o recálculo do valor de checksum. A figura 6 descreve esse processo. 


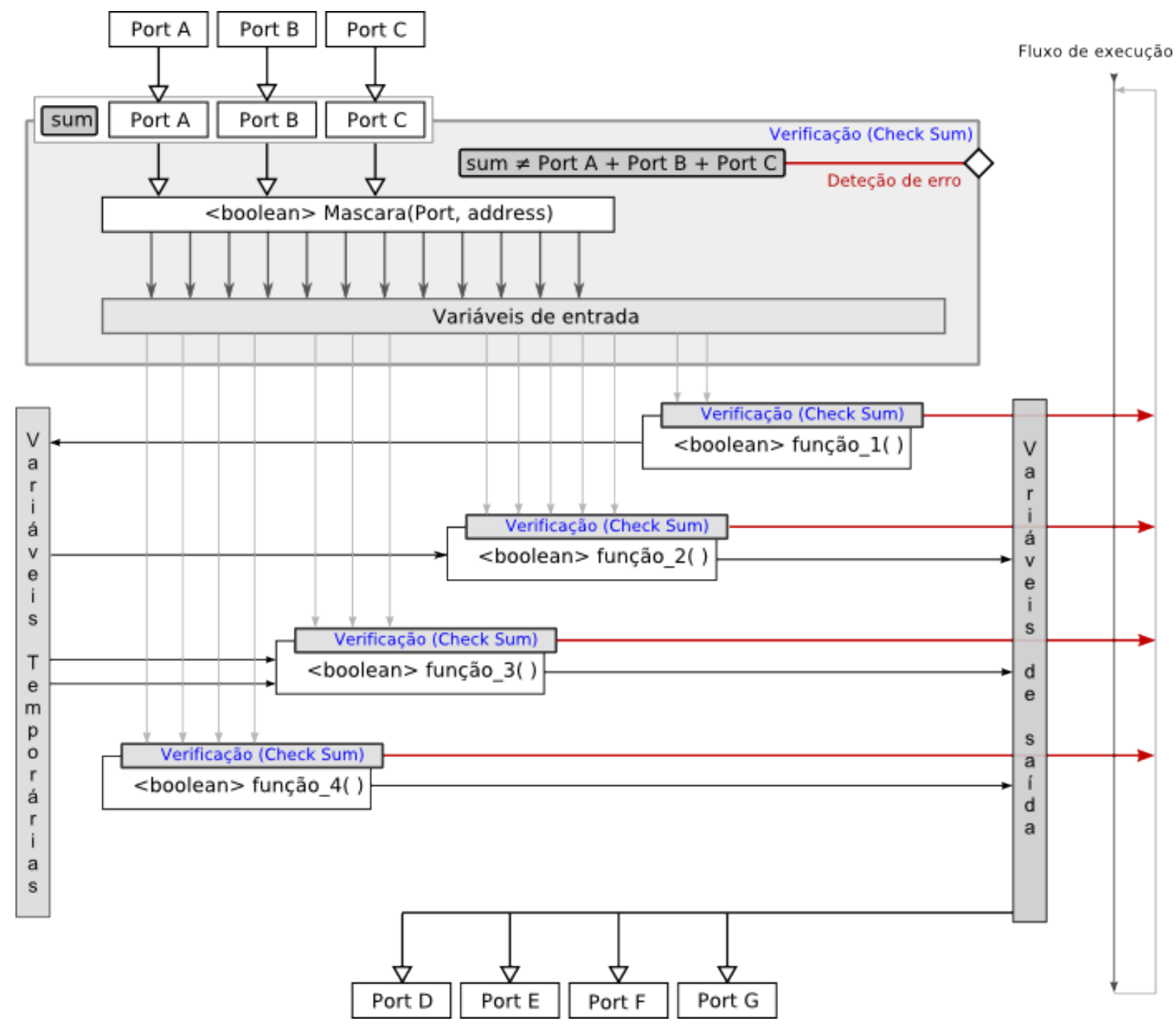

Figura 6 - Aplicação da técnica baseada em checksum

Podemos encontrar aplicações desse tipo de técnica em trabalhos de pesquisa recentes. Em (GHERMAN; EVAIN; CARTRON; SEYMOUR; BONHOMME, 2009) é apresentada uma proposta de proteção da memória principal baseada em hardware e com aplicação em nível de sistema. Tal como em abordagens baseadas em software, valores de checksum são armazenados e manipulados da mesma forma que os dados correntes. Assim, os valores de checksum ficam disponíveis e podem ser trocados entre a memória principal e o restante do sistema. Em conseqüência, as operações de detecção de erro podem ser executadas em níveis altos da hierarquia do sistema, oferecendo assim proteção implícita contra erros da 
memória principal, armazenagem secundária e interconexões, mesmo se esses subsistemas não possuam seus próprios mecanismos de proteção contra erros.

A proposta ainda promove a flexibilidade de aplicar ou não o módulo de proteção sobre as operações do sistema. Tal característica permite regular o custo de se aplicar um mecanismo de proteção sobre sistemas de aplicação crítica, de forma que se possa executar tarefas de diferentes níveis de criticidade.

\subsection{Código $\mathrm{BCH}$}

A técnica $\mathrm{BCH}$ aplicada ao experimento se caracteriza por ter tanto, a capacidade de detectar como a de corrigir possíveis erros produzidos sobre os dados de entrada. Neste estudo, tal técnica foi desenvolvida de forma que fosse possível corrigir até três erros simultâneos em um grupo de 8 bit's, que corresponde a uma porta de entrada. Para isso, são associados aos dados de cada porta, 9 bits adicionais representados pelos elementos "BCH" da figura 7.

O processo de codificação $\mathrm{BCH}$ ocorre no início de cada ciclo, a partir dos valores obtidos em cada uma das portas. Cada vez que se faz necessário a leitura das variáveis de entrada, o que corresponde a execução de uma das booleanas, o processo de decodificação é disparado e o acesso a informação passa pela correção de possíveis erros gerados durante a injeção de erros. 

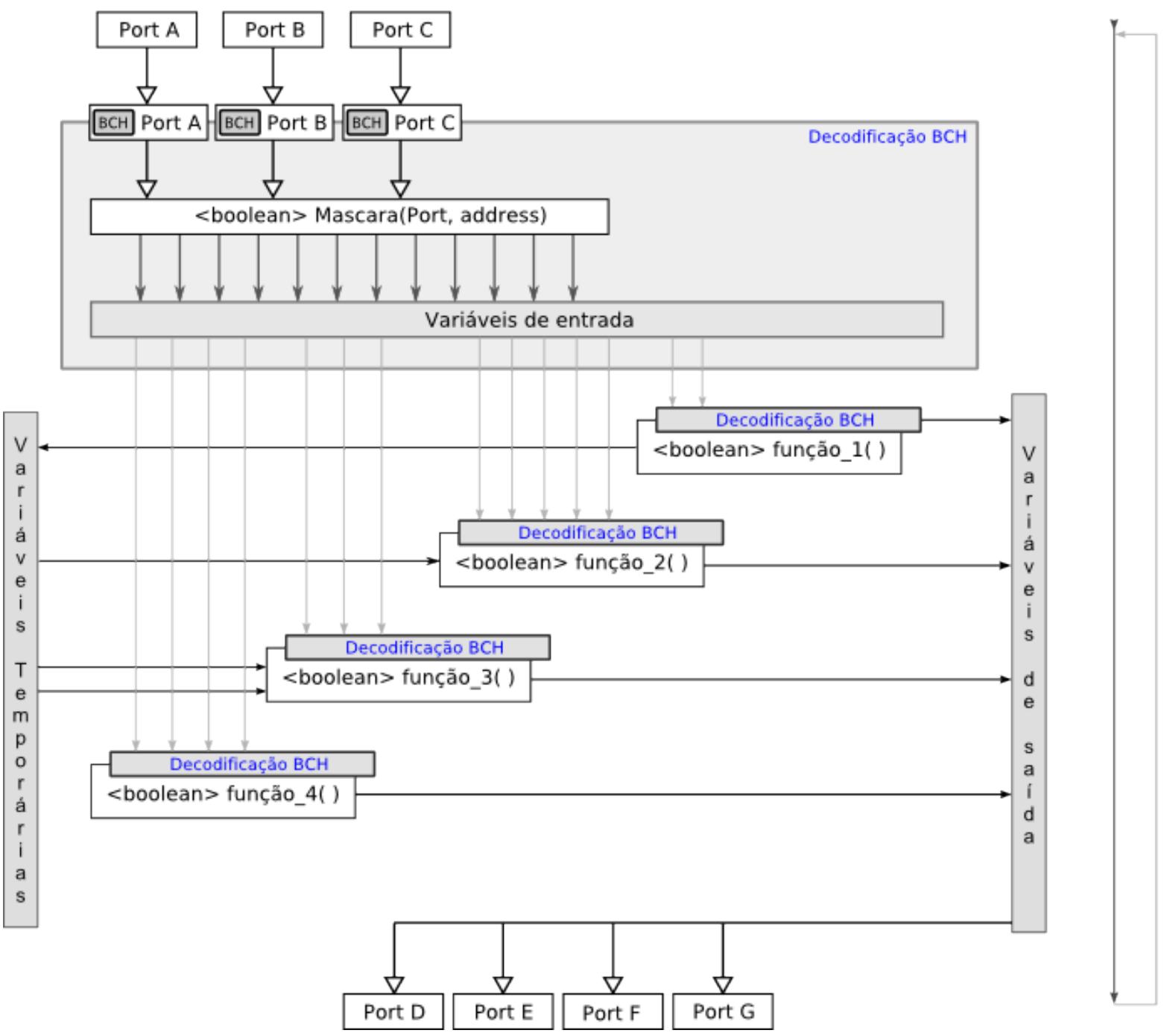

Figura 7 - Aplicação da técnicas baseada em BCH

Técnicas baseadas em correção de erros por BCH estão em amplo desenvolvimento, porém alguns problemas associados são recorrentes. Convencionalmente, um algoritmo iterativo Berlekamp-Massey (B-M) é usado no processo de decodificação $\mathrm{BCH}$ para resolver a equação chave, resultando em um longo período de iteração. Essa deficiência restringe a aplicação de código BCH para tratamento de erros de memória, por exemplo. Códigos Imai-Kamiyanagi (IMAI; KAMIYANAGI, 1977) podem aumentar o desempenho do processo de decodificação, porém aumentam dramaticamente o tamanho da matriz de memória, uma vez que ele necessita mais bits de paridade que códigos DEC BCH (RAO; 
FUJIWARA, 1989). O maior desafio encontrado para casos como estes, é como reduzir significamente a latência de decodificação - baixo desempenho - sem penalizar excessivamente o consumo de espaço (XUEQIANG; LIYANG; DONG; CHAOHONG; RUNDE, 2009).

\subsection{Backward recovery}

A ocorrência de um erro em um programa em tempo de execução o leva a um estado de inconsistência em relação ao que foi previsto na fase de codificação. Independente da complexidade ou tamanho do programa, é possível estabelecer pontos predeterminados de restauração que, em tese, representam estados livres de falha, chamados checkpoint. A técnica "recuperação por retrocesso" - backward recovery - faz uso dessa característica em conjunto com a parte do algoritmo responsável por detectar falhas. Desta forma o fluxo corrente do programa pode retroceder ao último ponto de restauração gravado pelo mecanismo ou mesmo ser reinicializado neste ponto. Portanto, se a falha ocorrer após o checkpoint estabelecido, o estado do ponto de restauração estará livre de falhas, assim como se a falha ocorrer após o processo de retorno, o estado do sistema também estará livre de falhas. Esse processo é representado pela figura 8 (PULLUM, 2001).

Para o estudo aqui apresentado, a técnica de backward recovery é aplicada sobre as variáveis de saída. Essa técnica é essencialmente aplicada sobre o processo de recuperação de erros, não exercendo, portanto qualquer influência sobre o processo de detecção. Para essa finalidade, foi usada uma rotina denominada "verificador de falhas inseguras" embarcada. Sua função é a mesma da 
rotina externa ao dispositivo alvo usado para levantar o tempo decorrido até a ocorrência de uma falha insegura.

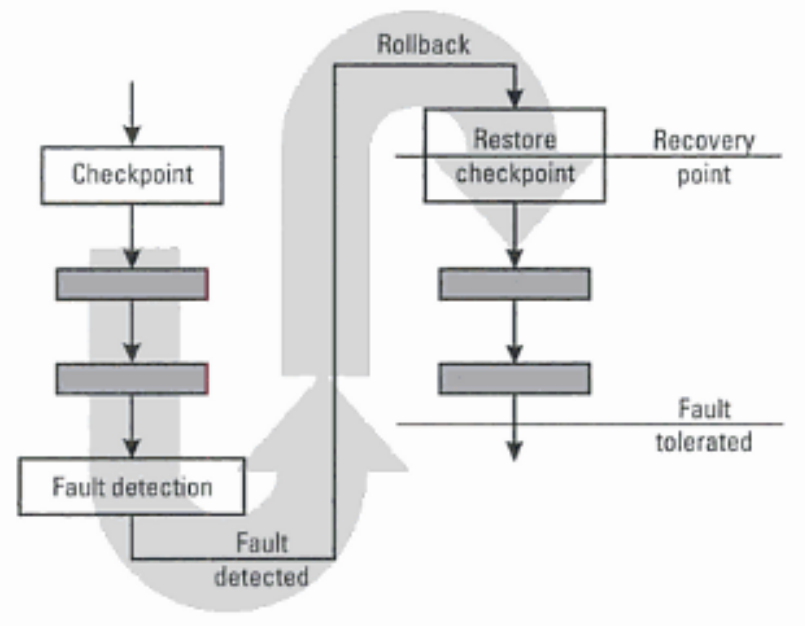

Figura 8 - Técnica "Backward recovery" (PULLUM, 2001)

Uma vez que uma falha é detectada pelo verificador embarcado, a técnica de backward tem a função de reconstruir os dados compostos pelas variáveis de saída a partir do estado anterior assumido pelo programa alvo. Esse estado anterior é considerado seguro uma vez que ele é armazenado ao final de cada ciclo, caso não haja a detecção de uma falha insegura.

Esse processo é descrito na figura 9. 


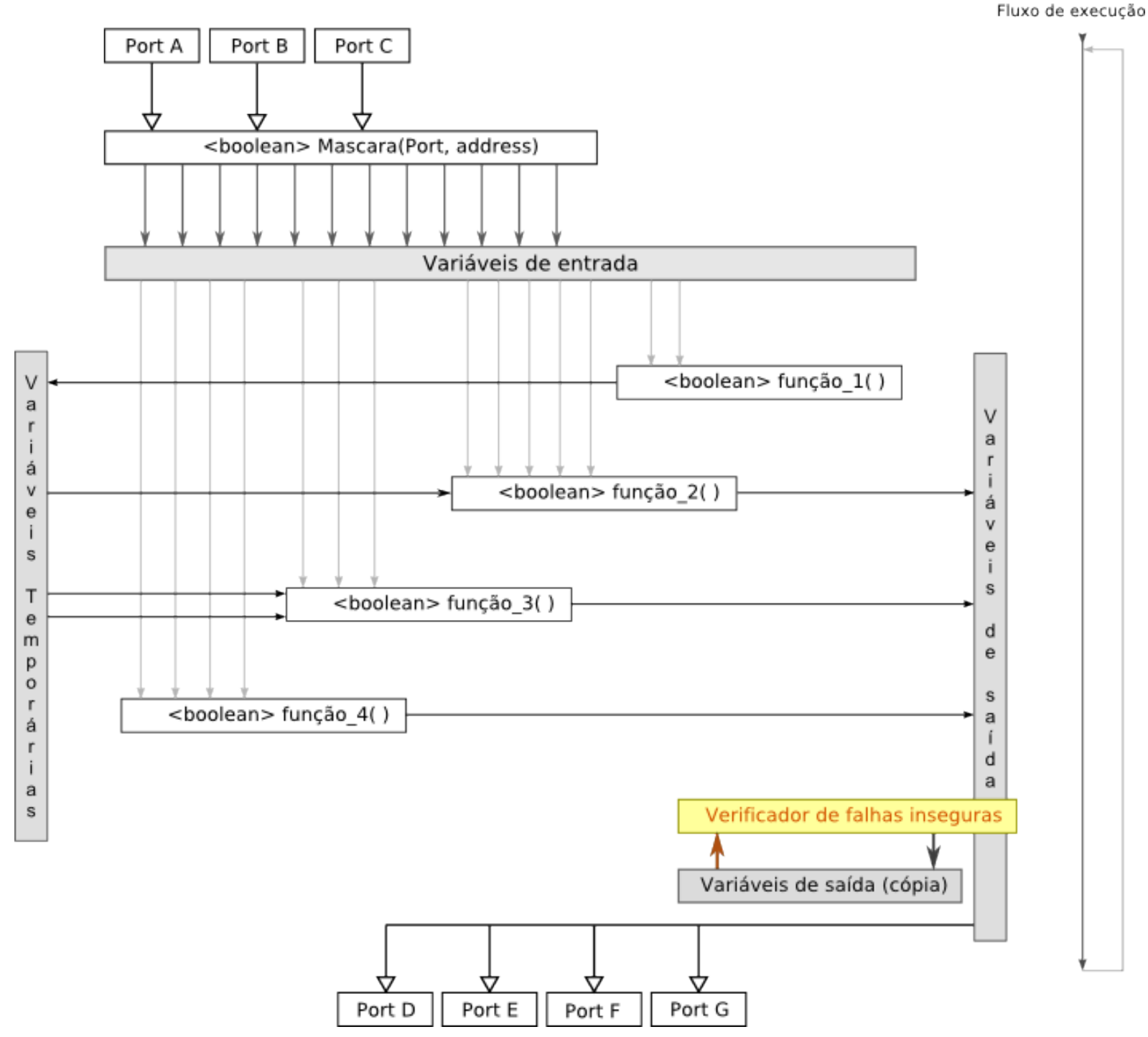

Figura 9 - Aplicação da técnica baseada em backward recovery

\subsection{Forward recovery}

Diferentemente da técnica backward recovery que na ocorrência e detecção de um erro, altera o fluxo original de um programa para um ponto anterior considerado livre de falhas, a técnica forward recovery desvia o fluxo do programa para um ponto que permita o sistema continuar operando. Neste ponto de desvio não há influência direta dos estados produzidos até então que podem ter sido alterados em função da ocorrência de uma falha. Além disso, esse ponto representa 
um estado de operação degradado do sistema. Esse estado degradado pode ser atingido através de um processo previamente especificado, assim como através de compensação de erro. A compensação de erro é produzida em muitos casos através de redundância, que por sua vez é capaz de gerar ao menos, uma resposta aceitável ao processo corrompido pelo erro. A figura 10 ilustra a técnica forward recovery em sistemas que recebem a aplicação de NVP - N Version Programming que produz paralelamente uma série de respostas a um mesmo estímulo (input) e uma unidade de detecção e tratamento de falhas realiza a compensação de erro selecionando a resposta considerada correta ou ao menos mais aceitável (PULLUM, 2001).

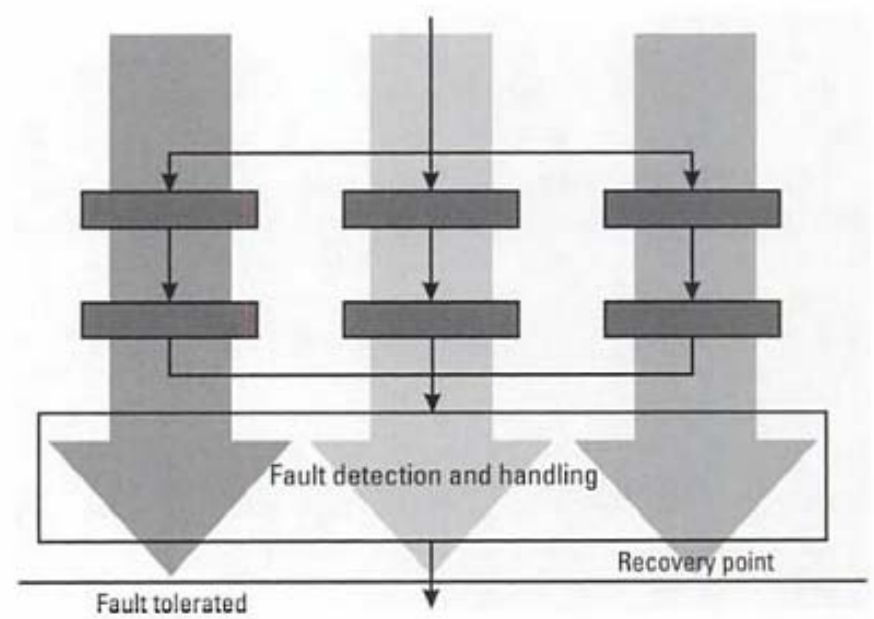

Figura 10 - Técnica "Forward recovery" (PULLUM, 2001)

A aplicação da técnica de forward recovery, representada pela figura 11 , tal como na técnica backward recovery, é feita sobre as variáveis de saída. Essa técnica é essencialmente aplicada sobre o processo de recuperação de erros, o que nos leva novamente a utilização da rotina "verificador de falhas inseguras"; responsável pela detecção de erros. Uma vez que uma falha é detectada pelo verificador, a técnica de forward recovery tem a função de recompor os dados 
compostos pelas variáveis de saída de tal forma que o sistema é levado a um estado de operação degradada. Esse estado é considerado seguro em função de sua influência sobre os elementos do simulador de campo. Podemos usar como exemplo o código de velocidade de todos os circuitos de via que passam a ter seu valor igual a zero, independente do resultado obtido pelas equações boolenas responsáveis por determinar o perfil de velocidade, durante a operação normal do simulador.

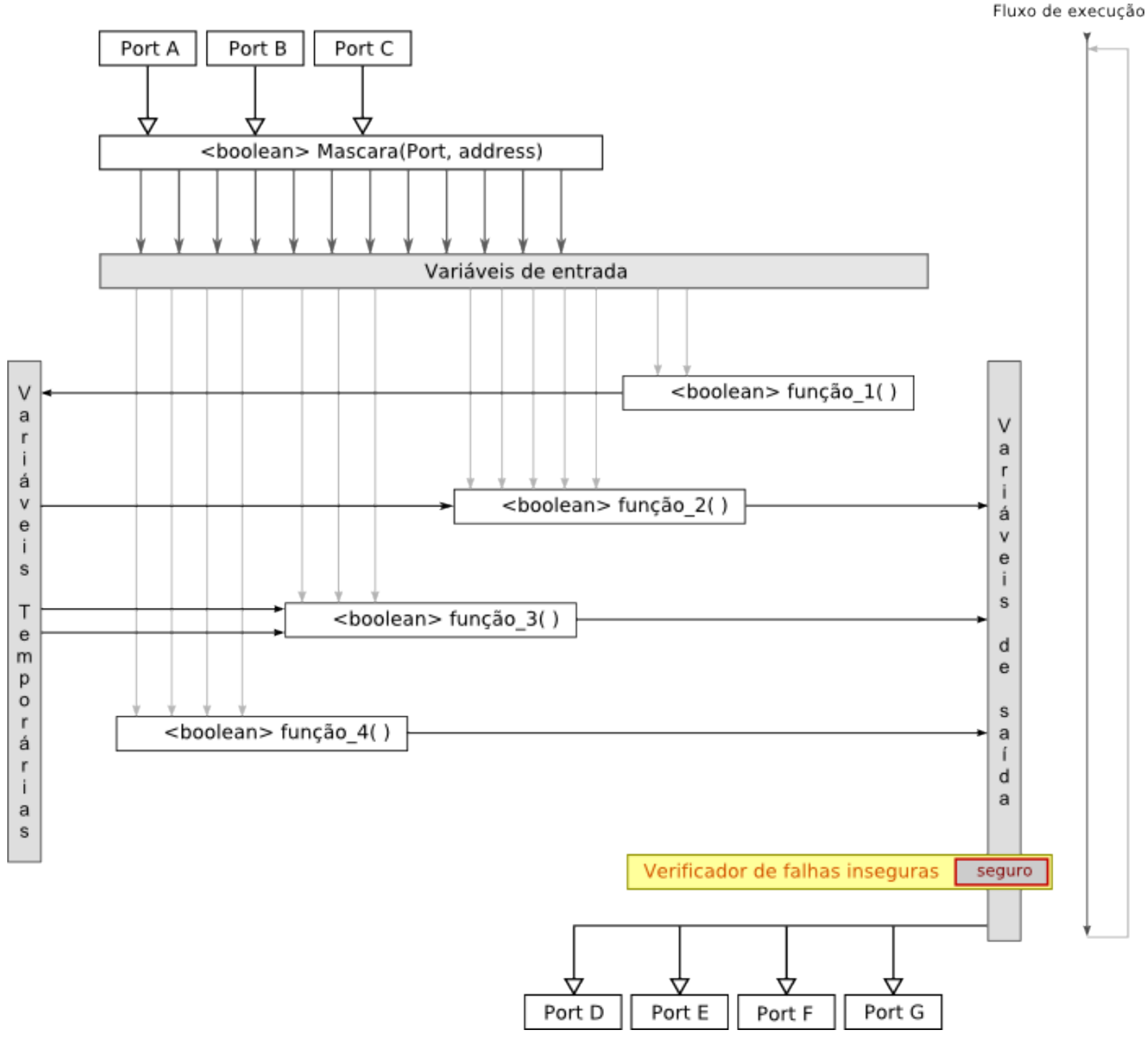

Figura 11 - Aplicação da técnica baseada em forward recovery 


\subsection{Duplicação de variáveis}

Nessa técnica, as variáveis de entrada e saída são duplicadas. A comparação de variáveis de entrada é feita toda vez que se faz necessária sua leitura. Já as variáveis de saída, são comparadas ao final de cada ciclo. Dessa forma, produz-se redundância espacial, o que reduz a probabilidade de ocorrência de falhas inseguras ou não, que tenham como origem um erro gerado sobre alguma dessas variáveis. Ao detectar um erro, o fluxo normal do programa é desviado para o seu início, impedindo, dessa forma, que as portas de saídas sejam atualizadas. Esse processo é descrito na figura 12.

Em (REBAUDENGO; SONZA; TORCHIANO; VIOLANTE, 1999) propõem uma abordagem baseada na introdução de redundância para dados e instruções de acordo com um conjunto de transformações sobre código de alto-nível. Os resultados preliminares do experimento desenvolvido mostraram que esse método é capaz de detectar uma alta percentagem de falhas, tendo um custo aproximado sobre o tamanho de código de duas vezes e sobre o desempenho, de cinco vezes.

Tal proposta foi explorada experimentalmente em (BENSO; REBAUDENGO; REORDA; CIVERA, 1998), através de um processo de injeção de falhas que difere em vários aspectos, da proposta do estudo aqui descrito. 


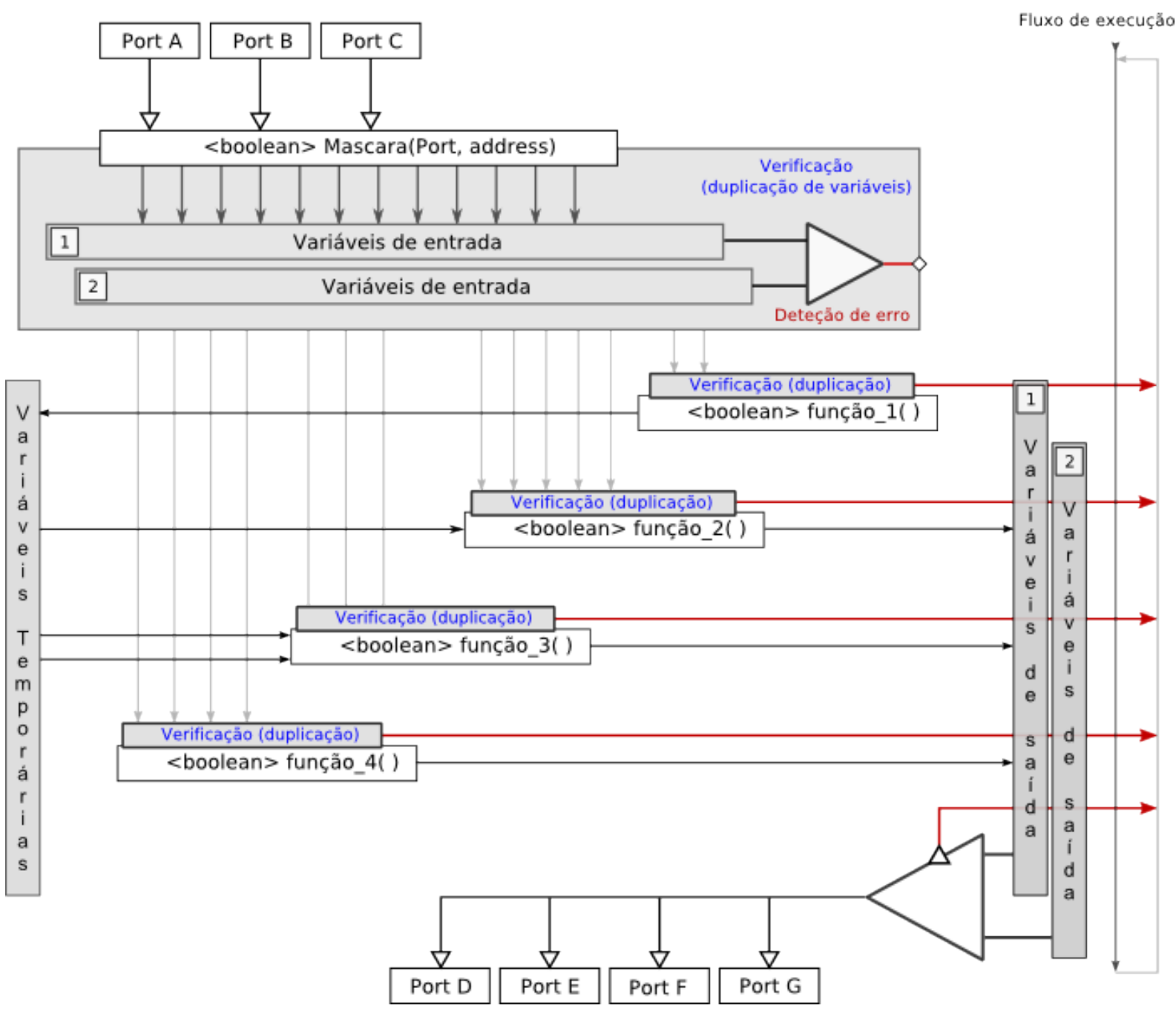

Figura 12 - Aplicação da técnica baseada em duplicação de variáveis

\subsection{Diversidade}

A técnica de diversidade, que também pode ser considerada neste estudo como duplicação de instruções, cria, tal como na técnica de duplicação de variáveis, redundância espacial como meio para se detectar erros. No código fonte do programa alvo, cada uma das equações booleanas é escrita duas vezes. A partir de análises feitas sobre o código de máquina gerado, observou-se que o processo de compilação, gerou da mesma forma duplicidade de instruções, o que garante a aplicação da técnica tal como planejado. Dessa forma, a detecção de um erro ocorre 
quando identificada diferença entre os resultados de booleanas funcionalmente idênticas, mas que fisicamente estão alocadas em posições distintas da memória.

Ao detectar um erro, o fluxo normal do programa é desviado para o seu início, impedindo dessa forma que as portas de saídas sejam atualizadas.

A figura 13 descreve esse processo.

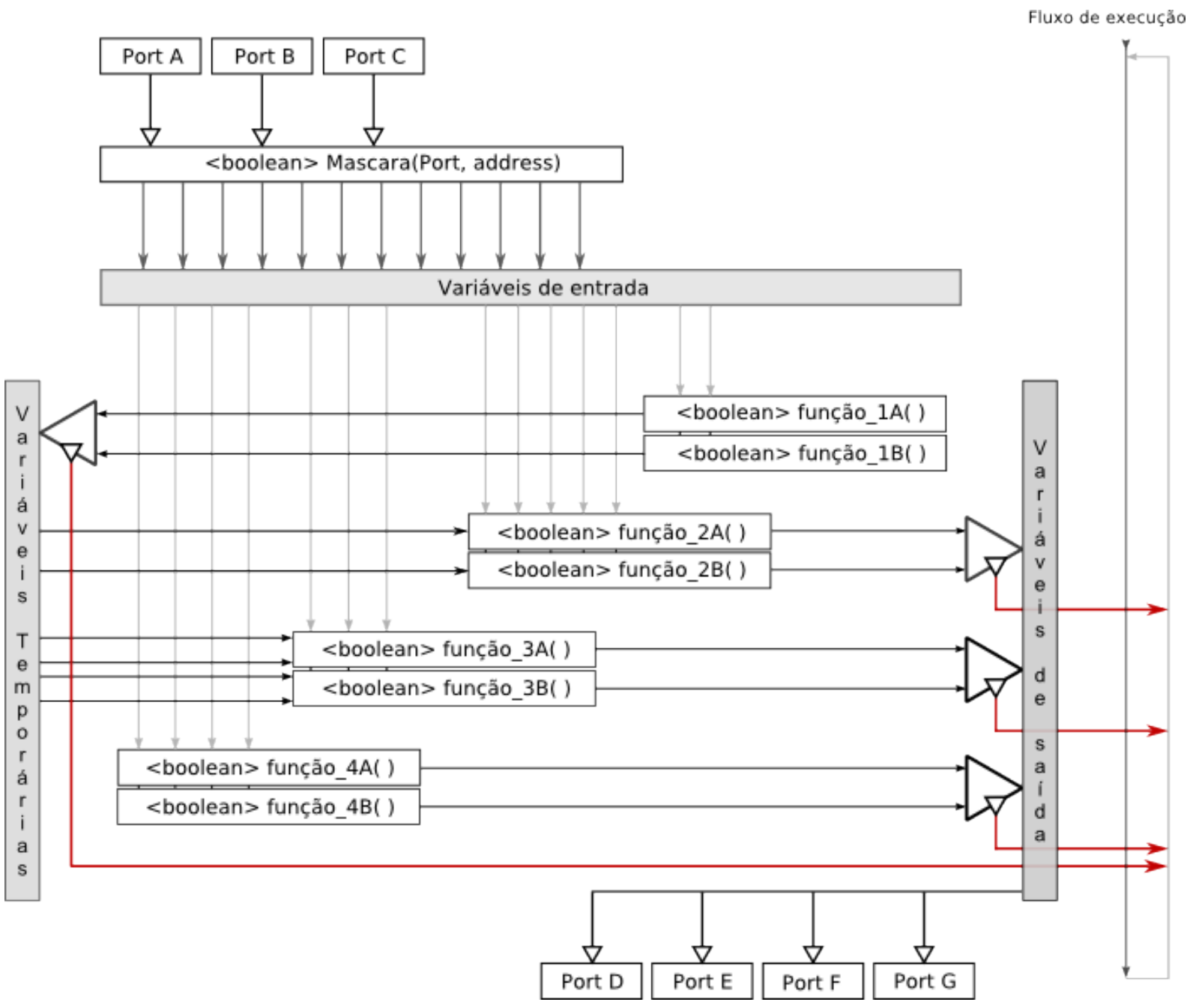

Figura 13 - Aplicação da técnica baseada em diversidade

A duplicação de instruções pode alcançar níveis de cobertura de erros relativamente altos, como podemos observar em trabalhos como $(\mathrm{OH}$; SHIRVANI; MCCLUSKEY, 2002). A cobertura de erro estimada é de cerca de 98,2\% em oito dos 
programas avaliados no trabalho; durante o experimento a cobertura de erro chegou a alcançar 98,5\%. Em contrapartida, pela adição de instruções extras no código original, os programas com EDDI - Erro Detection by Duplicated Instructions - se caracterizam pelo acréscimo no tamanho do código e perda de desempenho. Além disso, em função da utilização de registradores de uso geral como registradores "sombra", ocorre o efeito de "spilling", o que acarreta em mais perda desempenho devido à ocorrência de um número maior de operações sobre a memória. Essa conseqüência indesejada não deve ser levada em consideração de forma absoluta para todo tipo de algoritmo. Por exemplo, multiplicações em matrizes exigem o maior número de registradores disponíveis, para que os seus elementos possam ser ali mantidos. Já algoritmos baseados em Fibonacci exigem um pequeno número de registradores, uma vez que é necessário apenas manter os dois últimos valores calculados.

Finalizadas as versões do programa alvo que fazem uso de técnicas de programação defensiva individualmente, surge a possibilidade de aplicação destas em pares. As combinações de técnicas de programação defensiva e suas características são descritas no capítulo 5. 


\section{COMBINAÇÃO DE TÉCNICAS DE PROGRAMAÇÃO DEFENSIVA}

A partir desse ponto, serão aplicadas ao menos duas técnicas de programação defensiva sobre o programa alvo.

Um aspecto importante a ser considerado é a função a que se propõe a aplicação de uma determinada técnica de programação defensiva. Dentre as técnicas selecionadas para o experimento, pode-se distinguir paridade, checksum, duplicação de variávies e duplicação de instruções como técnicas cuja única função

é a de detectar falhas. Já backward recovery e forward recovery se propõem unicamente a corrigir falhas; e por fim $\mathrm{BCH}$ é a única que possui ambas as funções.

Em função das características descritas anteriormente, é possível observar que em certos casos (e.g. aplicação de técnicas que apenas detectam erros) surge a necessidade de suprir o processo de "correção e detecção" com uma rotina adicional. Para isso são usadas as rotinas complementares "seguro" e "verificador de falhas inseguras" que têm respectivamente as funções de corrigir e detectar falhas.

De forma resumida, a rotina "seguro" produz uma resposta considerada livre de erros inseguros e como efeito resultante gera uma condição de operação degradada do sistema. Essencialmente, a resposta dada pelo sistema quando a rotina "seguro" é ativada, pode ser definida como uma série de estados restritivos. Tal característica reproduz o processo de correção de erros. Já a rotina "verificador de falhas inseguras" identifica uma resposta do sistema considerada insegura e por meio dessa característica é capaz de reproduzir o processo de detecção de erros. 
Colocado dessa maneira, identificamos ainda, a relação de dependência entre as funções mencionadas: a correção de uma falha é efetiva apenas após a identificação da mesma através da detecção, exercida por outra técnica.

De maneira geral, as técnicas quando aplicadas individualmente podem assumir a função de detecção ou de correção - com exceção da técnica BCH que assume ambas as funções. Então, aplica-se uma rotina auxiliar, nos casos em que estas sejam necessárias para que o sistema em avaliação se torne tolerante a falhas. Em uma segunda etapa, onde se aplicam duas técnicas combinadas, a rotina auxiliar é substituída por uma técnica de programação defensiva. O que diferencia tais abordagens está na possibilidade de identificar padrões comuns entre as combinações e que esses nos levem a uma caracterização mais clara da aplicação de uma determinada técnica em detrimento de outras.

\subsection{Combinação da técnica forward recovery e demais técnicas}

As técnicas descritas nos tópicos anteriores que tem a função de detecção de erros - paridade, checksum, duplicação de variáveis e diversidade - são combinadas com a técnica forward recovery de maneira que a detecção de um erro cause a chamada da função "seguro". Dessa forma, a aplicação de tais combinações é similar ao que foi descrito anteriormente. O apêndice B contém o diagrama descritivo para estes casos. 


\subsection{Checksum e backward recovery}

Em um primeiro caso, aplica-se checksum e backward recovery, figura 14. A técnica de checksum como foi mencionado anteriormente, exerce sobre o sistema apenas a função de detecção de erros. Já a técnica backward exerce apenas a função de correção de erros. Assim, as variáveis de entradas são protegidas durante todo o ciclo e caso seja detectado um erro, o programa recupera os valores obtidos no ciclo anterior e os disponibiliza na saída.

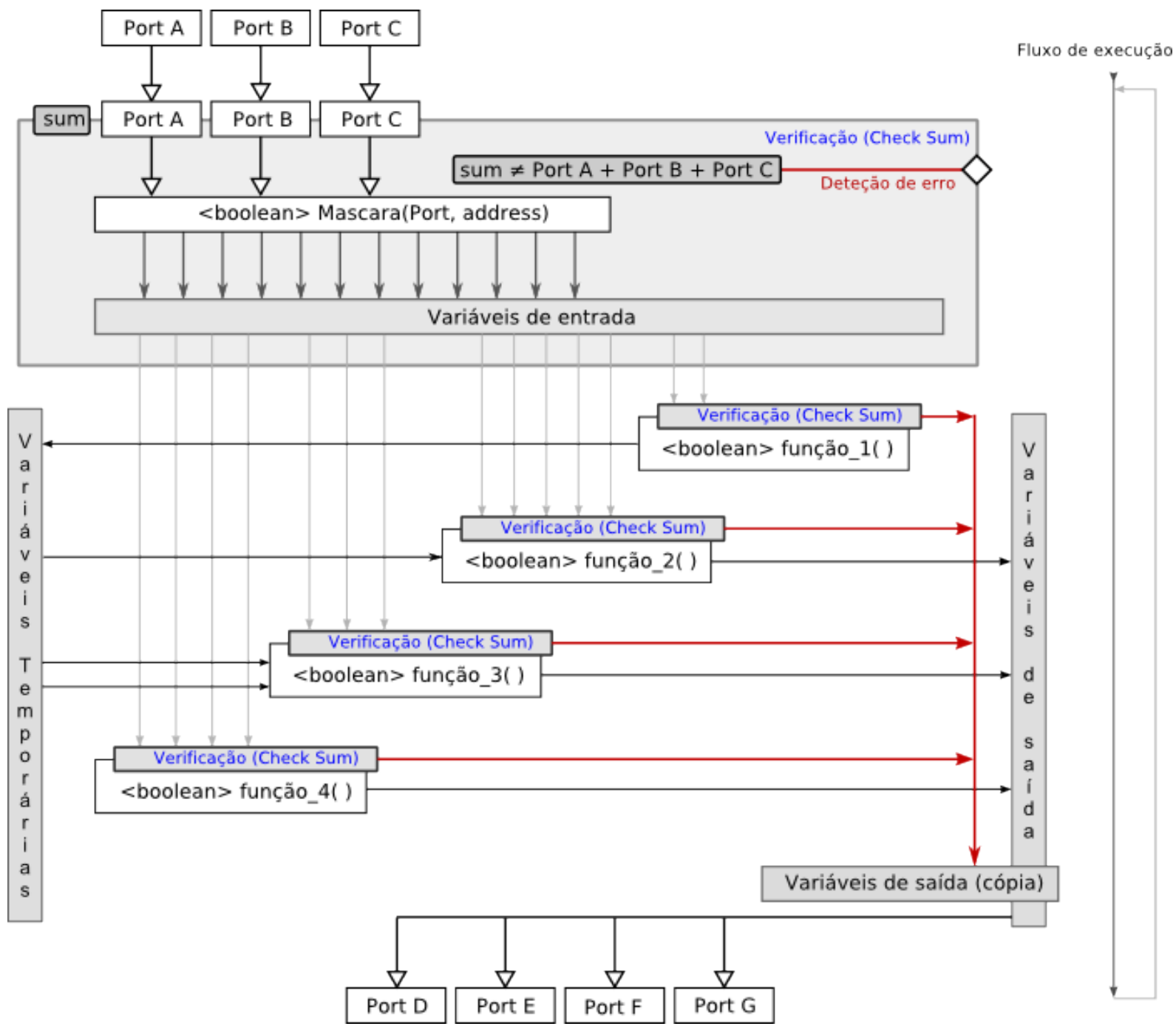

Figura 14 - Aplicação das técnicas backward recovery e checksum combinadas 


\subsection{Diversidade e backward recovery}

A figura 15 descreve a combinação entre as técnicas diversidade e backward recovery. A técnica de diversidade tem a função de detecção de falhas enquanto backward recovery a função de correção. Dessa forma, assim que uma falha é detectada através da diferença de resultados entre quaisquer booleanas funcionalmente iguais, o programa é desviado para o processo de correção que irá recuperar os valores de todas as variáveis de saída obtidos no ciclo anterior e disponibilizá-las.

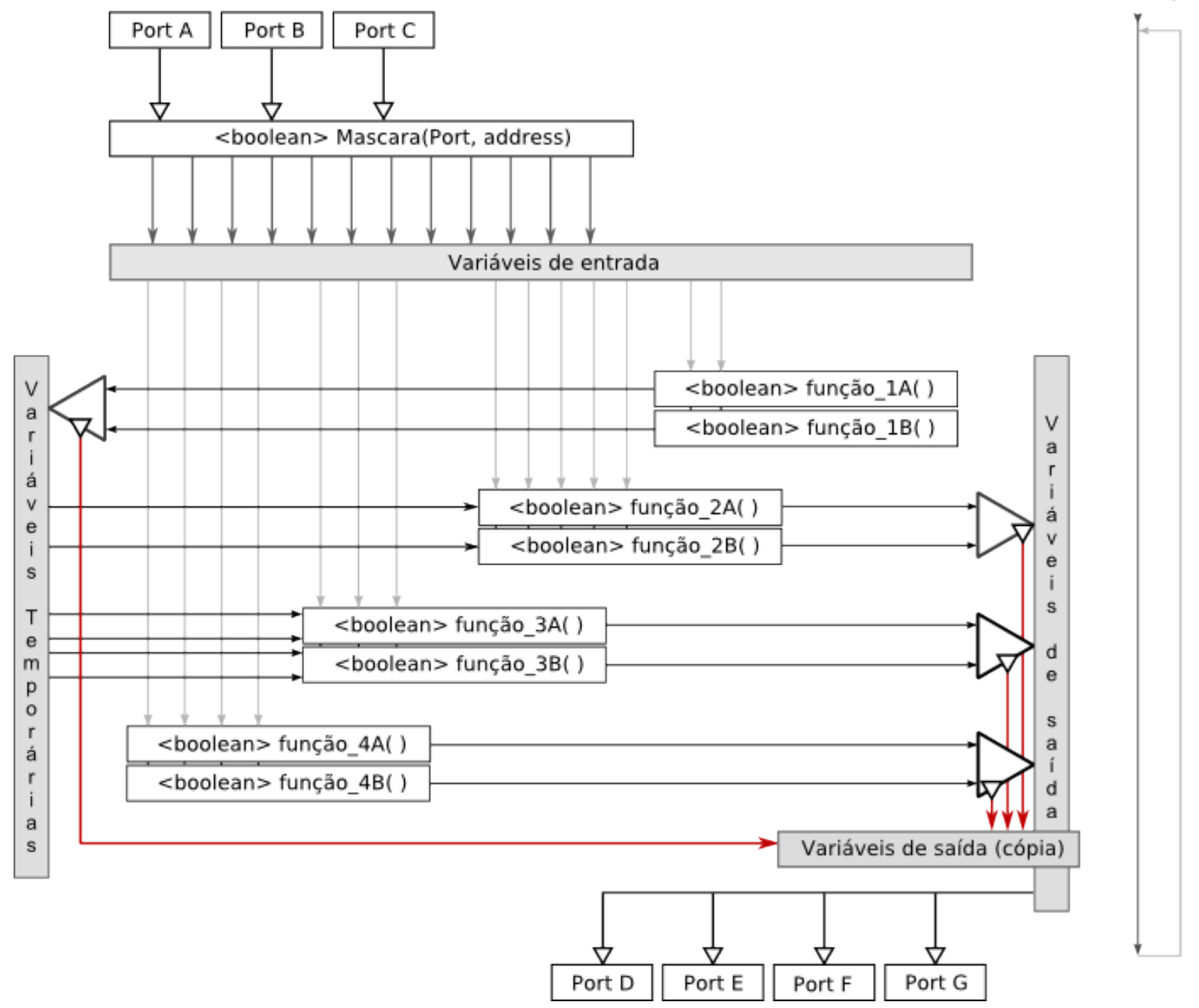

Figura 15 - Aplicação das técnicas backward recovery e diversidade combinadas 


\subsection{Paridade e backward recovery}

A figura 16 descreve a combinação entre as técnicas paridade e backward recovery. A técnica de paridade tem a função de detecção de falhas, enquanto backward recovery a função de correção. Dessa forma, assim que uma falha é detectada através da inconsistência de paridade de uma variável de entrada, o programa é desviado para o processo de correção, que irá recuperar os valores de todas as variáveis de saída obtidos no ciclo anterior e disponibilizá-las.

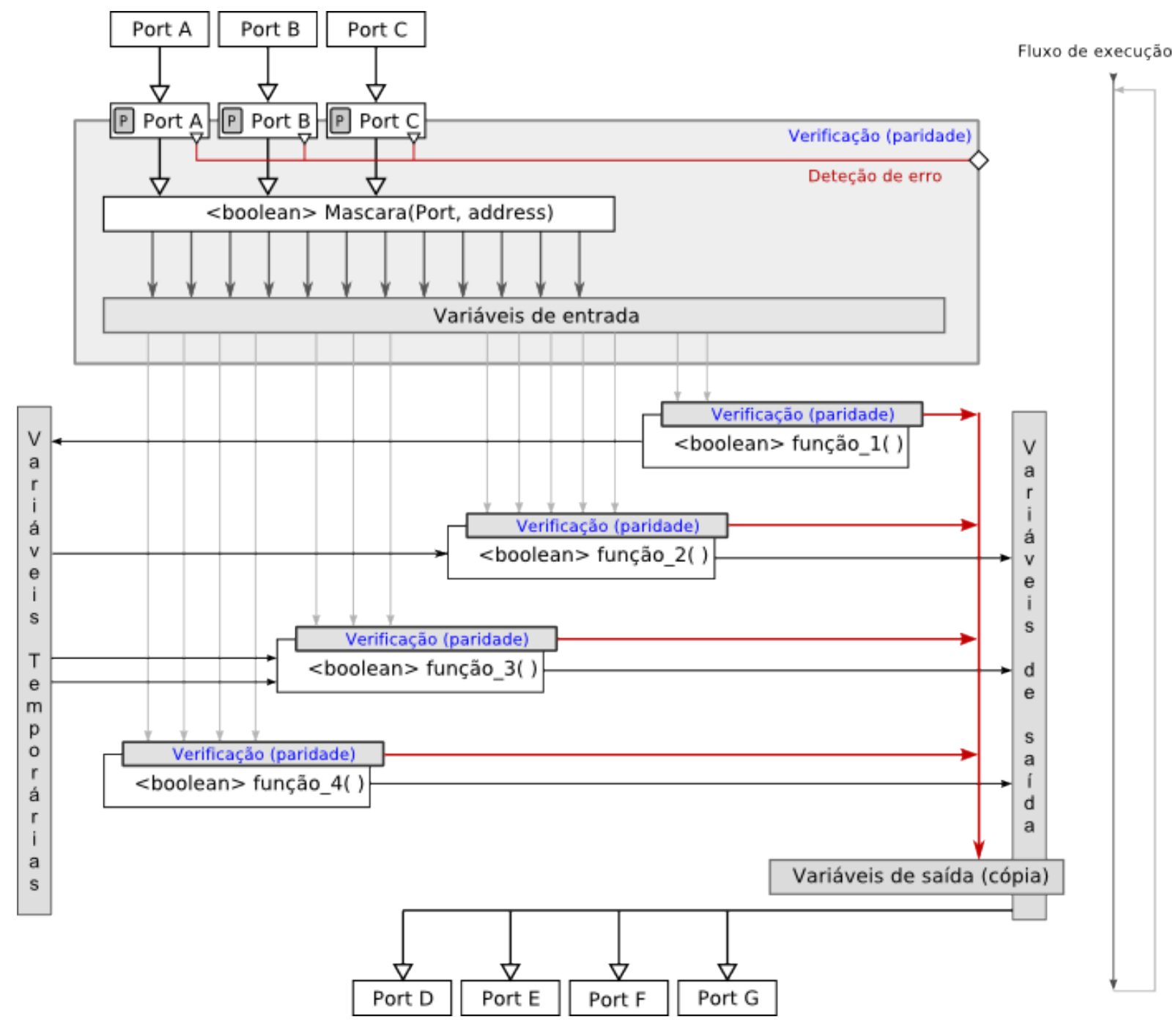

Figura 16 - Aplicação das técnicas backward recovery e paridade combinadas 


\subsection{Duplicação de variáveis e backward recovery}

A figura 17 descreve a combinação entre as técnicas de duplicação de variáveis e backward recovery. A técnica de duplicação de variáveis tem a função de detecção de falhas enquanto backward recovery a função de correção. Dessa forma, assim que uma falha é detectada através da diferença entre os valores de duas variáveis que representam na verdade, a mesma saída ou a mesma entrada, o programa é desviado para o processo de correção que irá recuperar os valores de todas as variáveis de saída obtidos no ciclo anterior e disponibilizá-las.

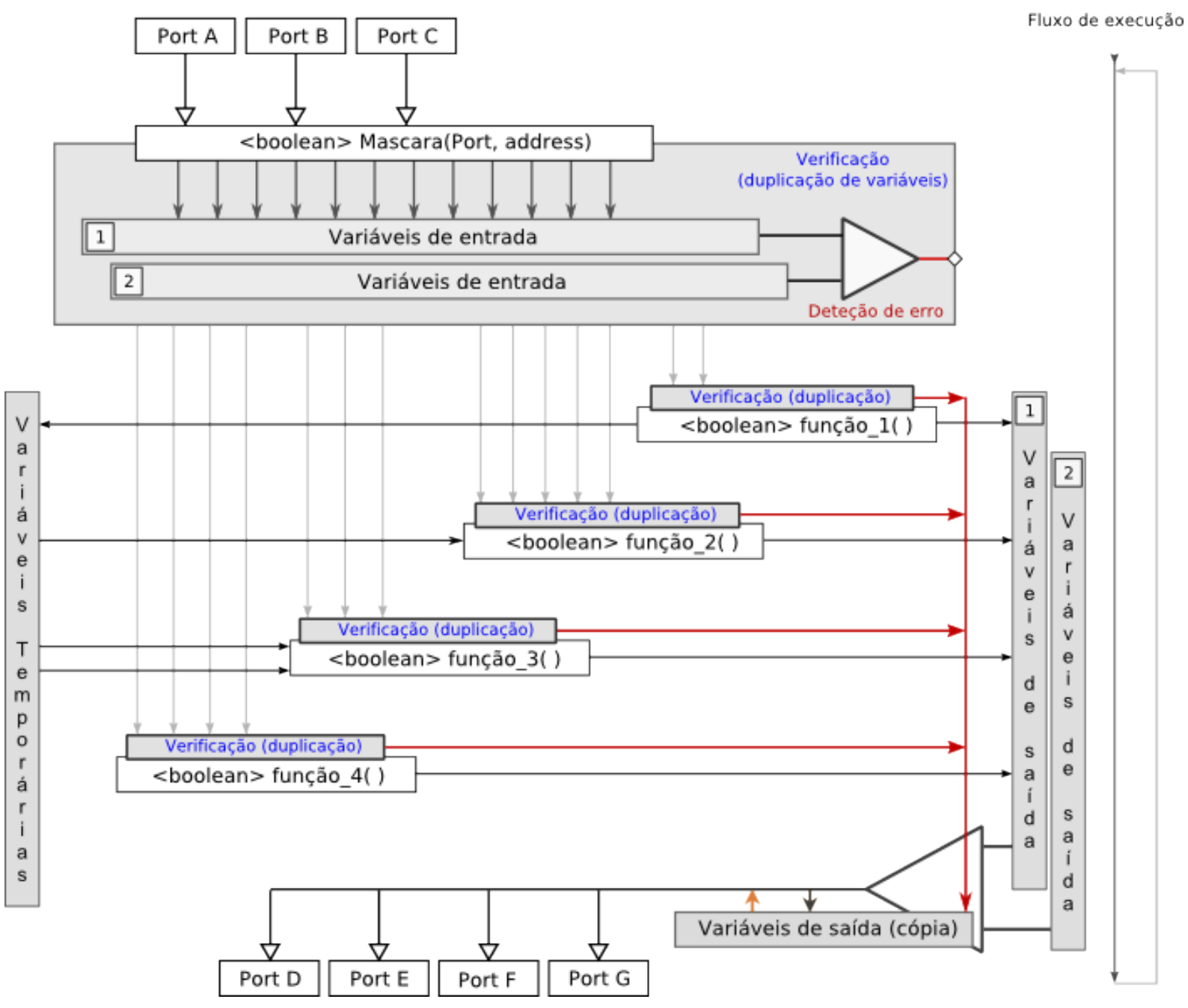

Figura 17 - Aplicação das técnicas duplicação de variáveis e backward recovery combinadas 


\subsection{BCH code e backward recovery}

A figura 18 descreve a combinação entre as técnicas de $\mathrm{BCH}$ e backward recovery. A técnica $\mathrm{BCH}$ contém os processos de detecção e correção integrados de tal forma, que a dissociação entre eles se torna pouco conveniente.

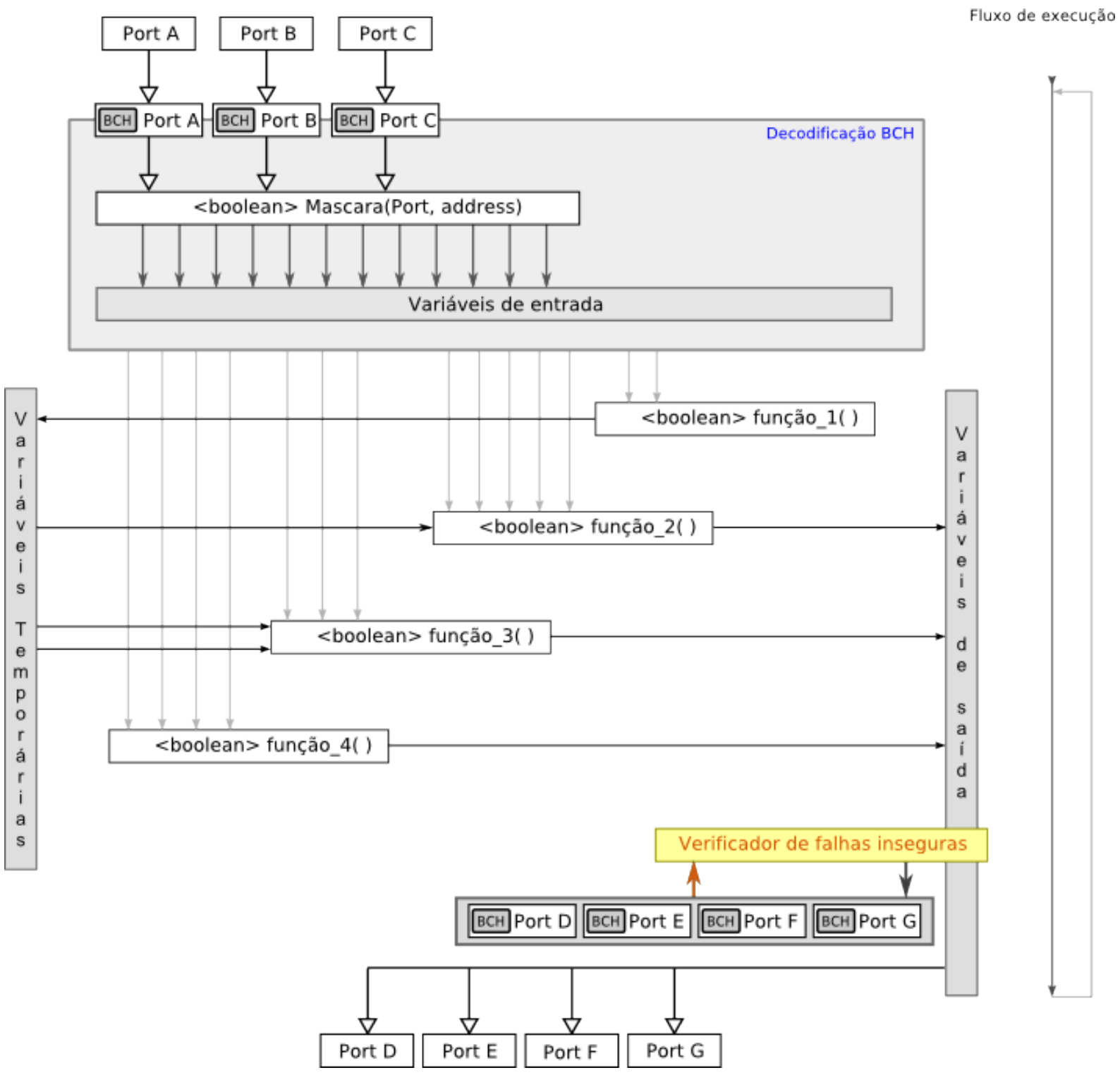

Figura 18 - Aplicação das técnicas $\mathrm{BCH}$ e backward recovery combinadas 
Dessa forma, ao combinarmos $\mathrm{BCH}$ e backward, que é essencialmente destinada a correção de falhas, o acréscimo de um terceiro processo, cuja função é exclusivamente detectar falhas, se torna necessário. Para essa finalidade a rotina "verificador de falhas inseguras", já descrita em outros tópicos, foi integrada ao programa.

Assim, quando tal rotina detecta uma falha através da inconsistência dos valores contidos nas variáveis de saída, o programa é desviado para o processo de recuperação. Esse processo é essencialmente a aplicação da técnica backward recovery, com a adição dos processos de codificação e decodificação $\mathrm{BCH}$. Dessa forma, os dados obtidos no ciclo anterior, necessários ao processo de recuperação, possuem uma proteção adicional por meio da técnica $\mathrm{BCH}$.

\section{7. $\mathrm{BCH}$ code e checksum}

A figura 19 descreve a combinação entre as técnicas $\mathrm{BCH}$ e checksum. A técnica $\mathrm{BCH}$ contém os processos de detecção e correção integrados. Já a técnica checksum exerce sobre o sistema apenas a função de detecção de erros. O padrão adotado para a integração entre as duas técnicas impõe primeiramente a aplicação da técnica $\mathrm{BCH}$, seguida da aplicação da técnica checksum. Optou-se por essa configuração porque na ocorrência de um erro, $\mathrm{BCH}$ tenta recuperar o dado de entrada original. Caso $\mathrm{BCH}$ obtenha sucesso a técnica checksum é transparente ao processo. Já em caso de insucesso, existe a chance de detecção de erro por checksum, e neste caso, haverá um desvio do fluxo do programa para o seu início. 


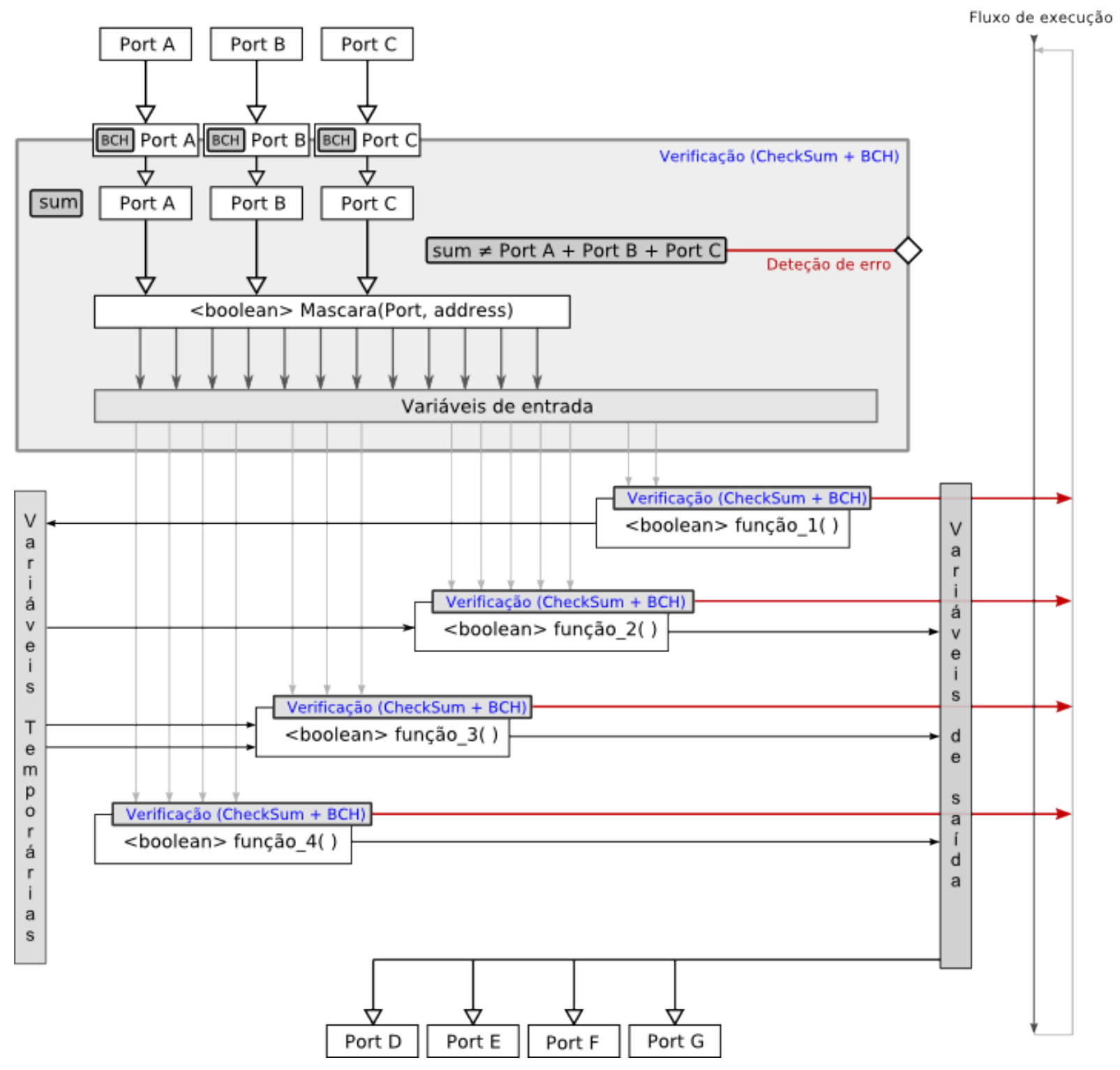

Figura 19 - Aplicação das técnicas BCH e Checksum combinadas

\section{8. $\mathrm{BCH}$ code e diversidade}

A figura 20 descreve a combinação entre as técnicas $\mathrm{BCH}$ e diversidade. A função da técnica $\mathrm{BCH}$ é detectar e recuperar os erros associados à corrupção dos dados de entrada. Já a técnica diversidade tem a função de detectar erros por meio de redundância espacial, onde cada função booleana é duplicada e os resultados comparados. Em caso de diversidade entre os resultados, o programa é desviado para o seu início. 


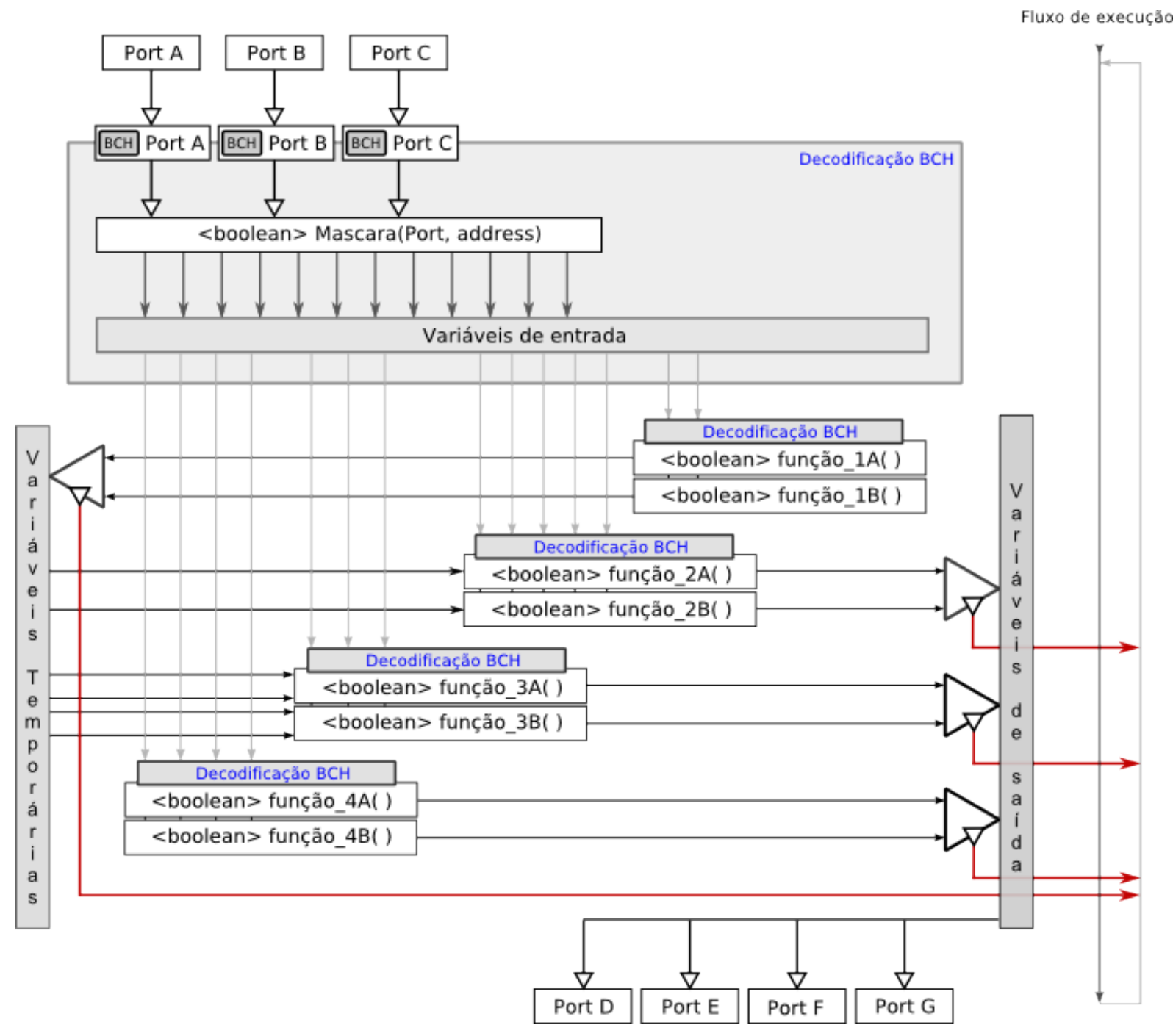

Figura 20 - Aplicação das técnicas BCH e diversidade combinadas

\section{9. $\mathrm{BCH}$ code e forward recovery}

A figura 21 descreve a combinação entre as técnicas $\mathrm{BCH}$ e forward recovery. A função da técnica $\mathrm{BCH}$ é detectar e recuperar os erros associados à corrupção dos dados de entrada. Para complementar a técnica forward recovery, que tem apenas a função de recuperar erros que se manifestem sobre os dados de saída, aplica-se a rotina "verificador de falhas inseguras". Além disso, cabe salientar que a técnica forward recovery foi implementada através da rotina "seguro". 


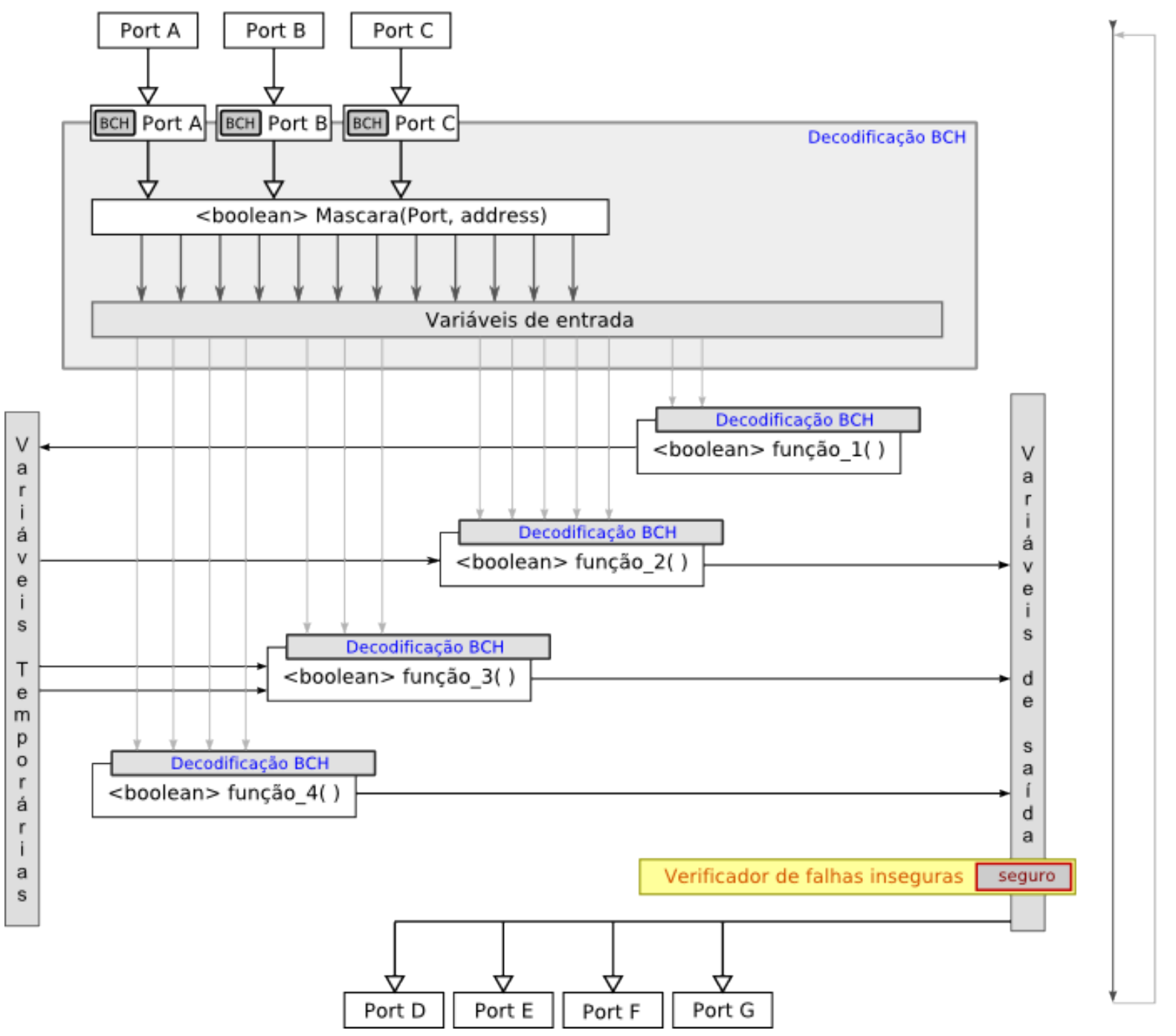

Figura 21 - Aplicação das técnicas $\mathrm{BCH}$ e forward recovery combinadas

\subsection{Paridade e BCH code}

A figura 22 descreve a combinação das técnicas paridade e $\mathrm{BCH}$. De forma similar a combinação entre as técnicas $\mathrm{BCH}$ code e checksum, a combinação entre paridade e $\mathrm{BCH}$ contém processos de detecção e correção integrados através dessa última e a técnica paridade tem apenas a função de detecção de erros. Além disso, o padrão adotado para a integração entre as duas técnicas impõe primeiramente a aplicação da técnica $\mathrm{BCH}$ seguida da aplicação da técnica paridade, pelas mesmas razões que as descritas anteriormente. 


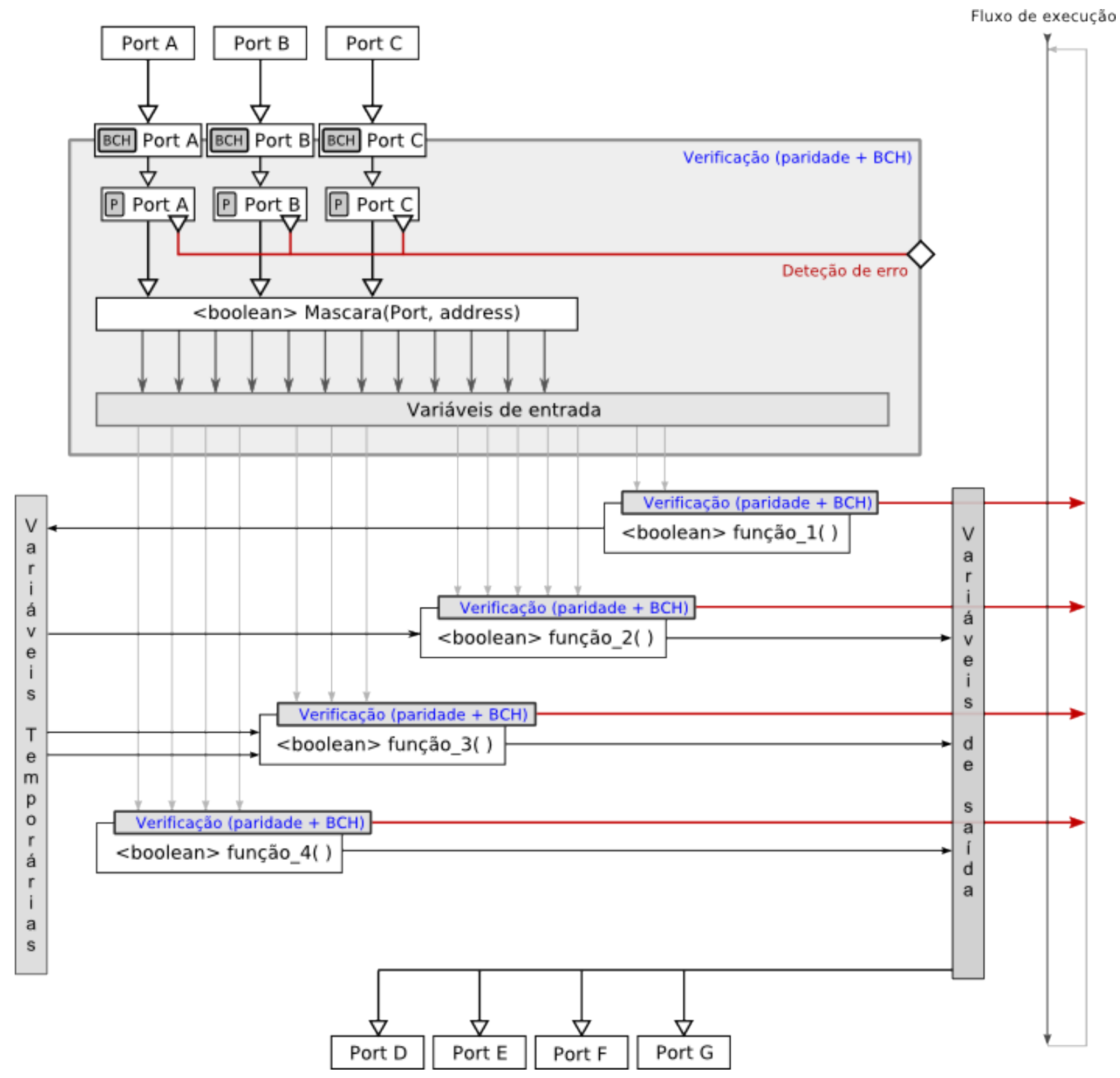

Figura 22 - Aplicação das técnicas BCH e paridade combinadas

\subsection{Duplicação de variáveis e $\mathrm{BCH}$ code}

A figura 23 descreve a combinação entre as técnicas $\mathrm{BCH}$ e duplicação de variáveis. Nessa combinação, a função da técnica $\mathrm{BCH}$ é detectar e recuperar os erros associados à corrupção dos dados de entrada. Já a técnica de duplicidade de variáveis tem a função de detectar erros por meio de redundância espacial, onde cada variável de saída é duplicada e os resultados comparados. 


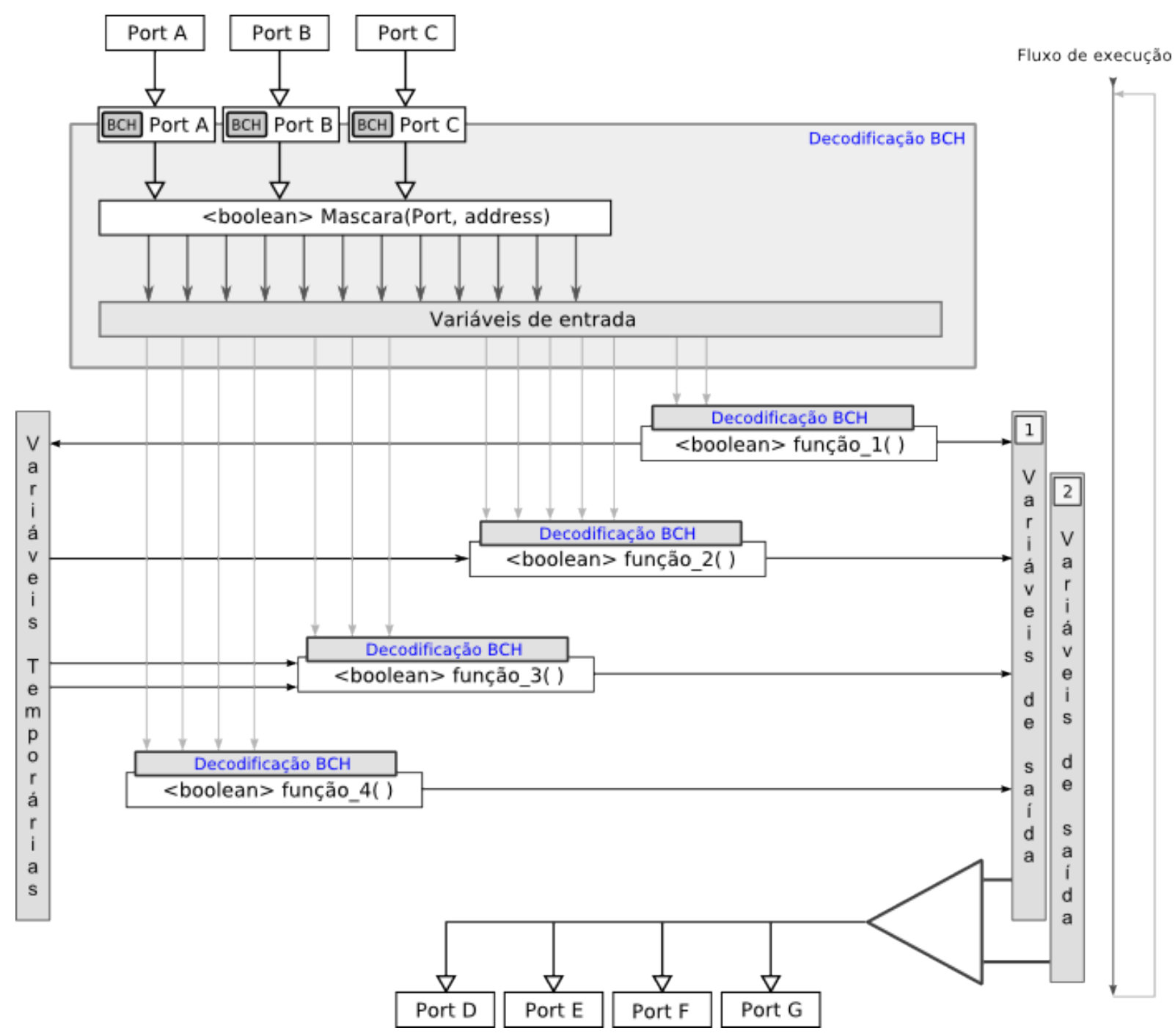

Figura 23 - Aplicação das técnicas de variáveis duplicadas e BCH combinadas

\subsection{Diversidade e checksum}

A figura 24 descreve a combinação entre as técnicas diversidade e checksum. A função da técnica checksum é detectar os erros associados à corrupção dos dados de entrada. Já a técnica diversidade tem a função de detectar erros por meio de redundância espacial, onde cada função booleana é duplicada e os resultados comparados. Em caso de diversidade entre os resultados, o programa é desviado para o seu início. 


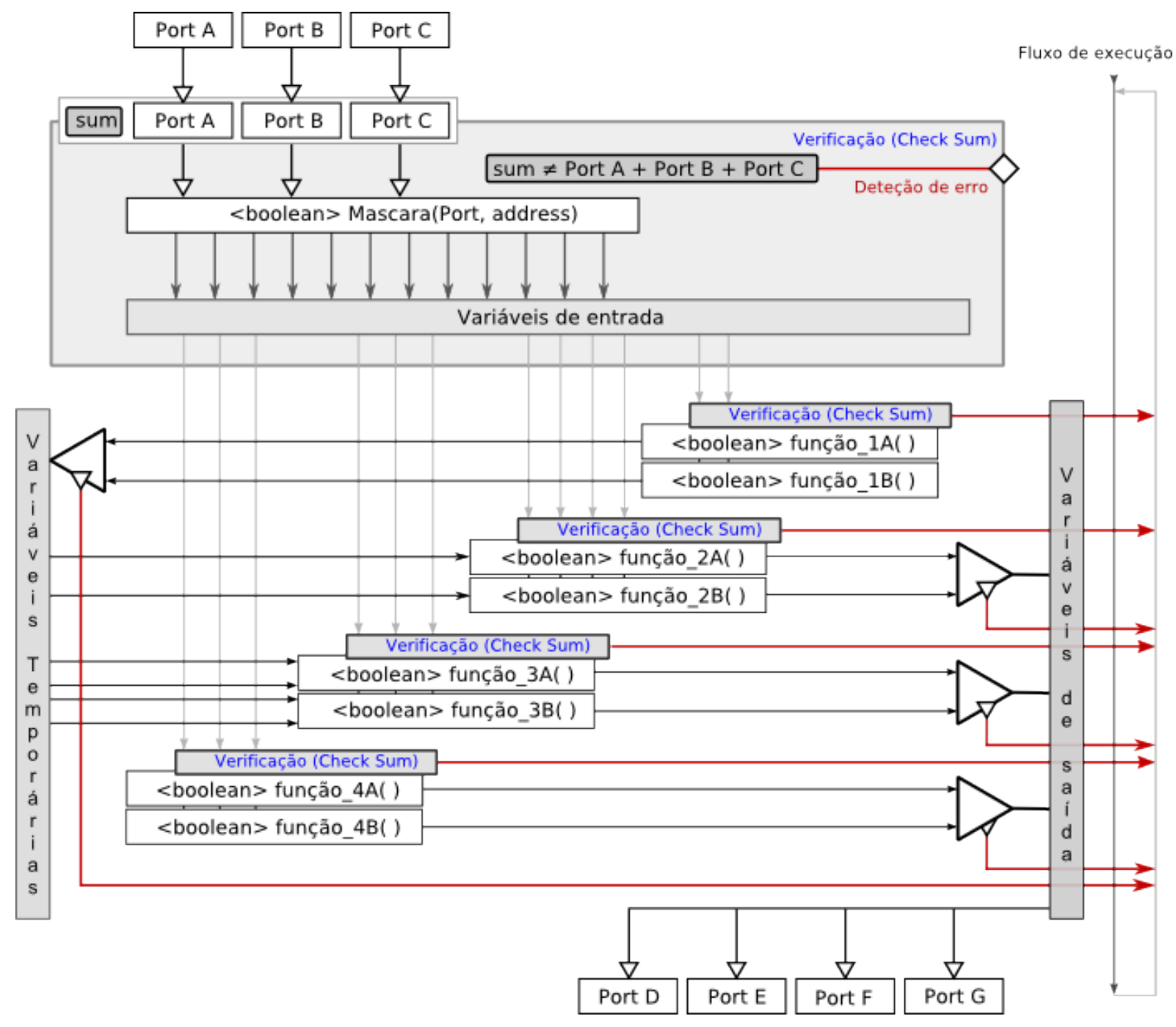

Figura 24 - Aplicação das técnicas de checksum e diversidade combinadas

\subsection{Paridade e checksum}

A figura 25 descreve a combinação entre as técnicas paridade e checksum. Ambas as técnicas, paridade e checksum exercem sobre o sistema a função de detecção de erros sobre as variáveis de entrada. Para este caso, observa-se que foi aplicada a união entre os domínios de detecção de cada uma das técnicas. Independentemente da ordem em que são aplicadas, o objetivo com essa combinação é a de "somar" a capacidade de detecção de ambas as técnicas. Dessa 
forma, quando um erro é detectado, seja por paridade ou por checksum, o programa é desviado para o seu início, impedindo assim a atualização das portas de saída.

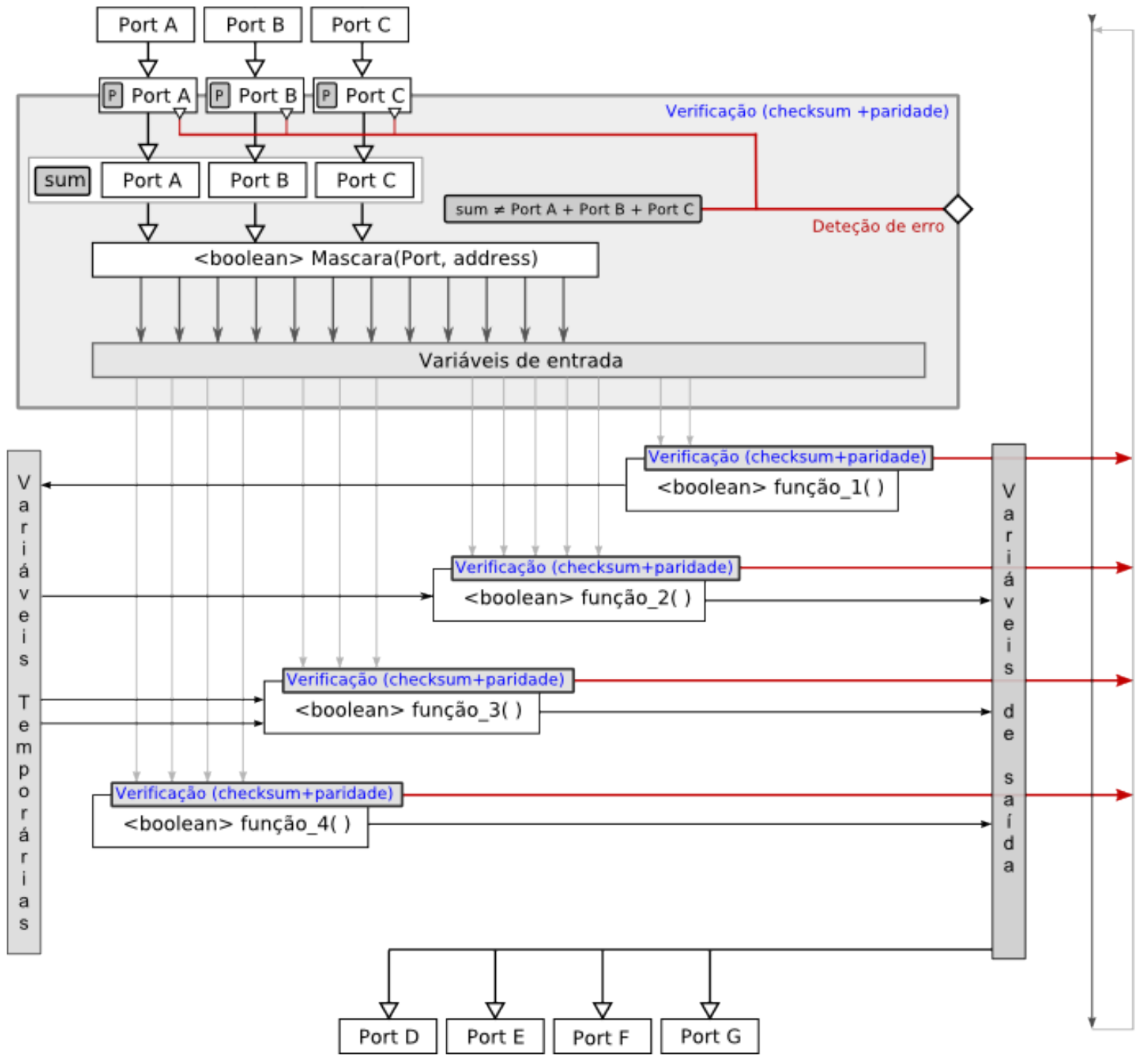

Figura 25 - Aplicação das técnicas checksum e paridade combinadas

\subsection{Duplicação de variáveis e checksum}

A figura 26 descreve a combinação entre as técnicas duplicação de variáveis e checksum. A função da técnica checksum é detectar os erros associados à corrupção dos dados de entrada. Já a técnica de variáveis duplicadas tem a função 
de detectar erros por meio de redundância espacial, onde cada variável de saída é duplicada e os resultados comparados. Em caso de diversidade entre os resultados, ou inconsistência por checksum, o programa é desviado para o seu início, impedindo a atualização das portas de saída.

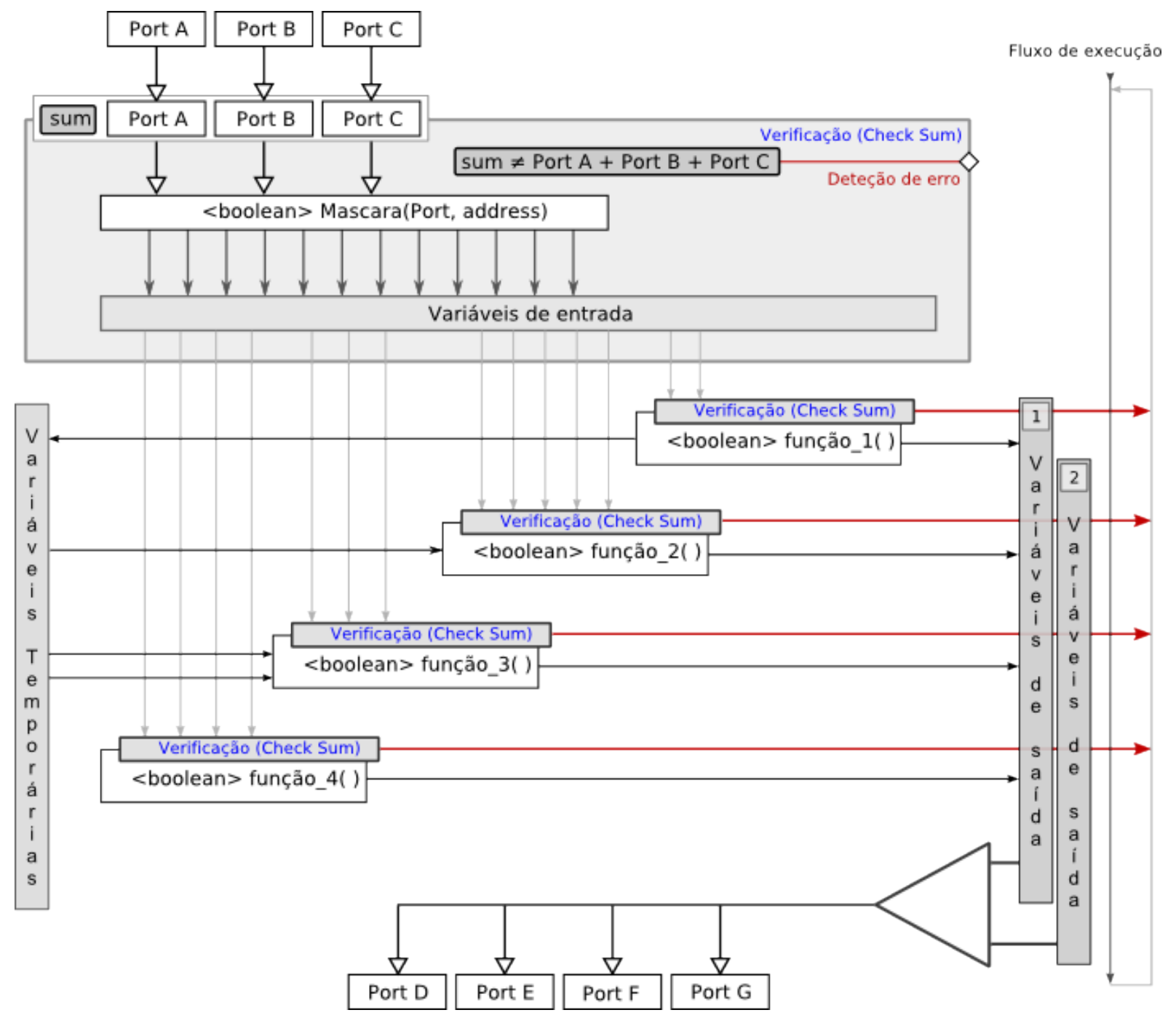

Figura 26 - Aplicação das técnicas de duplicação de variáveis e checksum combinadas 


\subsection{Diversidade e duplicação de variáveis}

A figura 27 descreve a combinação entre as técnicas duplicação de variáveis e diversidade. A técnica de duplicação de variáveis tem a função de detectar erros por meio de redundância espacial, onde variáveis de entrada e de saída são duplicadas e os resultados comparados.

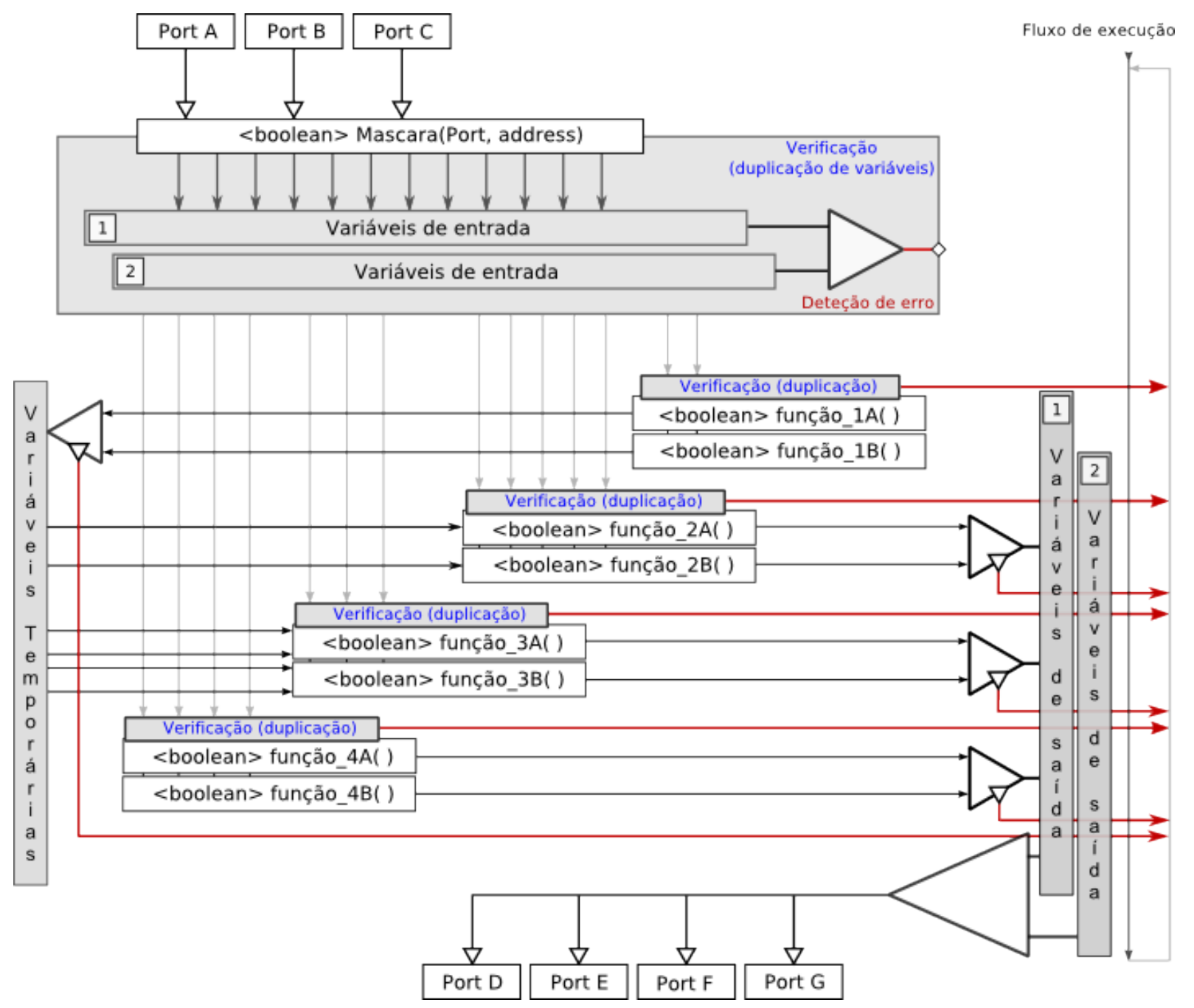

Figura 27 - Aplicação das técnicas de duplicação de variáveis e diversidade combinadas

A técnica diversidade também detecta erros por meio de redundância espacial, onde cada função booleana é duplicada e os resultados comparados. Em caso de 
diversidade, seja pelo resultado das booleanas ou pela comparação entre as variáveis de saída, o fluxo do programa é desviado para o seu início impedindo que as portas de saída sejam atualizadas.

\subsection{Forward e backward recovery}

A figura 28 descreve a combinação das técnicas forward e backward combinadas. Para este caso, ambas as técnicas exercem sobre o sistema a função de recuperação de erros. Por isso, foi aplicada a rotina complementar "verificador de falhas inseguras", com o objetivo de possibilitar que os erros sejam antes, detectados. O padrão adotado neste caso aplica primeiramente a técnica backward recovery com sua rotina de detecção própria. Essa abordagem permite que quando um erro é detectado, haja a tentativa de recuperá-lo através da cópia dos dados de saída obtidos no ciclo anterior. Caso tais dados também estejam corrompidos, o fluxo do programa segue para uma nova tentativa de recuperação através da rotina complementar "seguro", para por fim atualizar as portas de saída. Caso os dados sejam recuperados pela primeira técnica, a técnica forward se torna transparente dentro do processo.

Cabe salientar que se optássemos pela ordem inversa de aplicação das técnicas, estaríamos protegendo os dados recuperados pela rotina "seguro", desde sua aplicação sobre o fluxo do programa, até a nova verificação por meio de backward, ou seja, durante um intervalo de tempo muito curto. Em tese, através da ordem adotada, é mais provável que haja a corrupção dos dados de cópia, já que tais dados ficam vulneráveis até o ciclo seguinte. Isso nos permite avaliar a eficácia de ambas às técnicas de forma mais abrangente. 


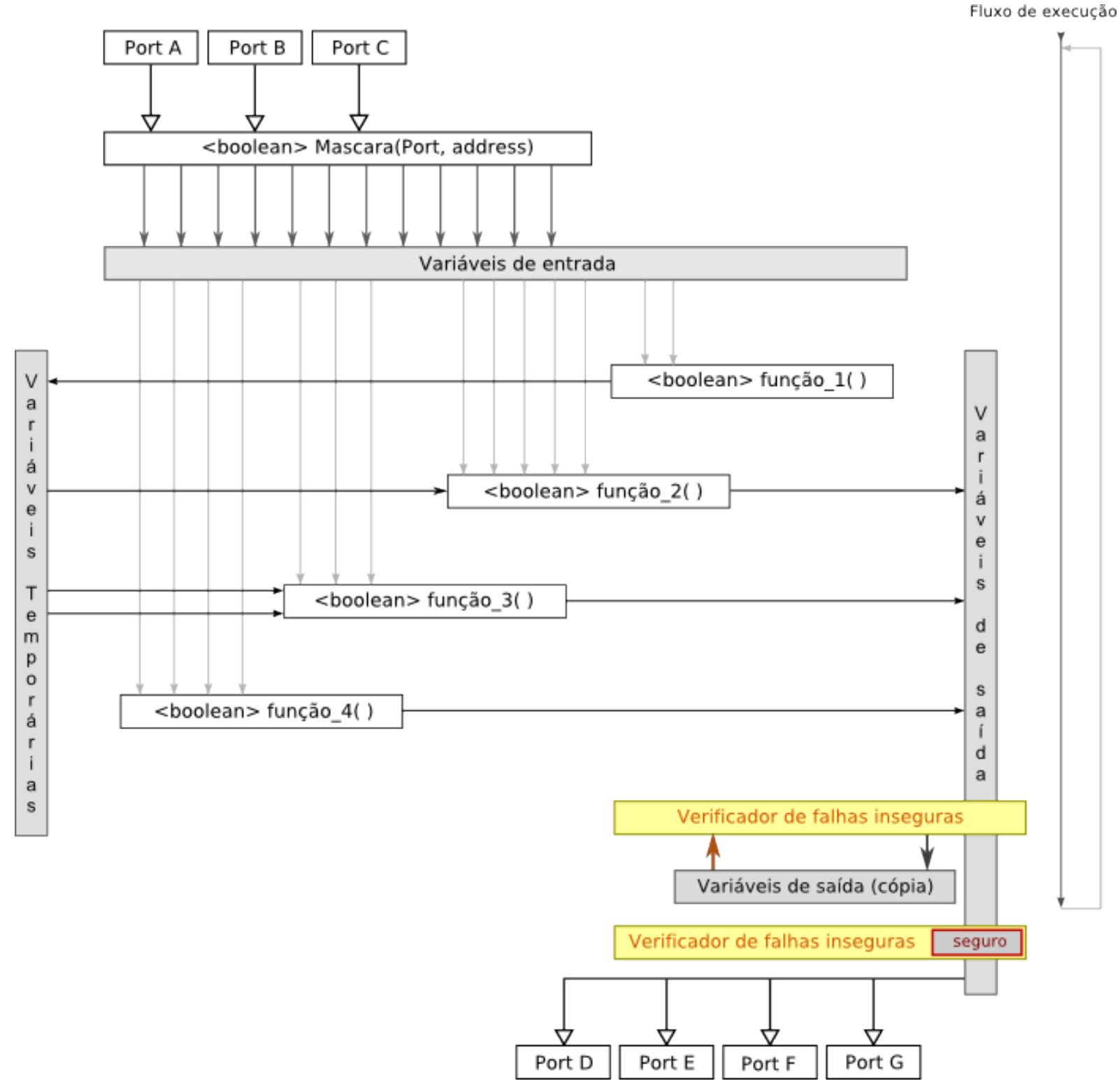

Figura 28 - Aplicação das técnicas forward recovery e backward recovery combinadas

\subsection{Paridade e diversidade}

A figura 29 descreve a combinação entre as técnicas paridade e diversidade. A função da técnica paridade é detectar os erros associados à corrupção dos dados de entrada. Já a técnica diversidade tem a função de detectar erros por meio de redundância espacial, onde cada função booleana é duplicada e os resultados 
comparados. Em caso de diversidade entre os resultados, o programa é desviado para o seu início impedindo assim que as portas de saída sejam atualizadas.

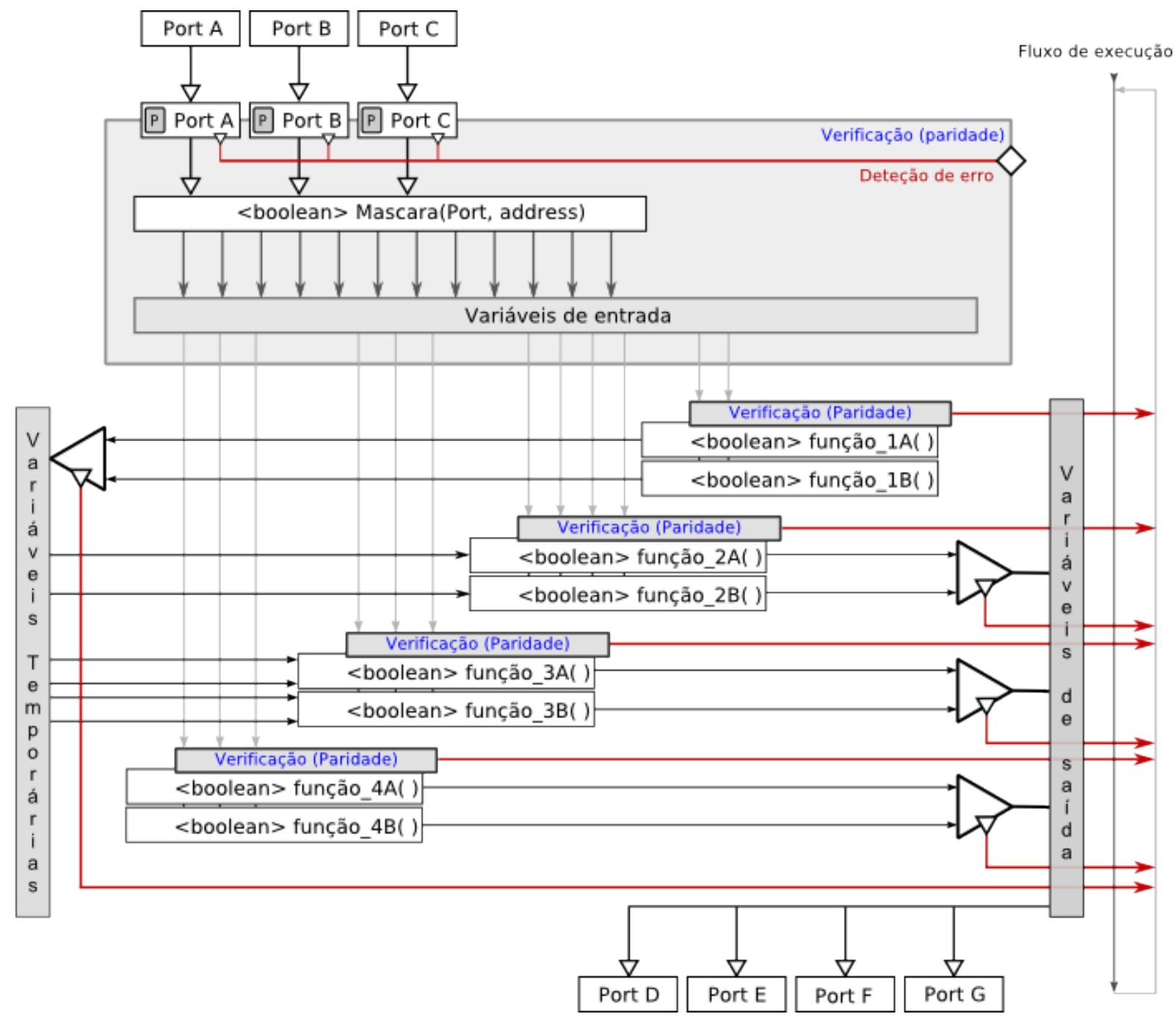

Figura 29 - Aplicação das técnicas de paridade e diversidade combinadas

\subsection{Duplicação de variáveis e paridade}

A figura 30 descreve a combinação entre as técnicas duplicação de variáveis e paridade. A função da técnica paridade é detectar os erros associados à corrupção dos dados de entrada. Já a técnica de duplicação de variáveis tem a função de detectar erros por meio de redundância espacial, onde cada variável de saída é 
duplicada e comparada com seu par. Em caso de diversidade entre os valores, o programa é desviado para o seu início impedindo assim que as portas de saída sejam atualizadas.

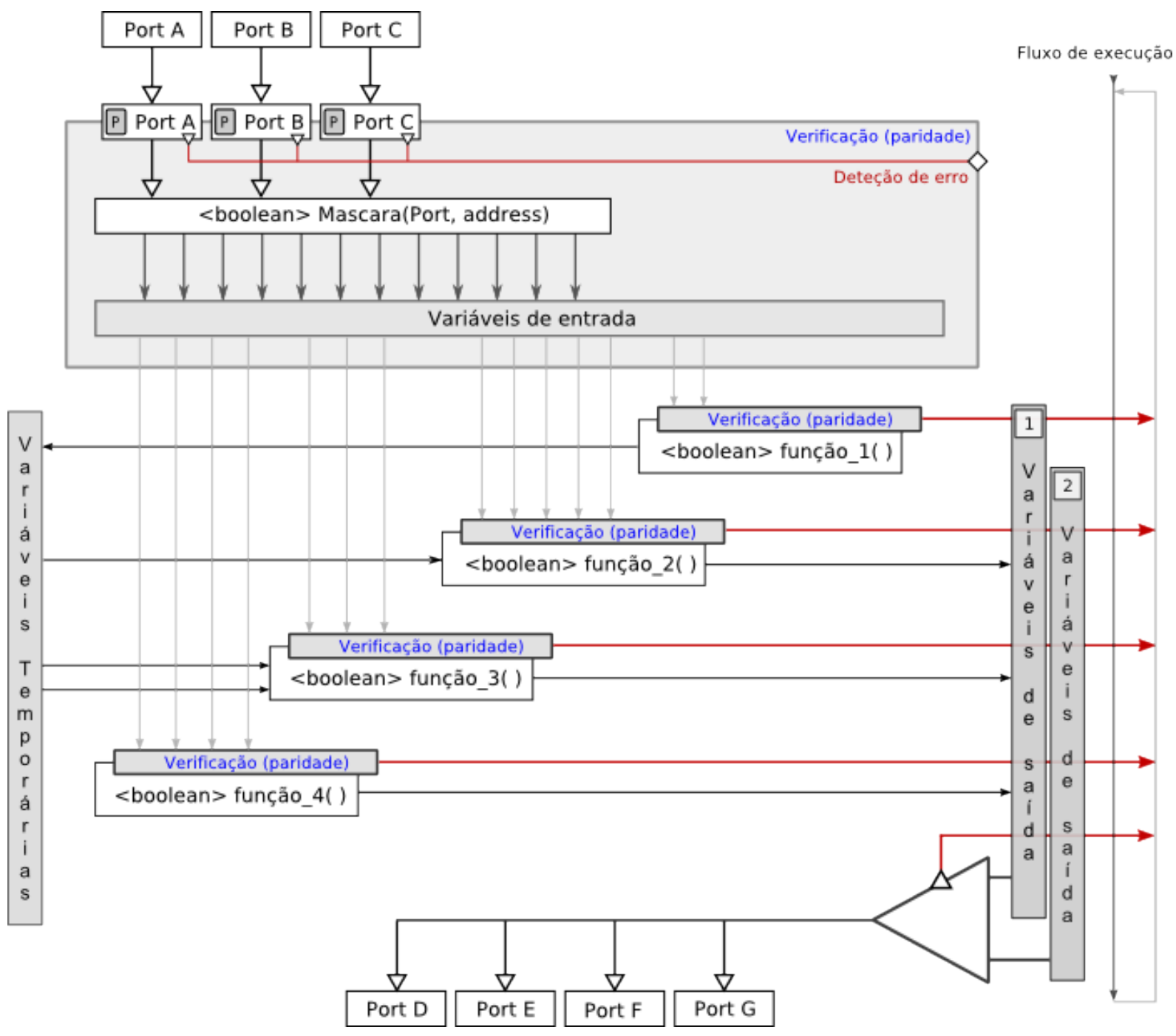

Figura 30 - Aplicação das técnicas de duplicação de variáveis e paridade combinadas

Até este ponto, foram descritos e discutidos os aspectos relacionados tanto a vulnerabilidade como também a proteção, através das técnicas de programação defensiva, do programa em estudo. No capítulo 6, são descritos os conceitos associados às diversas técnicas de injeção de erro, que produzem erros aleatórios em sistemas tipicamente baseados em microprocessamento. A partir de então, é 
descrita a técnica de injeção de erros considerada mais adequada aos objetivos propostos pelo estudo aqui apresentado. 


\section{INJEÇÃO DE ERROS}

Com o objetivo de avaliar o comportamento de um sistema sob o efeito de erros que afetem sua segurança, de modo que seja possível criar mecanismos que o tornem tolerante a erros, algumas técnicas foram desenvolvidas e estão em constante aprimoramento. As técnicas de injeção de erros podem acelerar a ocorrência e a propagação de erros dentro de um sistema e, assim, permitir a identificação de fraquezas em sua concepção.

Segundo (BENSO; PRINETTO, 2003) a injeção de erros é definida como a técnica de validação da dependabilidade baseada na realização de experimentos controlados e na observação do comportamento do sistema a partir da presença de erros explicitamente induzidos no sistema.

Além disso, a injeção de erros pode ser útil não apenas na fase de prototipação. Engenheiros fazem uso freqüente de simulações baseadas em injeção de falhas com o objetivo de avaliar a dependabilidade de um sistema, ainda em sua fase conceitual ou de projeto (HSUEH; TSAI; IYER, 1997).

As técnicas de injeção de erros cujo propósito é o de avaliar aspectos associados à dependabilidade, distinguem-se entre três categorias majoritárias: invasiva ou não invasiva, por execução ou simulação e aplicada ao software ou hardware.

\subsection{Técnicas invasivas e não invasivas}

Nessa primeira classificação, será feita a distinção entre técnicas invasivas e técnicas não invasivas. A distinção entre elas ocorre quando aplicadas a sistemas 
complexos e com alta dependência de tempo. Fica evidente que técnicas invasivas deixam "pegadas" sobre o processo dos sistemas em avaliação. Essas "pegadas" podem introduzir uma latência adicional que leve a consequências que não as diretamente associadas ao próprio erro. Por exemplo, em um sistema de tempo real, a resposta a um estímulo externo pode ser afetada pela carga de trabalho adicionada ao processamento em função da injeção do erro. Como será visto mais adiante, a simulação desenvolvida nessa pesquisa faz uso de rotinas de injeção de erro ativadas por interrupção. Tais rotinas consomem parte do tempo de processamento que seria dedicada ao programa principal e às técnicas de programação defensiva. Trata-se, portanto, de uma técnica invasiva.

Técnicas não invasivas não criam uma relação com a operação do sistema que possa ser detectada; exceto através do próprio erro injetado. Injeção de erros por emissão de partículas eletricamente carregadas sobre um processador é um exemplo. A influência de uma carga emitida sobre o sistema não depende da operação do mesmo.

\subsection{Técnicas por execução e simulação}

Na segunda classificação, as técnicas de injeção por execução têm seu propósito mais voltado à validação de sistemas baseados em projetos mais consolidados e, através de um mecanismo de injeção de erros, pode-se avaliar o seu comportamento segundo os efeitos produzidos pelo erro. Já para casos onde há a necessidade de avaliação de projetos em estágio preliminar, as técnicas de injeção de erros empregadas, o fazem sobre o modelo e, portanto por simulação.

Uma dificuldade existente para o tipo de abordagem por simulação, reside no 
fato de que projetos que ainda estão em sua fase inicial possuem predominantemente abstrações de alto nível e os detalhes de implementação não estão muito bem definidos nessa fase. Apesar de injeções por simulação se mostrarem interessantes nesse momento (projetos em fase inicial), essa abordagem exige uma precisa especificação de parâmetros, o que é difícil de obter.

Já em técnicas por execução, as suposições e considerações inerentes à fase inicial do projeto, antes inevitáveis, passam a ser comprovadas ou não, levando à determinação da dependabilidade do sistema a graus de acurácia extremamente vantajosos.

\subsubsection{Injeção de erros por simulação}

A injeção de erros por simulação tem sua origem na possibilidade de se construir de forma detalhada o sistema por meio de um software. Essa técnica dá ao software tanto a capacidade de representar as características físicas como a de reproduzir o comportamento de um sistema. Permite que erros simulados possam ser introduzidos e assim permitir a avaliação do comportamento do sistema à injeção de erros. Dentre as linguagens mais utilizadas com essa finalidade podemos citar VHSIC - VHDL (Very High Speedy Integrated Cicuits - Hardware Description Language). VHSIC é uma linguagem de programação para modelamento e desenho do hardware de sistemas digitais (KENNETH, 2008). Em geral a linguagem ganha o apoio de ferramentas EDA (Electronic Device Automation) e PLD (Programmable Logical Devices). A base para essa linguagem, o HDL (Hardware Description Language) é uma linguagem textual de programação de alto nível que inclui 
construções especializadas para descrever ou modelar o comportamento do hardware de um sistema.

A HDL permite que o comportamento de um sistema ou sua estrutura possa ser descrita em um nível abstrato e independente tecnologicamente. Um programa escrito em HDL tem uma aparência similar a um programa escrito em uma linguagem de programação de alto nível convencional. Entretanto, existem diferenças, tais como a inclusão de construções que dão suporte a descrições de concorrência, estrutura de hardware e temporalização.

\section{Vantagens da injeção de erros por simulação (BENSO; PRINETTO, 2003)}

- A reprodução de erros por simulação favorece todos os níveis de abstração de um sistema: axiomático, empírico e físico.

- O sistema real não sofre intrusão alguma durante os testes.

- $\quad$ O controle sobre o modelo de erros e mecanismos de injeção é completo.

- Baixo custo de automação computacional, que não requer nenhum tipo de hardware de propósito específico.

- Disponibiliza um "feedback" oportuno aos engenheiros de projeto.

- Alcança altos níveis de observabilidade e controlabilidade.

- Possibilita o desenvolvimento de modelos de erros transientes e permanentes.

- Permite modelamento de erros relacionadas à temporização, uma vez que o montante de tempo de simulação requerido para injetar erro é efetivamente zero. 


\section{Desvantagens da injeção de erros por simulação (BENSO; PRINETTO, 2003)}

- Modelos complexos exigem um grande esforço de desenvolvimento.

- Consumo de tempo.

- Modelos não se tornam disponíveis muito rapidamente.

- A acurácia dos resultados depende da qualidade do modelo desenvolvido.

- Os modelos podem não ser capazes de reproduzir de forma completa o comportamento do sistema, a partir do modelo de erros que se pretende simular.

\subsection{Técnicas aplicadas por hardware e por software}

A escolha entre injeção de erros por hardware ou software depende do tipo de erro em que se tem interesse e do esforço requerido para produzi-lo. Por exemplo, se há interesse em erros que mantenham um determinado valor em um ponto específico do circuito (stuck-at fault), a abordagem por injeção por hardware é preferível, por que se tem o controle da localização do erro. (HSUEH; TSAI; IYER, 1997).

Se o interesse está na corrupção de dados, tais como bit-flips em células de memória, como é o caso na pesquisa aqui apresentada, ambas as abordagens podem ser aplicadas. Por isso outros aspectos devem ser considerados no momento da escolha, tais como repetibilidade, acurácia, custo de tempo e recursos. 


\subsubsection{Injeção de erros por Hardware}

A injeção de erros por Hardware consiste na implementação de hardware adicional com a função de produzir erros sobre o sistema alvo. Podemos identificar duas categorias:

\section{a) Injeção de erros de Hardware com contato físico}

O Hardware, que tem como função injetar erros, entra em contato físico direto com o sistema alvo, de forma que sejam produzidas alterações na voltagem e corrente em pontos de conexão do sistema que fazem interface com elementos externos a ele. Para isso são usadas sondas, pontas de prova ou soquetes. Existem basicamente duas formas de se implementar a injeção de erros de hardware com contato físico: através de sondas ativas ou inserção de soquete. A primeira usualmente limita-se a produzir um "curto-circuito" entre dois ou mais pinos de conexão com o sistema alvo, para produzir corrente adicional sobre eles. As chances de se produzir um dano permanente no sistema, invalidando assim o experimento deste ponto em diante, deve ser levada em consideração. Na segunda técnica, usa-se uma interface capaz de se colocar entre o sistema e os elementos externos a ele. A inclusão desse elemento adicional tem o objetivo de produzir alterações na configuração física existente originalmente. Através dessa abordagem pode-se abrir, curto-circuitar ou mesmo produzir lógicas mais sofisticadas tais como a inversão e combinação (AND ou OR) entre os pinos do sistema. 


\section{b) Injeção de erros de Hardware sem contato físico}

O hardware injetor de erros, não entra em contato físico direto com o sistema alvo. Ao invés disso ele produz sobre o sistema alvo, algum fenômeno físico que cause internamente, correntes espúrias. Para isso usa-se radiação de íons pesados e ondas eletromagnéticas (SECALL, 2007).

Ambas as técnicas são apropriadas para casos em que se deseja chegar a pontos de difícil acesso do sistema alvo, sobretudo as técnicas sem contato físico. Além disso, por meio dessas técnicas, podem ser produzidos experimentos que tenham como requisito alta fidelidade quanto ao tempo. Isso permite que o disparo produzido pelo hardware de injeção de erros e a detecção de sua repercussão sobre o sistema alvo, sejam detectadas com baixa ou nenhuma perturbação.

\section{Vantagens da injeção de erros por hardware (BENSO; PRINETTO, 2003)}

- A injeção de erros por hardware tem acesso a locais que seriam difíceis de acessar através de outros meios. A injeção por radiação de íons pesados pode atingir locais de sistemas VLSI (Very Large Scale Intregation), que seriam impossíveis de atingir por outras técnicas.

- Esse tipo de técnica se aplica a sistemas onde a injeção de erros tem como requisito alta resolução de tempo - período entre disparo e monitoração.

- Para dispositivos atuais, em muitos casos, a única forma de se estimar a latência e cobertura de modo preciso é através de experimentos que fazem uso de injeção de erros por hardware.

- Esse tipo de técnica tem baixa perturbação sobre o sistema alvo. A perturbação nesse caso refere-se a alterações nas características do sistema exigidas pelo mecanismo de interferência que não tenham uma relação direta 
com o erro injetada. Por exemplo, em técnicas baseadas em software o sistema dedica parte de seu poder de processamento ao algoritmo que produz o erro.

- Essa técnica é mais adequada a modelos de erros de baixo nível.

- Essa técnica permite que um grande número de experimentos de injeção de erros possa ser executado graças à possibilidade de execução em tempo real.

- Executar injeção de erros em sistemas compostos de hardware e software reais possibilita a elaboração de modelos de erros que não haviam sido previstos originalmente.

- Experimentos de injeção de erros são realizados com o mesmo software que será usado em campo.

- Não existe a necessidade de validação e desenvolvimento de um modelo.

\section{Desvantagens da injeção de erros por hardware (BENSO; PRINETTO, 2003)}

- Essa técnica introduz um aumento no risco de dano ao sistema em teste.

- Alguns métodos de injeção de erros por hardware, tais como mutação de estado, requerem que o processador seja interrompido e reiniciado para que seja injetado o erro. Esse processo, nem sempre é adequado para monitoração e avaliação de latência.

- Baixa portabilidade.

- Conjunto de pontos de injeção e conjunto de erros injetáveis é limitado em algumas técnicas de injeção por hardware tais como injeção por contato direto com pinos do circuito (pin-level injection). 
- O tempo de configuração dedicado a cada experimento pode não justificar a vantagem obtida pela possibilidade de experimentação em tempo real.

- Exige hardware de propósito específico para realização dos experimentos.

\subsubsection{Injeção de erros por Software}

Uma das características mais atraentes em uma abordagem de injeção de erros por software é a versatilidade e baixo custo quando comparada com a abordagem por hardware. Em casos, onde o sistema é baseado em uma arquitetura que possua a camada de aplicação e a camada do sistema operacional é possível, por exemplo, avaliar a resposta de cada uma à injeção de erros. Quando o interesse esta na aplicação, a injeção é feita entre a duas camadas - figura 31. Quando se deseja avaliar a resposta do próprio sistema operacional, a injeção é feita interna a este, uma vez que o acesso a camada entre a máquina e o sistema operacional introduz uma série de dificuldades adicionais.

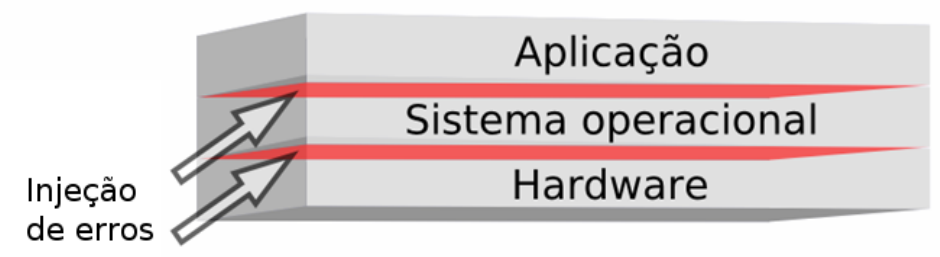

Figura 31 - Injeção de erros entre camadas

É possível vislumbrar um cenário interessante nesse aspecto em função do atual desenvolvimento da tecnologia de virtualização. A virtualização consiste em criar uma camada intermediária entre vários sistemas operacionais e um único hardware. Essa camada recebe comumente o nome de máquina virtual e é responsável por diversas tarefas de baixo nível, que podem representar uma vasta 
gama de opções quanto à avaliação da segurança por meio de injeção de erros por software.

A injeção de erros por software pode ser subdividida em duas categorias: em tempo de compilação e em tempo de execução.

\section{a) Injeção de erros por software em tempo de compilação}

Essa abordagem consiste em alterar o código fonte ou código assembly para que o seu efeito seja perceptível durante a execução do programa. Essa alteração tem como objetivo emular os efeitos de erros transientes, de hardware ou mesmo de software. Uma das possibilidades promovidas por esse tipo de abordagem é a emulação de erros permanentes encontradas tipicamente em falhas de hardware, além de ser extremamente simples de ser implementada.

\section{b) Injeção de erros por software em tempo de execução}

Essa abordagem faz uso de triggers como mecanismo de controle de injeção de erros:

- Por intervalo de tempo (time-out): faz uso de timers para disparar um erro decorrido um determinado espaço de tempo. Implementado por meio de hardware ou software, os timers devem estar ligados ao controle de interrupções do sistema. Naturalmente, essa técnica insere uma certa imprevisibilidade ao comportamento do sistema, promovendo assim uma boa semelhança em casos em que este está sob influência de erros de hardware intermitentes ou transientes.

- Por exceção / armadilha (exception/trap): diferentemente da técnica por intervalo de tempo, o disparo do erro é feito segundo uma determinada 
condição, que uma vez atingida, transfere o controle do software operacional para o software injetor de erros. Exemplo: o instante em que se faz o acesso a um determinado endereço de memória. Assim como no disparo por tempo, essa transferência de controle também está ligada ao controle de interrupções do sistema, garantindo assim a precedência do efeito do erro em relação às instruções operacionais em curso.

- Por inserção de código (Code insertion): se caracteriza por acrescentar instruções responsáveis por produzir o efeito de um erro, antes de uma instrução operacional qualquer. Essa técnica, diferentemente das anteriores, não interfere no controle de interrupções do sistema.

\section{Vantagens da injenção de erro por software (BENSO; PRINETTO, 2003)}

- Esse tipo de técnica pode ser direcionada para avaliação de sistemas operacionais e aplicativos, o que representa uma difícil aplicação para técnicas de injeção de erros baseadas em hardware.

- Essa técnica permite que um grande número de experimentos de injeção de erros possa ser executado graças à possibilidade de execução em tempo real.

- Executar injeção de erros em sistemas compostos de hardware e software reais possibilita a elaboração de modelos de erros que não haviam sido previstos originalmente.

- Não exige qualquer hardware de propósito específico, baixo custo de implementação.

- Não existe a necessidade de validação e desenvolvimento de um modelo. 


\section{Desvantagens da injeção de erros por software (BENSO; PRINETTO, 2003)}

- Momento de injeção de erros é limitado; em alguns casos exige implementação em código assembly.

- Não é possível injetar erros em locais não acessíveis pelo software. Por exemplo, não é possível por meio de software, alterar qualquer funcionalidade da unidade de controle (UC) de um processador que se baseie em arquitetura de unidade de controle não programável.

- Exige que o código fonte seja alterado para possibilitar a injeção de erros no sistema, implicando na geração de uma versão para testes e outra para campo.

- Observabilidade e controlabilidade limitadas. Na melhor das hipóteses a técnica seria capaz de corromper os registradores internos do processador que sejam visíveis ao programador.

- Erros permanentes são difíceis de produzir.

- A realização de experimentos pode afetar o controle temporal de execução de tarefas do sistema, o que pode representar uma alteração no comportamento original do sistema e assim invalidar parte dos testes.

A tabela 1 resume as características de cada um dos métodos de injeção de erros descritos anteriormente. 


\begin{tabular}{ccccc}
\hline & \multicolumn{2}{c}{ Hardware } & \multicolumn{2}{c}{ Software } \\
\hline & $\begin{array}{c}\text { Com } \\
\text { contato }\end{array}$ & $\begin{array}{c}\text { Sem } \\
\text { contato }\end{array}$ & Compilação & Execução \\
\hline Custo & Alto & Alto & Baixo & Baixo \\
\hline Perturbação & Nenhuma & Nenhuma & Baixa & Alta \\
\hline Risco de dano & Alto & Baixo & Nenhum & Nenhum \\
\hline $\begin{array}{c}\text { Resolução de } \\
\text { tempo }\end{array}$ & Alto & Alto & Alto & Baixo \\
(monitoramento) & & Registros de & $\begin{array}{c}\text { Registros de } \\
\text { memória } \\
\text { I/O }\end{array}$ \\
$\begin{array}{c}\text { Acessibilidade a } \\
\text { pontos da } \\
\text { injeção }\end{array}$ & Pino do & Interno ao & memória & Chip \\
\hline Controlabilidade & Alta & Baixa & Alta & Alta \\
\hline Disparo & Sim & Não & Sim & Sim \\
\hline Repetibilidade & Alta & Baixa & Alta & Alta \\
\hline
\end{tabular}

Tabela 1 - Classificação de métodos de injeção de erros: Hardware e Software (Fonte: HSUEH; TSAI; IYER, 1997)

A partir dos aspectos descritos nos tópicos anteriores, pode-se caracterizar o método de injeção de erros empregado na presente investigação. Primeiramente trata-se de um método de injeção de erros por software, cuja interferência sobre o programa alvo é feita em tempo de execução. A partir dessa caracterização, optouse pela injeção de erros por intervalo de tempo, uma vez que tal abordagem tem boa semelhança com casos em que o dispositivo alvo está sob influência de erros de hardware intermitentes ou transientes.

Sob outro aspecto, o método empregado é considerado invasivo, uma vez que parte do processamento é dedicado ao processo de injeção de erro. Além disso, o emprego de um simulador no lugar de um dispositivo físico, leva em consideração o fato de que se trata, na verdade, de um modelo que se aproxima do dispositivo real. 
Portanto, o método adotado nesta pesquisa deve ser classificado como um método de injeção de erros não invasivo, por simulação, por software e em tempo de execução.

\subsection{Modelo para ambiente de injeção de erros}

Na figura 32 é descrito um ambiente de injeção de erros. Esses ambientes são tipicamente compostos por um sistema alvo, um injetor de erros, um gerador de carga de trabalho, um coletor de dados, um monitor e um controlador. O injetor de erros pode produzir diferentes modos de erros, em diferentes localizações, instantes, durações; características estas definidas e estruturadas pela biblioteca de erros. O gerador de carga de trabalho, em conjunto com a biblioteca de trabalho, tem a função de produzir processos que são executados pelo sistema alvo. Esses processos podem alternar entre aplicações de qualquer natureza ou de natureza específica segundo os requisitos do projeto.

O monitor inicializa a coleta de dados caso identifique alguma relevância em seu conteúdo. O coletor armazena os dados, e através do analisador, gera a informação pertinente ao processo em estudo. Esse processo de análise pode ocorrer em tempo real ou não.

O controlador permite a integração dos elementos descritos anteriormente. Essa integração pode ser valiosa nos casos em que se deseja por exemplo, efetuar o disparo de injeção de erros a partir de informações coletadas, ou reinicializar o processo proveniente do gerador de carga de trabalho segundo alguma condição especial identificada pelo analisador de dados. Tais processos são apenas alguns 
exemplos que certamente produzem maior exatidão e precisão durante o desenvolvimento do experimento.

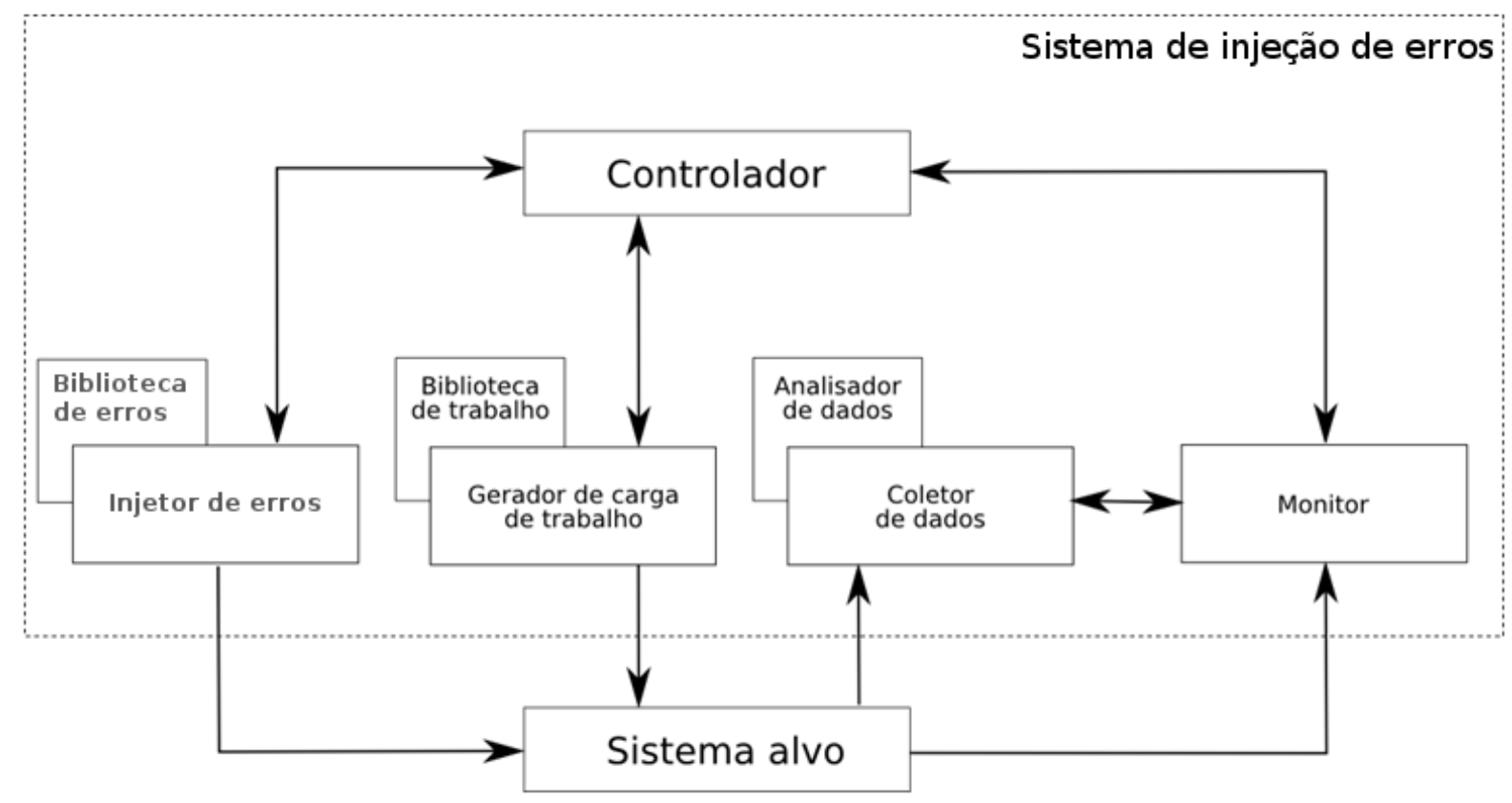

Figura 32 - Modelo para ambiente de injeção de erros

(Adaptado: HSUEH; TSAI; IYER, 1997)

\subsection{Modelo FARM}

O modelo FARM foi desenvolvido no LAAS-CNRS em meados dos anos 90 com a finalidade de caracterizar a técnica de injeção de erros segundo os conjuntos descritos a seguir. Quando a técnica de injeção de erros é aplicada ao sistema alvo, o domínio de entrada corresponde ao conjunto de entradas $\boldsymbol{F}$, o qual é descrito por um processo estocástico dos quais os parâmetros são caracterizados por uma distribuição probabilística; um conjunto de ativação $\boldsymbol{A}$, o qual consiste no conjunto de padrões de dados de teste destinados a exercitar os erros injetados, o domínio de saída corresponde a um conjunto de leituras $\boldsymbol{R}$ e um conjunto de medidas derivadas $\boldsymbol{M}$, o qual pode ser obtido apenas experimentalmente a partir de uma série de 
estudos de caso de injeção de erros (BENSO; PRINETTO, 2003). Os conjuntos $\boldsymbol{F}, \boldsymbol{A}$, $\boldsymbol{R}$ e $\boldsymbol{M}$ definem os atributos que caracterizam o estudo de um experimento de injeção de erros.

Os elementos $Z$ e $Y$ representam os estados internos do sistema. $Z$ em conjunto com $\mathrm{O}$ compõem a resultante $\mathrm{R}$ e $\mathrm{Y}$ em conjunto com I a ativação $A$.

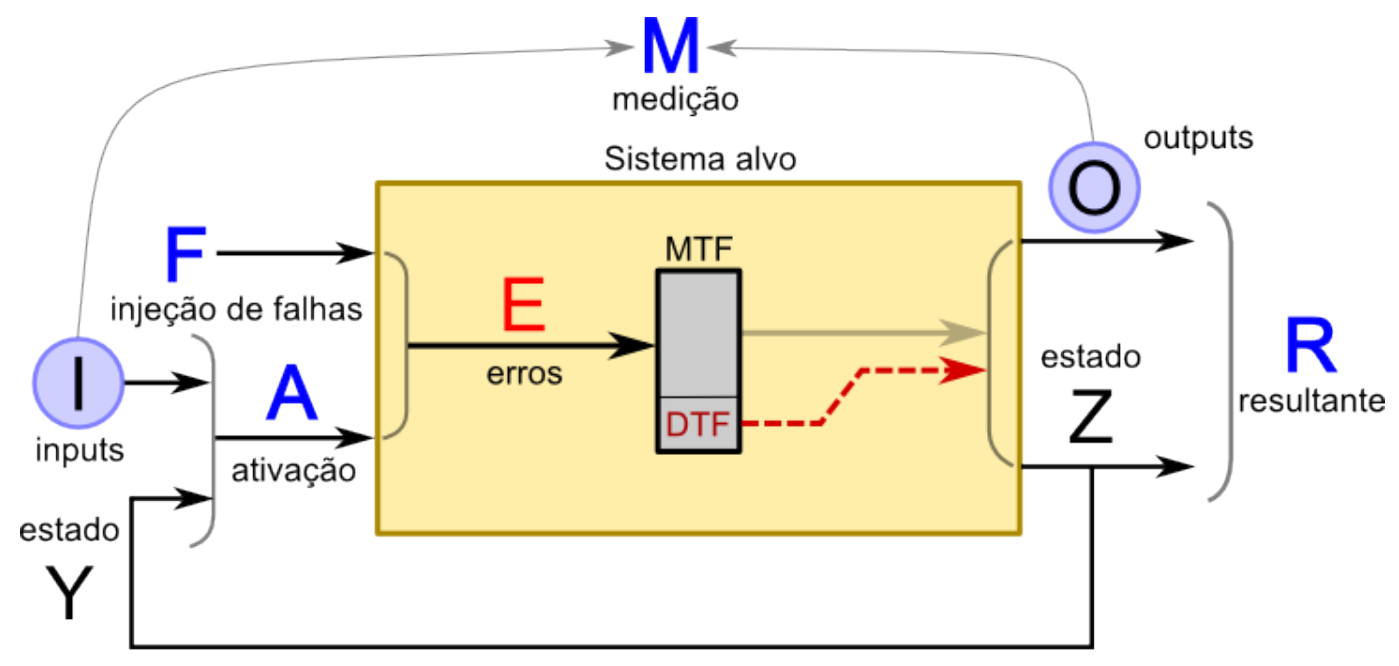

MTF: Métodos de tolerância a falhas

DTF: Deficiência na tolerância a falhas

Figura 33 - Modelo FARM

Existem para o modelo FARM três modelos de abstração (ARLAT; COSTES; CROUZET; LAPRIE; POWELL, 1993):

- Modelos axiomáticos: usam diagramas de blocos de confiabilidade, modelamento encadeado de Markov, redes de Petri estocásticas com o objetivo de construir modelos analíticos que representem, não só a estrutura, mas também as características de dependabilidade do sistema alvo.

- Modelos empíricos: refere-se a tipos de modelagem baseadas em observações empíricas, no lugar de relações matematicamente descritíveis do sistema modelado. 
- Modelos físicos: usando protótipos ou hardware e software do sistema implementado de fato, para se chegar ao modelo do sistema alvo.

No caso de sistemas tolerantes a erros, os modelos axiomáticos fornecem um meio de avaliação do comportamento do sistema tolerante a erros em resposta a um determinado erro. Apesar de os parâmetros de erros poderem ser obtidos através de análises estatísticas de dados do campo relativos aos componentes do sistema, a caracterização do comportamento do sistema e a atribuição de valores para parâmetros de execução e cobertura do sistema tolerante a erros são tarefas muito mais difíceis, uma vez que tudo o que sabemos desses dados não está necessariamente disponível e são específicos do sistema sob investigação. Por isso, os dados experimentais recolhidos de modelos empíricos ou físicos são necessários para confirmar ou negar as hipóteses na seleção de valores para os parâmetros do modelo axiomático (ARLAT; COSTES; CROUZET; LAPRIE; POWELL, 1993).

Em um modelo FARM podemos identificar dois domínios que se relacionam através de $f: E=\{I \times Y \times F\}$ e $S=\{O \times Z\}$, onde E é o domínio de entrada e $\mathrm{S}$ o domínio de saída. Assim, FARM descreve explicitamente o espaço de erros injetados sobre E. Sendo S resultado da aplicação de $f$ sobre E, dizemos que $f(t)$ é o vetor que pode ser observado quando a falha esta ativa e $f_{0}(t)$ é definido como o vetor "ausente de falha".

Um ponto importante durante a análise feita a partir de FARM sobre sistemas tolerantes a erros diz respeito à relação de $\mathrm{t}$ com o vetor $\mathrm{Z}$ - o estado interno do sistema. A avaliação de um sistema em qualquer instante não depende de todos os seus estados internos. Isso leva a divisão de $Z(t)$ em $Z_{v}(t)$ - que são as variáveis do sistema sensíveis em t, ou seja, as variáveis que em t impactam na operação do 
sistema - e $Z_{n}(t)$ - que são as variáveis do sistema não sensíveis em t. Essa divisão se torna um importante fator por resultar na caracterização da vulnerabilidade de um sistema, levando assim a afetar aspectos como a cadeia erro - falha, podendo inclusive afetar as características do controle de ativação de erros injetados.

A partir dos conceitos abordados neste capítulo, assim como nos anteriores, é possível elaborar um ambiente de testes, que tenha como objetivo, integrar todos os elementos necessários ao estudo aqui proposto e dessa forma, permitir a medição dos efeitos produzidos pela aplicação de técnicas de programação defensiva e injeção de erros, sobre um sistema eleito como estudo de caso. Os detalhes deste ambiente de testes são descrito no capítulo 7. 


\section{AMBIENTE DE TESTES}

Este capítulo destina-se a descrição detalhada do ambiente de testes usado para se obter as amostras de tempo para falhas inseguras.

\subsection{A simulação}

O ambiente de simulação desenvolvido para esse estudo é composto essencialmente, de três elementos principais: o simulador de campo, o simulador AVR e o verificador de erros inseguros. O simulador de campo tem a função de reproduzir os estados de elementos comumente encontrados em sistemas de sinalização metroferroviário, e.g. ocupação de circuitos de via e posição de máquinas de chave. O simulador AVR tem a função de reproduzir o funcionamento de um microcontrolador ATMEGA 128 do fabricante ATMEL, onde são inseridos o programa alvo, que contém a lógica de controle da movimentação dos trens, o algoritmo de injeção de erros e as técnicas de programação defensiva. A relação entre estes elementos é vista na figura 34.

O sistema simulado tem como objetivo reproduzir o processamento das informações provenientes do campo e a verificação do estado assumido pelo sistema. Tal verificação identifica, sob o contexto de controle da movimentação dos trens, se o sistema entrou em um estado que represente uma falha insegura e.g. seleção de código de velocidade diferente de zero com uma ocupação do circuito de via logo à frente. Uma vez identificado o estado inseguro, mede-se o tempo decorrido desde o instante inicial da simulação (com a injeção de erro) até a ocorrência da falha insegura. 


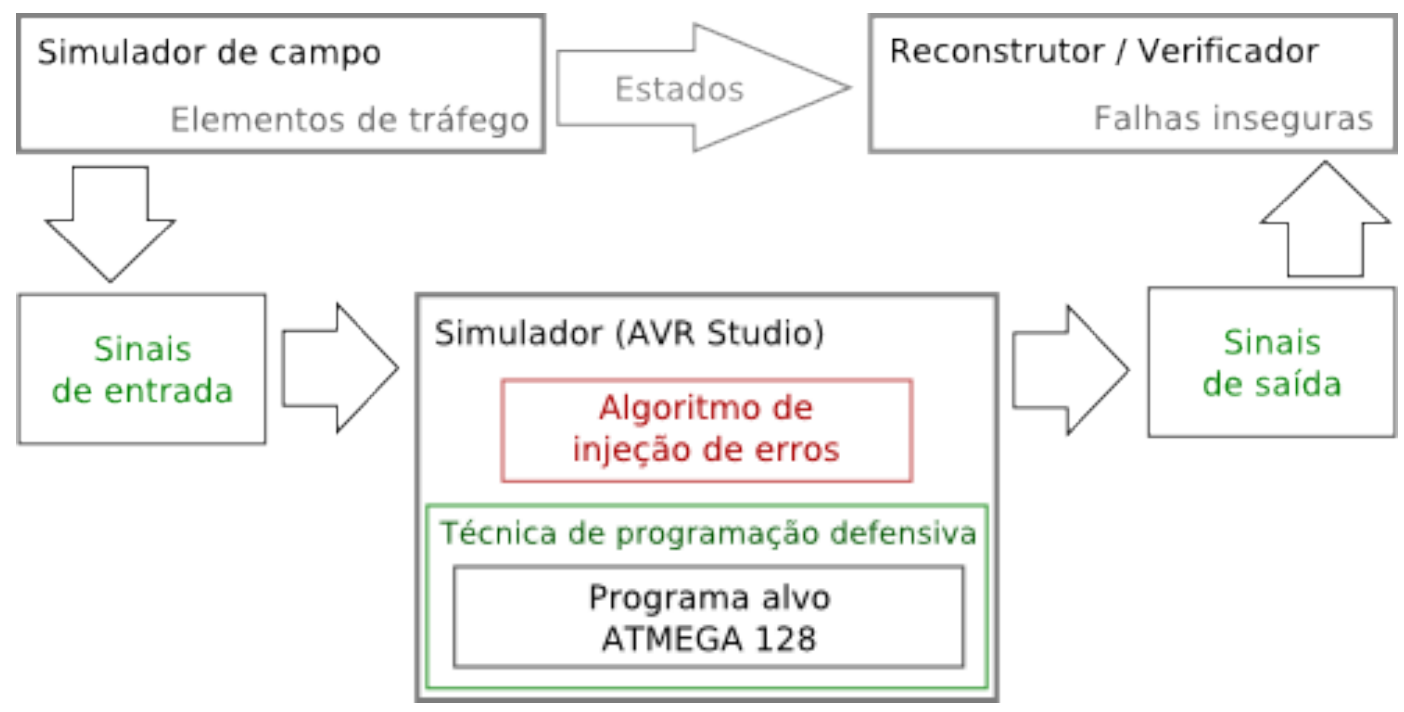

Figura 34 - Representação do processo de simulação

Uma das vantagens em se usar um simulador AVR está no fato de que a cada alteração do estado das portas de saída, um registro do ciclo de processamento é feito. Com o ciclo, é possível então identificar diferenças de tempo entre a ocorrência das falhas inseguras na ordem de 0,25 milionésimos de segundo, o que permite identificar alterações mínimas entre as amostras de tempo.

\subsection{O simulador de campo}

O simulador de campo foi inicialmente desenvolvido em uma pesquisa de doutorado que serviu de referência para a investigação realizada neste trabalho. Neste pesquisa de referência, (SECALL, 2007) desenvolveu uma plataforma que utilizava não apenas o simulador em uma estação Linux, como também o microcontrolador acoplado a ela por meio de um cabo paralelo. Para a injeção de erros foi utilizado um radiotransmissor em conjunto com um dispositivo de emissão de campo denominado Stripline. 
O simulador de campo tem a função de reproduzir o funcionamento dos elementos de campo que compõem parte de um sistema de controle de tráfego metroferroviário real. Os elementos de campo considerados essenciais ao experimento podem ser identificados na figura 35 que representa a IHC - Interface Humano Computador - utilizada.

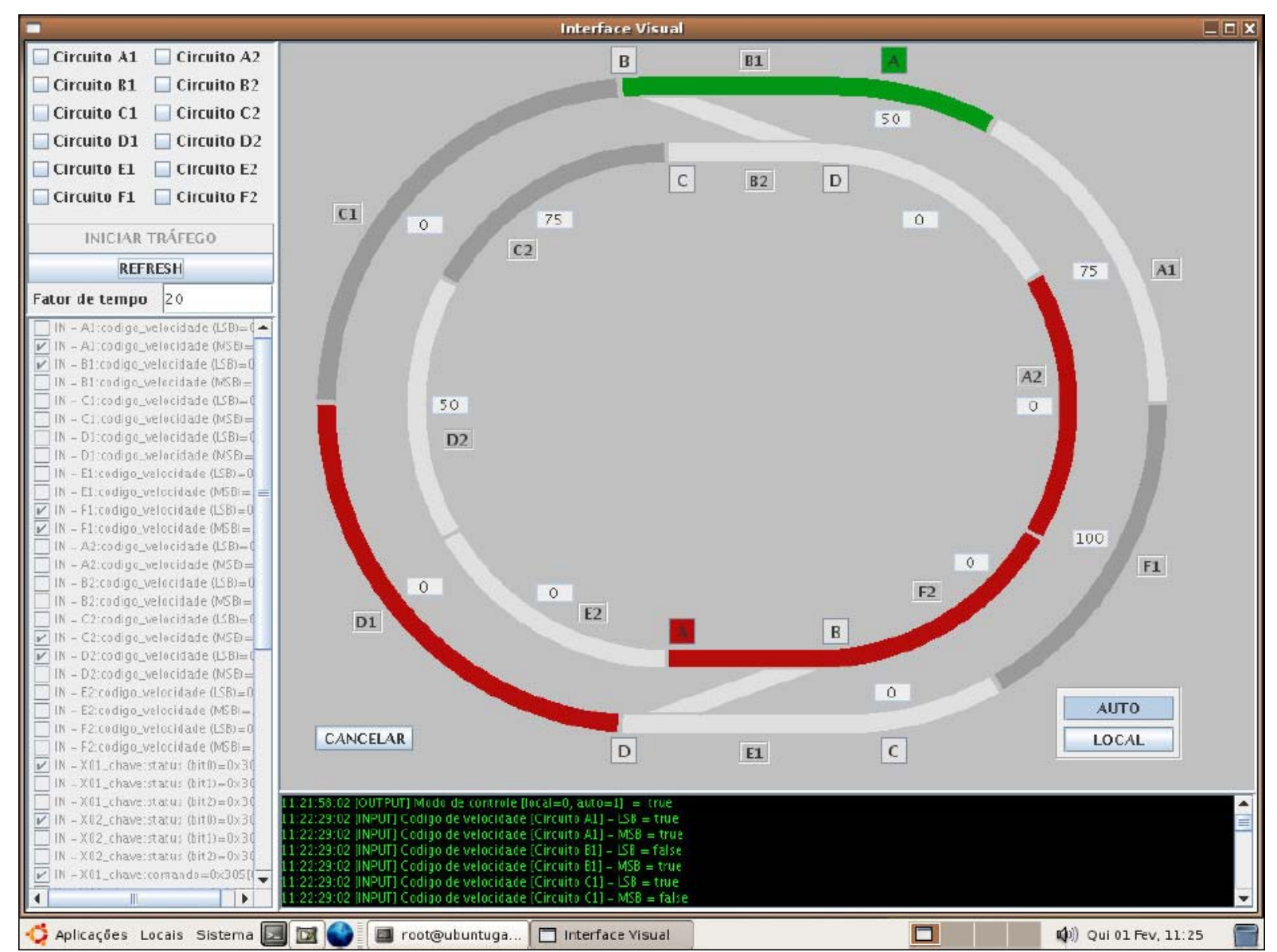

Figura 35 - Interface do simulador de campo (SECALL, 2007)

Primeiramente, são descritos alguns conceitos associados aos elementos que compõem o controle de tráfego metroferroviário aqui simulado.

Circuito de via: trecho de via ferroviária que é capaz de detectar a presença de um trem em toda sua extensão. O estado denominado "circuito de via ocupado" indica que um trem está fisicamente sobre a área delimitada pelo circuito de via. A 
partir da figura 35 pode-se dizer que os circuitos de via identificados como D1, F2 e A2 estão ocupados.

Código de velocidade: código que representa a velocidade máxima que um trem pode desempenhar estando este dentro da área delimitada pelo circuito de via. A partir da figura 35 pode-se dizer que, por exemplo, o circuito de via A1 permite que um trem desenvolva no máximo $75 \mathrm{Km} / \mathrm{h}$, enquanto estiver sobre este circuito.

Via: Conjunto de circuitos de via dispostos em sequência de forma a permitir o deslocamento contínuo de um trem. Na figura 35, pode-se identificar duas vias em formato circular: a externa, denominada via 1, e a interna denominada via 2. Observe que os circuitos de via são identificados com uma letra seguida do número que representa a via.

Máquina de Chave: Uma chave permite que um trem, ao se deslocar, seja transferido de uma via para outra. Os dois estados possíveis para esses tipos de elementos são normal e reverso. O estado normal mantém o trem em sua trajetória original, enquanto reverso transfere o trem de uma via para outra. Na figura 35, pode-se identificar duas máquinas de chave representadas por faixas transversais que ligam as duas vias.

Região de intertravamento: A região de intertravamento é composta essencialmente por uma máquina de chave e os circuitos de via conectados por ela. Por se tratar de uma região que possibilita a mudança ou não do trajeto de um trem, quatro pontos - chamados de gates - são inseridos, criando os limites dessa região, 
de forma a definir a passagem de um trem por ela. Esse pontos são representados na figura 35 por pequenos quadrados, identificados pelas letras A, B, C e D.

Rota: Uma rota define os pontos pelos quais um trem, ao se deslocar, transita através da região de intertravamento. Na figura 35, cada uma das regiões de intertravamento possui três rotas possíveis: $A B, D C$ e $D B$, sendo as rotas $A B$ e $D C$ classificadas como sendo rotas em normal - em função do estado normal da chave - e a rota DB classificada como rota em reverso.

É importante ressaltar, neste ponto, alguns aspectos diretamente ligados a questões de segurança que envolve os elementos anteriormente descritos. Considere, como exemplo, o código de velocidade de um circuito de via, quando selecionado pelo sistema. Obrigatoriamente, esse código deve ser definido como 0 $\mathrm{Km} / \mathrm{h}$ em casos onde o circuito de via logo à frente - em relação ao deslocamento de um trem - esteja ocupado. Caso contrário, o sistema aplicaria uma condição que levaria ao choque iminente de duas composições. São exatamente condições como esta que são identificadas pelo elemento verificador descrito no início deste tópico.

Sendo assim, o simulador de campo foi concebido de forma que o conjunto de elementos que o compõe permitisse a avaliação de aspectos de segurança presentes em sistemas de controle de tráfego metroferroviário reais, representados aqui em escala reduzida.

Portanto, o simulador é composto de duas vias: via um, composta por seis circuitos - A1, B1, C1, D1, E1 e F1 - e via dois, composta por cinco circuitos de via A2, B2, C2, D2, E2 e F2. Cada circuito de via recebeu um elemento que representa a velocidade máxima que um trem pode desempenhar, em seu interior. Além disso, 
as duas vias são interligadas por duas regiões de manobra delimitadas pelos gates A, B, C e D correspondentes.

\subsection{O dispositivo alvo}

Como dispositivo alvo foi usado um software que simula o microcontrolador ATMEGA 128 da fabricante ATMEL. O software simulador utilizado foi desenvolvido pelo próprio fabricante. Na figura 36 está representada sua arquitetura. O ATMEGA 128 é um microcontrolador CMOS de baixa potência de consumo, de 8-bits e baseado em arquitetura RISC.

Esse microcontrolador possui ao todo 7 portas que podem ser programadas para ter a função de entrada ou saída. Para o experimento, as portas de entrada recebem os dados produzidos pelo simulador de campo. Em seguida, o processamento de uma série de regras lógicas chamadas booleanas - programa alvo - produz o resultado que é transferido, através das portas de saída, para o verificador de falhas inseguras. 


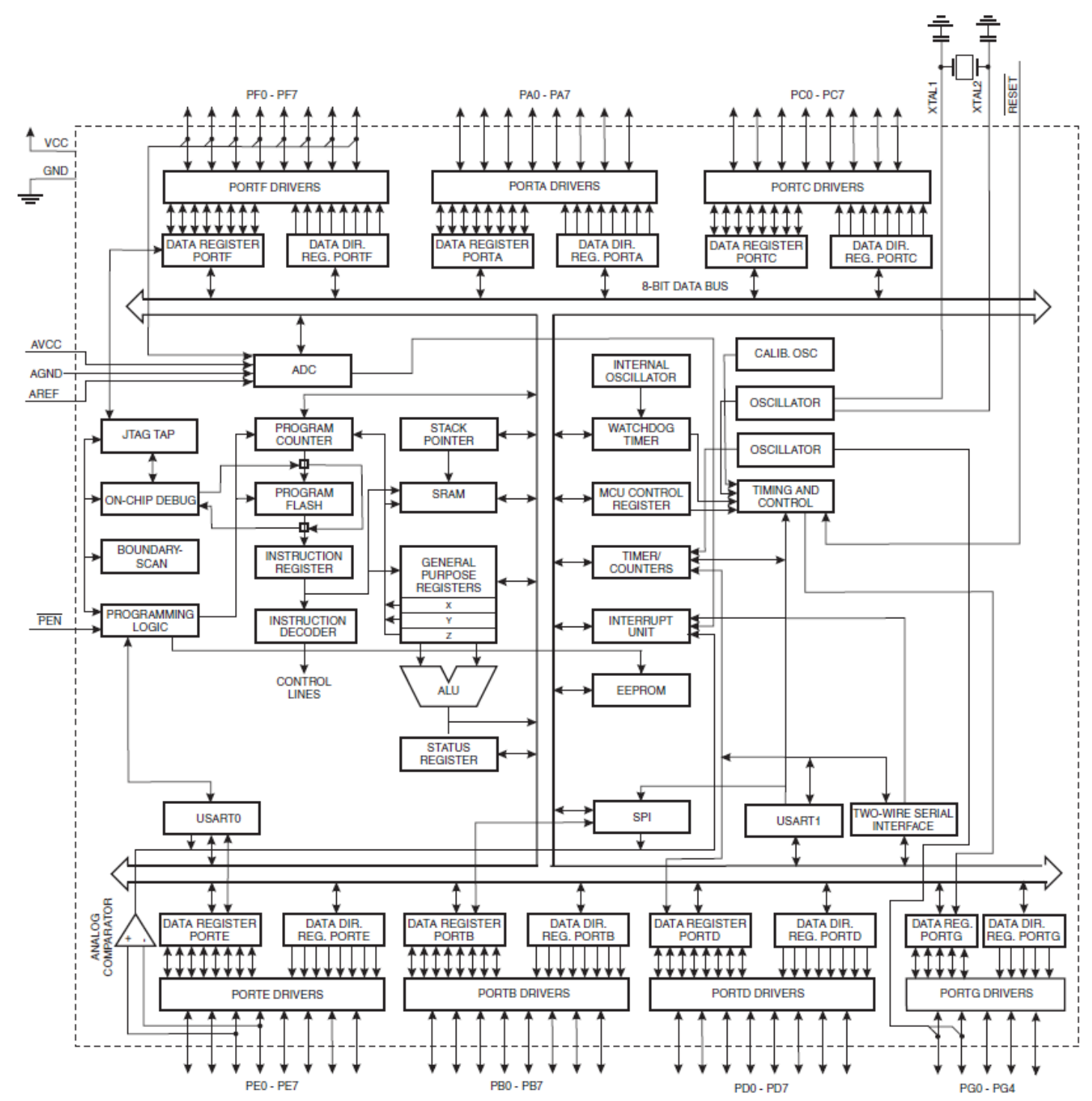

Figura 36 - Arquitetura do microcontrolador ATMEGA-128

Para simular este dispositivo, foi usado o ambiente de desenvolvimento integrado AVR Studio 4. Esse software disponibiliza um conjunto de recursos voltados ao desenvolvimento de aplicações para microcontroladores AVR de 8 bits, dentre os quais um simulador onde podem ser visualizados e manipulados alguns dos principais componentes dessa classe de microcontroladores e.g. registradores, memória, interrupções. A figura 37 demonstra o programa simulando 0 processamento de uma série de booleanas utilizadas no estudo. 


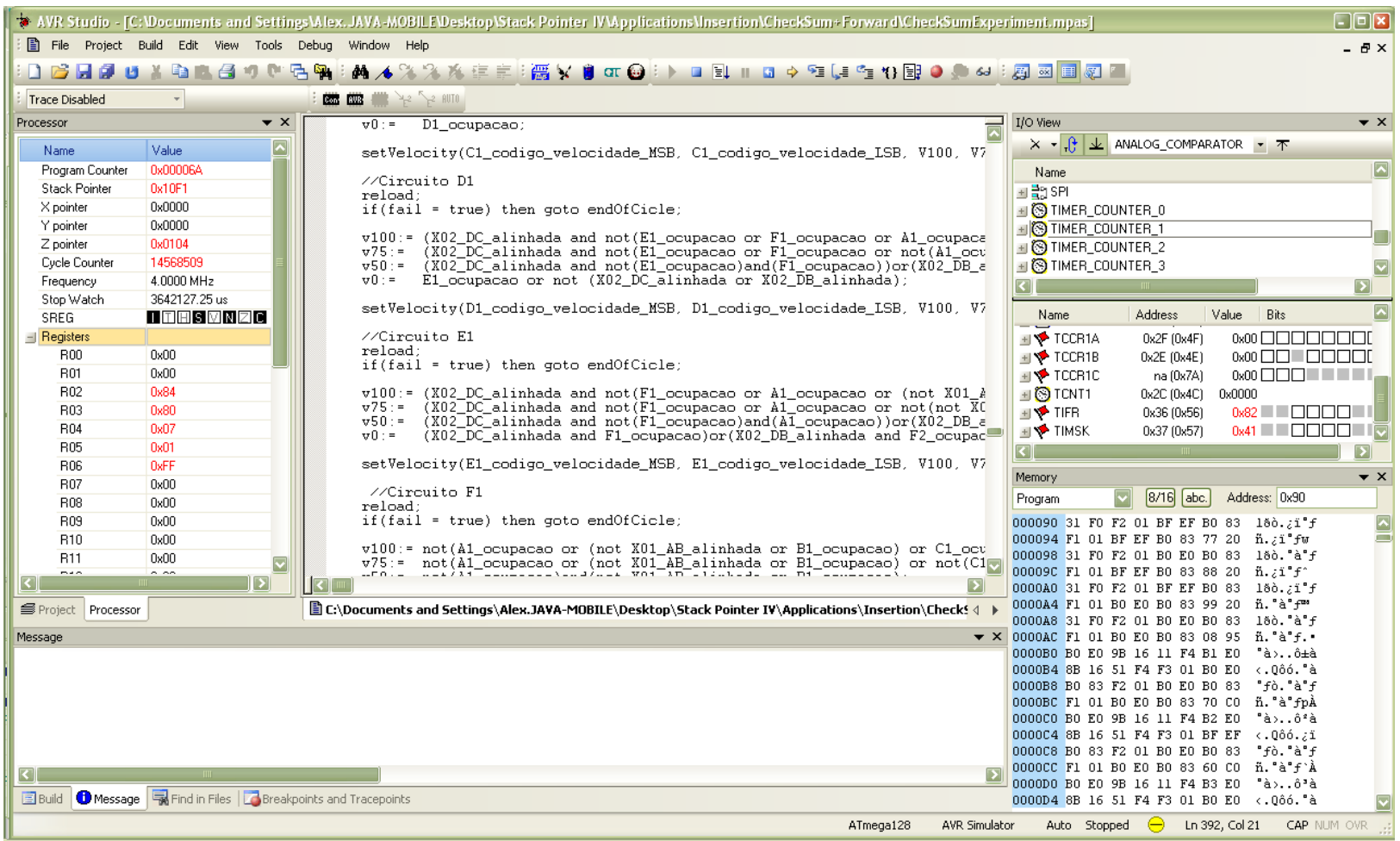

Figura 37 - Simulador AVR Studio

\subsection{O reconstrutor / verificador}

Para que seja possível verificar se o estado corrente da simulação representa um estado considerado inseguro são usados dois elementos desenvolvidos com essa finalidade: o reconstrutor de estado e o verificador de falhas inseguras.

Primeiramente, a simulação produz um relatório que contém o estado de cada uma das portas de saída, de forma que apenas a alteração do valor de saída produz o que se denomina de evento de porta. O evento de porta é composto pelo ciclo de processamento e o valor em hexadecimal adquirido pela porta, e.g. "000002456:0C". Cada porta possui o seu próprio arquivo de eventos. A função do reconstrutor de estado é gerar uma sequência de eventos que sincronize o estado de todas as portas de saída e portas de entrada. Além disso, o reconstrutor converte cada um 
dos valores em seus respectivos significados para que estes possam ser avaliados pelo verificador de falhas inseguras.

De posse dos dados necessários, o Verificador compara o estado corrente com uma lista de estados inseguros previamente definidos. Caso seja identificado que o estado corrente representa uma falha insegura, o ciclo de processamento é convertido em tempo e, por fim, classificado e registrado.

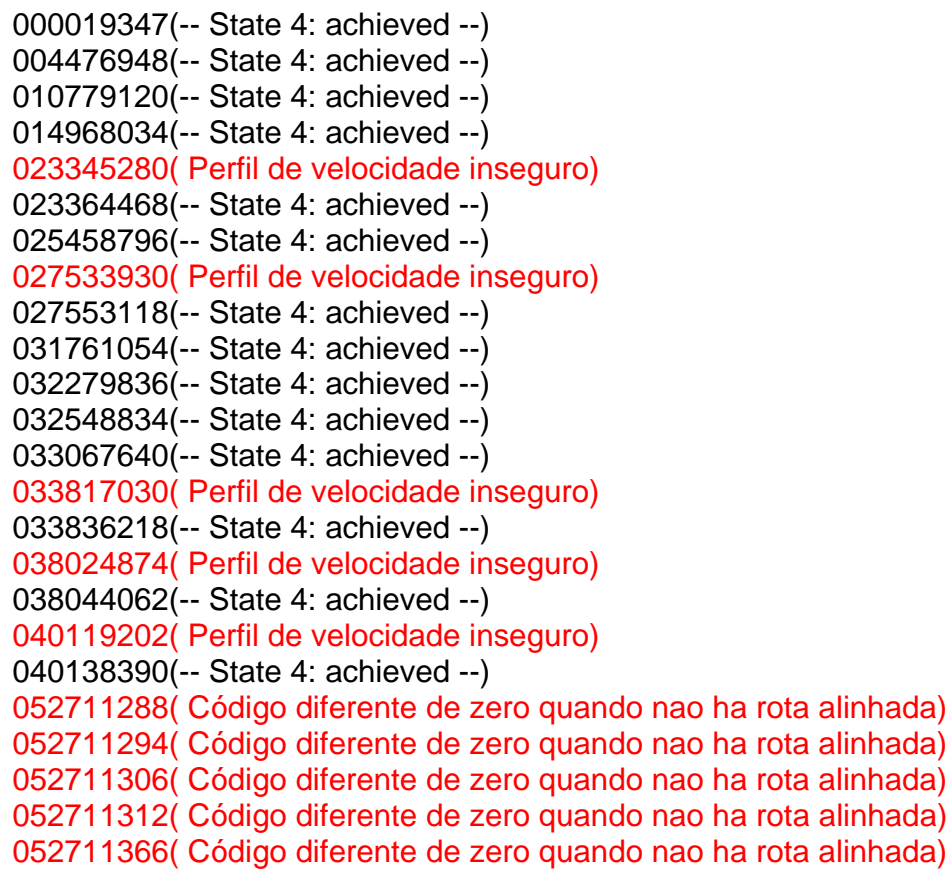

No exemplo anterior, a simulação produz até o ciclo 23345280 estados considerados seguros, quando então é identificada uma falha descrita como "perfil de velocidade inseguro". Tendo como referência de estado seguro do ciclo 19347, obtêm-se uma amostra de tempo para falha insegura de 5,83148 segundos.

$$
t_{f}=\frac{\left(\text { ciclo }_{f}-\text { ciclo }_{0}\right)}{\text { clock }}
$$

onde $t_{f}$ é o tempo para falha insegura, ciclo $_{f}$ o ciclo em que é identificada a primeira ocorrência de falha insegura, cicloo o ciclo em que é identificado o estado seguro inicial e clock a frequência do microprocessador. É importante observar que o valor 


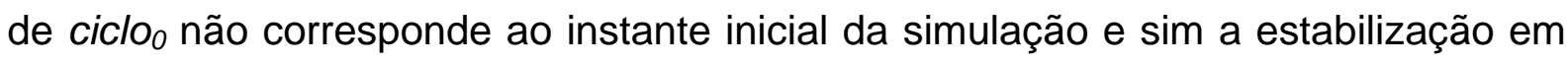
um estado seguro. Antes que o sistema adquira um estado seguro, há um breve período de estados inválidos, uma vez que nos primeiros ciclos o sistema passa pela atualização de suas portas de saída.

\subsection{Injeção de erros}

A injeção de erros por software foi desenvolvida de forma a produzir bit flip's em elementos de memória do microcontrolador. Esses elementos são compostos pelo conjunto de registradores de propósito geral e células de memória de dados. O evento que produz a alteração de um bit qualquer o faz através de interrupções controladas por tempo. Assim, foi desenvolvido um algoritmo para injeção de erros em registradores e outro para injeção de erros em memória e cada qual associado a interrupções temporizadas distintas, como ilustrado na figura 38.

A injeção de erros ocorre a uma taxa constante: para registradores um erro a cada 4,096 milisegundos e para memória um erro a cada 16,384 milisegundos. Tais valores foram obtidos experimentalmente, tendo como principal preocupação a latência na a obtenção de falhas inseguras. Um pequeno acréscimo no tempo de cada ensaio levaria o conjunto de todos os ensaios necessários, a uma duração excessiva, uma vez que foram realizados 1.189 ensaios. Em contrapartida, taxas de injeção de erros excessivamente altos poderiam produzir médias de tempo para falhas inseguras, muito similares para todas as técnicas, em função da improbabilidade de geração de resultados corretos pelo programa alvo.

Dessa forma, após diversas simulações, foram obtidos os valores mencionados anteriormente, e estes foram aplicados em todos os ensaios. 


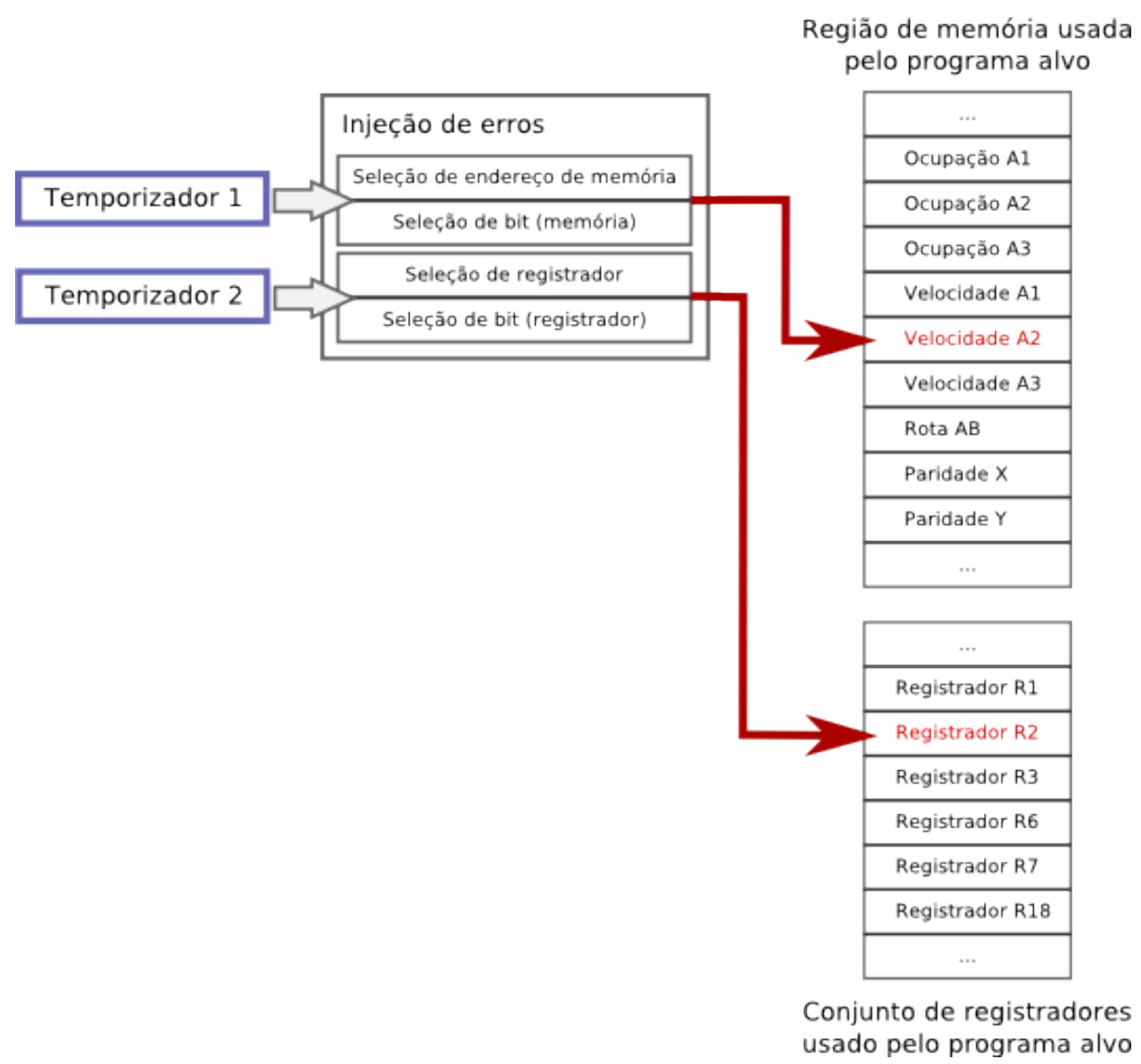

Figura 38 - Processo de injeção de erros

\subsection{Considerações quanto à injeção de erros}

É importante salientar que o mecanismo de injeção de erros, seja ele sobre registradores ou sobre células de memória, parte do princípio de que apenas os recursos de memória utilizados pelo programa, podem sofrer perturbação, ou seja, não são produzidos erros em registradores ou células de memória que não estejam sendo utilizados. Esse princípio se torna importante, uma vez que a aplicação de cada uma das técnicas de programação defensiva produz uma versão do programa alvo que usa uma quantidade de memória e registradores maior ou menor em 
relação às demais e, portanto, de diferentes perfis de vulnerabilidade. Com isso, evita-se uma distorção nos resultados de amostras de tempo em função da quantidade de elementos de memória utilizada, uma vez que a probabilidade de produção de uma falha decorrente de um erro tem relação direta com esse aspecto.

\section{a) Injeção de erros em registradores}

Primeiramente, o algoritmo faz uso de três variáveis de controle que tem as seguintes funções: selecionar registrador que será afetado, selecionar o bit que terá seu valor invertido e limitar o conjunto de registradores afetados. A injeção de erros em registradores é feita de forma indireta. Essencialmente os erros são produzidos sobre a pilha que armazena temporariamente o valor de todos os registradores usados pelo programa, assim que é ativada uma interrupção. Dessa forma, quando ocorre a interrupção gerada pelo temporizador associado à injeção de erros em registradores, o valor de cada registrador é armazenado na pilha. Em seguida, o algoritmo responsável pelo bit flip, produz o erro sobre essa pilha e assim que o programa volta para o ponto de processamento em que ele se encontrava antes da interrupção, o valor de cada um dos registradores é recuperado, produzindo então o bit flip sobre o registrador selecionado. O valor que define o limite de registradores que podem ser afetados evita que sejam injetados erros em posições da pilha que não correspondam a um registrador.

\section{b) Injeção de erros sobre memória}

O mecanismo que injeta erro em células de memória é muito semelhante ao mecanismo de injeção de erros sobre registradores, salvo o fato de que a pilha não está envolvida neste processo. Basicamente, são selecionados uma posição de 
memória e um bit e, através do algoritmo de injeção de erros, produz-se o erro. Novamente, o limite correspondente ao número de células de memória que podem ser afetadas é imposto e, dessa forma, evita-se injetar erros em células não utilizadas.

O ambiente de testes descrito neste capítulo, permite em fim, que sejam feitas medições voltadas ao aspecto de segurança do sistema. A partir dos resultados obtidos por simulação, são elaboradas análises com o objetivo de avaliar a resposta do sistema em estudo, segundo a aplicação de cada uma das técnicas programação defensiva e combinações entre elas. Tais análises são descritas no capítulo 8. 


\section{ANÁLISE DOS RESULTADOS}

A análise dos resultados obtidos através das simulações foi orientada no sentido de possibilitar a identificação de alterações no comportamento adquirido pelo programa original, após a aplicação de técnicas de programação defensiva. Dentre as várias alterações no comportamento, a segurança foi usada como parâmetro de comparação.

O parâmetro de segurança usado neste estudo é o tempo médio para falha insegura - MTTUF (Mean Time To Unsafe Failure). Esse parâmetro é tipicamente usado como métrica, em conjunto com outros, na avaliação da segurança de um sistema. Em software o tempo para a ocorrência de uma falha, seja esta insegura ou não, leva em consideração a possibilidade de presença de erros no código (bugs) ou interferências que produzam bit-flips em elementos de memória; sendo este último, o método usado para obter os resultados descritos a seguir.

De forma geral, as simulações foram conduzidas tendo como parâmetro de mediação o MTTUF e os resultados analisados através da função de densidade de probabilidade de falha insegura e taxa de falhas inseguras.

A função de densidade de probabilidade de falha insegura pode assumir uma dentre várias distribuições (e.g. distribuição normal) em função da forma como é conduzido o experimento e dos parâmetros utilizados. Nessa investigação, o programa alvo é caracterizado por processar um conjunto de variáveis de entrada e gerar um resultado, representado por um conjunto de variáveis de saída. Essas variáveis de saída podem assumir valores que representem três possibilidades: resultado correto, resultado incorreto seguro ou resultado incorreto inseguro. Para 
nossa avaliação, esses resultados são divididos em apenas duas possibilidades: presença ou ausência de resultado inseguro.

Tais resultados são obtidos através de forma cíclica e ininterrupta, sob a influência de injeção de erros a uma taxa constante. Dessa forma, o que temos é essencialmente um teste binomial (sucesso, insucesso) onde se pretende calcular qual a probabilidade de falha insegura durante o tempo de simulação. Dito de forma mais especifica, o objetivo é obter a probabilidade de ocorrência de falha insegura em diversos intervalos de tempo, partindo de um instante inicial - inicialização do programa alvo.

Através dos resultados obtidos, observa-se que a curva que representa a função de densidade de probabilidade de falhas inseguras, assume uma forma aproximada de distribuição exponencial (curvas Weibull com $\beta$ próximo a "1"). Essa característica indica que a taxa de falhas inseguras assume valores que tendem a se manter constantes durante o tempo de simulação. As características e propriedades de distribuições Weibull são detalhadas no tópico a seguir.

Mesmo em casos em que a distribuição se distancia levemente da forma exponencial, adquirindo um pico de distribuição diferente de $t=0$, percebe-se uma forte tendência onde as amostras de tempo para falhas inseguras têm maior frequência de valores próximos a $t=0$. Essa tendência em se obter distribuições com enviesamento positivo se manteve para todas as técnicas e suas combinações.

A figura 39 descreve uma curva de distribuição de densidade de probabilidade de falha insegura, obtida durante o experimento, sobreposta pelo histograma correspondente. Pode-se observar em intervalos de tempo próximos a $t=0$, valores de probabilidade maiores quando comparados a intervalos de tempo distantes de $\mathrm{t}=$ 0. Esse exemplo corresponde aos resultados obtidos quando aplicadas as técnicas 
de programação defensiva $\mathrm{BCH}$ e diversidade combinadas. Pode-se afirmar que o mesmo padrão é observado em praticamente todas as demais técnicas e combinações de técnicas de programação defensiva.

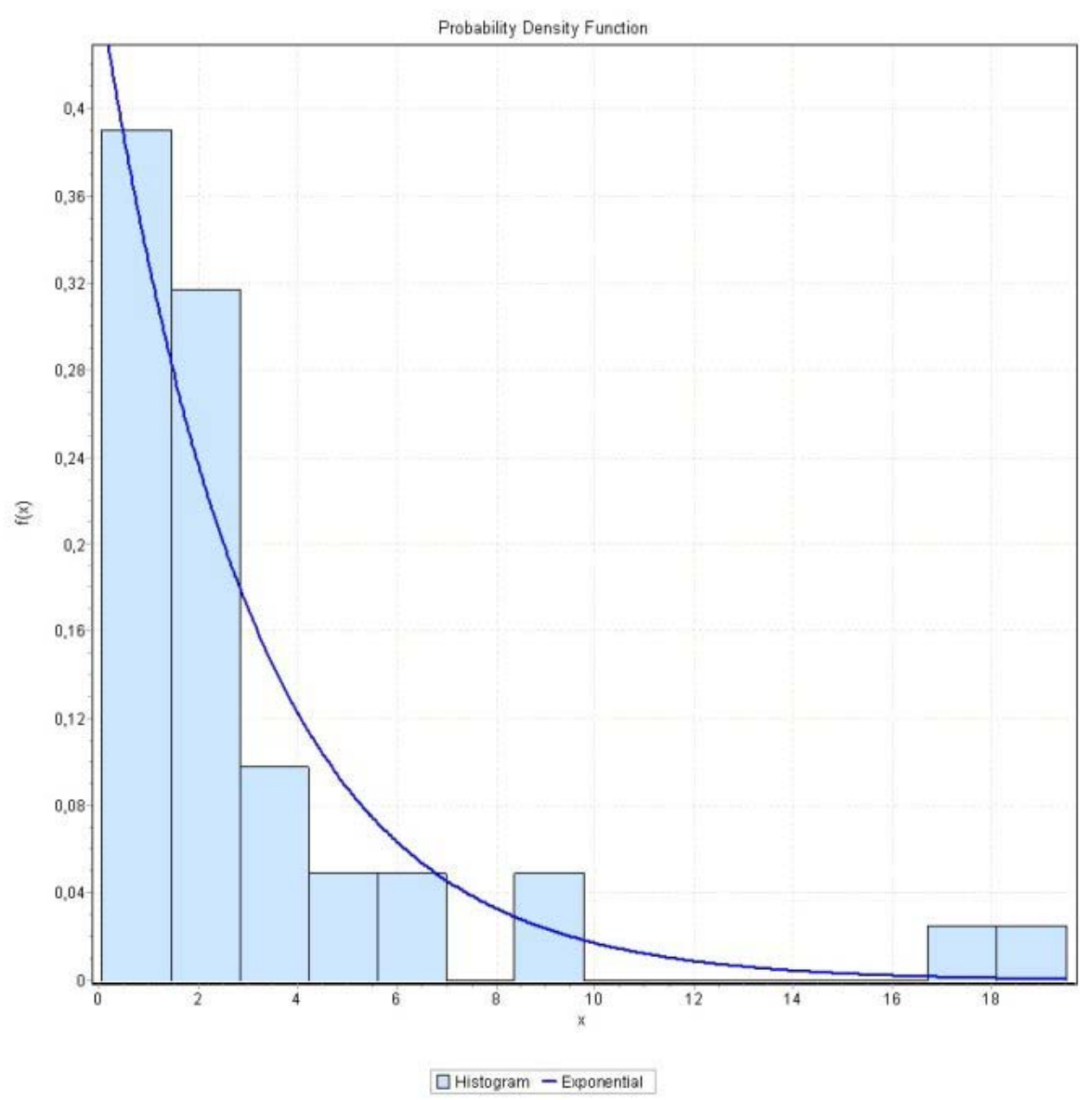

Figura 39 - Distribuição típica obtida através de simulação

Nesse momento os resultados obtidos pela simulação foram avaliados quanto a sua aderência à distribuição. O software de análise utilizado com essa finalidade foi o Weibull++. Já o método aplicado para a avaliação quanto à aderência foi o teste de Chi-Quadrado (RUBIN, 2009). Esse teste retorna a probabilidade do respectivo valor crítico ser menor do que o valor calculado. Altos valores, perto de um, indicam 
que há uma diferença significativa entre a distribuição teórica e o conjunto de dados experimentais. A partir dos testes de aderência pode-se observar que a distribuição de Weibull (homônimo do software de análise) obteve a melhor aderência em relação a outras distribuições (log-normal, normal, gamma, Pareto, etc..).

\subsection{A distribuição de Weibull}

Para todos os resultados obtidos experimentalmente foi aplicada a aproximação por distribuição de Weibull. Nesse sentido algumas características importantes dessa distribuição passam a ser pertinentes a análise dos dados obtidos.

A função taxa de falha, para quaisquer variáveis aleatórias não negativas com função de distribuição cumulativa de falha $F(t)$ e função de densidade de probabilidade de falha $f(t)$ é definida como $\lambda(t)=f(t) /(1-F(t))$. Ela é normalmente empregada para distribuições que modelam "tempos de vida" aleatórios e está relacionada à probabilidade de que o tempo de vida chega ao seu fim dentro do próximo incremento de tempo de duração $d$ dado que a função taxa de falhas em $(t+d)$ excedeu a taxa de falhas em $(t)($ SCHOLZ, 2008).

No caso da função taxa de falhas Weibull, observa-se que ela é crescente em $\mathrm{t}$, quando $\beta>1$, decrescente em $\mathrm{t}$, quando $\beta<1$, e constante em $\mathrm{t}$, quando $\beta=1$ (Distribuição exponencial).

Quando $\beta>1$, a parte ou o sistema para o qual o tempo de vida é modelado pela distribuição Weibull, comporta-se como se estivesse "envelhecendo" no sentido de que o sistema mais velho tem uma chance maior de falha durante o próximo pequeno incremento de tempo $d$ que o sistema mais jovem. 
Quando $\beta<1$ (incomum) o sistema tem maiores chances de sobreviver ao próximo pequeno incremento de tempo $d$ assim que ele se torna mais "velho". Frequentemente, essa situação está associada à tendência de que após algumas falhas iniciais a "taxa de sobrevivência" se torna melhor com o passar da idade, aspecto bastante característico da fase de mortalidade infantil em equipamentos eletro-eletrônicos..

Para $\beta=1$ não há "envelhecimento", o sistema é tão bom ou saudável quando aquele que tem sobrevivido até então, através de t. Desde que o valor de $\beta$ seja 1 , tem-se uma função exponencial com igualà média. Tal valor para $\quad \beta$ refere-se também a um modelo de falha aleatória no sentido de que as falhas são devidas a choques externos que seguem um processo de Poisson.

Vale salientar que, para a versão original do programa alvo (versão que não possui nenhuma técnica de programação defensiva), o $\beta$ alcançado é de $0,89, \eta$ de 0,24 e média experimental de 0,31, o que indica um sistema onde a função taxa de falha insegura é levemente descendente.

Um ponto importante nesse momento diz respeito ao pico de probabilidade para a distribuição de taxa de falha insegura, representado pelo valor de moda, uma das medidas de tendência central comumente utilizada em análises estatísticas. A moda é o valor que detém o maior número de observações, ou valores mais freqüentes. Esse valor é importante porque poderia definir qual o intervalo de tempo concentraria a maior parte dos tempos para a falha insegura em uma determinada versão do programa. A partir desse valor seria possível determinar o quanto uma técnica de programação defensiva produz a tendência de gerar amostras de tempo para falha insegura maiores que outras. Porém, a tendência da maioria dos resultados em adquirir forma exponencial, acaba por eliminar o uso do valor de 
moda, como parâmetro de comparação. Esse aspecto orienta uma investigação muito mais centrada nas funções de densidade de probabilidade e taxa de falhas inseguras.

$\mathrm{Na}$ tabela 2, são descritos os valores de média de tempos para as falhas insegura (em segundos) e os parâmetros beta $(\beta)$ e eta(n) da distribuição de Weibull utilizada, obtidos para cada uma das técnicas e combinações de técnicas de programação defensiva.

\begin{tabular}{lccc} 
Técnica & Média para falha insegura (s) & Beta $(\beta)$ & Eta $(\eta)$ \\
\hline Checksum + Forward & 0,1256 & 1,0987 & 0,1161 \\
\hline Diversidade & 0,2826 & 0,8136 & 0,2356 \\
\hline Programa alvo & 0,3143 & 0,8911 & 0,2367 \\
\hline Diversidade + Checksum & 0,3582 & 0,7425 & 0,2473 \\
\hline Diversidade + Forward & 0,3636 & 1,0344 & 0,3801 \\
\hline Diverdade + Backward & 0,4648 & 0,7981 & 0,3900 \\
\hline Paridade + Backward & 0,4770 & 1,0630 & 0,4746 \\
\hline Paridade + Checksum & 0,4840 & 1,2164 & 0,4862 \\
\hline Paridade + Forward & 0,4852 & 1,3712 & 0,4890 \\
\hline Checksum + Backward & 0,4908 & 0,9473 & 0,4912 \\
\hline Checksum & 0,5300 & 0,7812 & 0,4695 \\
\hline Paridade & 0,7847 & 0,7834 & 0,7956 \\
\hline Duplicação + Forward & 0,8530 & 0,5940 & 0,7202 \\
\hline Paridade + Diversidade & 1,0846 & 0,9659 & 0,9853 \\
\hline Duplicação + Backward & 1,4950 & 0,6665 & 1,4028 \\
\hline Backward & 1,5637 & 0,7508 & 1,3701 \\
\hline Backward + Forward & 2,2847 & 0,8965 & 2,3568 \\
\hline Backward + BCH & 2,9016 & 0,7278 & 2,5445 \\
\hline Diversidade + BCH & 3,0474 & 0,9454 & 2,7726 \\
\hline BCH & 3,0506 & 0,7934 & 2,9455 \\
\hline Duplicação + Checksum & 3,5081 & 1,0202 & 3,4448 \\
\hline Duplicação & 3,5263 & 0,9217 & 3,2562 \\
\hline Duplicação + Diversidade & 4,6733 & 1,1836 & 4,6699 \\
\hline Duplicação + Paridade & 7,0140 & 1,0233 & 6,7765 \\
\hline Duplicação + BCH & 7,4122 & 0,8111 & 4,9457 \\
\hline Forward + BCH & 7,7945 & 0,6994 & 5,0835 \\
\hline Forward & 9,3688 & 0,3890 & 4,6714 \\
\hline Checksum + BCH & 10,6912 & 0,3460 & 4,9878 \\
\hline Parity + BCH & 20,0146 & 0,6370 & 11,3619 \\
\hline & & & \\
\hline
\end{tabular}


$\mathrm{Na}$ figura 40 estão representados os valores da tabela 2, ordenados pela média de tempos para falha insegura.

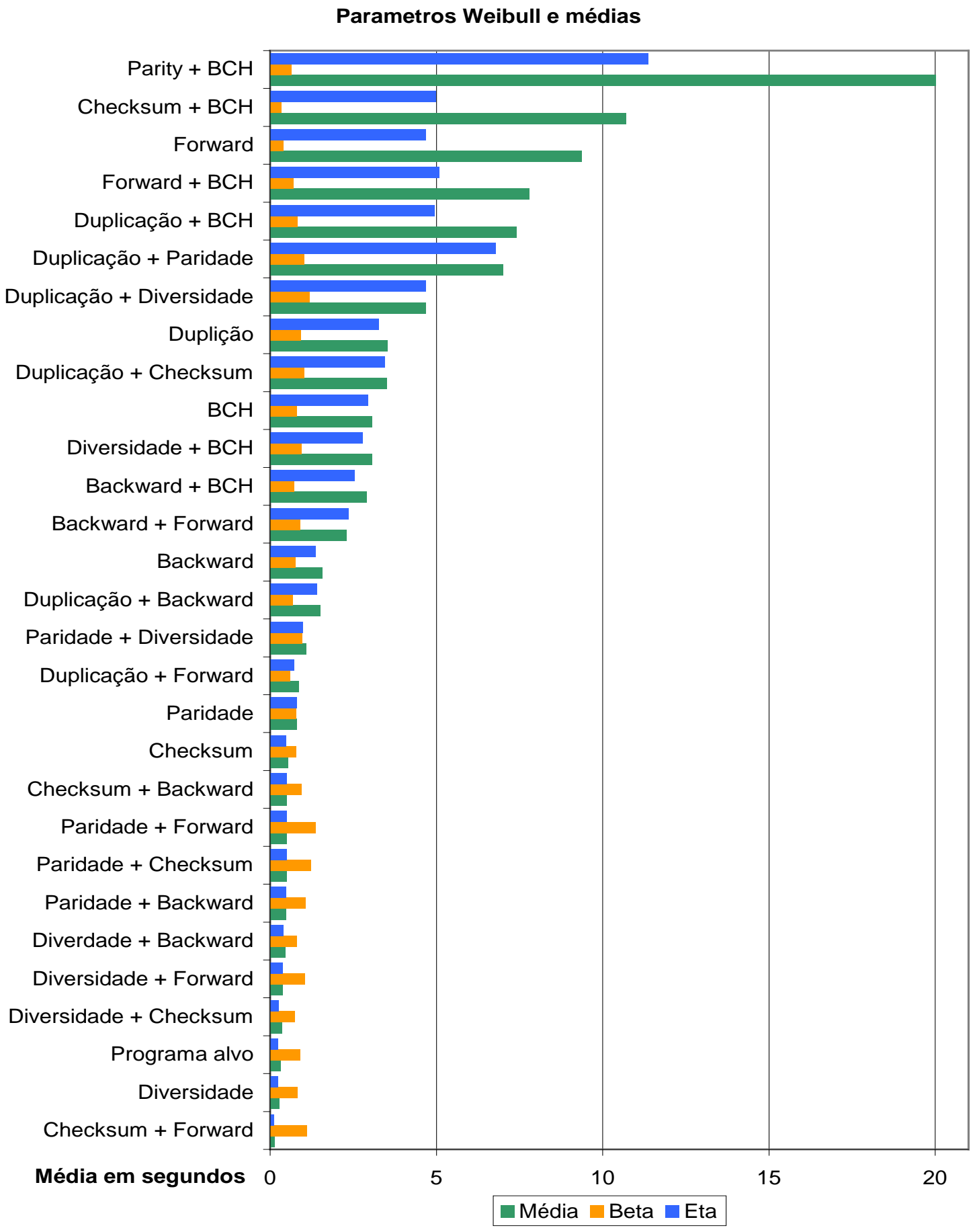

Figura 40 - Média de tempos para falha insegura e parâmetros Weibull 
Pode-se observar a partir dos valores obtidos que há uma correlação mais visível entre os valores de média (MTTUF - mean time to unsafe failure) e o parâmetro Eta segundo a distribuição Weibull. Já o parâmetro Beta segue uma tendência de proximidade ao valor 1 , o que indica tratar-se de um fenômeno onde a taxa de falhas é constante. Esse aspecto pode representar uma característica importante, segundo a qual a comparação entre as diversas técnicas de programação defensiva ganha um parâmetro centralizador, que permanece praticamente inalterado, mesmo que outros aspectos (e.g. tamanho de código) variem em função da aplicação de diferentes versões do programa alvo.

\subsection{Tempo de processamento dedicado}

Com a aplicação das técnicas de programação defensiva sobre o algoritmo original (programa alvo), há um consumo de tempo de processamento dedicado à parte defensiva e a parte funcional de cada uma das versões do programa. Esse aspecto se torna importante em função da possibilidade de que parte das falhas produzidas incida sobre a própria técnica defensiva. Esse efeito pode produzir uma resposta errônea durante a detecção ou correção de um primeiro erro produzido sobre a parte funcional.

Na figura 41, cada uma das versões do programa é comparada segundo a parcela de tempo que é dedicada à técnica de programação defensiva e a parcela de tempo dedicada à parte funcional do programa. Esses valores são estimados a partir do acréscimo de tempo de processamento observado em cada versão do programa, quando comparados ao tempo de processamento consumido pela versão original (programa alvo). 
Tempo de processamento

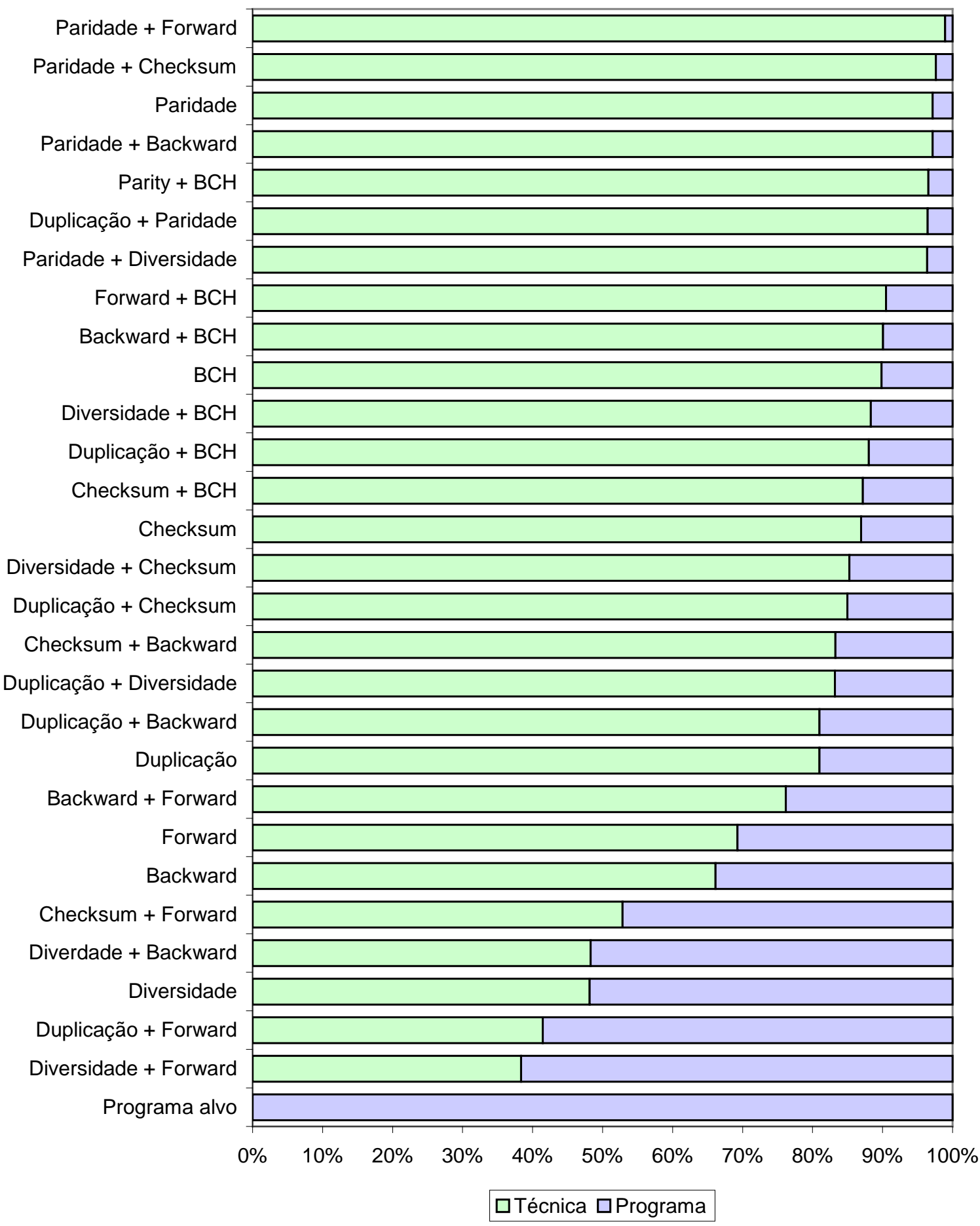

Figura 41 - Tempo de processamento dedicado a técnica e ao programa

Por meio desse levantamento pode-se observar que não há, a princípio, correlação entre os valores de tempo de processamento dedicado à técnica ou ao 
programa e demais parâmetros usados na análise. Dentre os parâmetros avaliados, estão inclusos tempo médio de falhas inseguras e parâmetros Weibull.

\subsection{Análise de combinações entre técnicas de programação defensiva}

Para a seguinte análise foram selecionadas as combinações de técnicas de programação defensiva que se mantêm iguais em estrutura quando utilizadas em conjunto com uma outra técnica de programação defensiva. Tal análise é fundamental no sentido de se manter uma coerência lógica na comparação entre técnicas de programação defensiva que não precisam ser alteradas em função da combinação sob teste.

Inicialmente, foram descartadas as combinações que não podem ser decompostas em suas técnicas originais. Em certos casos uma técnica A pôde ser aplicada isoladamente sem a necessidade de uma rotina auxiliar que a complementasse, o que não acontece com uma técnica B. A combinação das técnicas $A$ e $B$, elimina a necessidade da rotina auxiliar em $B$, uma vez que tal necessidade é suprida pela própria técnica A. Dessa forma, são desconsiderados os casos que fariam comparação entre a técnica $A$, a técnica B e sua rotina auxiliar e técnica A e B combinadas.

Tais casos ficam evidentes com o uso das técnicas Backward Recovery e Forward Recovery, que quando testadas isoladamente, utilizam uma rotina auxiliar para detecção de erros denominada VEI - Verificador de Erros Inseguros.

Nas combinações de técnicas de programação defensiva em que são aplicadas Forward ou Backward, a rotina VEI é sempre removida e em seu lugar é aplicada uma técnica de detecção de erros. Nesses casos a combinação é 
descartada, pois não se manteve a técnica original de forward ou backward. A tabela 3 descreve as combinações selecionadas para avaliação. As combinações em vermelho itálico não foram avaliadas nesta análise, em particular.

\begin{tabular}{lll}
\hline Técnica A & Técnica B & Técnicia A + B \\
\hline Paridade & Checksum & Paridade + Checksum \\
\hline Paridade & BCH & Paridade + BCH \\
\hline Paridade & Duplicação & Paridade + Duplicação \\
\hline Paridade & Diversidade & Paridade + Diversidade \\
\hline Paridade & Forward + VFI & Paridade + Forward \\
\hline Paridade & Backward + VFI & Paridade + Backward \\
\hline Checksum & BCH & Checksum + BCH \\
\hline Checksum & Duplicação & Checksum + Duplicação \\
\hline Checksum & Diversidade & Checksum + Diversidade \\
\hline Checksum & Forward + VFI & Checksum + Forward \\
\hline Checksum & Backward + VFI & Checksum + Backward \\
\hline BCH & Duplicação & BCH + Duplicação \\
\hline BCH & Diversidade & BCH + Diversidade \\
\hline BCH & Forward + VFI & BCH + Forward \\
\hline BCH & Backward + VFI & BCH + Backward \\
\hline Duplicação & Diversidade & Duplicação + Diversidade \\
\hline Duplicação & Forward + VFI & Duplicação + Forward \\
\hline Duplicação & Backward + VFI & Duplicação + Backward \\
\hline Diversidade & Forward + VFI & Diversidade + Forward \\
\hline Diversidade & Backward + VFI & Diversidade + Backward \\
\hline Forward + VFI & Backward + VFI & Forward + Backward \\
\hline
\end{tabular}

Tabela 3 - Seleção de combinações para análise

Uma vez concluída a seleção das versões que serão avaliadas, as curvas correspondentes às taxas de falhas inseguras para a técnica $A$, técnica $B$ e técnica $A+B$, são traçadas. Para melhor compreensão dos gráficos, o seguinte padrão de cores foi adotado: azul e verde correspondem às técnicas A e B; laranja corresponde à combinação $A+B$.

Um aspecto importante que deve ser notado é o fato de que praticamente todas as curvas para taxa de falhas inseguras obtidas, assumem um tendência de queda sutil ou mesmo de valor constante. Esse aspecto está ligado ao parâmetro 
beta de distribuições Weibull, que para a maioria das versões, assume valor próximo a um. A observação desta característica tornou-se um importante parâmetro de comparação entre técnicas de programação defensiva e seus resultados obtidos experimentalmente.

No primeiro exemplo (figura 42) são comparadas as curvas correspondentes às taxas de falhas inseguras geradas a partir das técnicas duplicação de variáveis, $\mathrm{BCH}$ e duplicação de variáveis combinada com $\mathrm{BCH}$. As três versões adquiriram uma leve tendência de queda, sendo $\mathrm{BCH}$ a de queda mais intensa; o valor de beta obtido por essa versão é justamente o menor dentre as três versões.

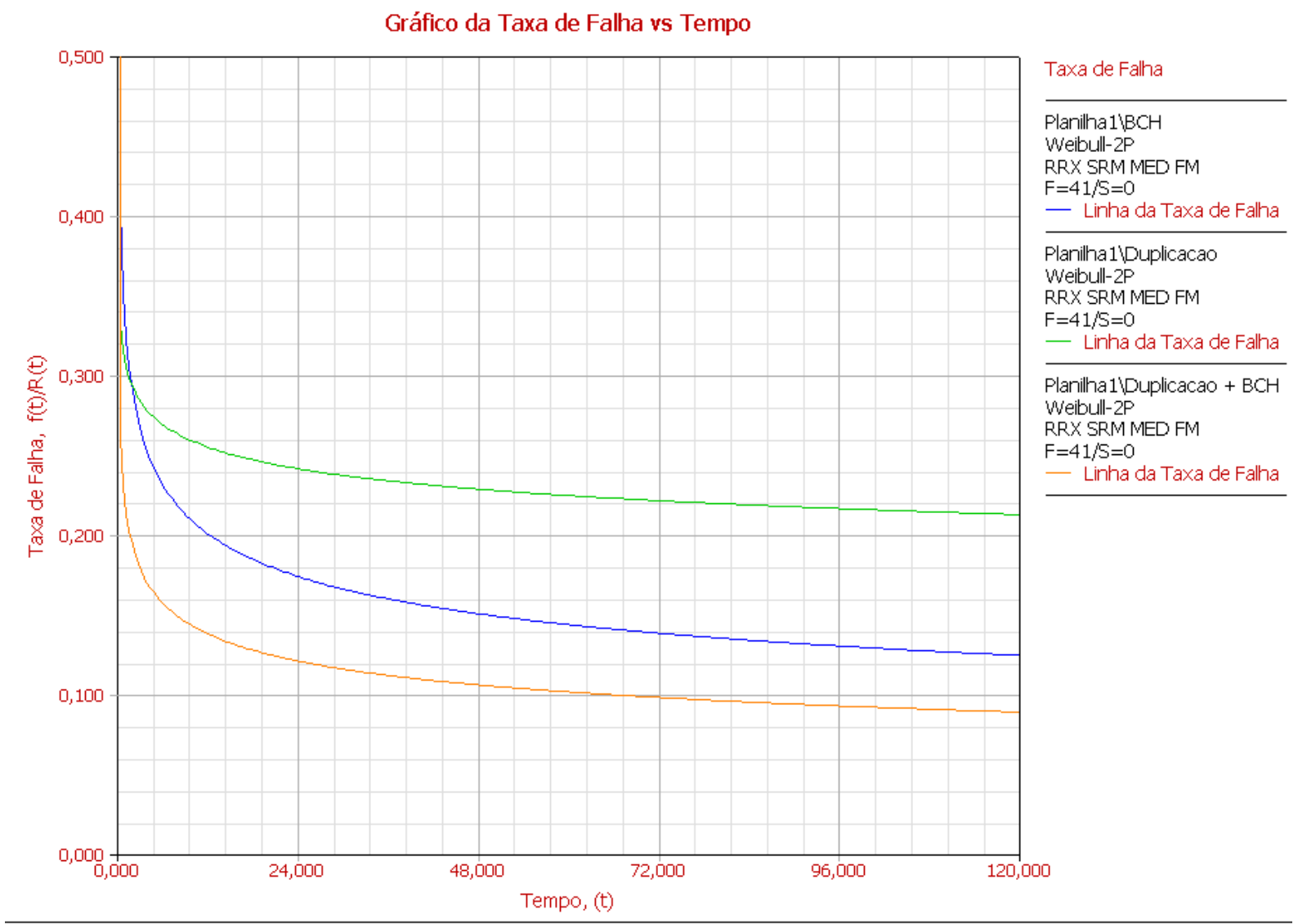

Planilha1 $\mathrm{BCH}: \quad \beta=0,7934, \eta=2,9455, \rho=0,9801$

Planilha1:Duplicacao: $\quad \beta=0,9217, \eta=3,2562, \rho=0,9861$

Planilha1:Duplicacao + BCH: $\quad \beta=0,8111, \eta=4,9457, \rho=0,9787$

Figura 42 - Taxas de falhas inseguras (Técnicas BCH e duplicação de variáveis) 
Levando-se em consideração o valor aproximado de taxa de falhas inseguras para cada uma das versões, observa-se que a versão duplicação de variáveis obteve a maior taxa dentre as três, seguida por $\mathrm{BCH}$, que obteve um valor intermediário e finalmente, a combinação de ambas acabou por obter a menor taxa de falhas inseguras.

A próxima comparação de técnicas de programação defensiva faz uso de $\mathrm{BCH}$ e paridade (figura 43). As similaridades com o caso anterior estão presentes na tendência sutil de queda e no fato de que a combinação entre as técnicas obteve uma taxa de falhas inseguras menor que ambas as técnicas originárias.

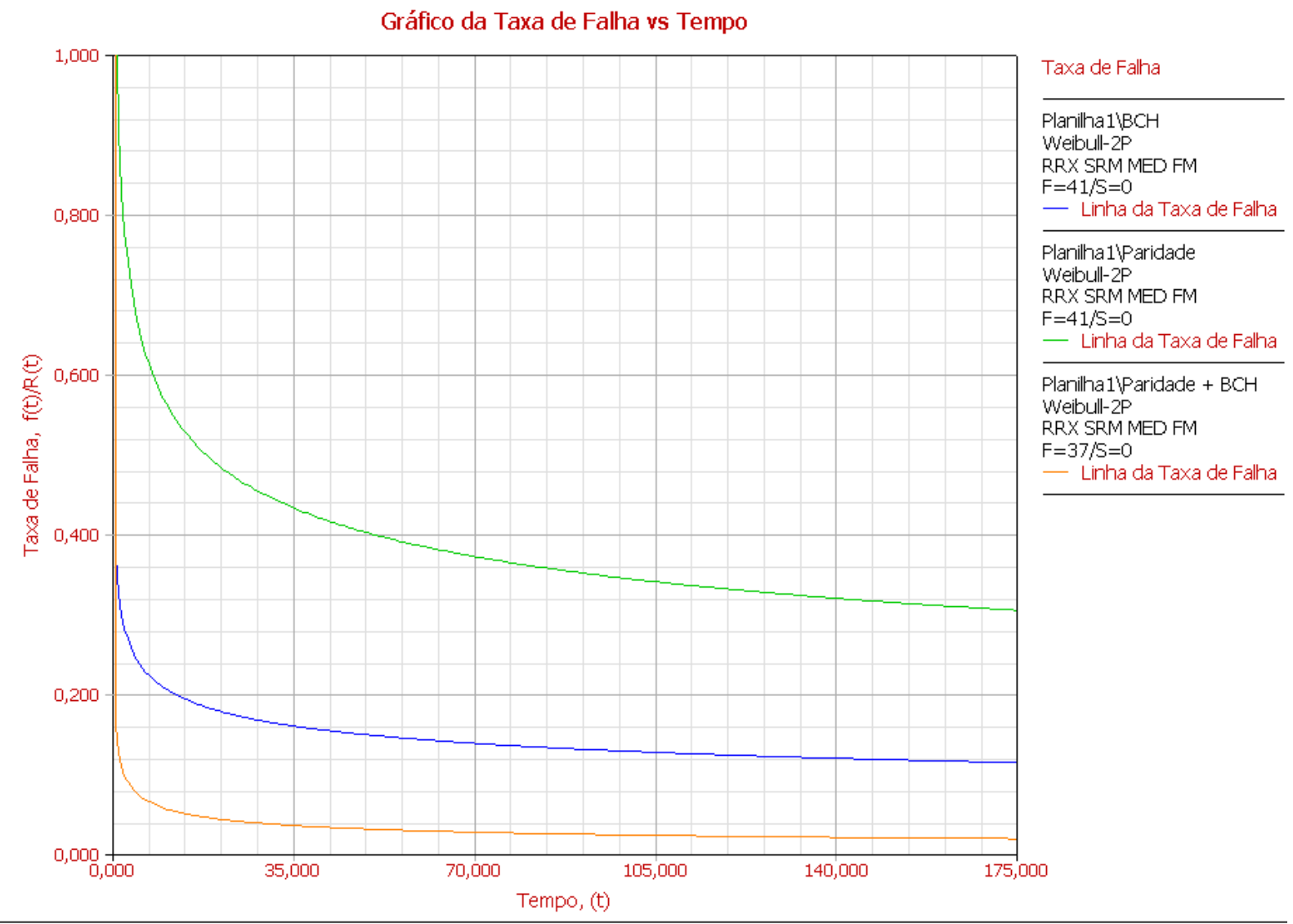

Planilha1 $\mathrm{BCH}: \quad \beta=0,7934, \eta=2,9455, \rho=0,9801$

Planilha1 Paridade: $\quad \beta=0,7834, \eta=0,7956, \rho=0,9786$

Planilha1YParidade $+\mathrm{BCH}: \quad \beta=0,6370, \eta=11,3619, \rho=0,9819$

Figura 43 - Taxa de falhas inseguras (Técnicas BCH e paridade) 
Deve-se observar que apesar das similaridades, os valores aproximados para taxa de falhas inseguras se diferenciam em certo grau. Observa-se que há uma técnica comum $(\mathrm{BCH})$ a ambos os casos e por isso esta possui o mesmo valor para a taxa de falhas inseguras. Ao comparar a taxa de falhas inseguras para as combinações, observa-se que no caso presente obteve-se menor taxa de falhas inseguras, apesar de possuir a segunda técnica (paridade) taxa de falhas inseguras maior quando comparado a segunda técnica (duplicação de variáveis) do caso anterior.

No próximo caso, a comparação é feita a partir das técnicas $\mathrm{BCH}$ e Checksum (figura 44).

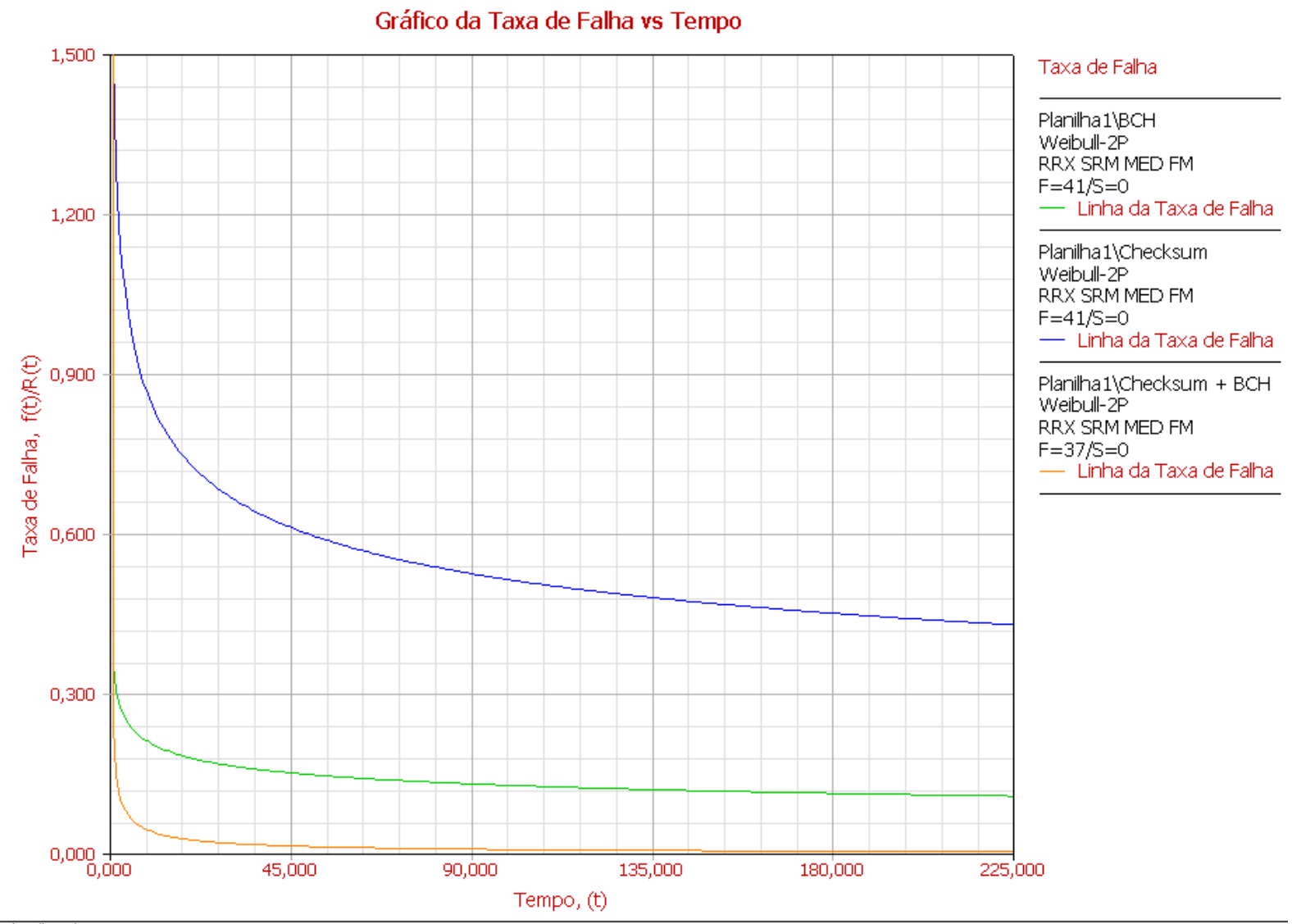

Planilha1'BCH: $\quad \beta=0,7934, \eta=2,9455, \rho=0,9801$

Planilha1)Checksum: $\quad \beta=0,7812, \eta=0,4695, \rho=0,9542$

Planilha1 \Checksum + BCH: $\quad \beta=0,3460, \eta=4,9878, \rho=0,9212$

Figura 44 - Taxa de falhas inseguras (Técnicas BCH e Cheksum) 
Novamente, uma das técnicas é comum ao caso anterior, $\mathrm{BCH}$. É possível observar que a segunda técnica (checksum para este caso) obteve valores de taxa de falhas inseguras maiores, quando comparado ao caso anterior (paridade), porém, o valor obtido pela combinação sempre é menor do que os valores de taxa de falhas inseguras das técnicas isoladas.

No próximo caso, as técnicas paridade e duplicação de variáveis são combinadas e avaliadas (figura 45). Diferentemente de todos os casos anteriores, uma das curvas, a curva de combinação das técnicas, obteve valor de Beta maior que um.

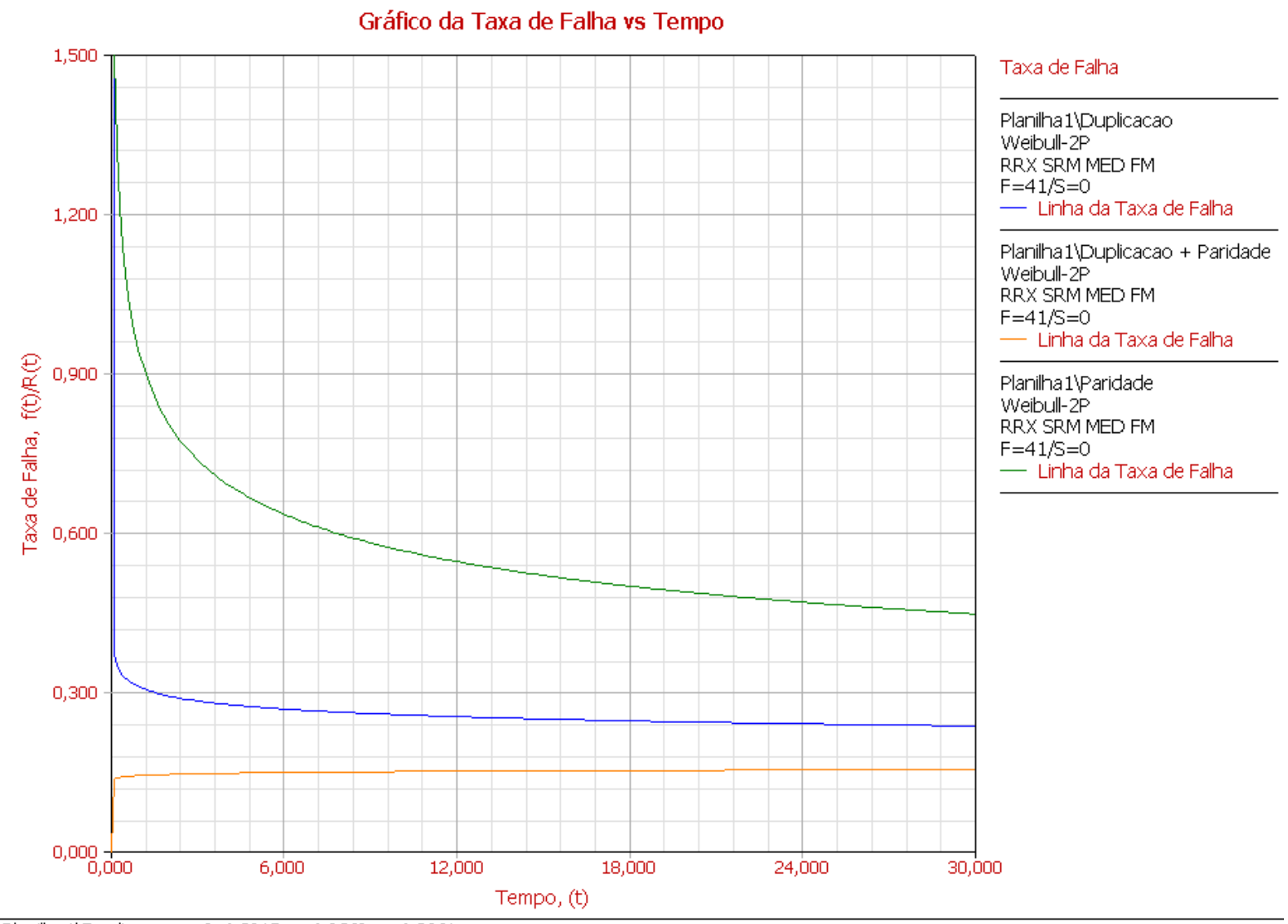

Planilha1:Duplicacao: $\quad \beta=0,9217, \eta=3,2562, \rho=0,9861$

Planilha1:Duplicacao + Paridade: $\quad \beta=1,0223, \eta=6,7765, \rho=0,9834$

Planilha1 Paridade: $\quad \beta=0,7834, \eta=0,7956, \rho=0,9786$

Figura 45 - Taxa de falhas inseguras (Técnicas duplicação de variáveis e paridade) 
Logo, o efeito sobre a curva de taxa de falhas inseguras é observado pelo aumento gradual do seu valor em t. Porém, Beta assume um valor muito próximo a um, o que acaba produzindo na verdade, uma curva de valor praticamente constante. De fato, pode-se observar em todas as versões, sejam elas compostas por uma ou duas técnicas, uma forte tendência em manter o valor de Beta próximo a um.

Para o próximo caso, as técnicas combinadas são $\mathrm{BCH}$ e diversidade (figura 46). Diferentemente de todos os casos anteriores, a curva correspondente à combinação entre as técnicas de programação defensiva sugere, de forma sutil, que o seu valor de taxa de falhas inseguras seja maior que a taxa de uma das duas técnicas originárias.

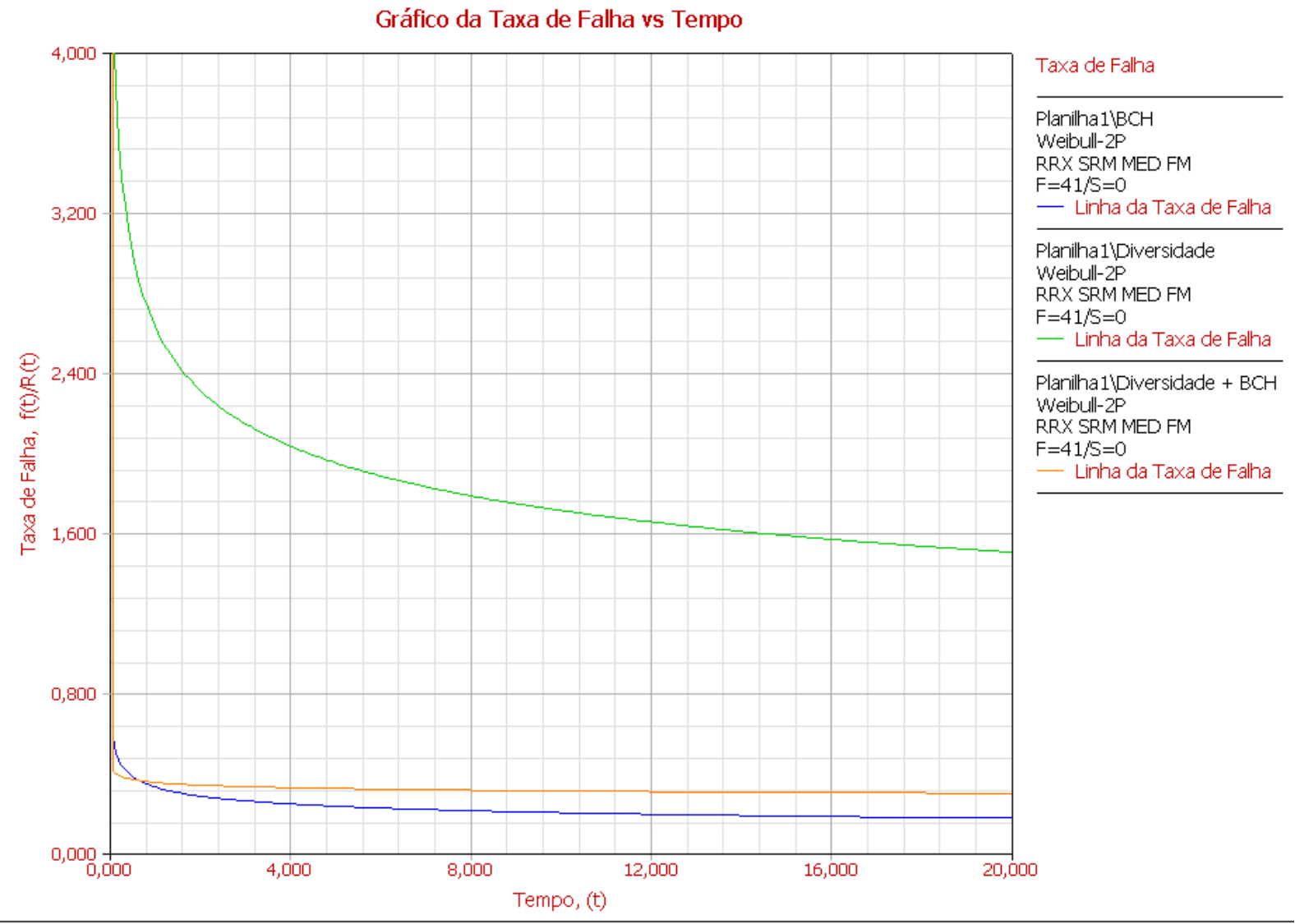

Planilha1 $\mathrm{BCH}: \quad \beta=0,7934, \eta=2,9455, \rho=0,9801$

Planilha1 Diversidade: $\quad \beta=0,8136, \eta=0,2356, \rho=0,9513$

Planilha1 $\backslash$ Diversidade $+\mathrm{BCH}: \quad \beta=0,9454, \eta=2,7726, \rho=0,9775$

Figura 46 - Taxa de falhas inseguras (Técnicas diversidade e BCH) 
Porém, não se pode descartar a possibilidade de que a diferença, por ser mínima, represente na verdade um problema de aproximação aplicada sobre as amostras obtidas experimentalmente. Pode-se, portanto, atribuir valores de taxa de falhas inseguras iguais ou similares tanto para a técnica $\mathrm{BCH}$ como para a técnica que combina $\mathrm{BCH}$ e diversidade.

No próximo caso, as técnicas checksum e duplicação de variáveis são combinadas e avaliadas (Figura 47). De forma similar ao caso anterior, os resultados obtidos por uma das técnicas e pela combinação da qual esta faz parte, se aproximaram a ponto de considerarmos uma única taxa de falhas inseguras para ambas.

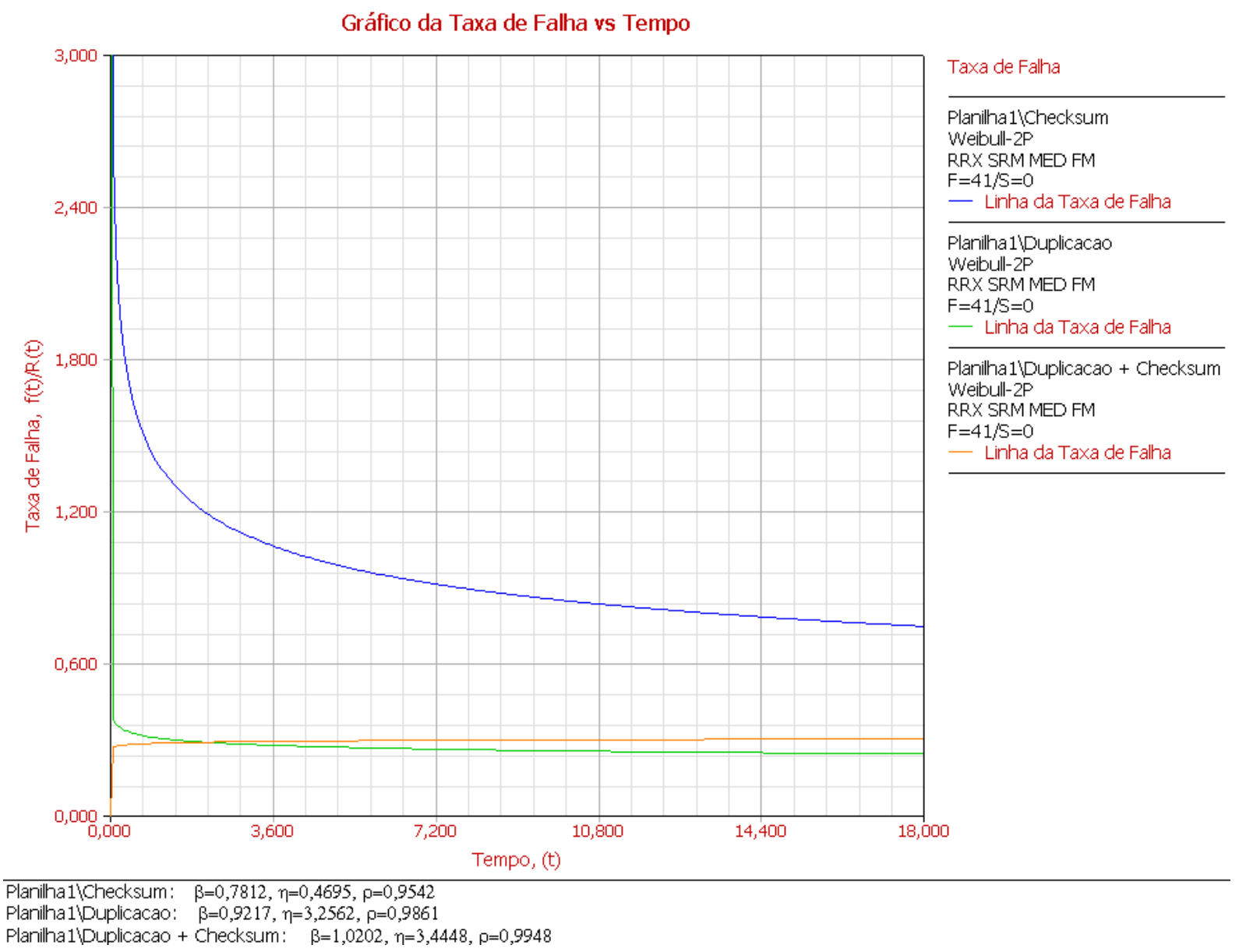

Figura 47 - Taxa de falhas inseguras (Técnicas Checksum e duplicação de variáveis) 
O que diferencia este, do caso anterior, pode ser observado no valor de beta maior que um, para a curva correspondente a combinação de técnicas. Por isso tal curva sugere um aumento do valor de taxa de falhas inseguras em t. Porém, como já foi observado anteriormente, tal valor é muito próximo a um, o que na verdade dá a curva uma tendência de constância em t.

Para o próximo caso, as técnicas combinadas são duplicação de variáveis e diversidade (Figura 48). As características observadas neste caso se assemelham ao caso anterior.

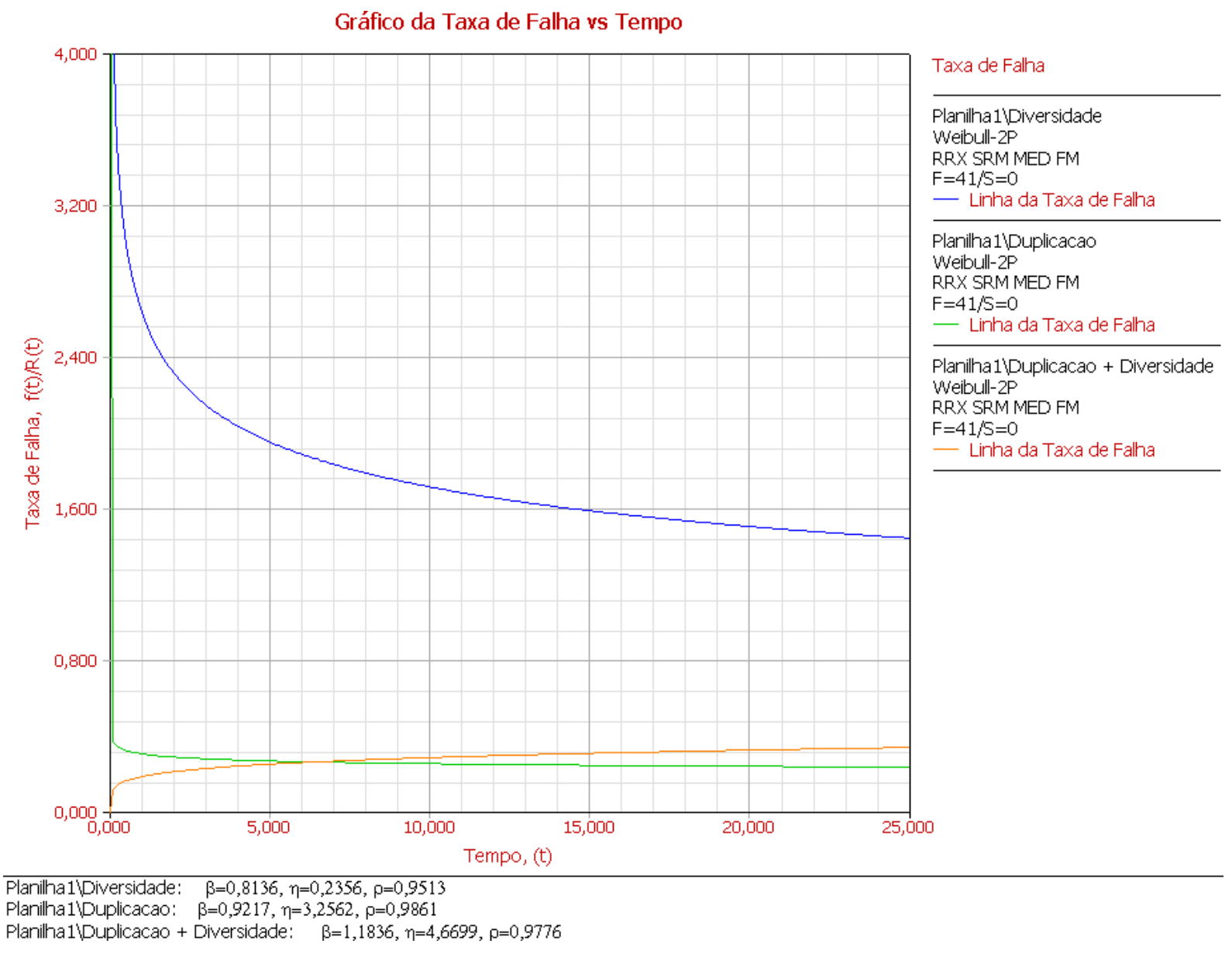

Figura 48 - Taxa de falhas inseguras (Técnicas duplicação de variáveis e diversidade)

Para o próximo caso, as técnicas combinadas são diversidade e paridade (figura 49). Nos casos anteriores, o valor de taxa de falhas insegura correspondente 
à combinação entre as técnicas de programação defensiva se aproximou do valor de uma das técnicas originárias. Neste caso, a combinação obteve valores de taxa de falhas insegura maiores que uma das técnicas (paridade).

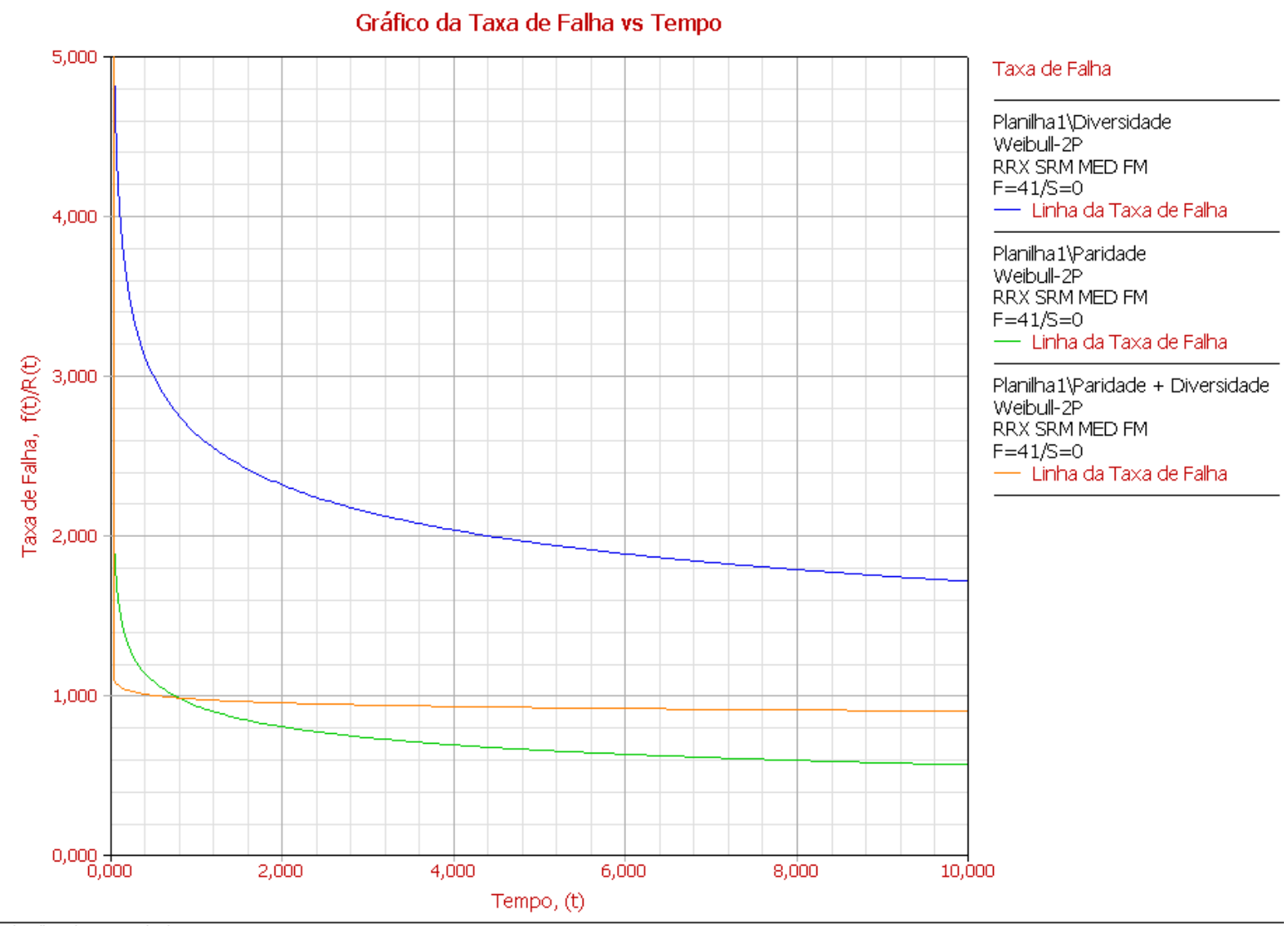

Planilha1 Diversidade: $\quad \beta=0,8136, \eta=0,2356, \rho=0,9513$

Planilha1YParidade: $\quad \beta=0,7834, \eta=0,7956, \rho=0,9786$

Planilha1 Paridade + Diversidade: $\quad \beta=0,9659, \eta=0,9853, \rho=0,9740$

Figura 49 - Taxa de falhas inseguras (Técnicas diversidade e paridade)

Para o próximo caso, as técnicas combinadas são diversidade e checksum (figura 50). Da mesma forma que no caso anterior a combinação de técnicas obteve valores para taxa de falhas insegura maiores que uma das técnicas (checksum).. 


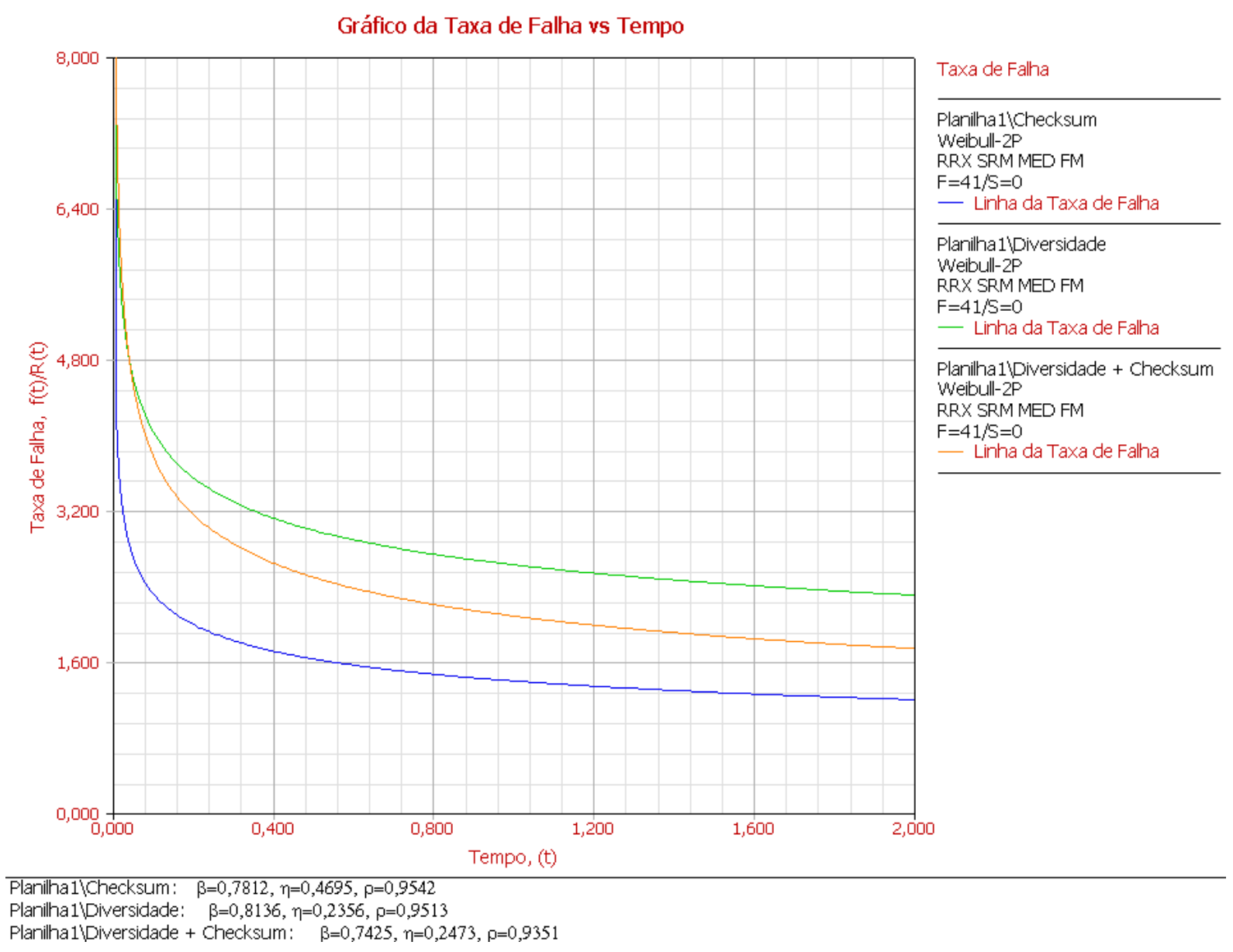

Figura 50 - Taxa de falhas inseguras (Técnicas diversidade e checksum)

No próximo caso, as técnicas backward recovery e forward recovery são combinadas e avaliadas (Figura 51). O resultado obtido reflete que a taxa de falhas inseguras da combinação, foi maior que os valores correspondentes às taxas de falhas de ambas as técnicas, descrevendo um efeito extremo. Como em ambas as técnicas originais é usado o algoritmo $\mathrm{VEI}$, existe a possibilidade de que na combinação das técnicas, o algoritmo VEI agora duplicado, tenha sofrido maior interferência do mecanismo de injeção de erros, aumentado a taxa de falhas inseguras. 


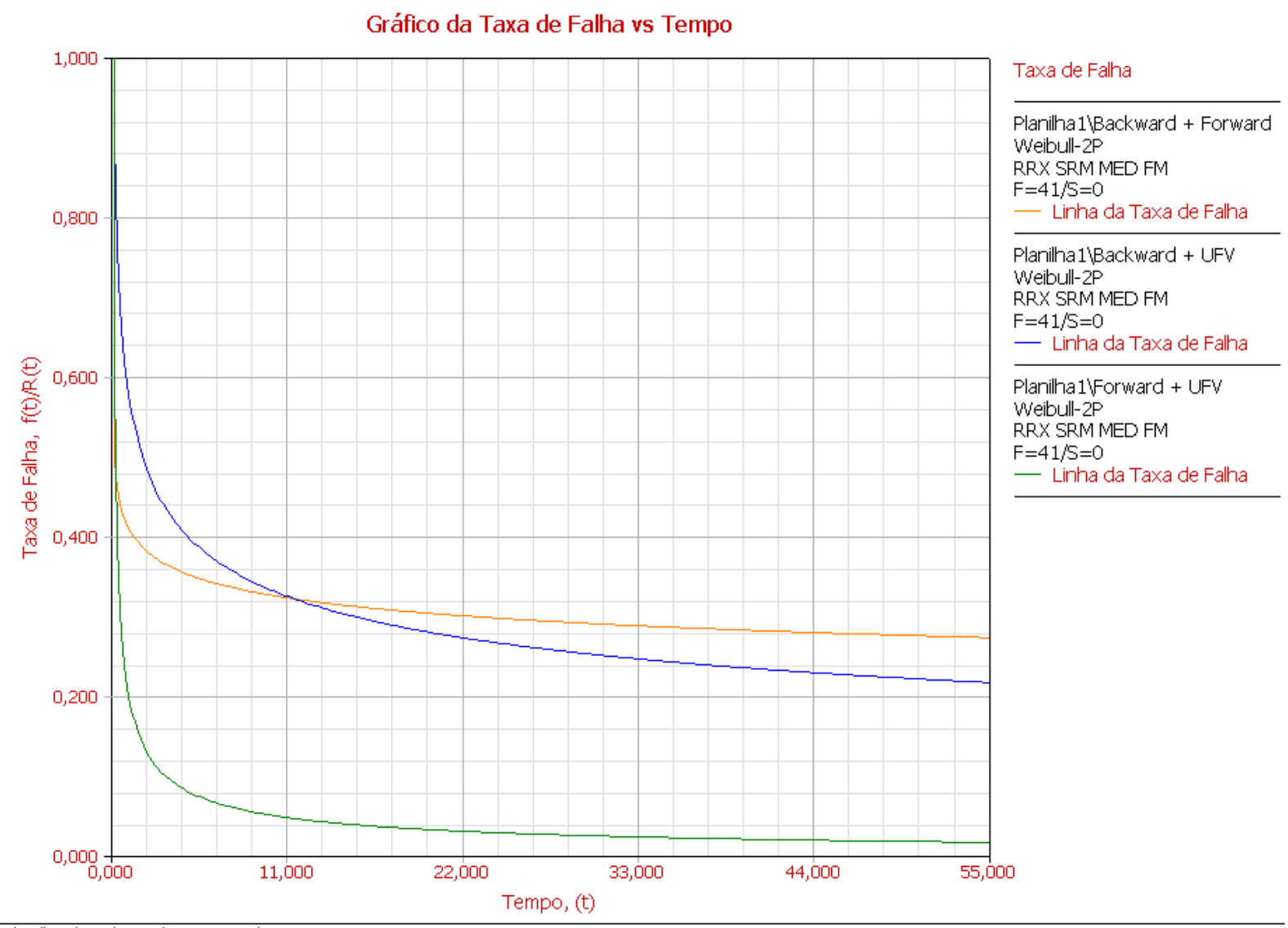

Planilha1)Backward + Forward: $\quad \beta=0,8965, \eta=2,3568, \rho=0,9854$

Planilha1)Backward + UFV: $\quad \beta=0,7508, \eta=1,3701, \rho=0,9886$

Planilha1 Forward + UFV: $\quad \beta=0,3890, \eta=4,6714, \rho=0,9075$

Figura 51 - Taxa de falhas inseguras (Técnicas backward recovery e forward recovery)

Para esse último caso, as técnicas checksum e paridade são combinadas e avaliadas (figura 52). De forma similar ao caso anterior, a taxa de falhas insegura obtida pela combinação de técnicas assume valores maiores que ambas as técnicas originárias. Porém neste caso, além desse efeito, observa-se que a combinação de técnicas obteve também um valor de Beta maior que um, transferindo à curva uma tendência de crescimento em t.

Essa característica adicional leva os resultados deste caso em particular a se distanciarem dos demais. De fato, apenas com 5 segundos de simulação - vide figura 52 - o valor para taxa de falhas insegura correspondente à combinação de 
técnicas é exageradamente maior do que qualquer uma das técnicas originárias, quando comparados aos casos anteriores.

Após uma análise mais detalhada, não foram identificadas características associadas aos algoritmos utilizados, que justificassem tal efeito. Porém, algumas constatações associadas a ambas as técnicas poderiam, ao menos, caracterizar tal resultado. A primeira constatação indica que, a combinação entre paridade e checksum produz um alto consumo de tempo de processamento dedicado à proteção de dados. Na verdade, o programa alvo permanece $98 \%$ do tempo - figura 41 - verificando a consistência de dados, o que eleva a probabilidade de que um erro seja produzido durante tal processo. É importante lembrar, que o processo de verificação, também faz uso de registradores de propósito geral, que por sua vez, são susceptíveis aos erros injetados pelo processo adotado nesta investigação.

Uma segunda constatação, diz respeito aos resultados obtidos segundo a curva de taxa de falhas. Dentre todas as técnicas, aquelas que obtiveram os maiores valores para taxa de falhas inseguras são exatamente: paridade, checksum e combinação entre paridade e checksum.

E finalmente, a combinação entre paridade e checksum é aplicada de forma que, a execução de uma equação booleana é precedida de um processo de detecção de erro extremamente lento, quando comparado ao tempo de execução da própria booleana. Esse fator se destaca das demais versões, uma vez que apenas aquelas que fazem uso de $\mathrm{BCH}$, têm característica semelhante; exceto pelo fato de ser $\mathrm{BCH}$ a única técnica que processa detecção e correção de erros, simultaneamente.

Talvez, tais fatores aplicados em maior ou menor grau pelas outras versões do programa alvo, não sejam capazes de atingir o "ponto de saturação" que produza 
o efeito constatado pela combinação entre paridade e checksum e, com menor intensidade, por algumas outras combinações. O efeito constatado mencionado, diz respeito à produção de uma maior taxa de falhas inseguras, a partir da combinação de duas técnicas de programação defensiva, que deveriam, ao menos em tese, se complementar.

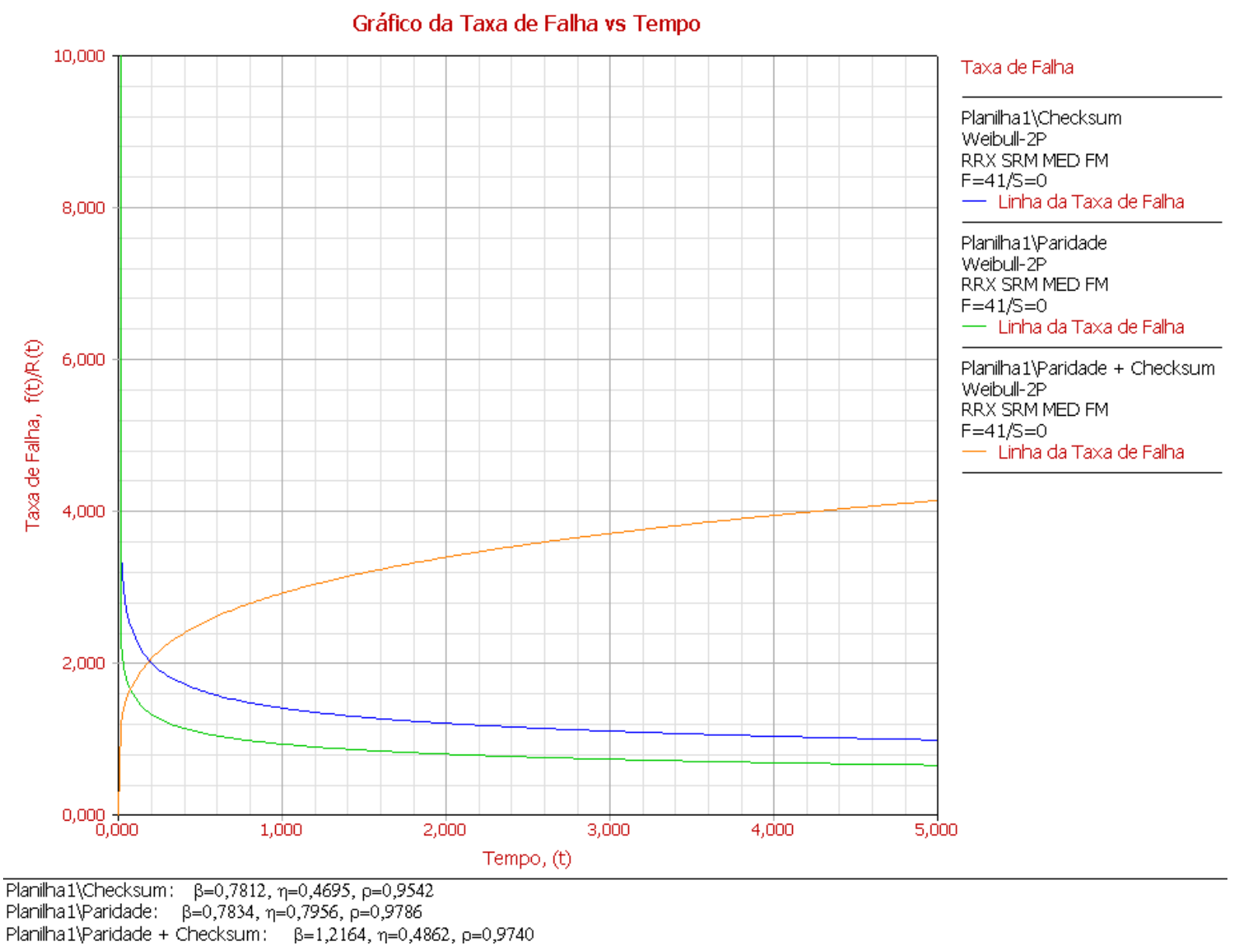

Figura 52- Taxa de falhas inseguras (Técnicas checksum e paridade)

8.4. Comparação de resultados para métodos de injeção de falhas distintos

Dentre todas as versões dos programas que receberam a aplicação de técnicas de programação defensiva, algumas também foram testadas através de 
outro método de injeção de erros em (SECALL, 2007). Esse método é baseado em rádio frequência e faz uso do mesmo modelo de processador e simulador de campo. Os elementos em comum permitem que se faça uma comparação entre os resultados obtidos para as duas técnicas de injeção de erros: Rádio frequência e software.

É importante salientar que técnicas de injeção de erros por hardware e software tem características distintas. O objetivo da análise comparativa é o de avaliar as técnicas de programação defensiva de forma relativa, de forma que seja possível identificar propriedades que destaquem uma determinada técnica em relação às demais, seja pelo valor da média, seja pelo valor de outros parâmetros.

Outro aspecto importante relacionado às duas técnicas de injeção de erros, está na classificação atribuída a cada uma delas. A técnica utilizada na pesquisa aqui apresentada pode ser classificada como uma técnica de injeção de erros por software, invasiva e por simulação. Já a técnica utilizada em (SECALL, 2007) pode ser classificada como uma técnica de injeção de erros por hardware, não invasiva e por execução. Sendo assim, a comparação dos resultados obtidos experimentalmente deve levar em consideração que se trata de uma plataforma de testes que possui elementos em comum, porém utilizando técnicas de injeção de erros de natureza distinta.

Uma das características importantes que distinguem os métodos de injeção de erros por hardware e software está no fato de que técnicas por software não são capazes de atingir todos os elementos de um processador. Pode-se usar como exemplo a injeção de erros sobre a unidade de controle - UC do processador. Através de rádio frequência, seria possível, ao menos em tese, produzir efeitos 
sobre esse componente, com o objetivo de se produzir uma resposta errônea. Por meio de software, reproduzir um erro interno da unidade de controle não é viável.

Outro aspecto de relevante que torna distintos os dois métodos de injeção de erros, para o este caso em particular, está associada à possibilidade de mutação de código de máquina. Para a injeção de erros por software, optou-se pela não alteração de instruções durante a execução do programa, uma vez que o conjunto de instruções do microcontrolador ATMEGA 128, que permitem a escrita sobre o próprio código, o fazem por seções de memória (pages).

Portanto, deve-se considerar a possibilidade de que a técnica de injeção de erros por rádio frequência é capaz de, ao menos em tese, produzir mutações de código durante o experimento.

Os resultados comparados podem ser vistos nas figuras 53 e 54 . Em (SECALL 2007), algumas técnicas de programação defensiva possuem duas versões. Em uma delas, caso seja detectado um erro, a rotina "seguro", já mencionada anteriormente, é chamada. Na segunda versão, caso seja detectado um erro, o programa não gera resultado, ou seja, as variáveis de saída não são atualizadas. Apenas as técnicas forward recovery e backward recovery não possuem duas versões.

Sendo assim, na primeira comparação (figura 53), nenhuma técnica faz uso da rotina "seguro". Já na segunda (figura 54), todas as técnicas que não possuem recurso de correção de erro próprio (paridade, duplicação de variáveis, diversidade e checksum), utilizam a rotina seguro para essa finalidade.

Os gráficos descrevem os resultados para software e rádio frequência, através de valores de média normalizados para os MTTUF (tempo médio para falha 
insegura), de forma que a versão que não contém nenhuma técnica de programação defensiva - programa alvo - tenha valor um.

As comparações feitas entre os valores de MTTUF das figuras 53 e 54 não permitem identificar claramente o impacto produzido pela aplicação de qualquer técnica de programação defensiva, em relação às demais, sem que para isso seja levada em consideração, a influência do tipo de método de injeção de erros utilizada.

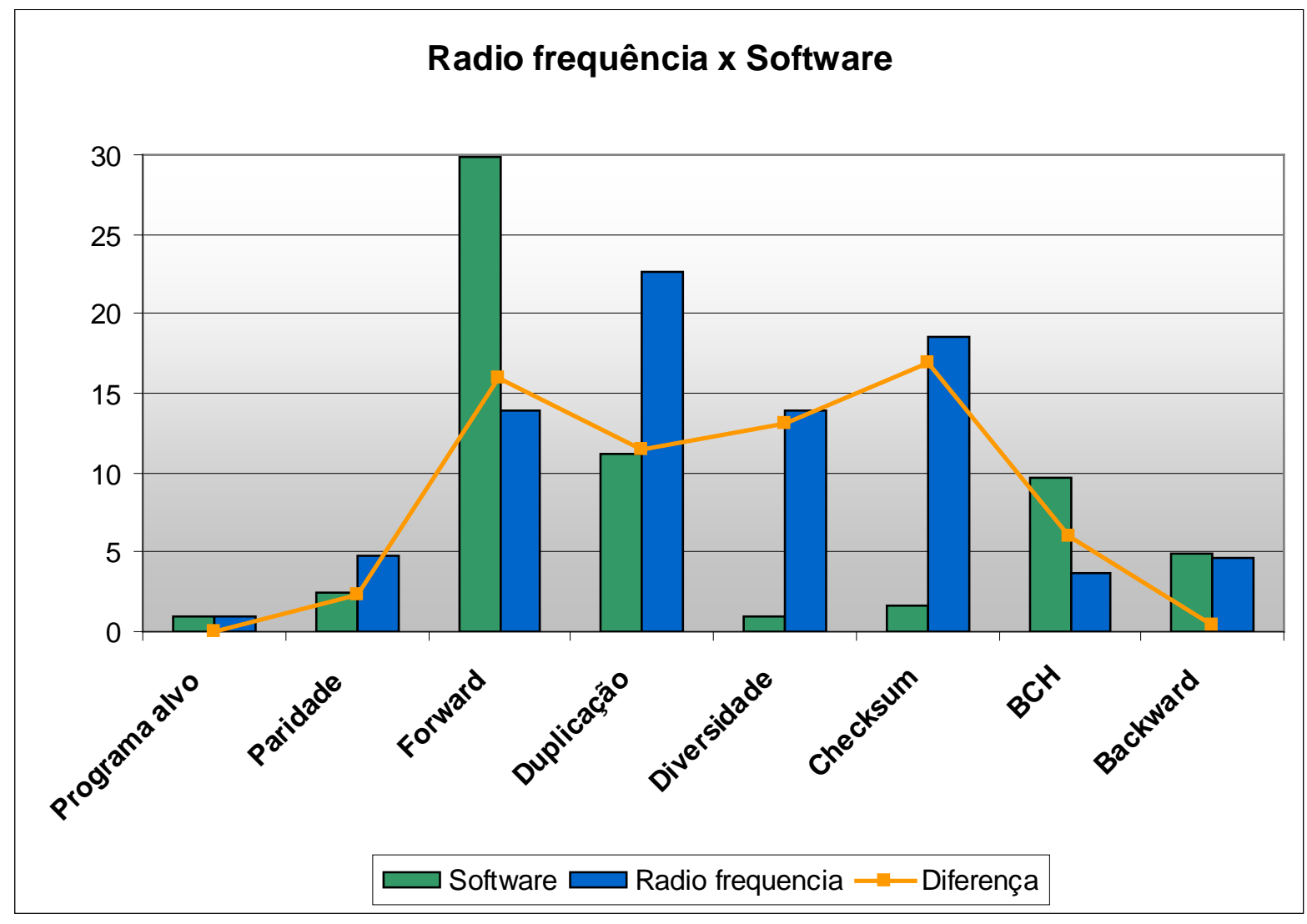

Figura 53 - Comparação entre resultados obtidos através injeção de falhas por software e por radio frequência (sem rotina "seguro") 


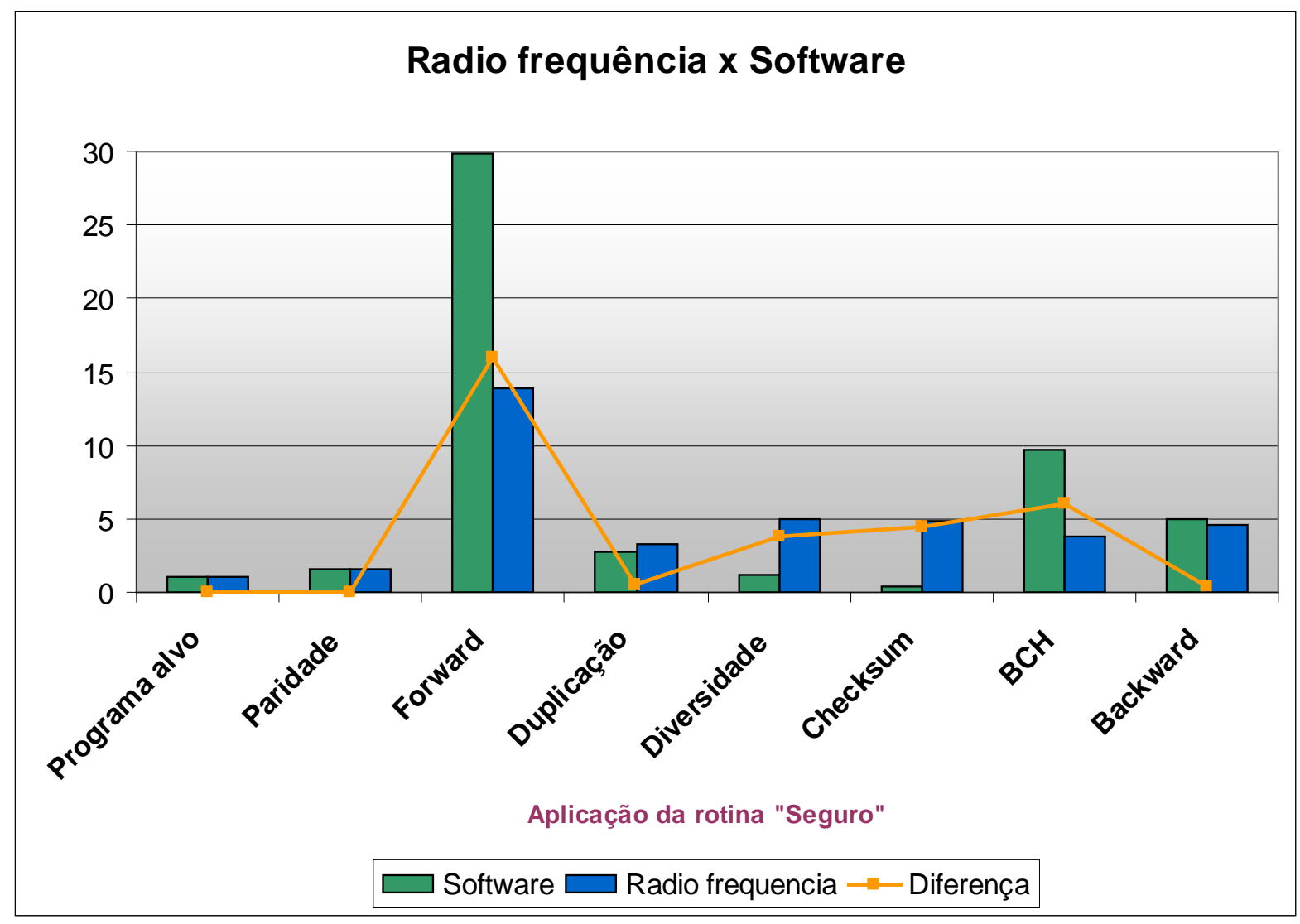

Figura 54 - Comparação entre resultados obtidos através injeção de falhas por software e por radio frequência (aplicação de rotina "seguro")

$\mathrm{Na}$ figura 53, por exemplo, a técnica forward recovery adquire um valor de média para falhas inseguras, maior que a técnica duplicação de variáveis, se aplicado o método de injeção de erros por software. Em contrapartida, caso seja aplicado o método de injeção de erros por rádio frequência, a relação se inverte, e a técnica de duplicação de variáveis passa a ter um valor de média para falhas inseguras maior, se comparada a técnica forward recovery.

Tal efeito pode ser atribuído ao fato de que o método por rádio frequência, é mais abrangente, quanto à totalidade de elementos do sistema que podem ser afetados pelos erros. Esse aspecto evidencia o impacto produzido pela injeção de erros sobre determinadas partes e sua consequente influência, sobre a resposta do sistema como um todo. A influência de cada parte do sistema, tendo cada uma delas 
características próprias, torna plausível supor que seguem padrões distintos de resposta em relação de injeção de erros. Por isso, a seletividade obtida a partir do método de injeção de erros por software, permite a identificação de padrões de resposta a erros, segundo o tipo de elemento que compõe o sistema, dada a sua função e características próprias.

$\mathrm{Na}$ figura 55 podem ser observadas as curvas correspondentes à taxa de falhas inseguras obtidas através de injeção de erros por rádio frequência. Os resultados foram obtidos através do estudo desenvolvido por (SECALL, 2007).

A notória diferença em relação aos resultados obtidos por injeção de erros por software está no fato de que para todos os casos da pesquisa em (SECALL, 2007), com exceção da técnica paridade, a taxa de falhas insegura tem tendência de crescimento em relação ao tempo de simulação. Este aspecto colabora no sentido de praticamente inviabilizar uma comparação efetiva entre os resultados de ambas as técnicas de injeção de erros, já que o processo envolvido na geração de erros torna a ocorrência de falhas inseguras completamente diferentes do ponto de vista da física do processo.

As curvas de taxa de falhas inseguras em função do tempo indicam uma tendência crescente para erros injetados por hardware. Já para erros injetados por software tais curvas adquirem uma tendência de valor constante no tempo. O aspecto que poderia, ao menos em tese, explicar tal comportamento pode estar associado ao fato de que a injeção de erros por software se restringe a atingir elementos de memória - registradores de propósito geral e células de memória enquanto erros injetados por hardware são capazes de atingir todos os demais elementos que compõem o dispositivo alvo. 


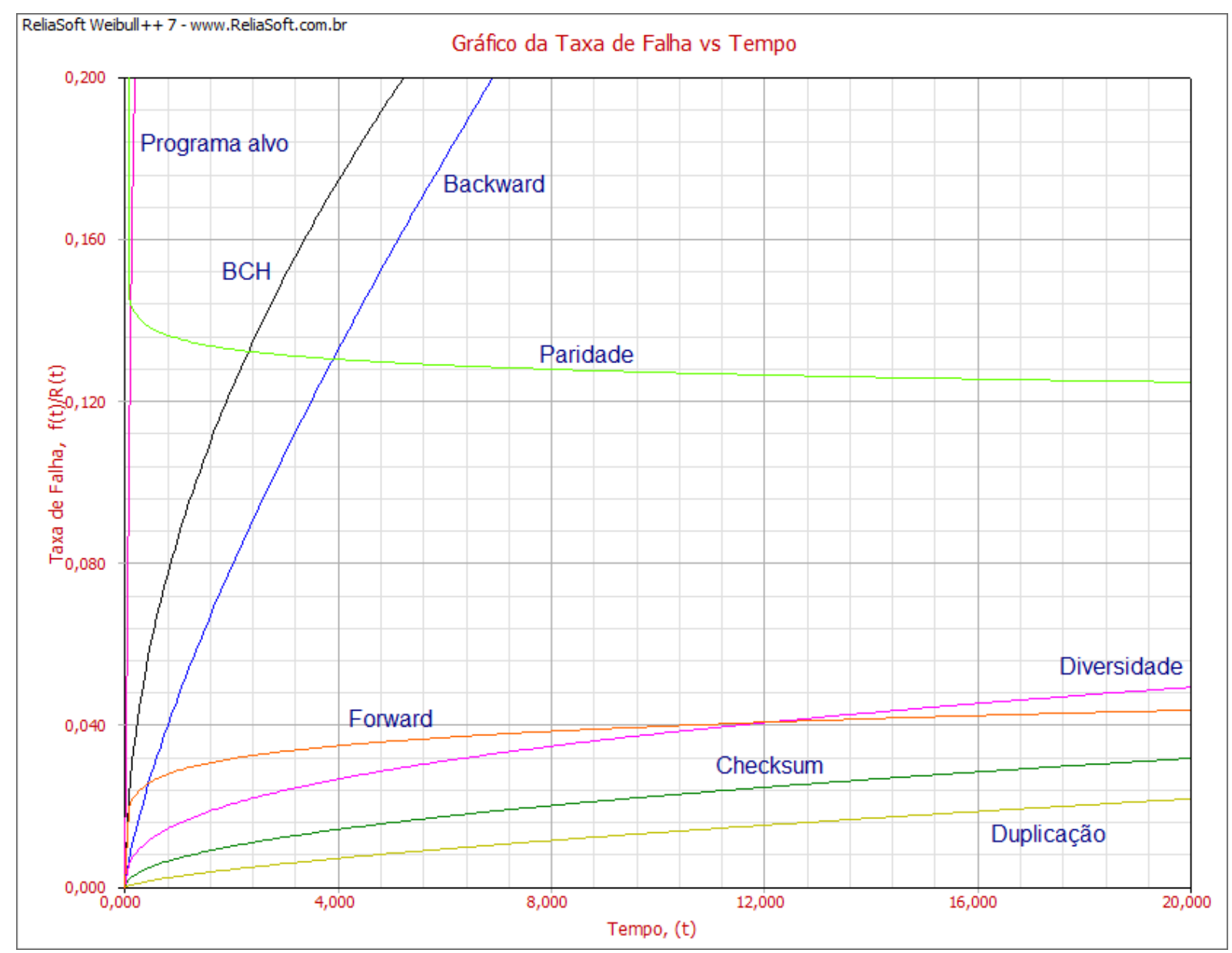

Figura 55 - Taxa de falhas inseguras com injeção de falhas por radio frequência)

A capacidade de atingir outros elementos do dispositivo alvo abre a possibilidade de que alguns erros possam ao longo do tempo de simulação, se manter inócuos de forma cumulativa. Erros em elementos como células de memória que contem o código executável podem não se manifestar assim que produzidos, mas à medida que se acumulam durante a simulação, aumentam a probabilidade da ocorrência de falhas. Tal característica pode também ser aplicada a células de memória que contem registros de propósito especifico responsáveis pelo controle do processamento. Tais elementos não são susceptíveis aos erros produzidos pelo processo de injeção de erros por software desenvolvido para este estudo, diferentemente do estudo desenvolvido por (SECALL, 2007). 


\section{CONCLUSÕES E CONSIDERAÇÕES FINAIS}

Esta pesquisa permitiu a avaliação de diversos aspectos associados ao comportamento adquirido por um sistema tolerante a erros, em função da aplicação de técnicas de programação defensiva e da injeção de erros por software.

A injeção de erros por software traz consigo uma deficiência associada ao fato de que, por meio deste método, partes de um microprocessador não são susceptíveis a erros produzidos por ela. Por outro lado, este mesmo método permite o controle sobre a seleção dos elementos que serão afetados pelos erros, o que pode ser extremamente vantajoso em um estudo da natureza como o aqui apresentado. Esse aspecto permite, por exemplo, a avaliação quanto à segurança de um sistema quando erros aleatórios ocorrem apenas sobre o conteúdo armazenado em memória, ou apenas sobre registradores de propósito geral, ou mesmo sobre as instruções que compõem o programa. A seleção de partes inacessíveis ao software exige a aplicação de injeção de erros por hardware, porém a seletividade por hardware impõe o uso de técnicas com certo grau de complexidade.

De forma geral, a opção pela técnica de injeção de erros por software, explorada nesta investigação, permitiu uma adequada obtenção dos resultados como também abriu a possibilidade de estudos futuros de maior abrangência, uma vez que a plataforma de simulação é flexível o bastante, a ponto de permitir o estudo de outros tipos de sistemas. Dentre as possibilidades, seria possível desenvolver sistemas baseados em outras linguagens de programação (e.g. C/C++, Basic, Java), outras abordagens de programação (e.g. uso de interpretadores ou JIT - compilação just-in-time), outras técnicas de programação defensiva (e.g. redundância tripla) e 
diferentes abordagens de injeção de erros (e.g. aplicação de erros exclusivamente em instruções de máquina).

A aplicação de técnicas de programação defensiva não se limitou neste estudo, a sua introdução isolada. A combinação de técnicas em pares possibilitou a caracterização dos efeitos produzidos nos casos onde o programa alvo foi enriquecido com diversos grupos de elementos protegidos por técnicas de programação diferentes, trazendo ao estudo a possibilidade de análises mais ricas.

Aos resultados experimentais obtidos foram aplicadas análises que permitiram inclusive, a identificação de comportamentos não previstos. Imaginavase, no início, que a combinação de técnicas de programação defensiva produziria efeitos complementares positivos quando comparados aos efeitos produzidos pelas técnicas de programação defensiva aplicadas isoladamente. A constatação contrária a essa premissa abre a possibilidade de novas hipóteses que expliquem tal fenômeno. Dentre os aspectos associados a tais possibilidades, vale destacar que, o comportamento adquirido pelo programa alvo, é o resultado da influência de diversos efeitos produzidos não apenas pelas técnicas de programação defensiva, mas também pela própria natureza do algoritmo em estudo. Por exemplo, em tese, todas as versões do programa alvo, com exceção de $\mathrm{BCH}$, possuem a característica de memória de erro efêmera. Esse termo diz respeito, neste estudo, ao processo cíclico em que o algoritmo lê as entradas, processa-as e gera a saída sem que os erros injetados em um ciclo influenciem o seguinte. Portanto, a cada ciclo todos os dados são renovados, produzindo assim uma distribuição de probabilidade discreta através de uma série de tentativas de sucesso em sequência, independentes. Essa característica impede, em teoria, que as curvas de distribuição de probabilidades obtenham o valor moda diferente de zero, característica essa, não encontrada em 
alguns casos. As possíveis causas desse efeito poderiam estar associadas ou a um aumento da probabilidade de falha à medida que os ciclos do programa são concluídos com sucesso ou a uma quantidade de amostras insuficientes. Ambos exigem uma investigação mais incisiva sobre o efeito descrito.

Além disso, algumas características associadas às técnicas de programação defensiva, podem levar a resultados que sofram influência tanto do efeito direto da proteção, como também de um efeito colateral. Por exemplo, a técnica $\mathrm{BCH}$ faz uso, neste estudo, de matrizes geradoras que consomem um espaço em memória relativamente extenso e que tem certa subutilização, em função da natureza do programa alvo. Tais características podem resultar em um número excessivo de erros silenciosos, em comparação às demais técnicas, o que inclusive pode ter levado as técnicas que usam $\mathrm{BCH}$ a obter os melhores resultados.

Em geral, a investigação desenvolvida neste trabalho também possibilita a elaboração de hipóteses que exijam maior grau de profundidade empírica.

Além disso, para a maioria dos estudos experimentais, pôde-se observar que os resultados expressos sob a forma de curva de taxa de falhas insegura, não só permitem diferenciar o comportamento do algoritmo original quando submetido à aplicação de uma determinada técnica ou combinação destas, como também permitem que sejam feitas projeções que avaliem certos aspectos de segurança envolvidos neste processo.

Fazendo uso de curvas de taxa de falhas inseguras como parâmetro de comparação entre as versões do programa alvo produzidas, é possível destacar algumas delas. As versões que obtiveram as menores taxas de falhas inseguras em função do tempo são Checksum combinada com BCH, Forward Recovery e Paridade combinada com $\mathrm{BCH}$. De fato, a técnica $\mathrm{BCH}$ - aplicação do código de 
Hocquenghem, Bose e Ray-Chaudhuri - se destaca por alcançar taxas de falhas inseguras menores que as demais técnicas, não apenas se usada isoladamente, mas também se usada em conjunto com outras técnicas.

Em contrapartida, as versões que fazem uso de técnicas paridade, checksum e a combinação das duas, obtiveram taxas de falhas inseguras maiores quando comparadas às demais.

Além das comparações simples, são comparados grupos compostos de três versões do programa alvo. Tal comparação é feita a partir de duas versões do programa alvo que possuam cada qual, uma única técnica de programação defensiva, enquanto a terceira versão contém a combinação de tais técnicas.

Através desse princípio foram identificados dois padrões predominantes para taxa de falhas inseguras. Estes padrões estão representados nas figuras 56 e 57.0 primeiro padrão, denominado padrão "A", foi encontrado com maior frequência em comparação ao padrão "B". Em resumo, pode-se identificar no padrão "A" a complementação positiva entre as técnicas de programação defensivas. Já o padrão "B", indica um desvio dessa característica. Para ambos os padrões, pode-se concluir que a aplicação de técnicas de programação defensiva leva a resultados que indicam a possibilidade de melhoria no aspecto de segurança.

Além dos padrões denominados $A$ e $B$, outros, em menor número, foram encontrados. Essencialmente, tais padrões indicam a ocorrência de efeitos não previstos inicialmente. São casos, em que a resultante da combinação entre duas técnicas, adquiriu um valor de taxa de falhas acima, de ao menos uma das técnicas. 


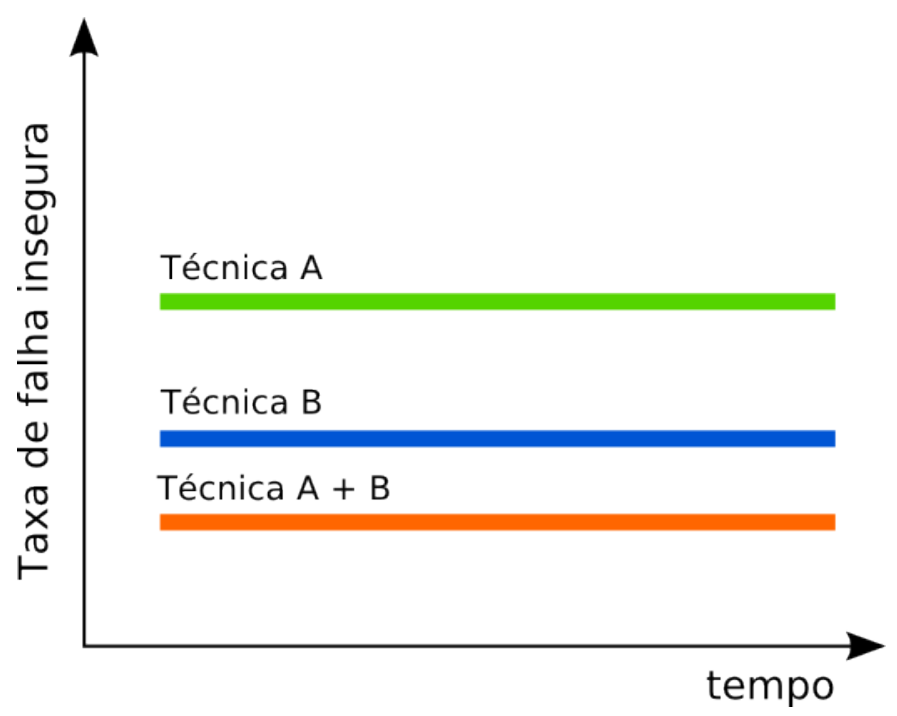

Figura 56 - Padrão "A" para taxa de falhas inseguras identificado em combinações de técnicas de programação defensiva

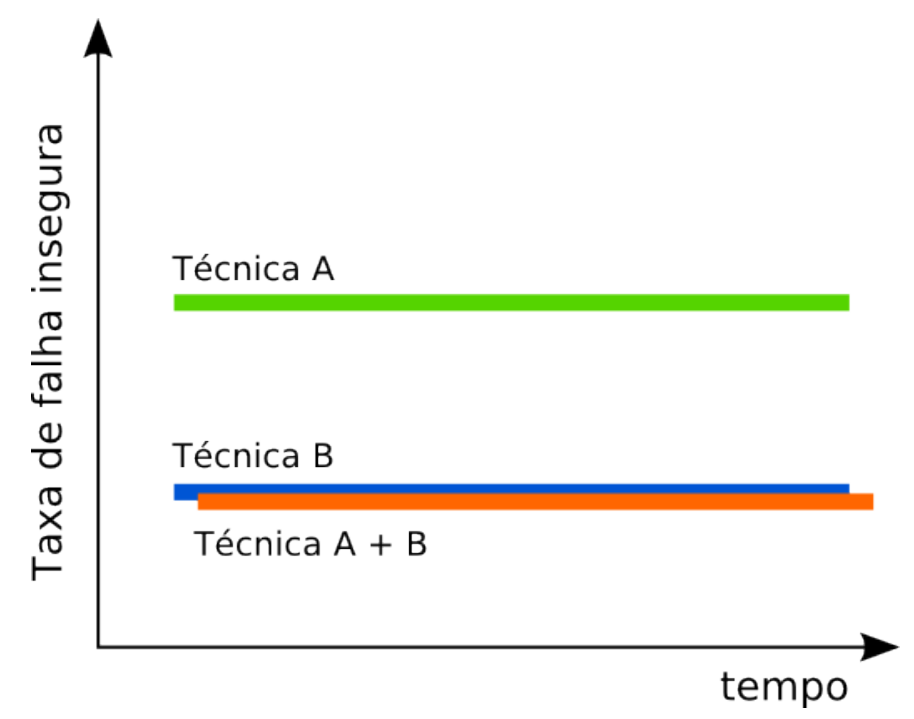

Figura 57 - Padrão "B" para taxa de falhas inseguras identificado em combinações de técnicas de programação defensiva

A aplicação dos conceitos ou resultados aqui expostos em sistemas de maior complexidade pode ser objeto de estudos posteriores, que levem em consideração outros aspectos que não foram abordados nesta pesquisa.

Pode-se, por fim, observar que a característica de seletividade, presente na injeção de erros por software e de difícil implementação na injeção de erros por hardware, permitiu a caracterização de técnicas de programação defensiva em 
função da aplicação de erros, sobre um grupo particular de elementos do sistema. Tal aspecto representa uma abordagem que tem como principal vantagem, o desenvolvimento de estudos que lidam com a complexidade presente em sistemas compostos por dispositivos microprocessados.

Os valores de tempo para falha insegura, obtidos por meio desse estudo, podem ser consultados através do apêndice C. Os gráficos correspondentes às funções de densidade de probabilidade de falha insegura e funções cumulativas da distribuição para falhas inseguras, podem ser consultados através do apêndice A. 


\section{REFERÊNCIAS}

ARLAT, J. et al Fault injection and dependability evaluation of fault-tolerant systems, computer. IEEE Computer Society, v. 42, n. 8, p. 913 - 923, 1993

AVIZIENIS, A., LAPRIE, J.C., RANDELL, B., LANDWEHR, C. Basic concepts and taxonomy of dependable and secure computing. IEEE Transaction on Dependable and Secure Computing, v. 1, n. 1, p. 11 - 33, January-March, 2004

Benso A., PRINETTO P. Fault injection techniques and tools for embedded systems reliability evaluation. Boston: Kluwer Academic, 2003

Benso A., Rebaudengo, M., Impagliazzo, L., Marmo, P. Fault-list collapsing for fault-injection experiments. In: Reliability and Maintainability Symposium, Anaheim, CA, USA. IEEE - Institute of Electrical \& Electronics Engineers, 1998, p. $383-388$

Benso A., Rebaudengo M., Reorda M.S., Civera P.L. An integrated HW and SW fault injection environment for real-time systems. In: IEEE International Symposium on Defect and Fault Tolerance in VLSI Systems, Austin, Texas, IEEE - Computer Society, 1998, p. 117 - 122

CARRASCO R. A., JOHNSTON M. Non-binary error control coding for wireless comunication and data storage. s.I., John Wiley \& Sons, 2008,

DUNPHY, J. E ROGSTAD, S. Discrete event simulation of NASA's remote exploration and experimentation project - REE. In: International Conference on Dependable Systems and Networks, Göteborg, Sweden, IEEE Computer Society, 2001

GHERMAN V. et al System-level hardware-based protection of memories against softerrors. In: Design, Automation \& Test in Europe Conference \& Exhibition, 2009, Nice, France, p. 1222 - 1225

HORIGUCHI M., ITOH K, Nanoscale memory repair. New York: Springer; London: Dordrecht Heidelberg, 2010.

HSUEH M., TSAI T.K., IYER R.K. Fault injection techniques and tools. IEEE Computer Society, v. 30, n. 4, p. 75 - 82, 1997

HWANG S. H. , CHOI S. G. A reliability testing environment for off-the-shelf memory subsystems. Texas A\&M University, 2000.

IMAI H., KAMIYANAGI Y. A construction method for double-error correcting codes for application to main memories. In: IECE Japan, J60-D, p. 861 - 868, 1977

INIEWSKI K. Radiation effects in semiconductors. CRC Press, Boca Raton, 2010, p. $358-381$ 
KENNETH L.S. VHDL for engineers. Prentice Hall, New Jersey, 2008.

Laplante P.A. Real time systems design and analysis. $3^{\text {th }}$. ed. John While \& Sons, 2004.

NULL L., LOBUR J. The essentials of computer organization and Architecture. Jones and Bartlett Publishers International, Sudbury, Massachusetts, 2006.

PULLUM L.L. Software fault tolerance techniques and Implementation. Artech House, Norwood, Massachusetts, 2001.

RAO T.R.N., FUJIWARA E. Error-control coding for computer systems. PrenticeHall, Englewood Cliffs, New Jersey, 1989.

ReBAUdENGo, M. et al Soft-error detection through software fault-tolerance techniques. In: International Symposium on Defect and Fault Tolerance in VLSI Systems, 1999, Albuquerque, New Mexico, IEEE - Computer Society, 1999, p. 210 218

RUBIN A. Statistics for evidence-based practice and evaluation. $2^{\text {nd }}$ ed. Brooks/Cole, Belmont, 2009, p. 187 - 199

SCHOLZ, F. Inference for the weibull distribution, Stat 498B Industrial Statistics., 2008, p.7

SCHRIMPF R.D., FLEETWOOD D.M. Radiation effects and soft errors in integrated circuits and electronic devices. World Scientific, Singapore, 2004. 339 p

SECALL J. M. Avaliação comparativa do impacto do emprego de técnicas de programação defensiva na segurança de sistemas críticos. Tese Doutorado em Engenharia - Escola Politécnica, Unversidade de São Paulo, São Paulo, 2007

SPRINGER, P. L. Assessing application vulnerability to radiation-induced SEUs in memory. In: International Conference on Dependable Systems and Networks, Göteborg, Sweden, IEEE Computer Society, 2001

SRIDHARAN V. et al Reducing data cache susceptibility to soft errors. IEEE Transactions on Dependable and Secure Computing, v. 3, n. 4, p. 353 - 364, 2006

XUEQIANG W. et al A high-speed two-cell BCH decoder for error correcting in MLC NOR flash memories. IEEE Transactions on Circuits and Systems II: express briefs, v. 56, n. 11, p. 865 - 869, 2009

ZARAGOZA R. H. The art of correcting code. $2^{\text {nd }}$ ed. John Wiley \& Sons, San Jose State University, 2006. 


\section{APÊNDICE A}

Nas figuras a seguir são descritas as curvas das funções de densidade de probabilidade de falha insegura e funções cumulativas da distribuição para falhas inseguras (probabilidade de falha insegura) de todas as técnicas de programação defensiva desenvolvidas para este estudo.

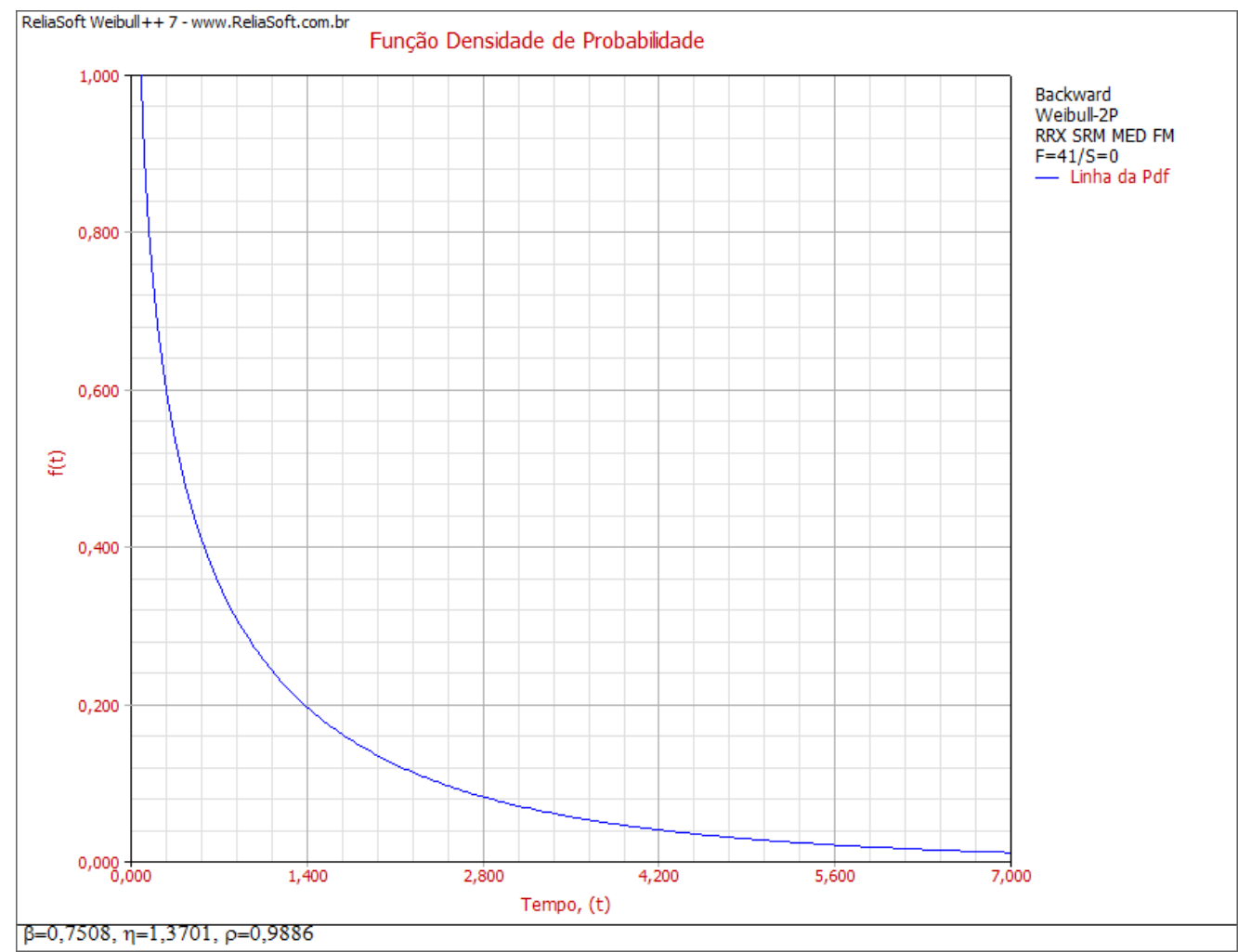

Figura 58 - Função de densidade de probabilidade para falhas inseguras: técnica de programação defensiva backward 


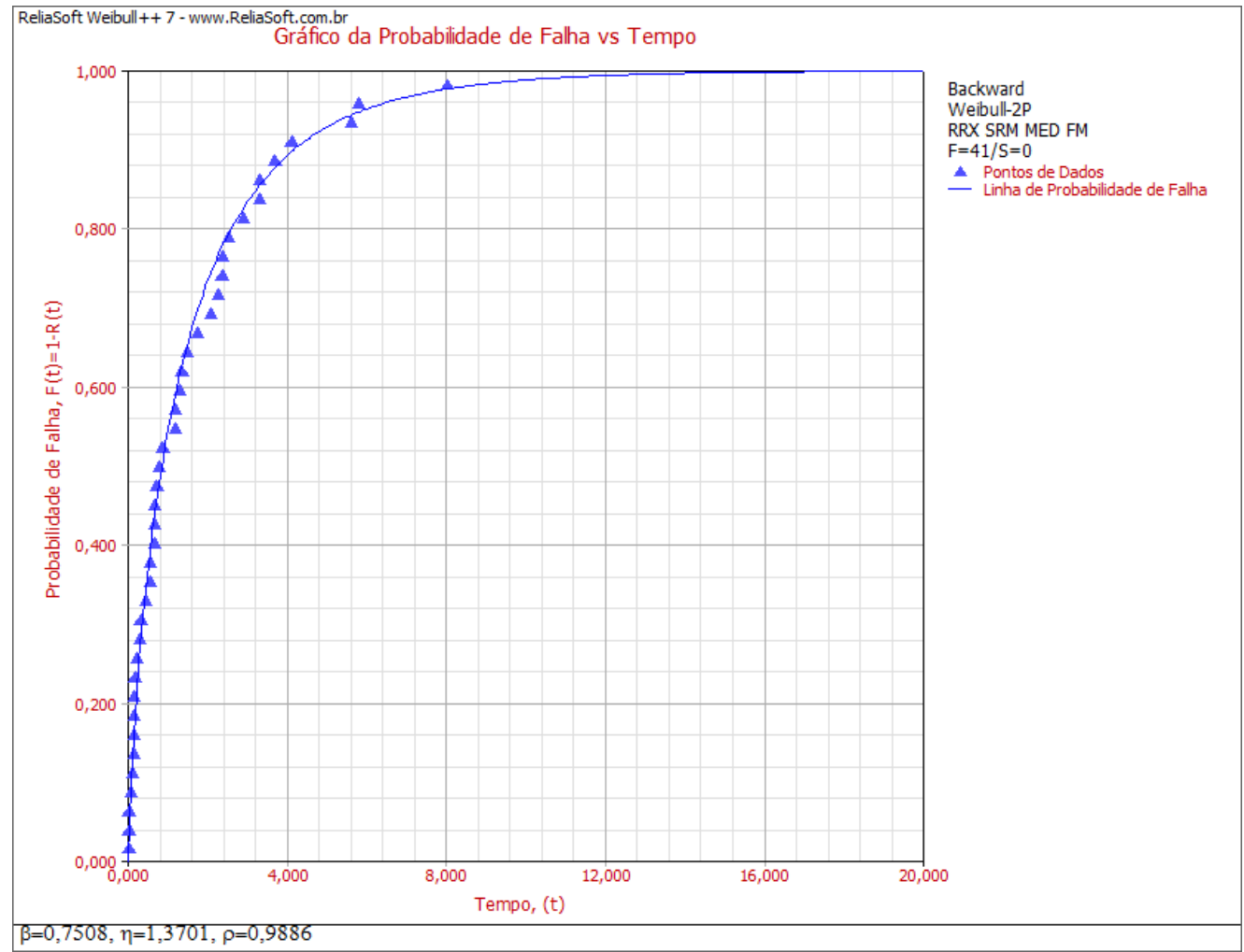

Figura 59 - Gráfico de probabilidade de falha insegura: Técnica backward

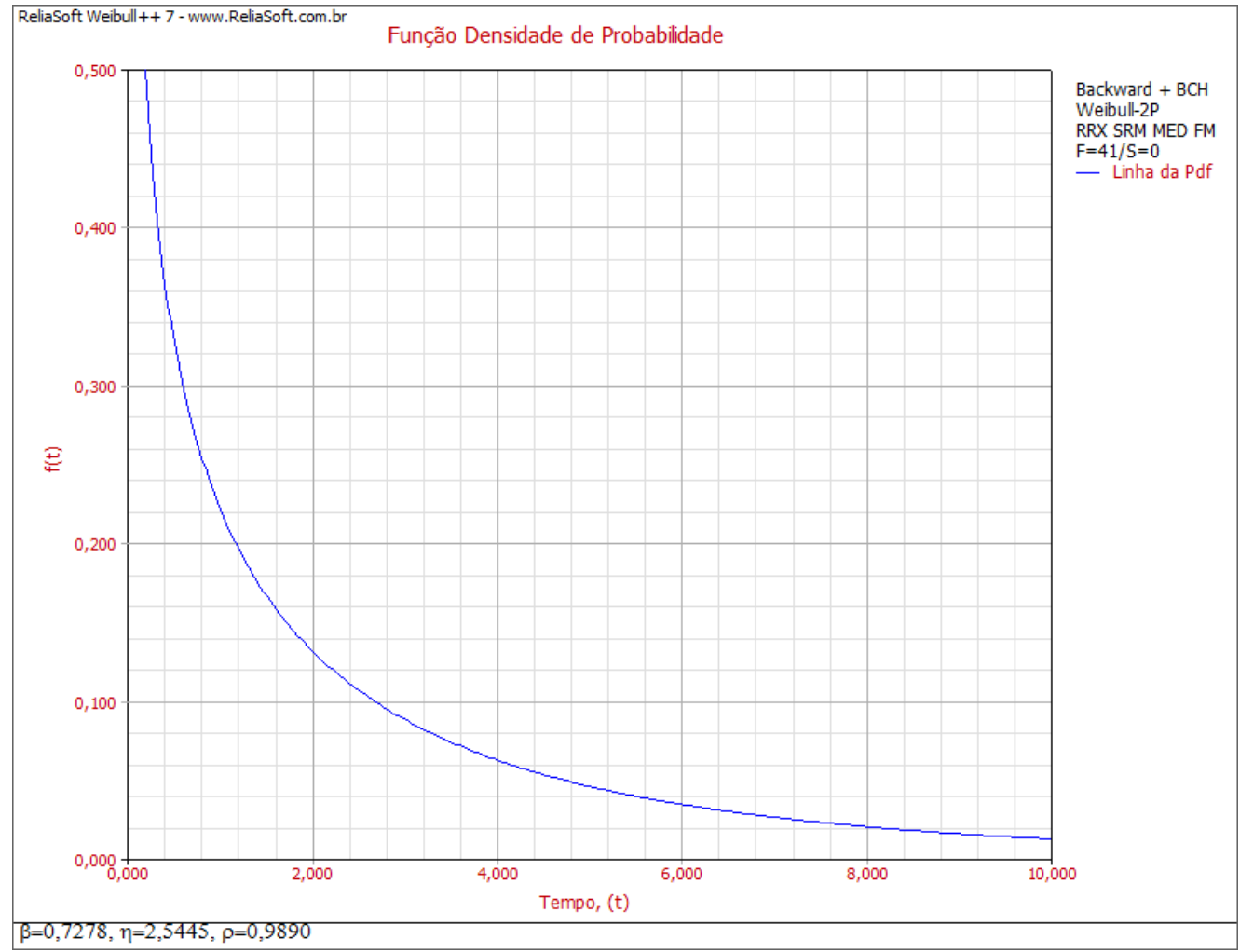

Figura 60 - Função de densidade de probabilidade para falhas inseguras: técnica de programação defensiva backward e $\mathrm{BCH}$ combinadas 


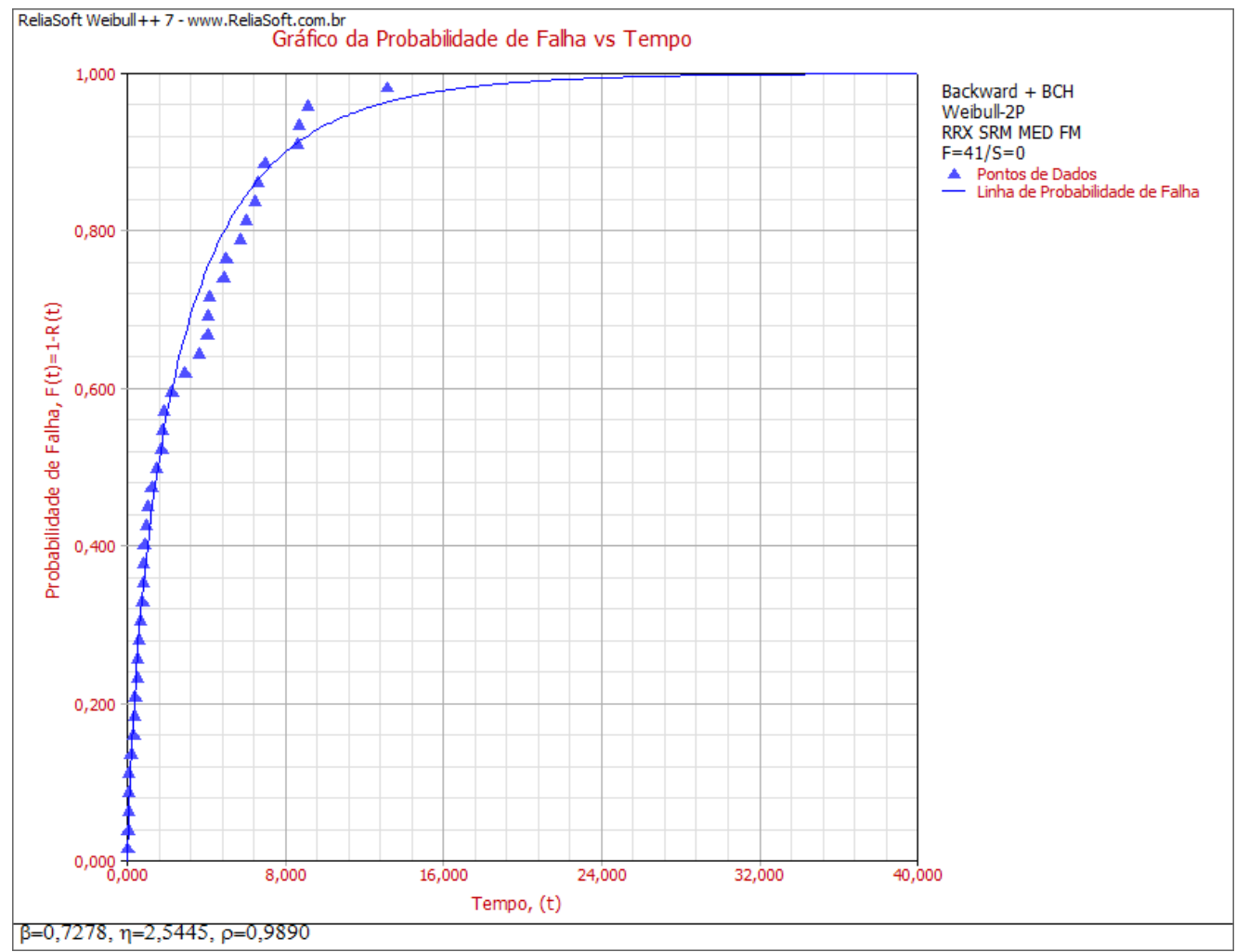

Figura 61 - Gráfico de probabilidade de falha insegura: Técnica backward e BCH combinadas

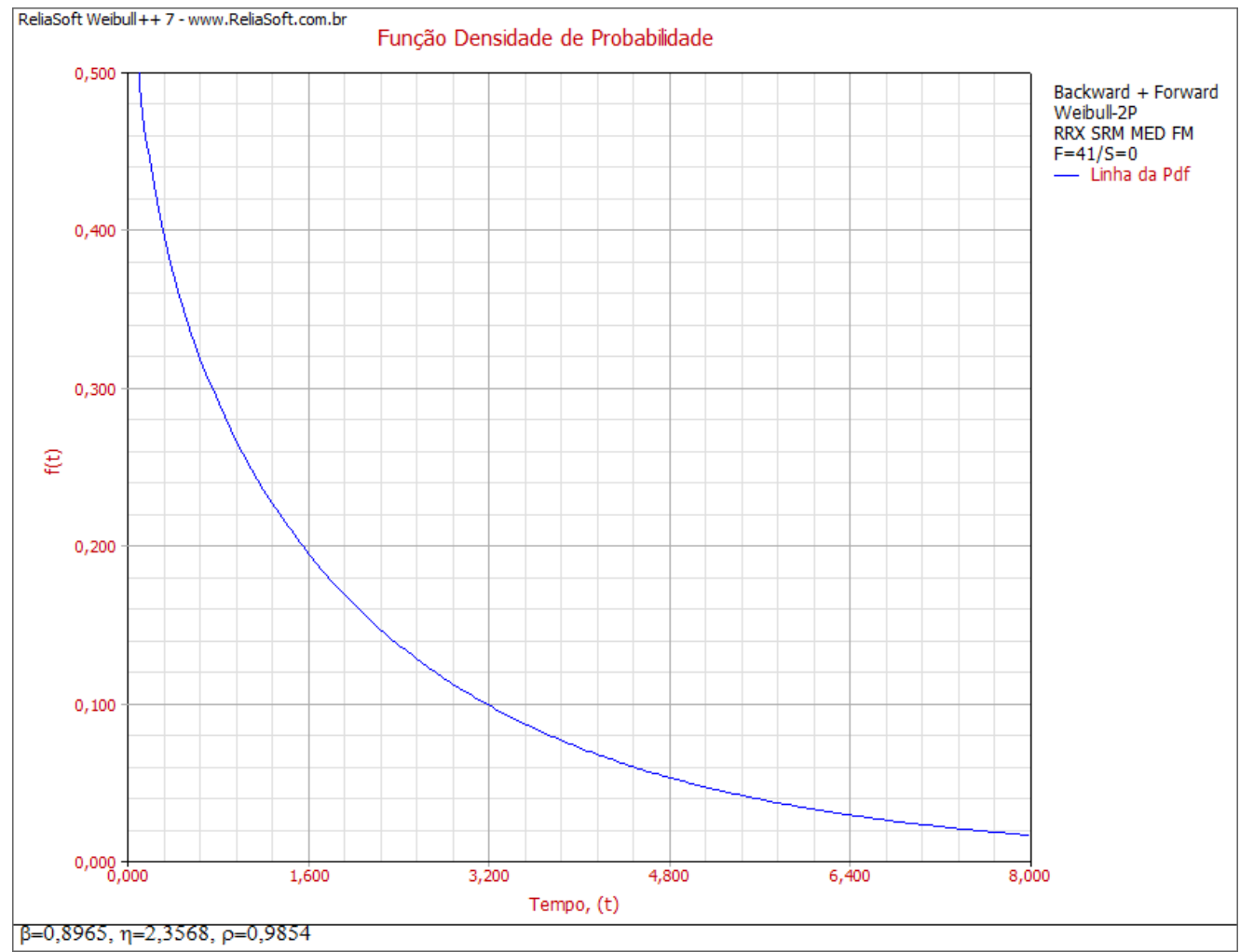

Figura 62 - Função de densidade de probabilidade para falhas inseguras: técnica de programação defensiva backward e forward combinadas 


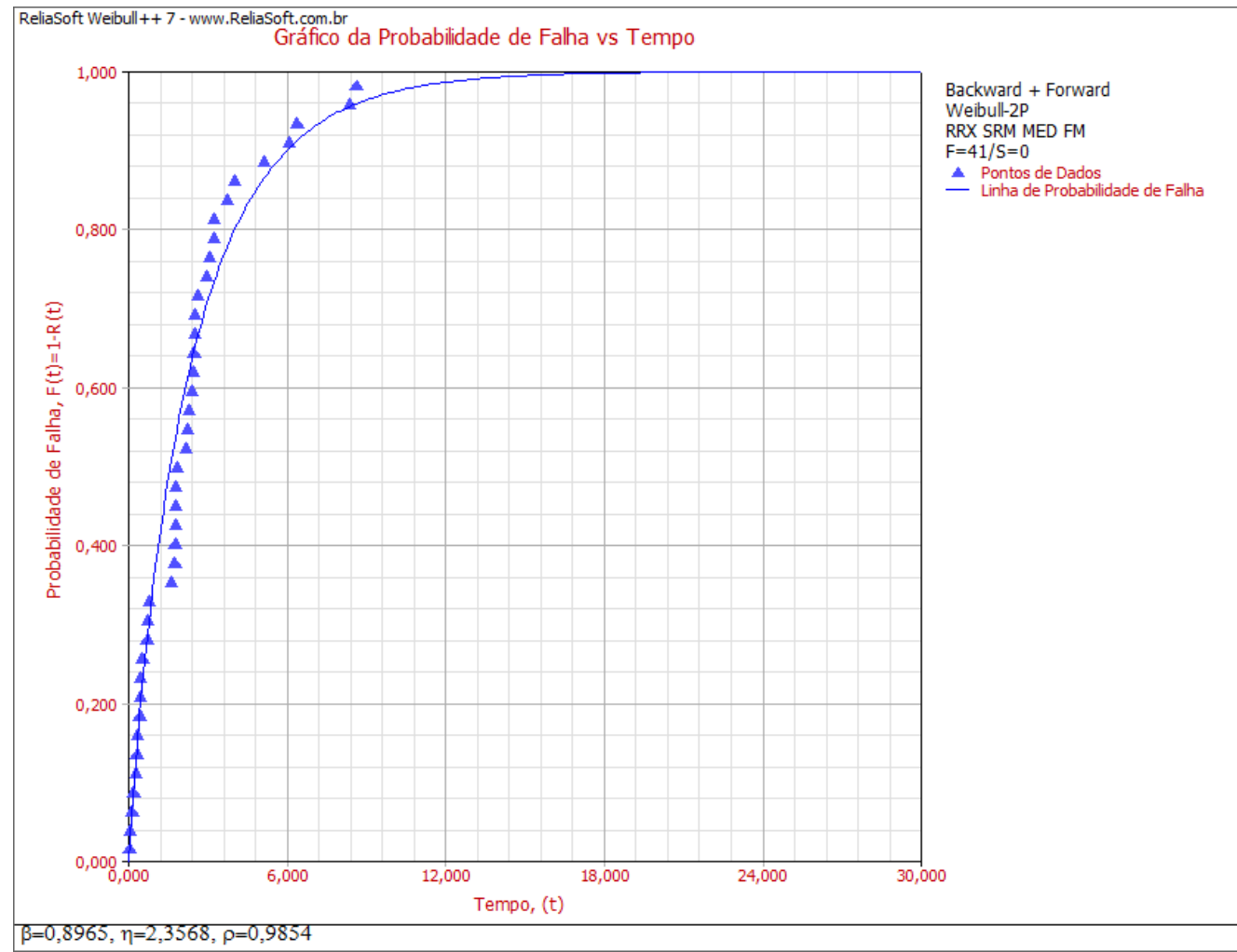

Figura 63 - Gráfico de probabilidade de falha insegura: Técnica backward e forward combinadas

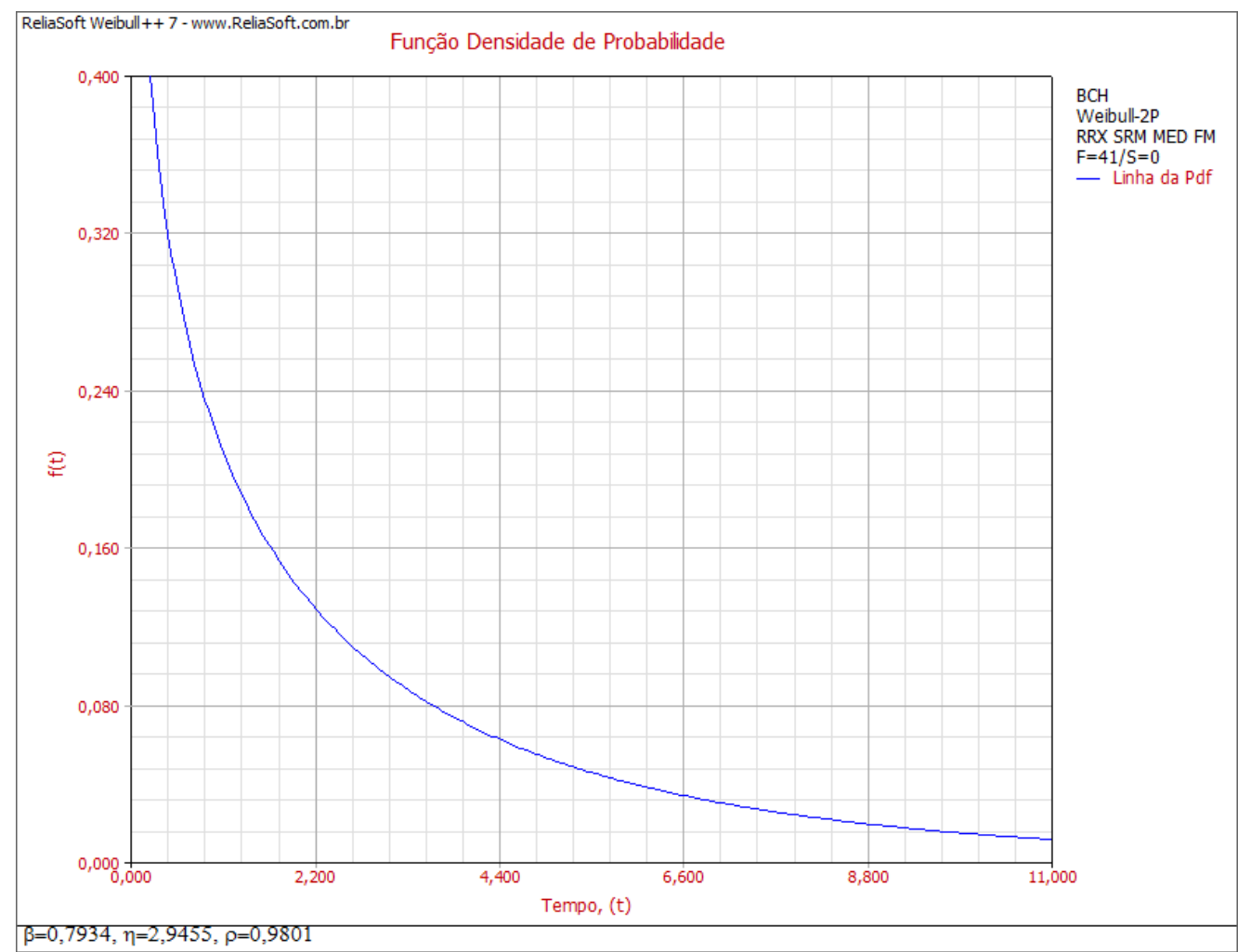

Figura 64 - Função de densidade de probabilidade para falhas inseguras: técnica de programação defensiva $\mathrm{BCH}$ 


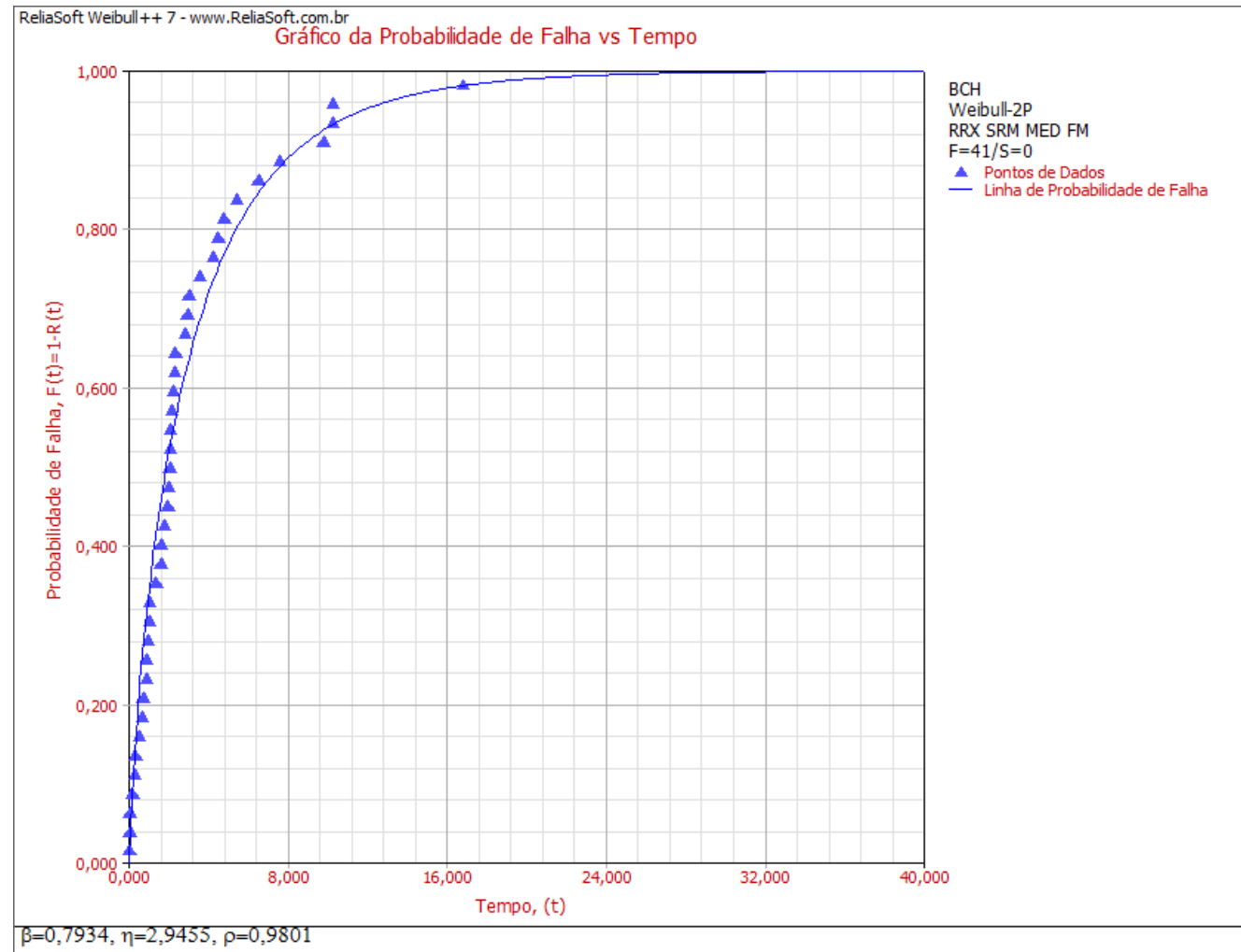

Figura 65 - Gráfico de probabilidade de falha insegura: Técnica $\mathrm{BCH}$

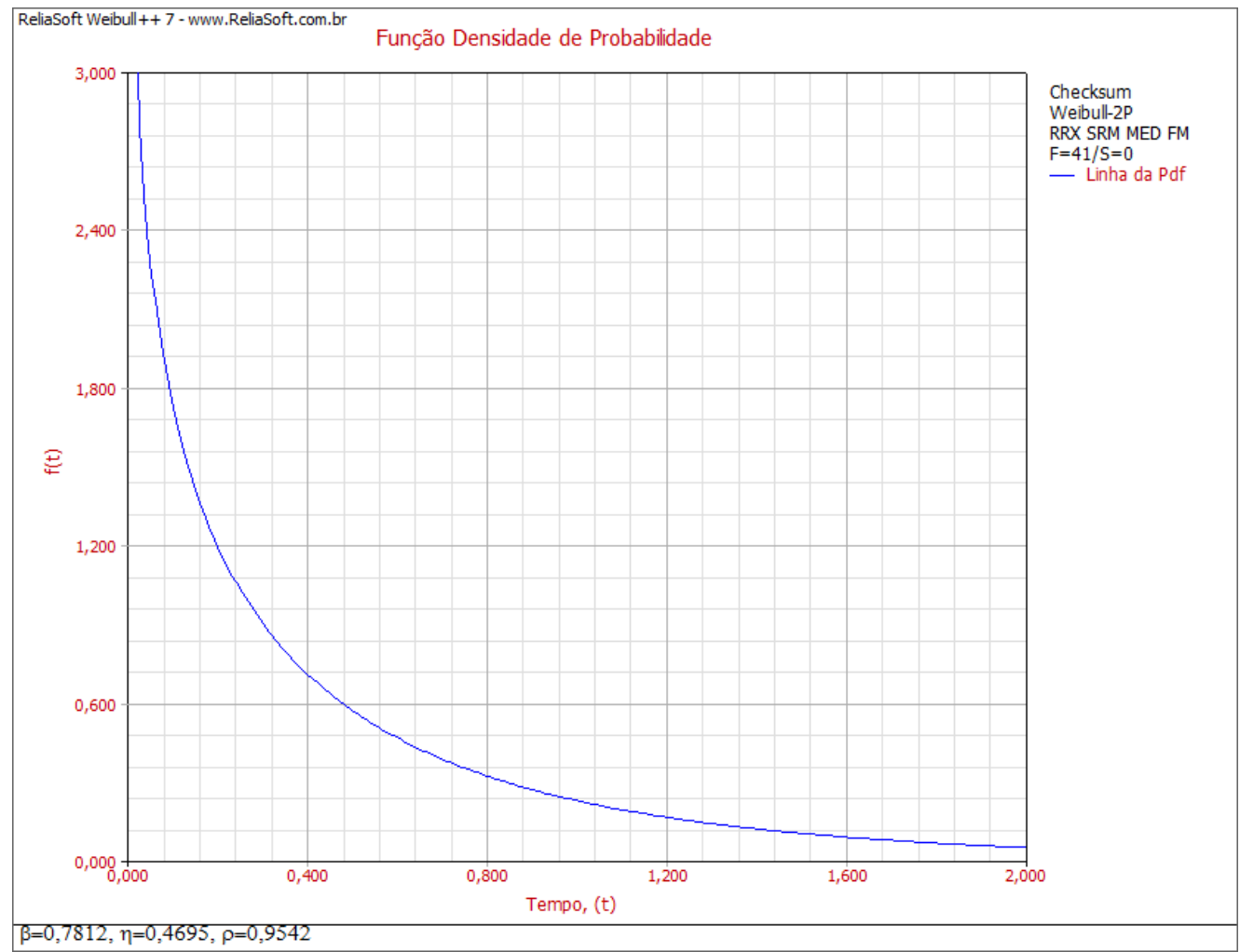

Figura 66 - Função de densidade de probabilidade para falhas inseguras: técnica de programação defensiva Checksum 


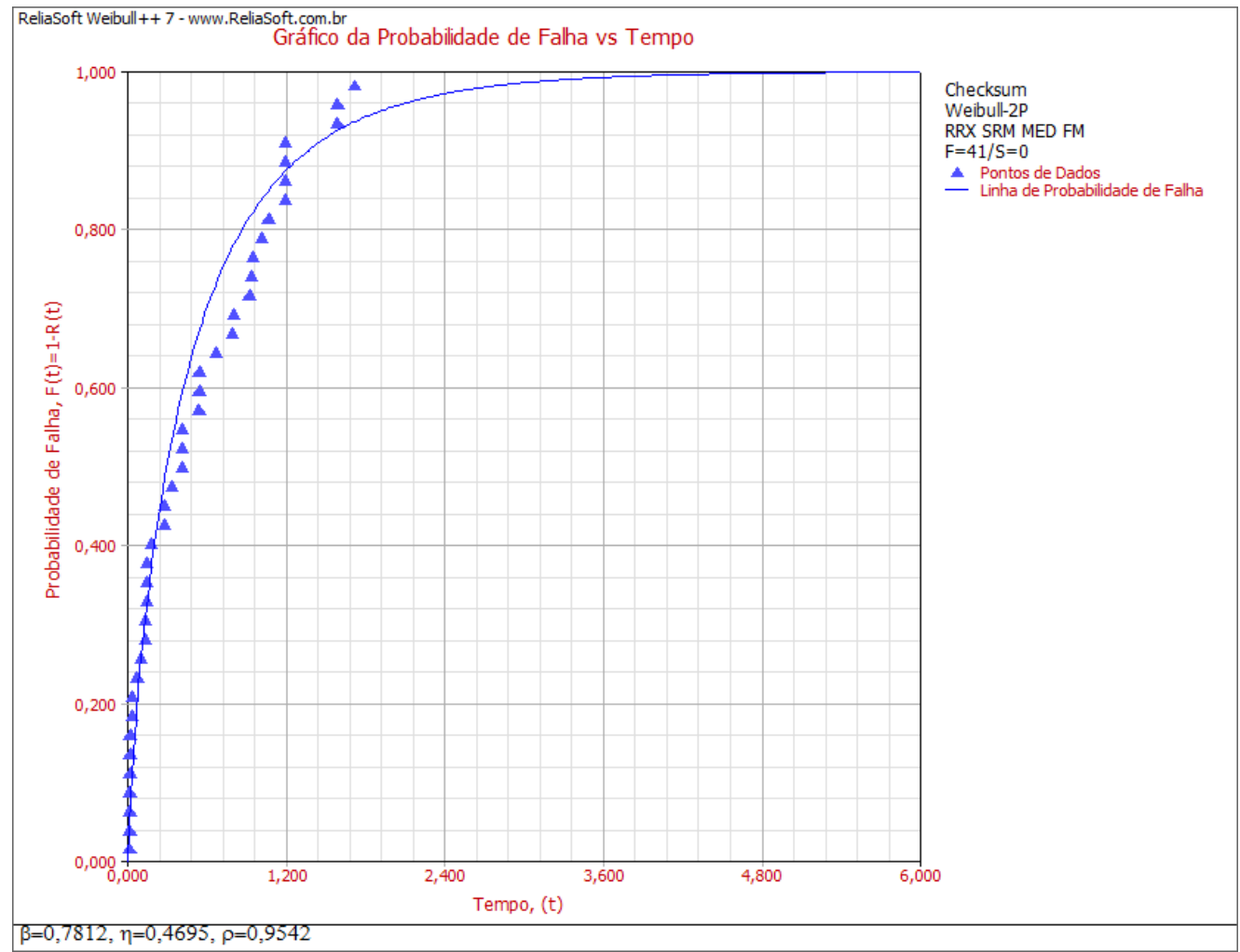

Figura 67 - Gráfico de probabilidade de falha insegura: Técnica Checksum

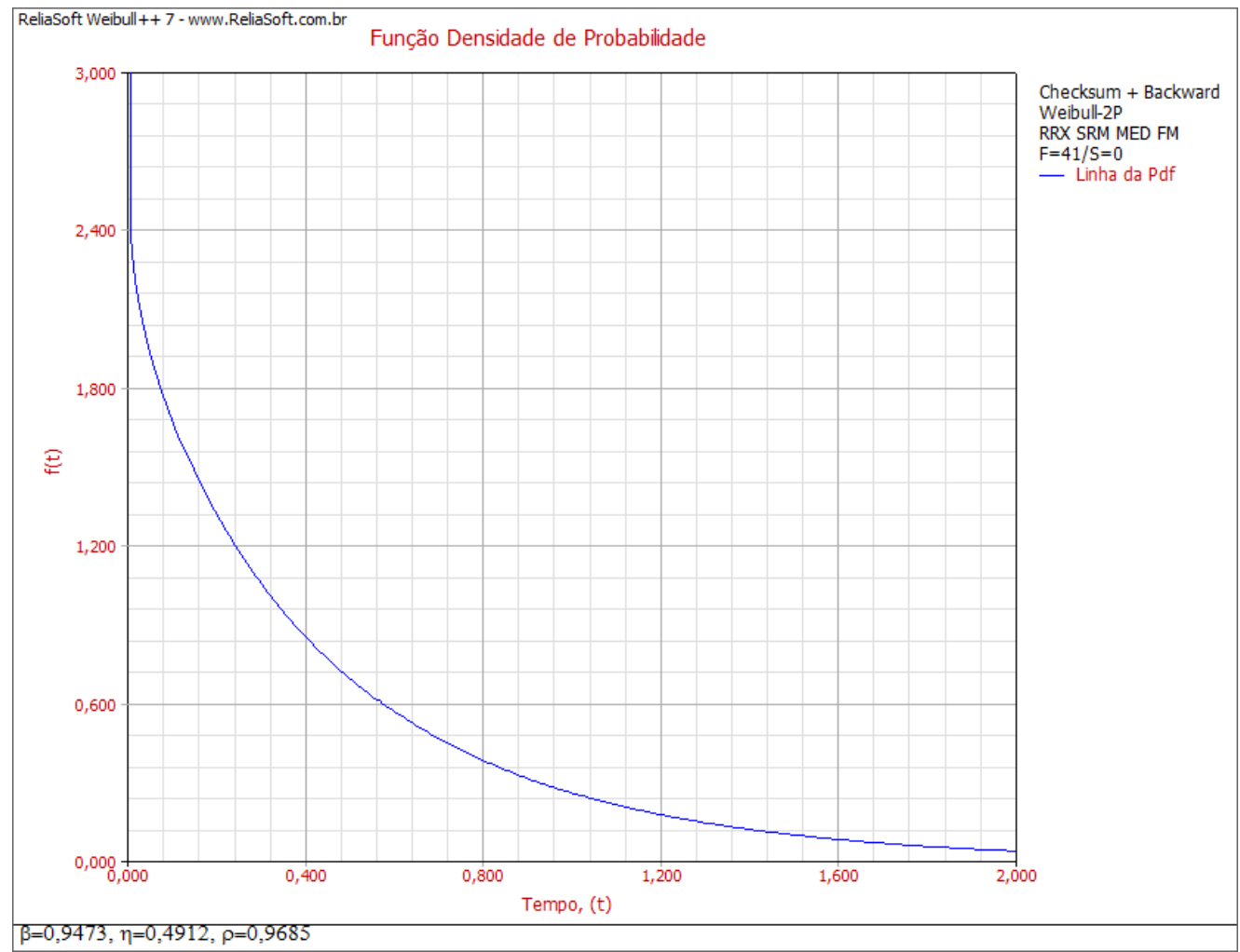

Figura 68 - Função de densidade de probabilidade para falhas inseguras: técnica de programação defensiva checksum e backward combinadas 


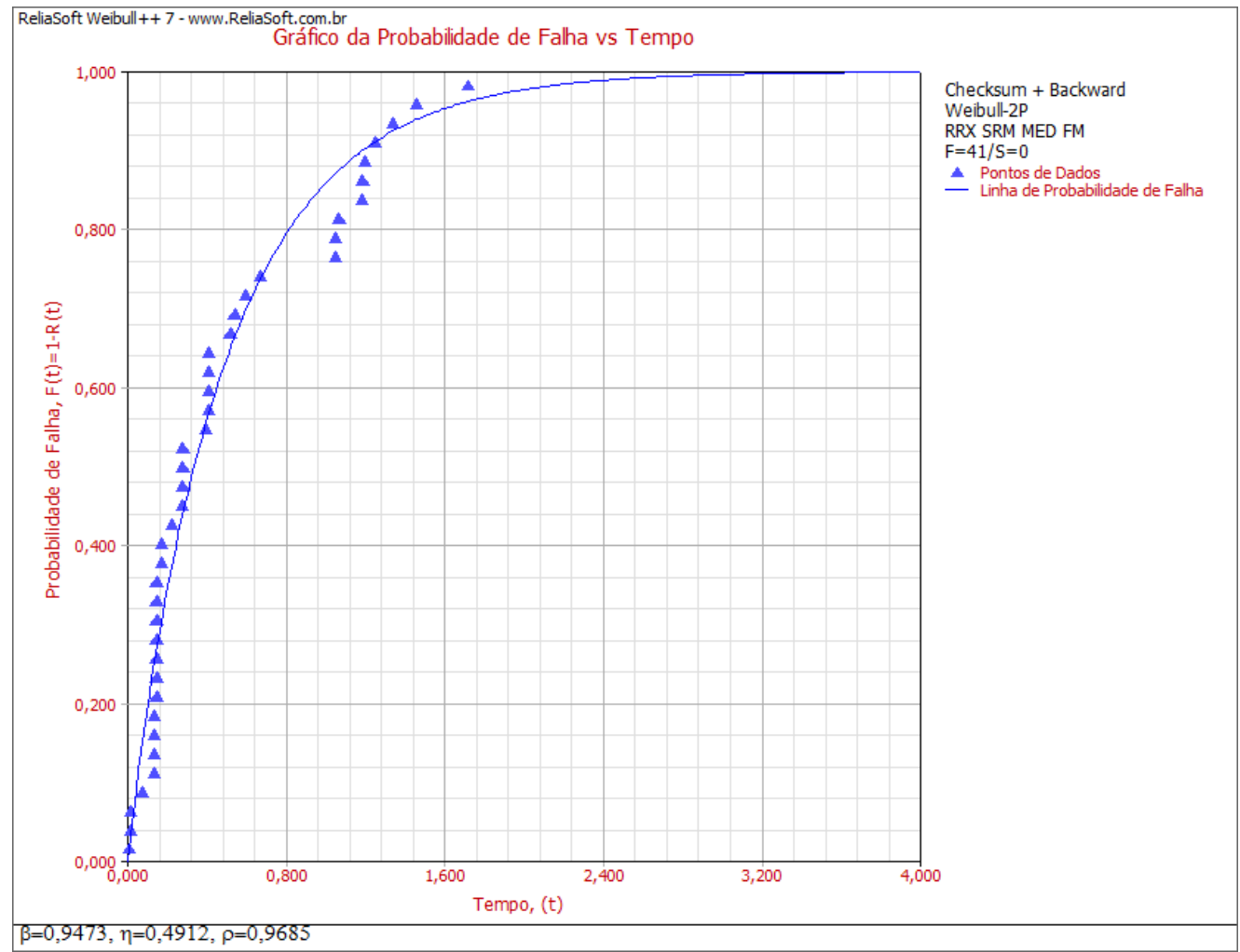

Figura 69 - Gráfico de probabilidade de falha insegura: Técnica checksum e backward combinadas

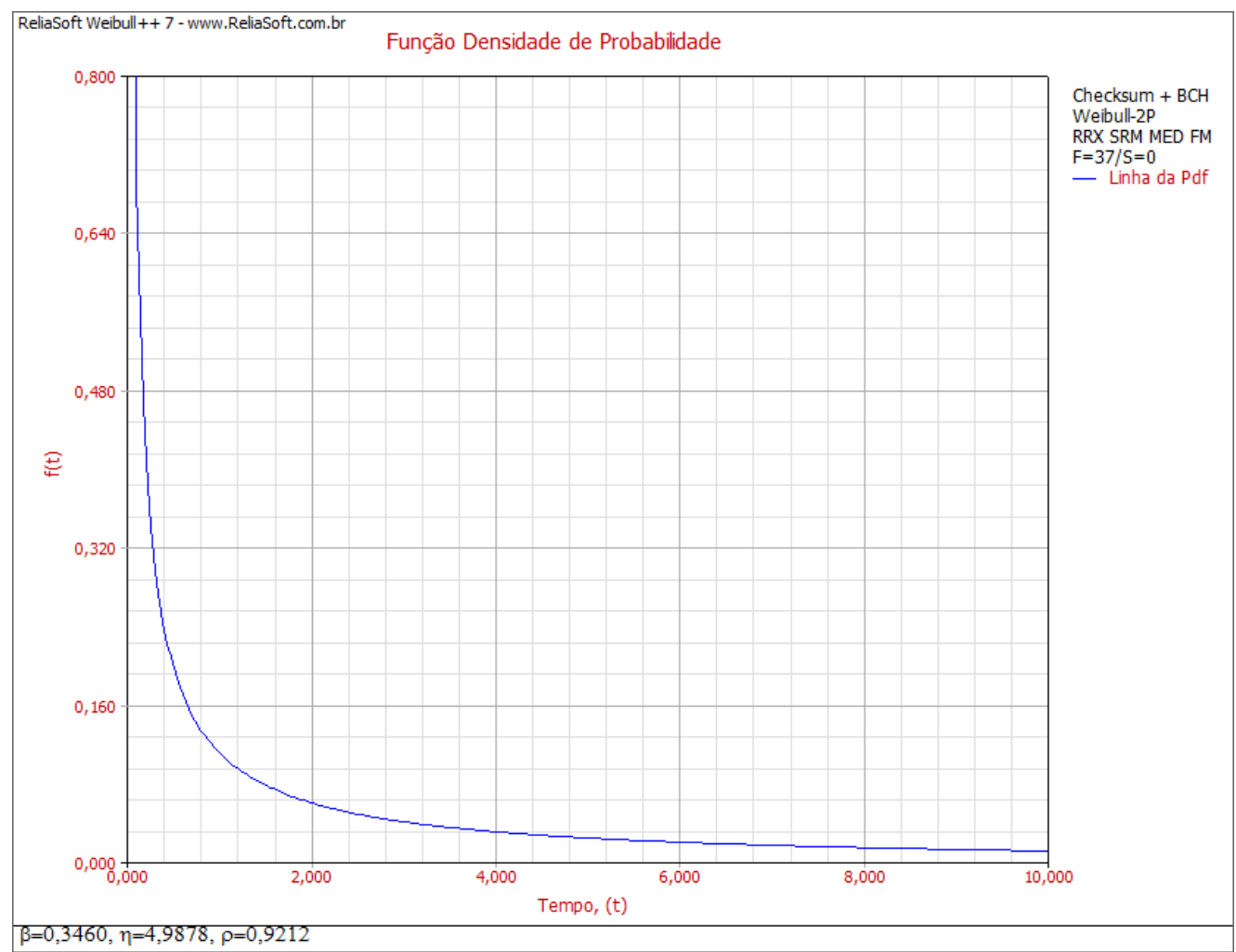

Figura 70 - Função de densidade de probabilidade para falhas inseguras: técnica de programação defensiva checksum e BCH combinadas 


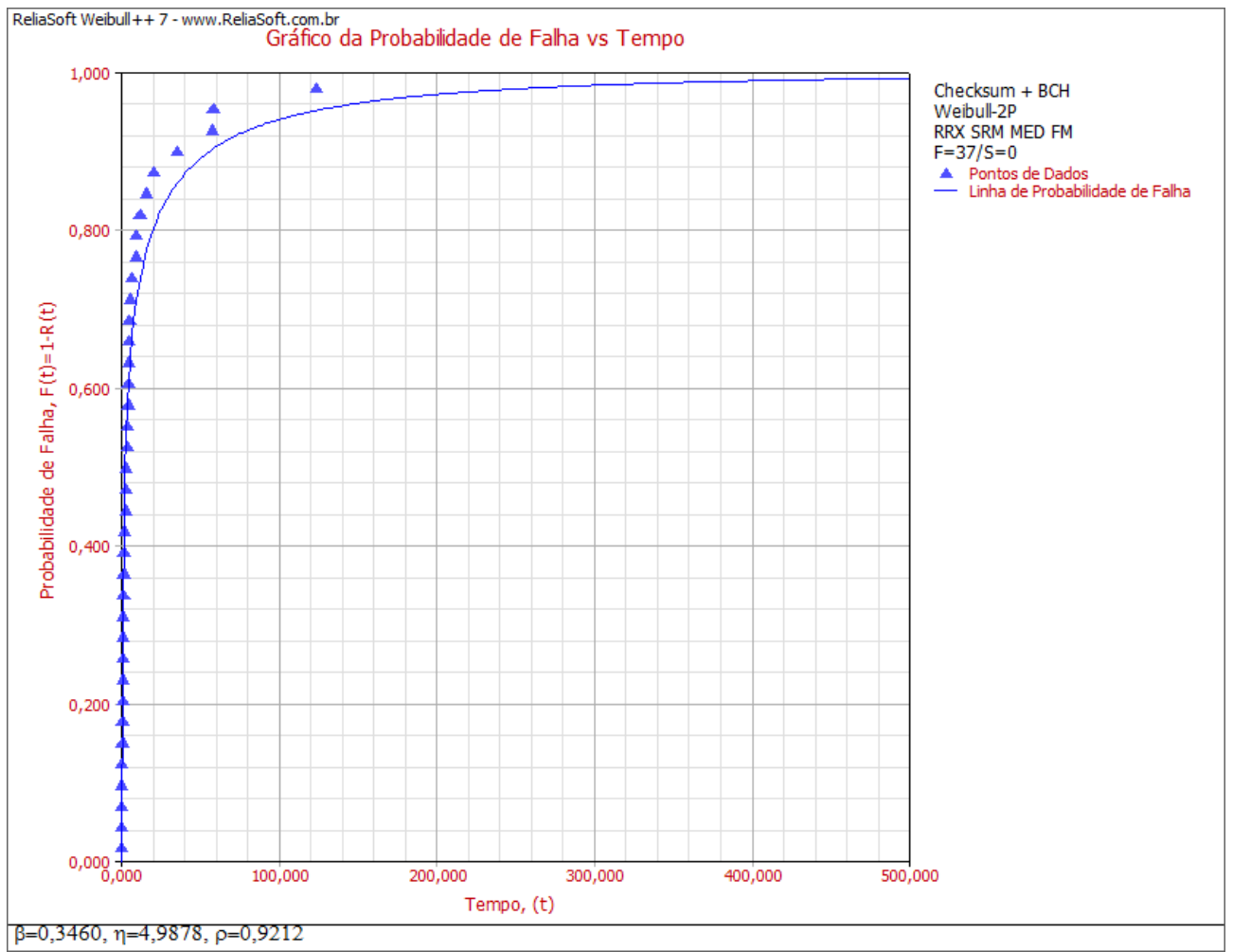

Figura 71 - Gráfico de probabilidade de falha insegura: Técnica checkusm e BCH combinadas

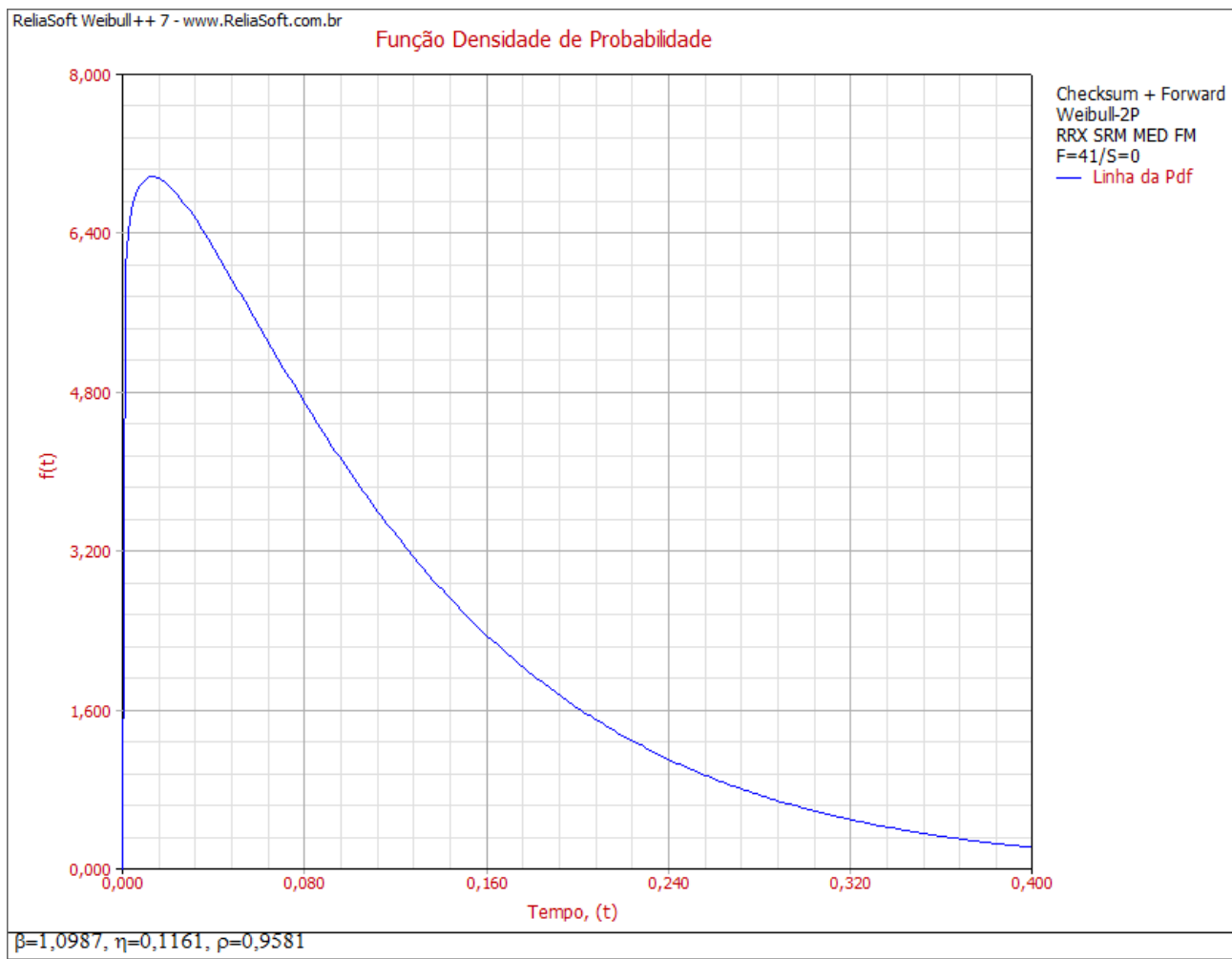

Figura 72 - Função de densidade de probabilidade para falhas inseguras: técnica de programação defensiva checksum e forward combinadas 


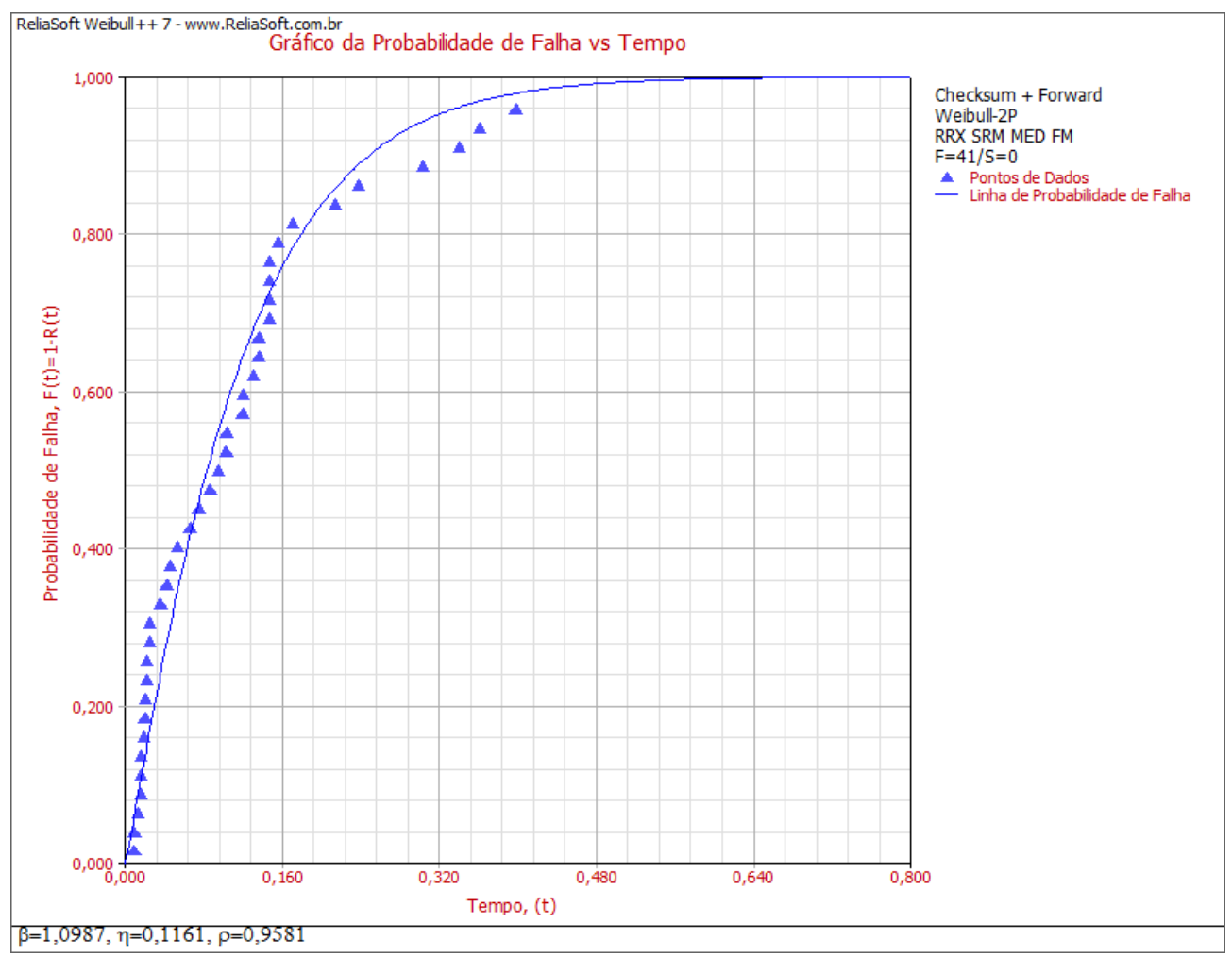

Figura 73 - Gráfico de probabilidade de falha insegura: Técnica checksum e forward combinadas

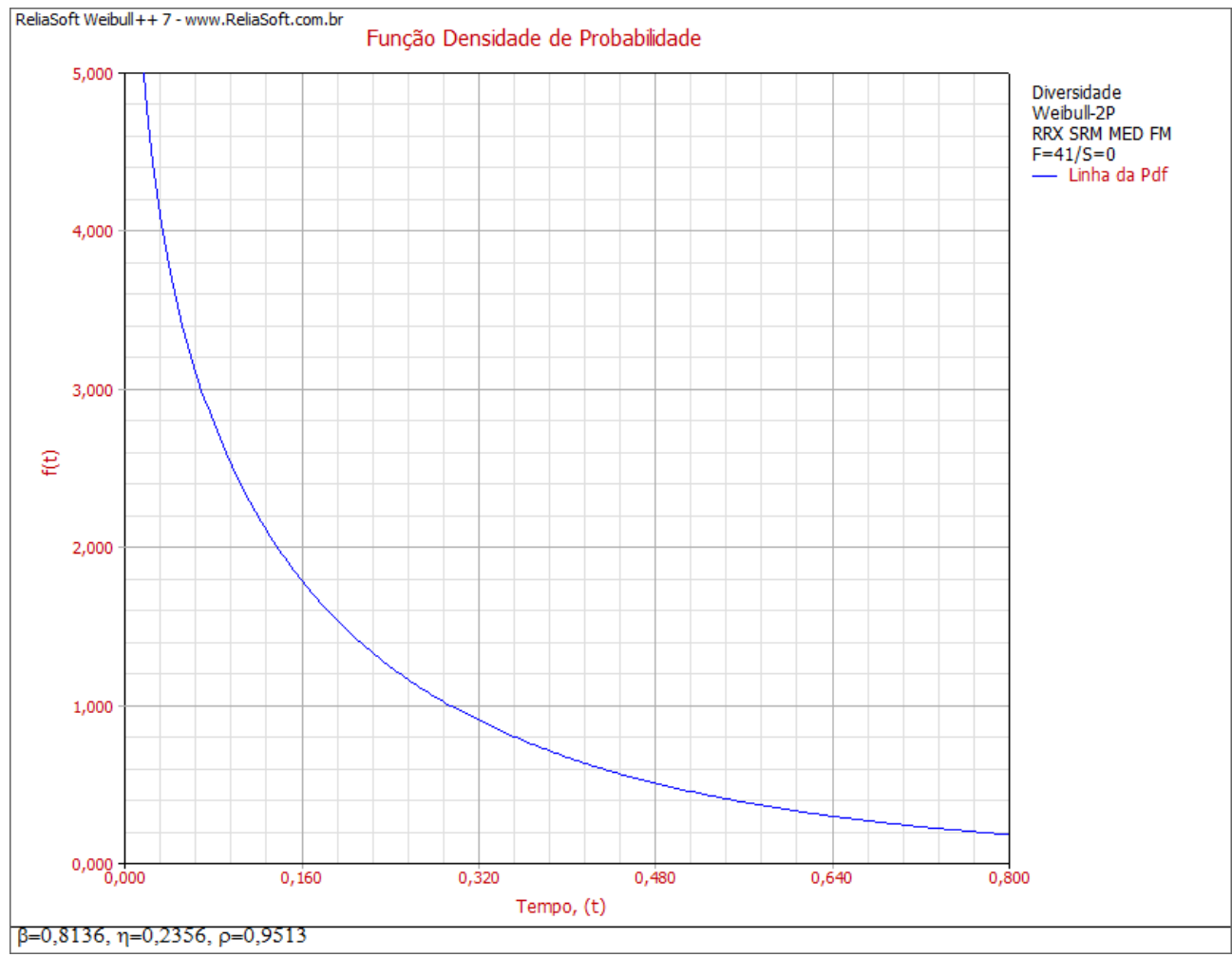

Figura 74 - Função de densidade de probabilidade para falhas inseguras: técnica de programação defensiva diversidade 


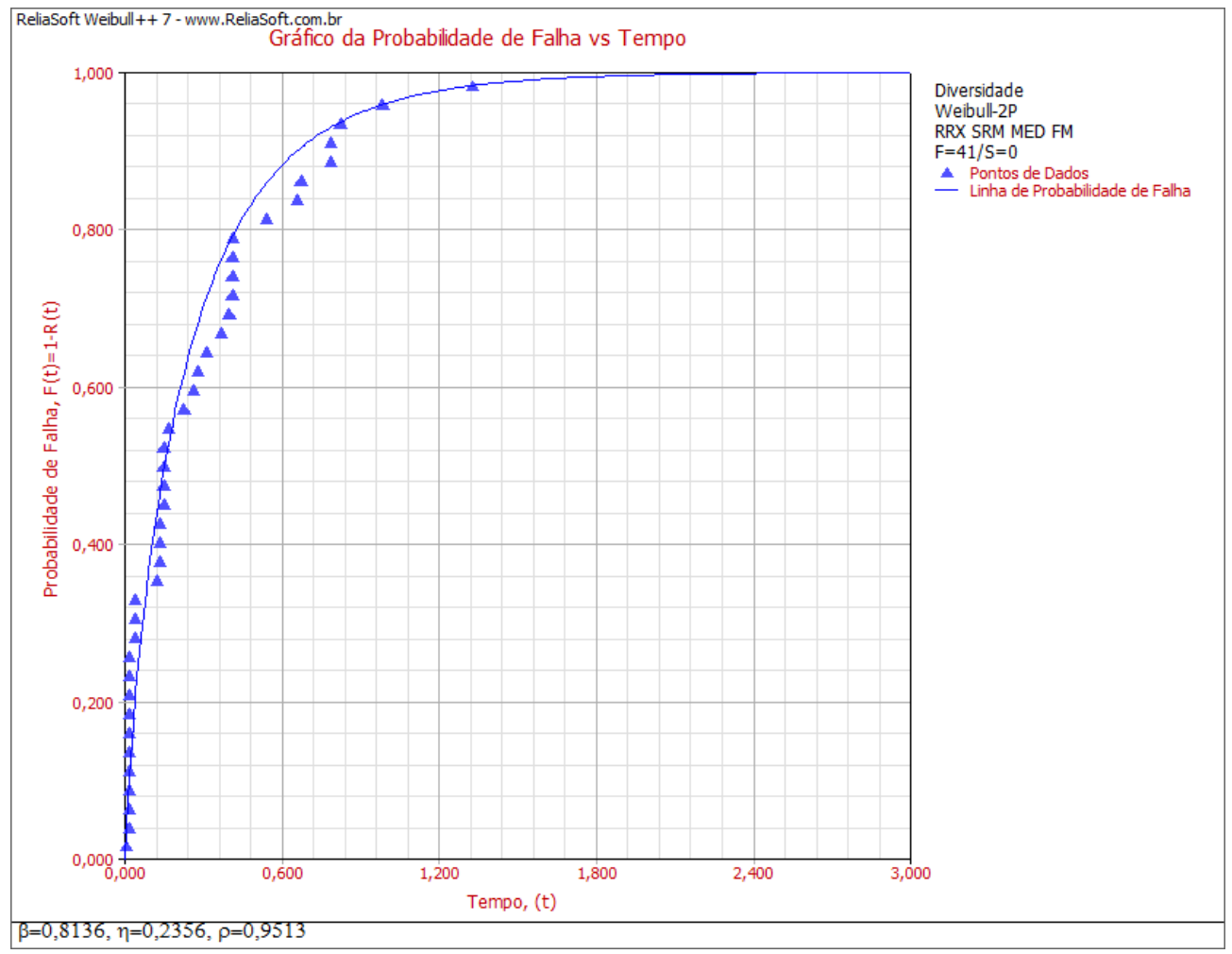

Figura 75 - Gráfico de probabilidade de falha insegura: Técnica diversidade

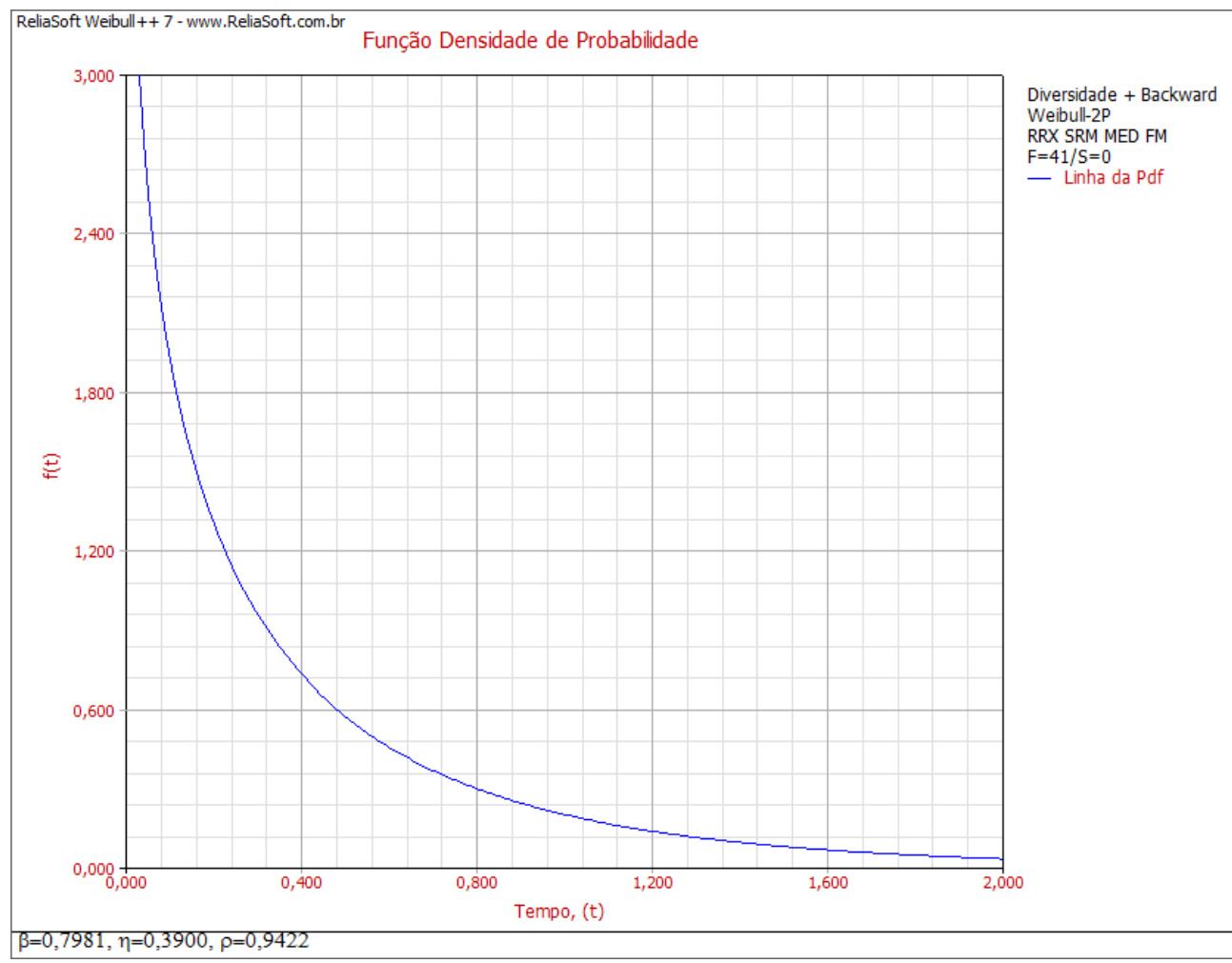

Figura 76 - Função de densidade de probabilidade para falhas inseguras: técnica de programação defensiva diversidade e backward combinadas 


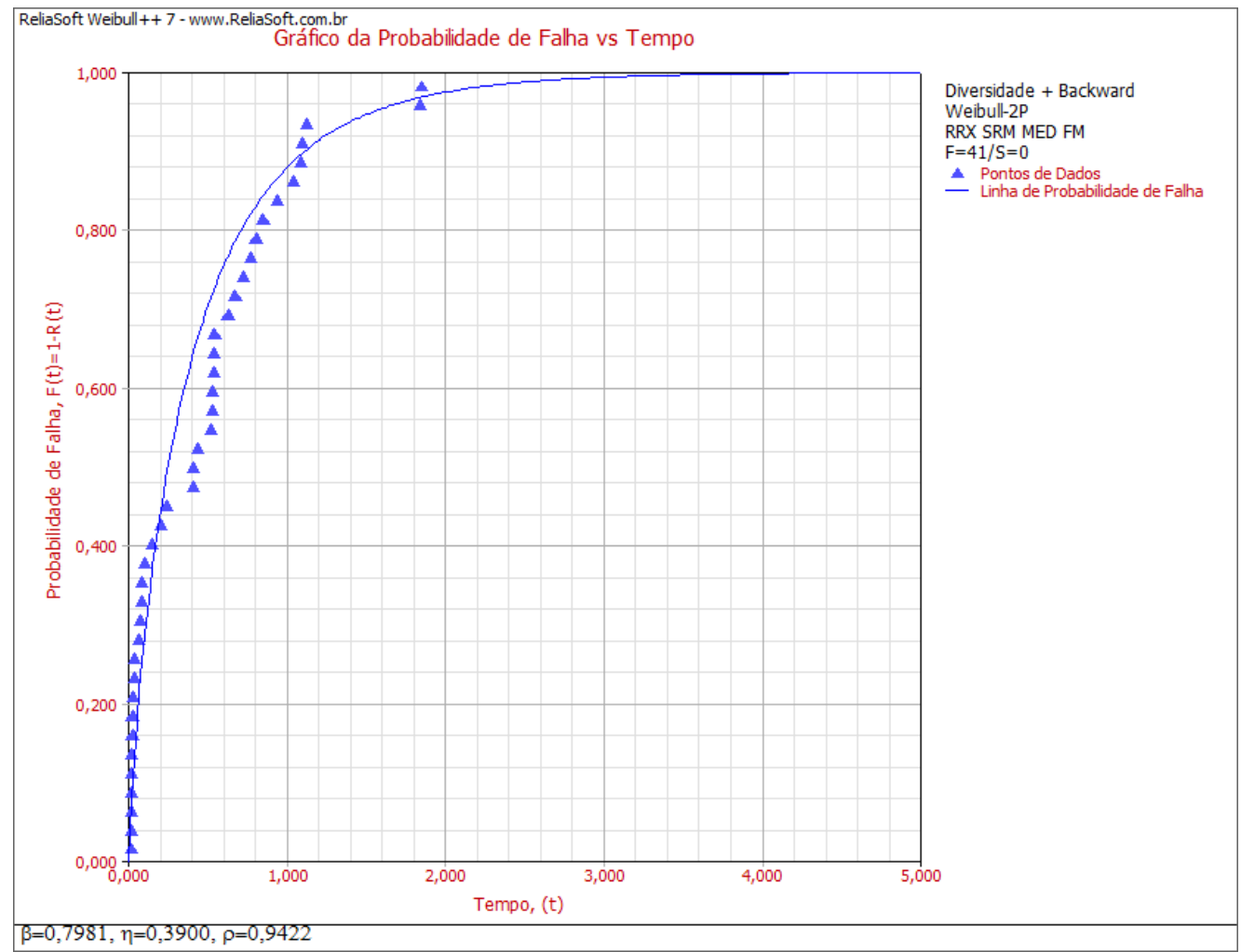

Figura 77 - Gráfico de probabilidade de falha insegura: Técnica diversidade e backward combinadas

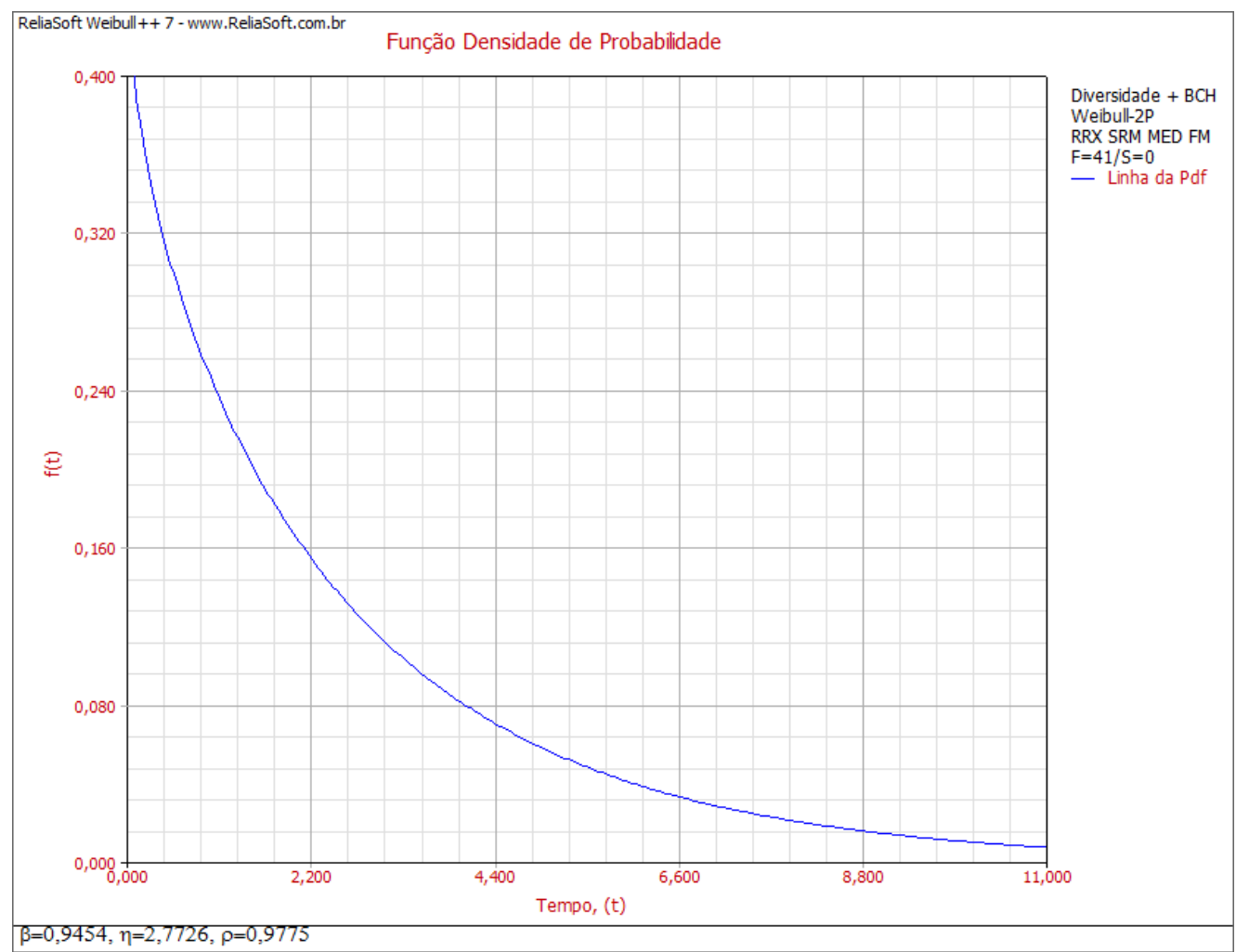

Figura 78 - Função de densidade de probabilidade para falhas inseguras: técnica de programação defensiva diversidade e $\mathrm{BCH}$ combinadas 


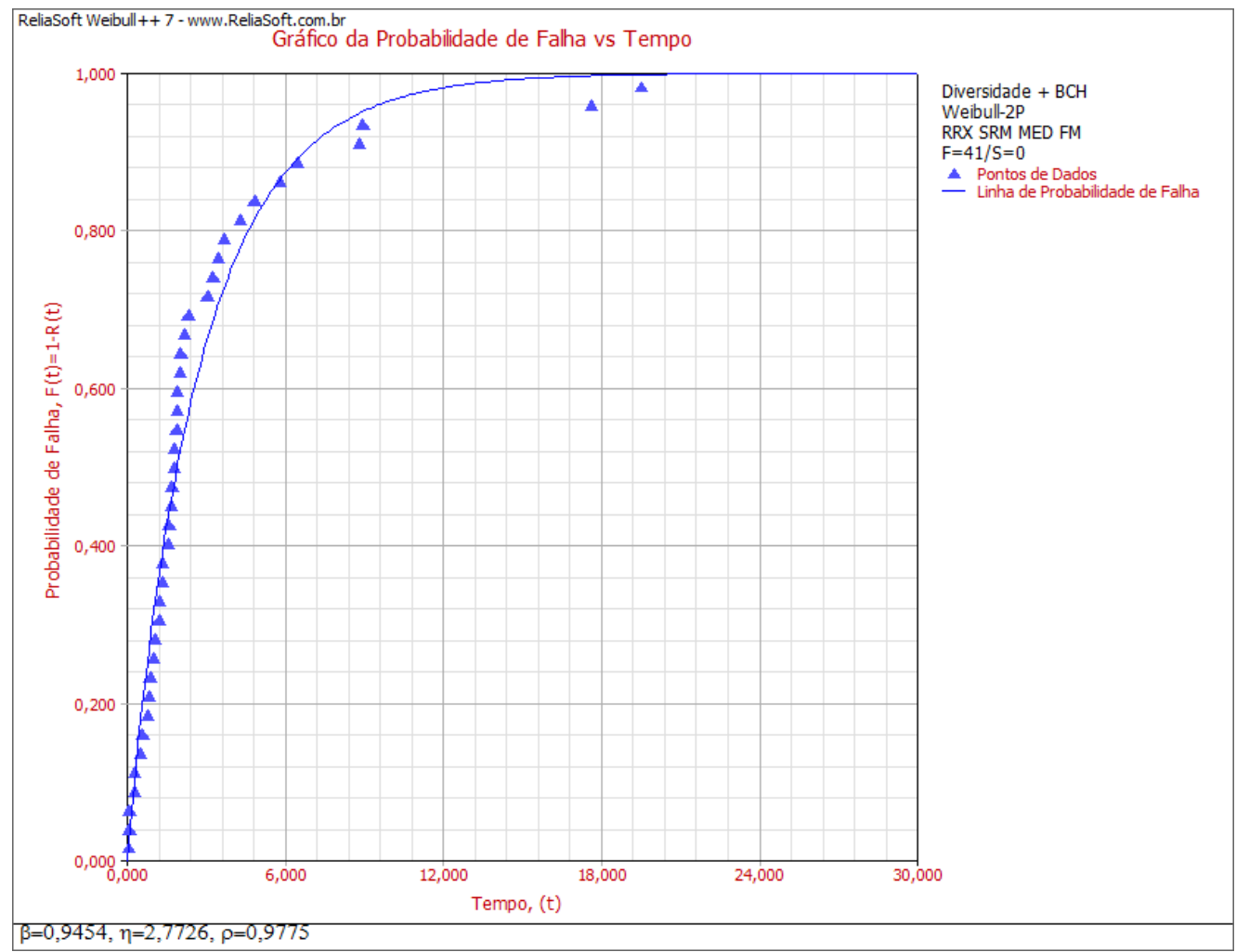

Figura 79 - Gráfico de probabilidade de falha insegura: Técnica diversidade e $\mathrm{BCH}$ combinadas

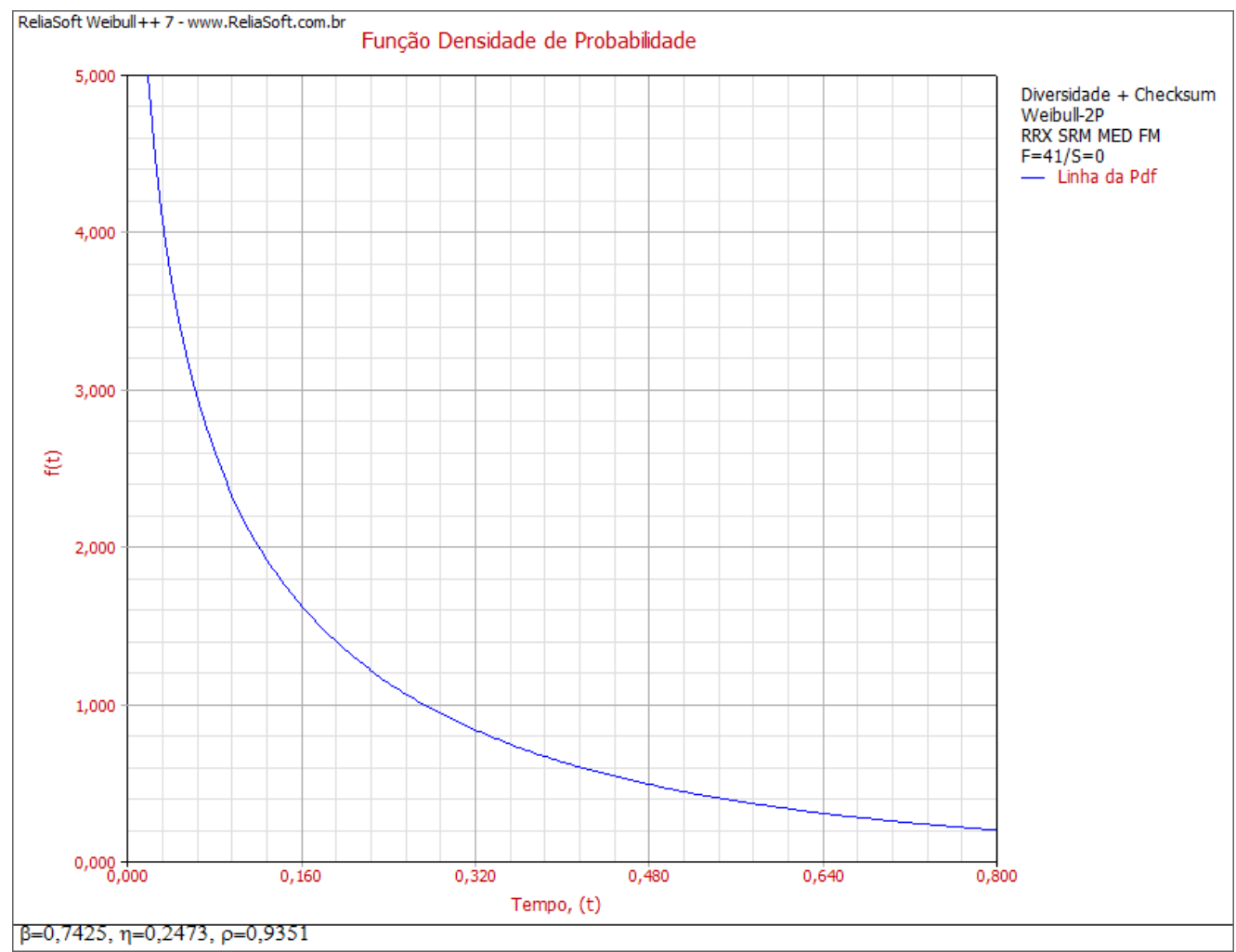

Figura 80 - Função de densidade de probabilidade para falhas inseguras: técnica de programação defensiva diversidade e checksum combinadas 


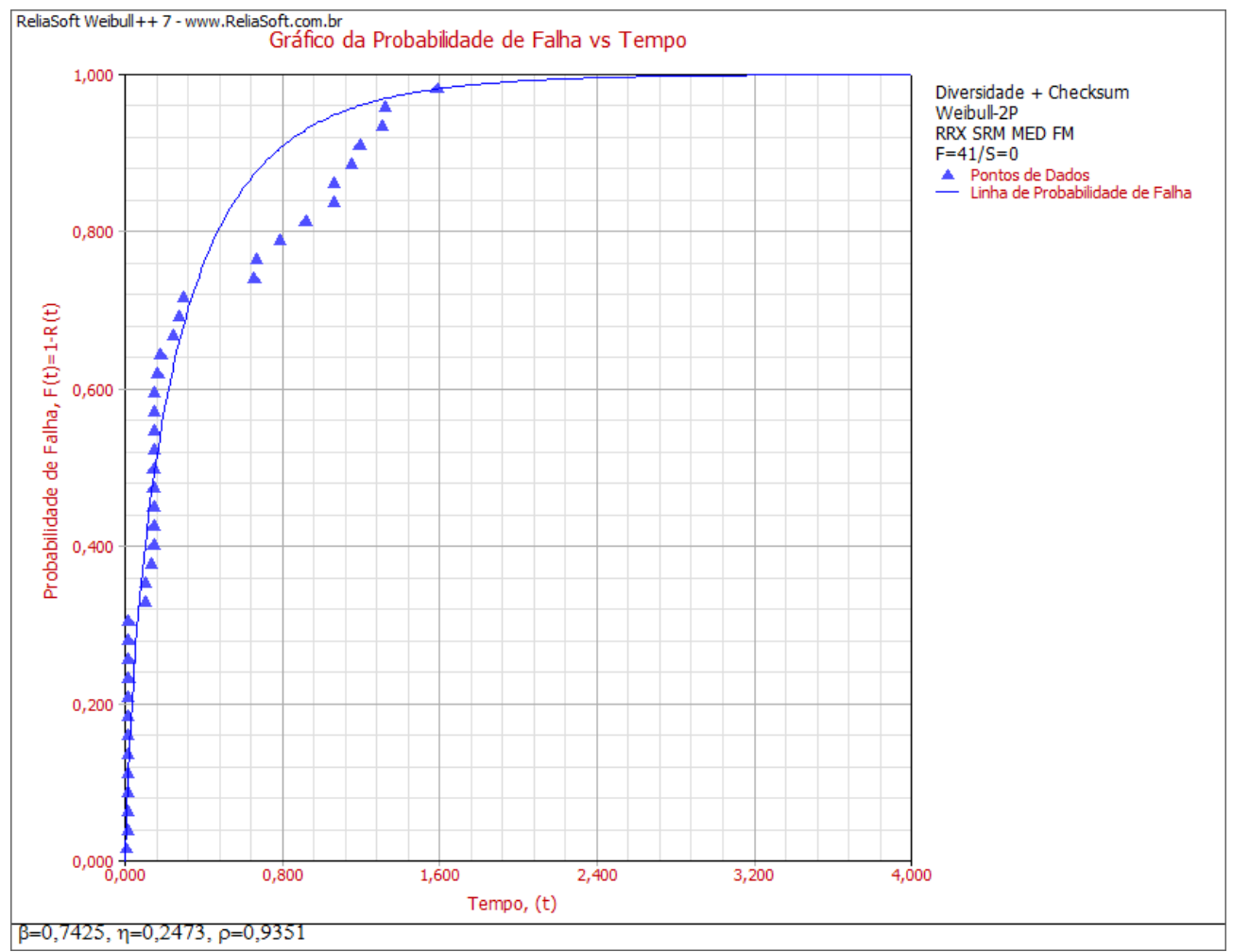

Figura 81 - Gráfico de probabilidade de falha insegura: Técnica diversidade e checksum combinadas

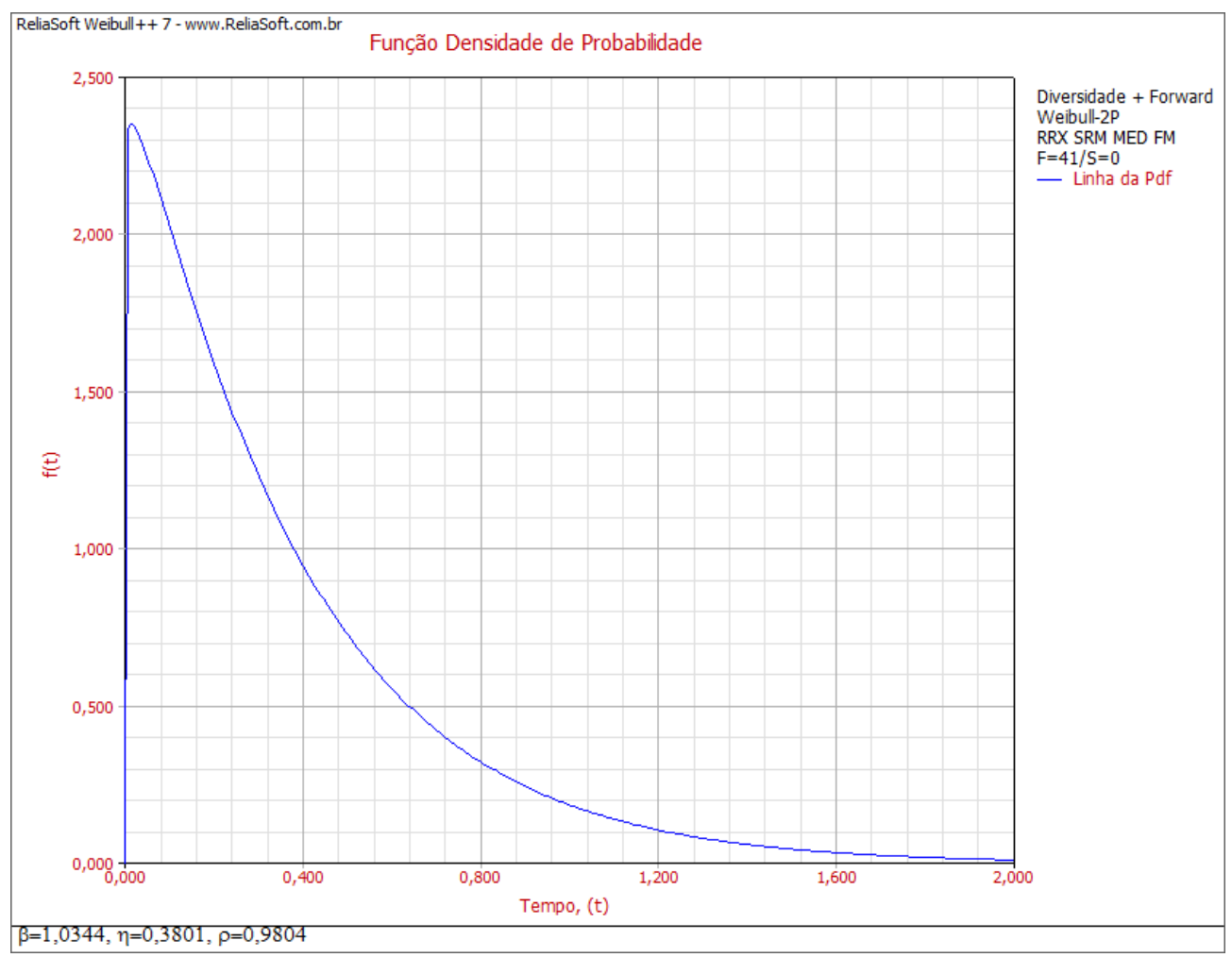

Figura 82 - Função de densidade de probabilidade para falhas inseguras: técnica de programação defensiva diversidade e forward combinadas 


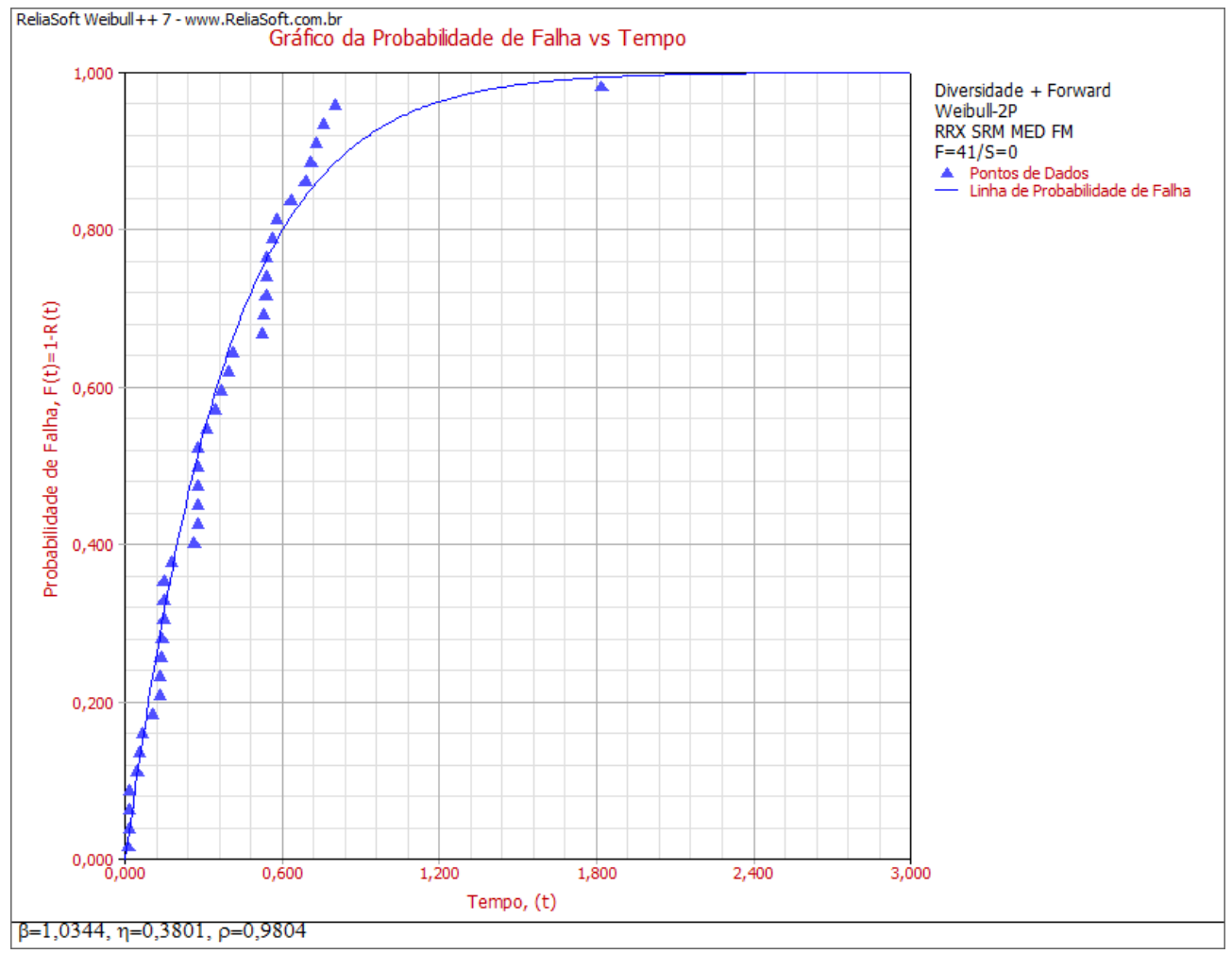

Figura 83 - Gráfico de probabilidade de falha insegura: Técnica diversidade e forward combinadas

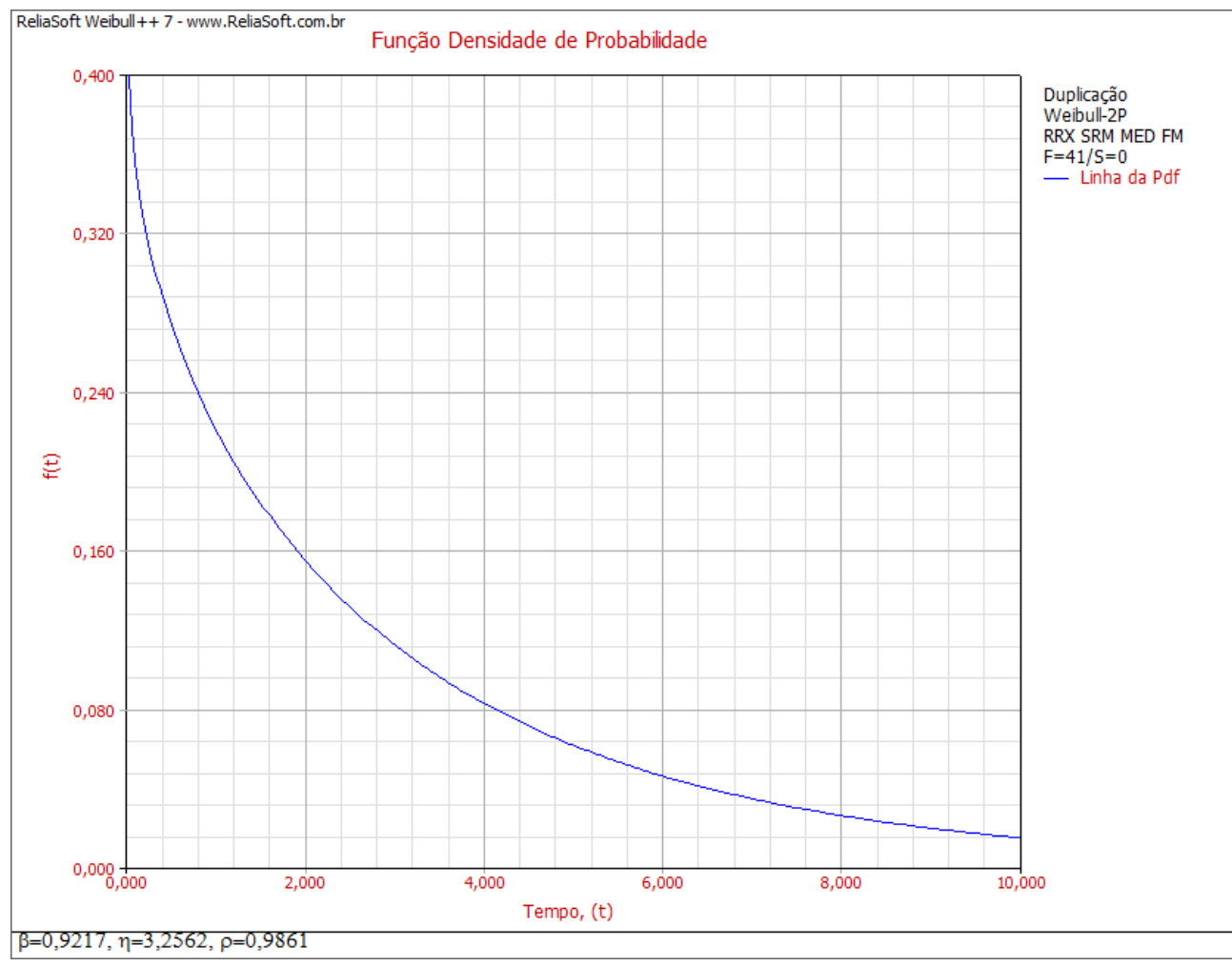

Figura 84 - Função de densidade de probabilidade para falhas inseguras: técnica de programação defensiva duplicação de variáveis 


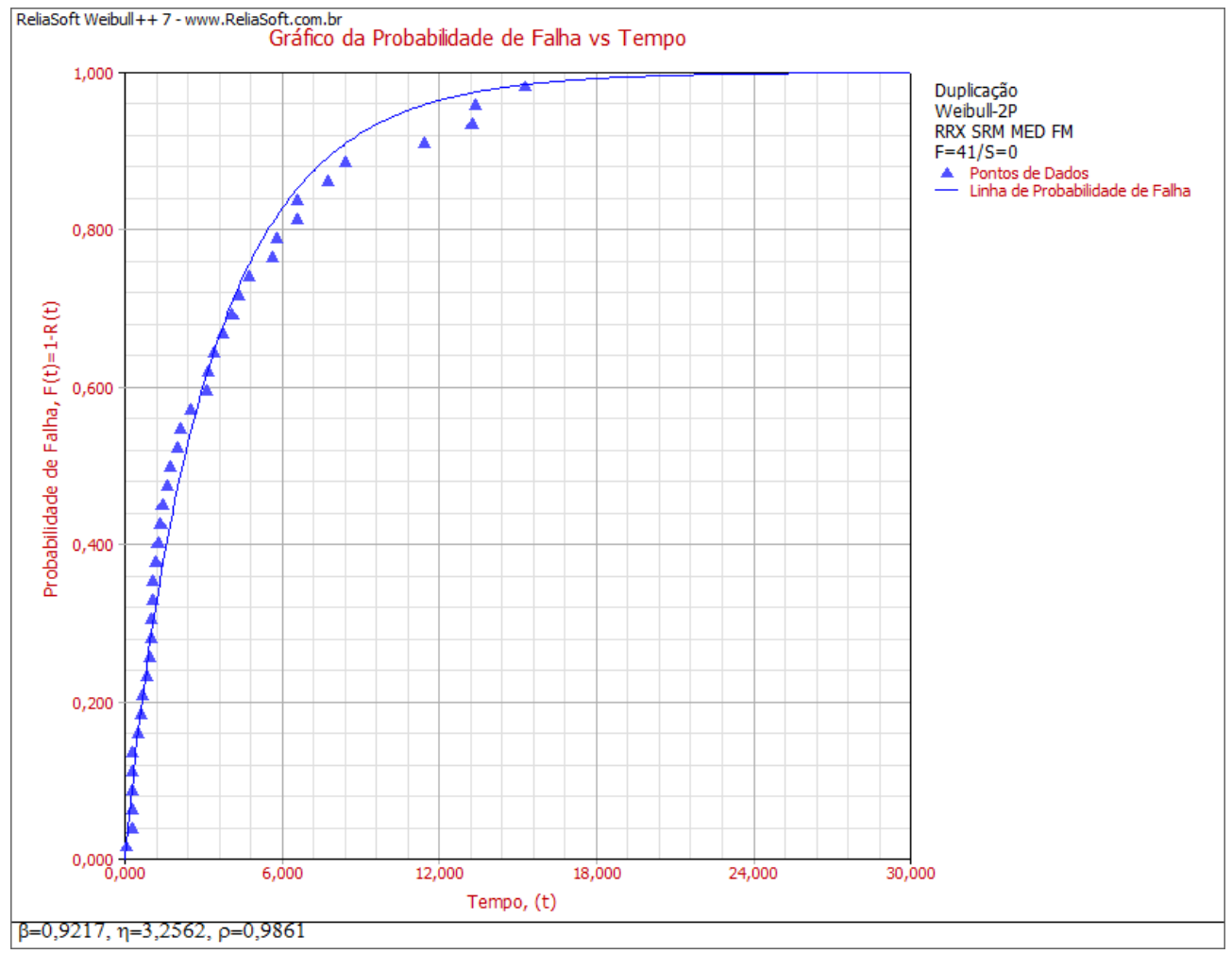

Figura 85 - Gráfico de probabilidade de falha insegura: Técnica duplicação de variáveis

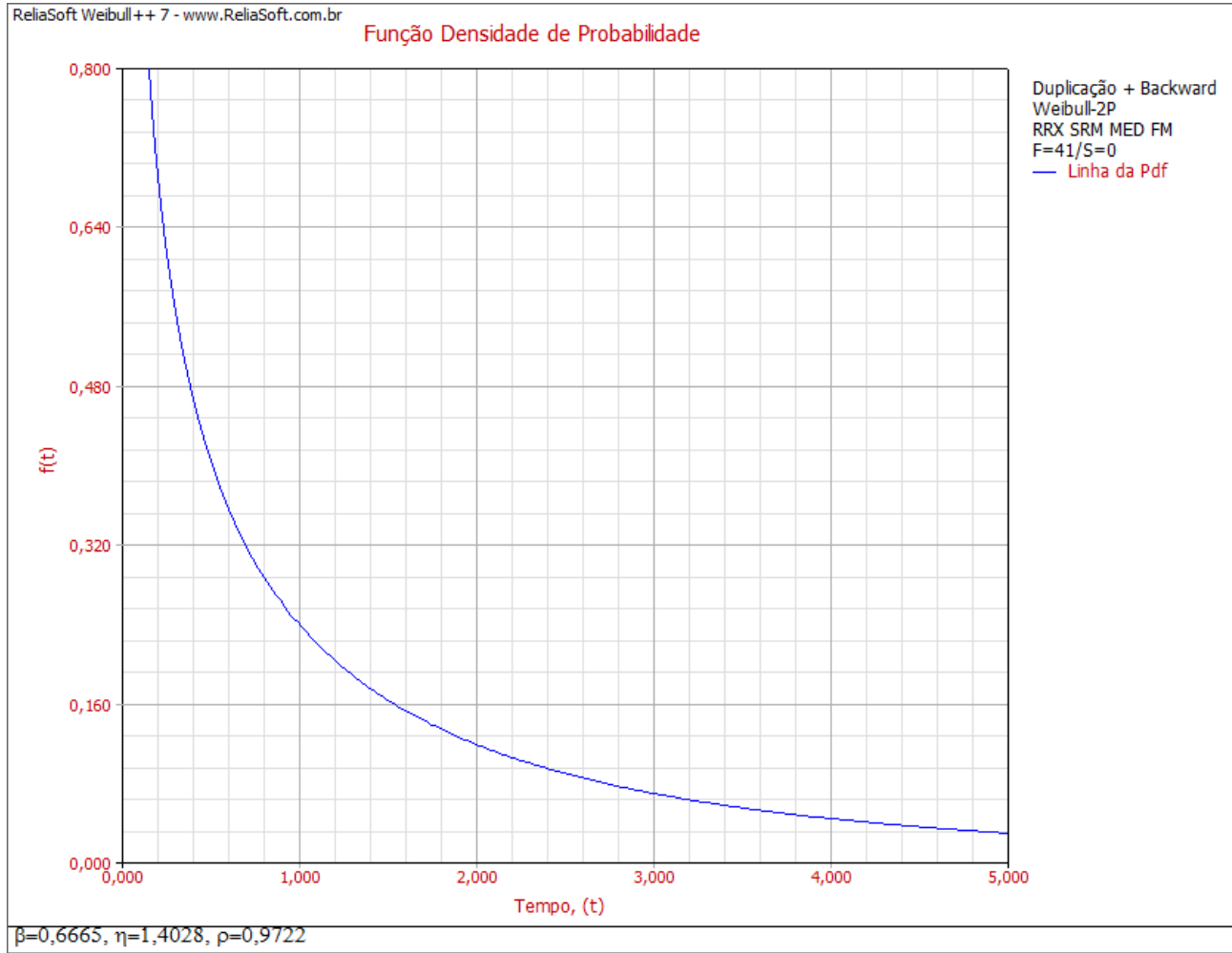

Figura 86 - Função de densidade de probabilidade para falhas inseguras: técnica de programação defensiva duplicação de variáveis e backward combinadas 


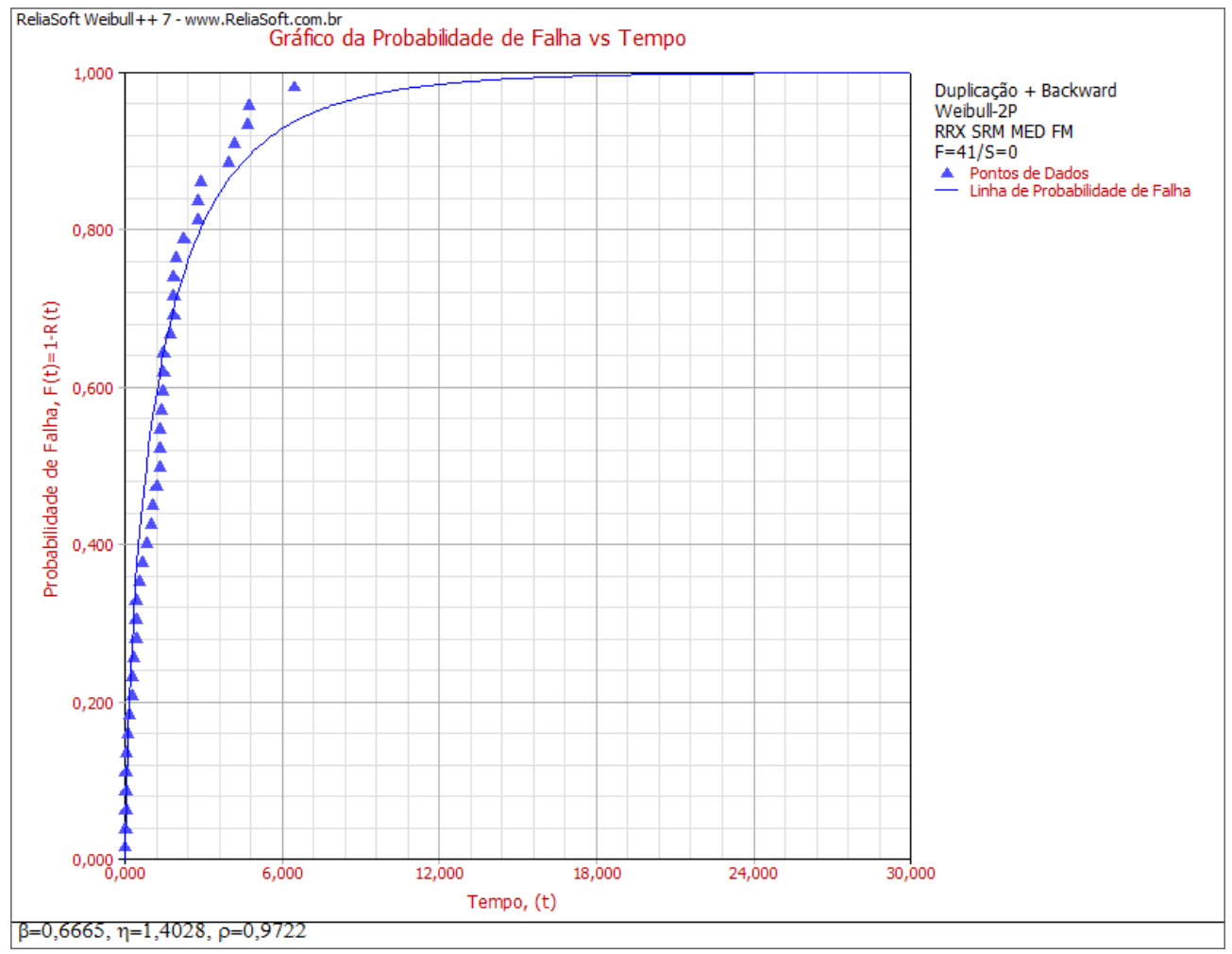

Figura 87 - Gráfico de probabilidade de falha insegura: Técnica duplicação de variáveis e backward combinadas

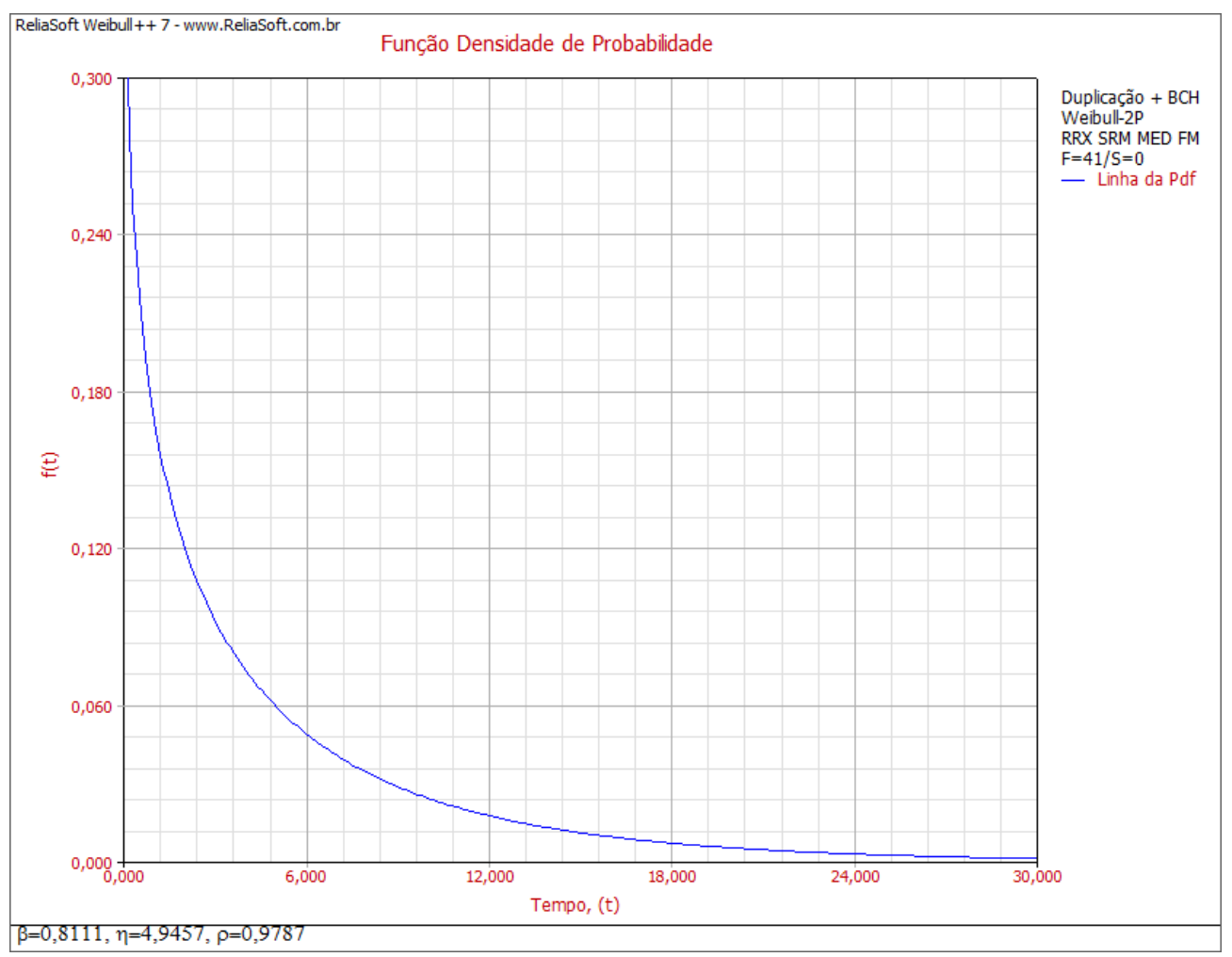

Figura 88 - Função de densidade de probabilidade para falhas inseguras: técnica de programação defensiva duplicação de variáveis e $\mathrm{BCH}$ combinadas 


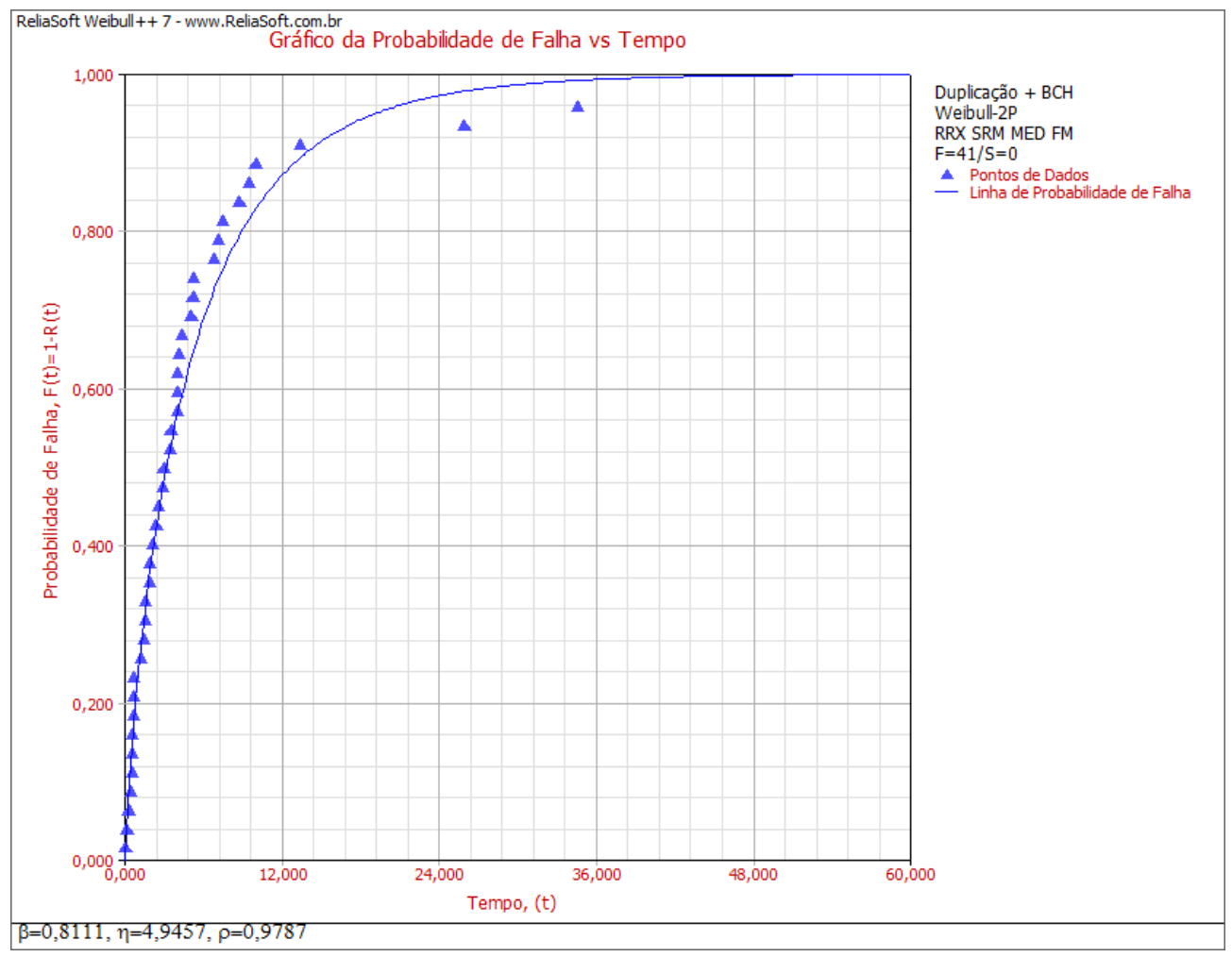

Figura 89 - Gráfico de probabilidade de falha insegura: Técnica duplicação de variáveis e BCH combinadas

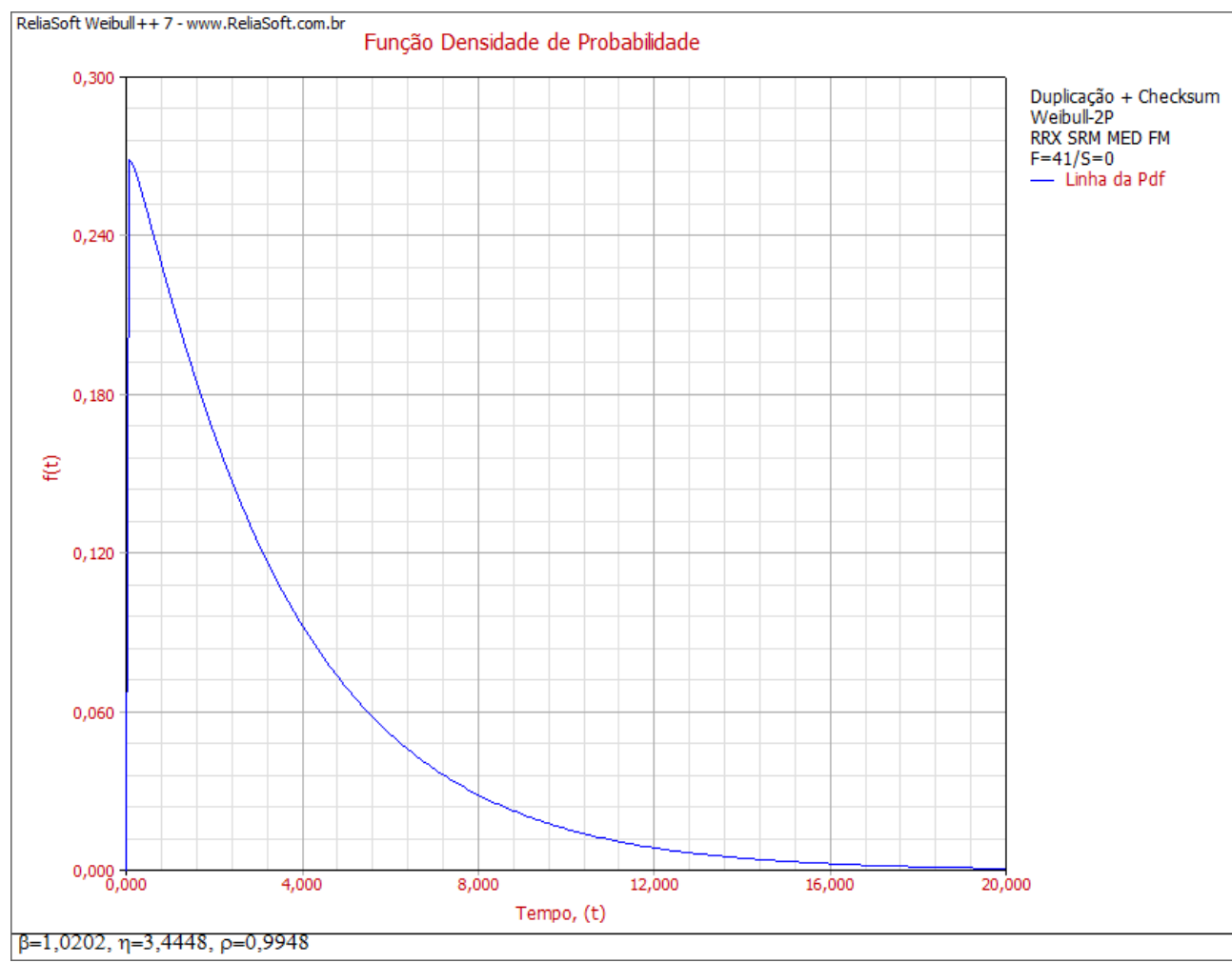

Figura 90 - Função de densidade de probabilidade para falhas inseguras: técnica de programação defensiva duplicação de variáveis e checksum combinadas 


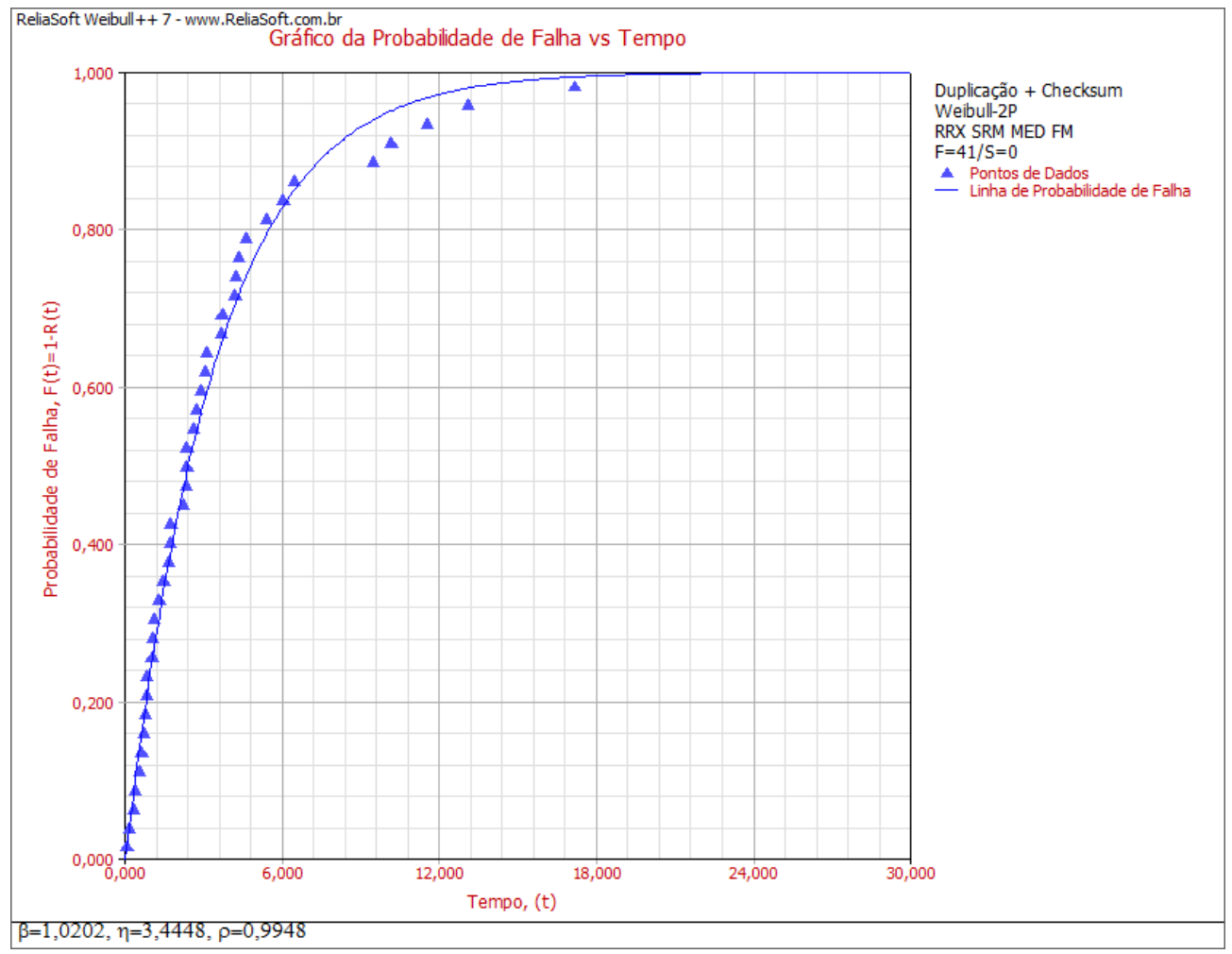

Figura 91 - Gráfico de probabilidade de falha insegura: Técnica duplicação de variáveis e checksum combinadas

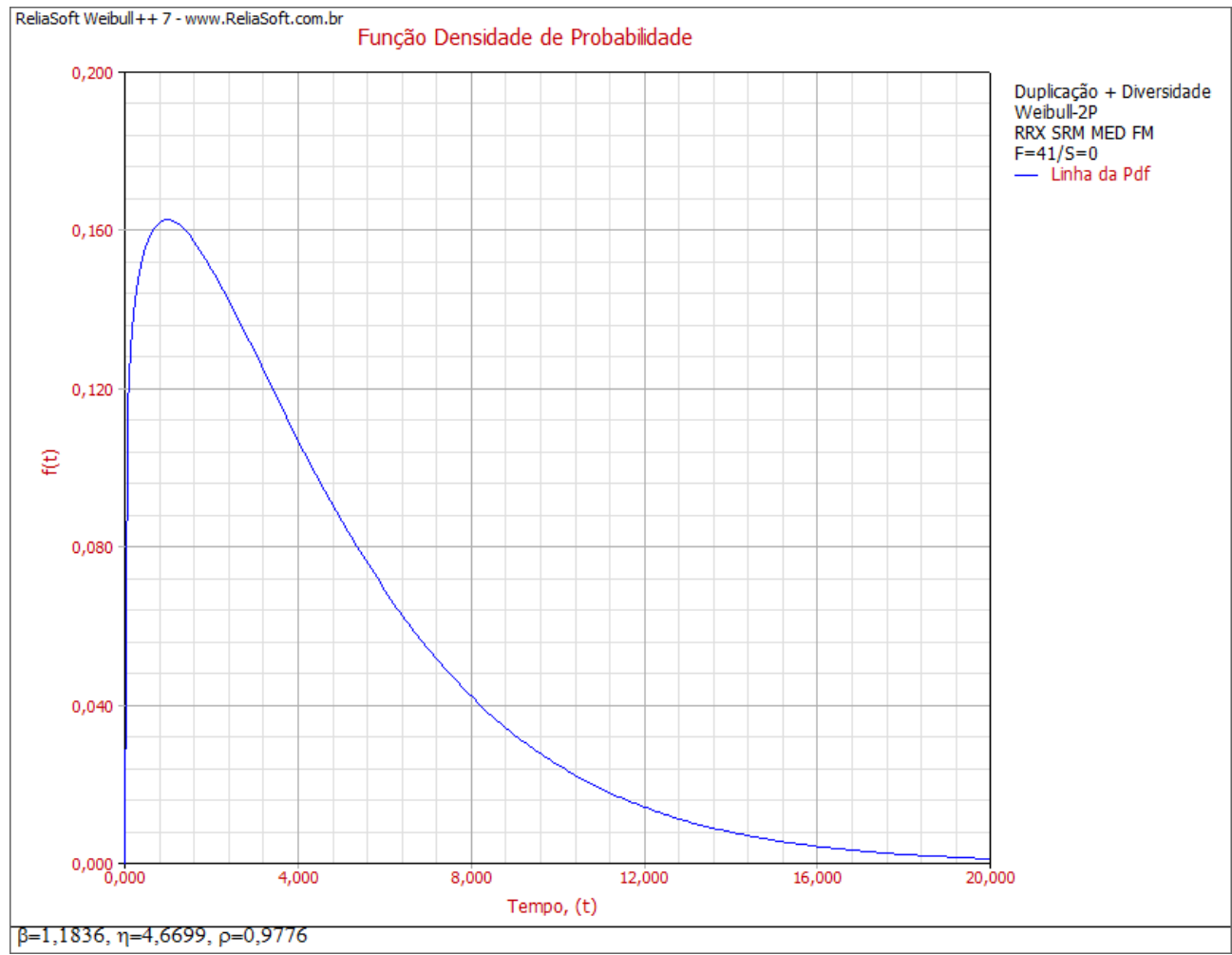

Figura 92 - Função de densidade de probabilidade para falhas inseguras: técnica de programação defensiva duplicação de variáveis e diversidade combinadas 


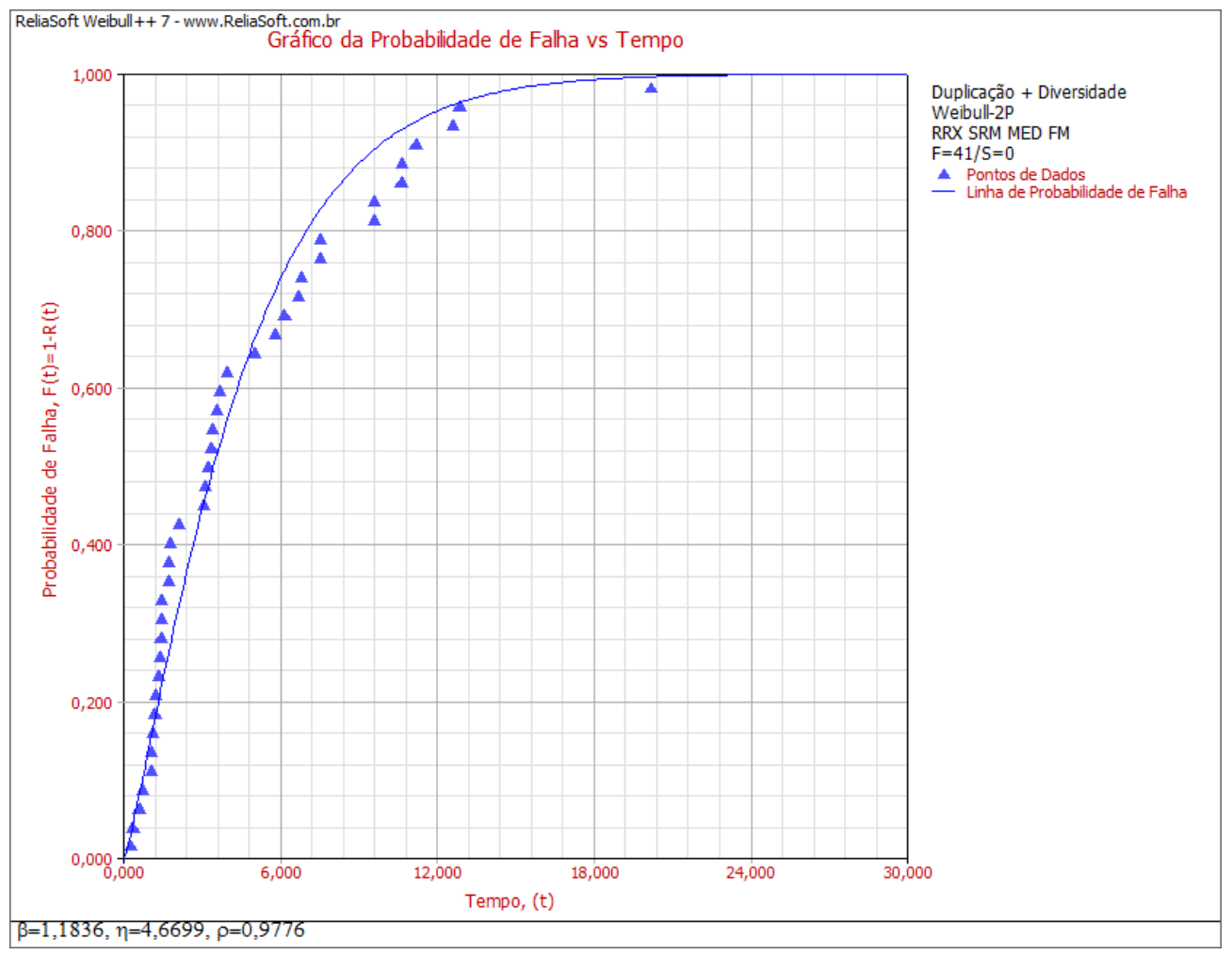

Figura 93 - Gráfico de probabilidade de falha insegura: Técnica duplicação de variáveis e diversidade combinadas

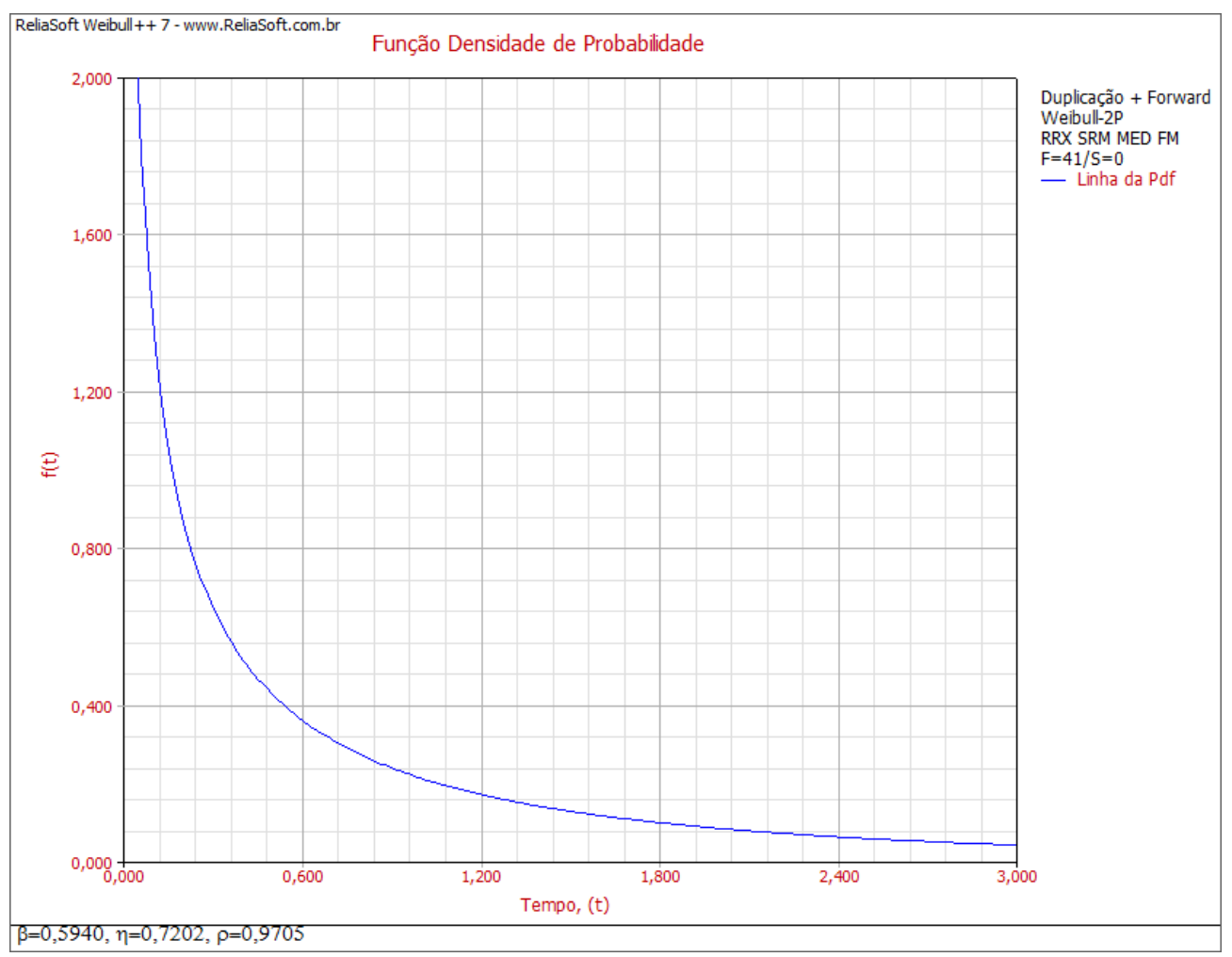

Figura 94 - Função de densidade de probabilidade para falhas inseguras: técnica de programação defensiva duplicação de variáveis e forward combinadas 


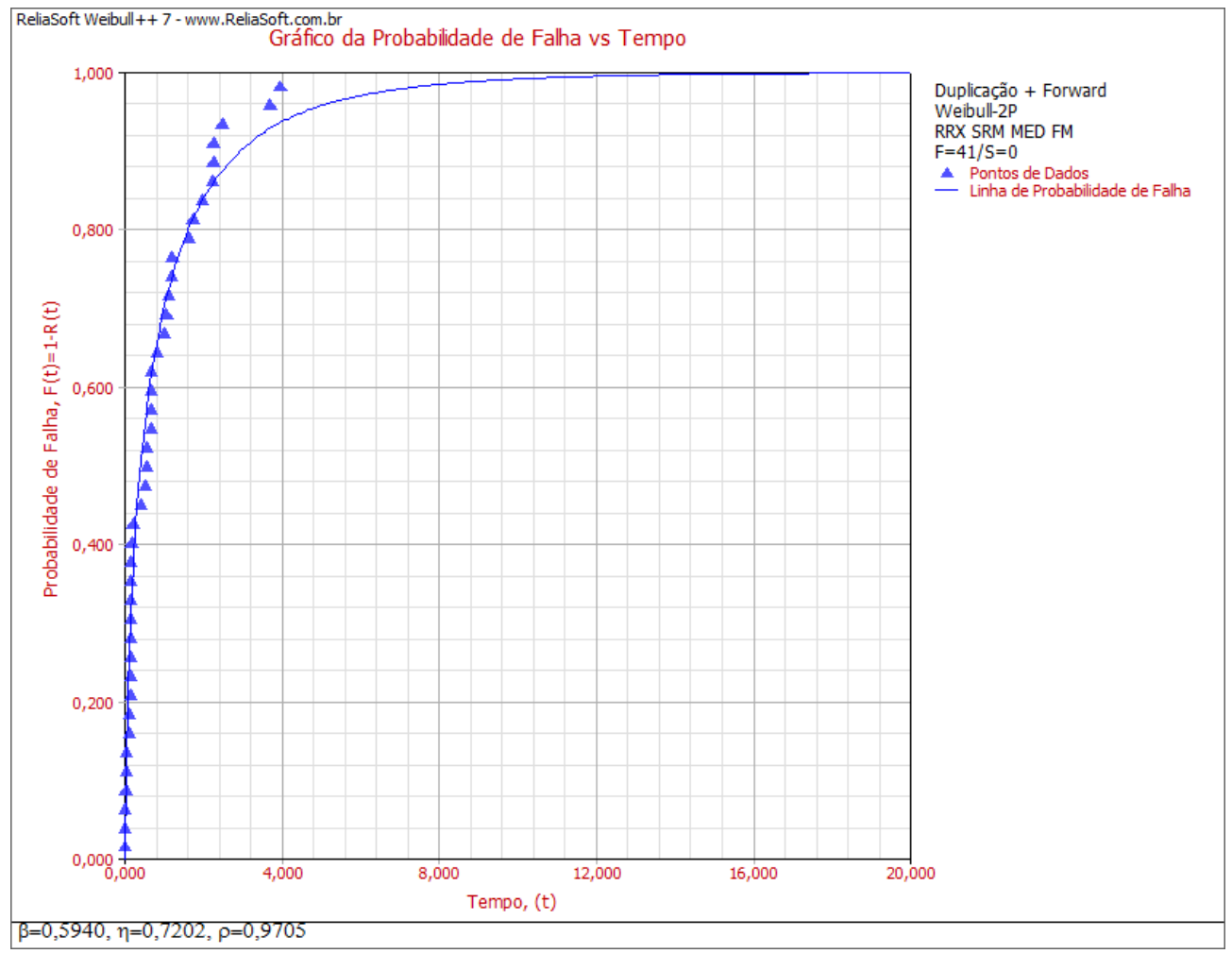

Figura 95 - Gráfico de probabilidade de falha insegura: Técnica duplicação de variáveis e forward combinadas

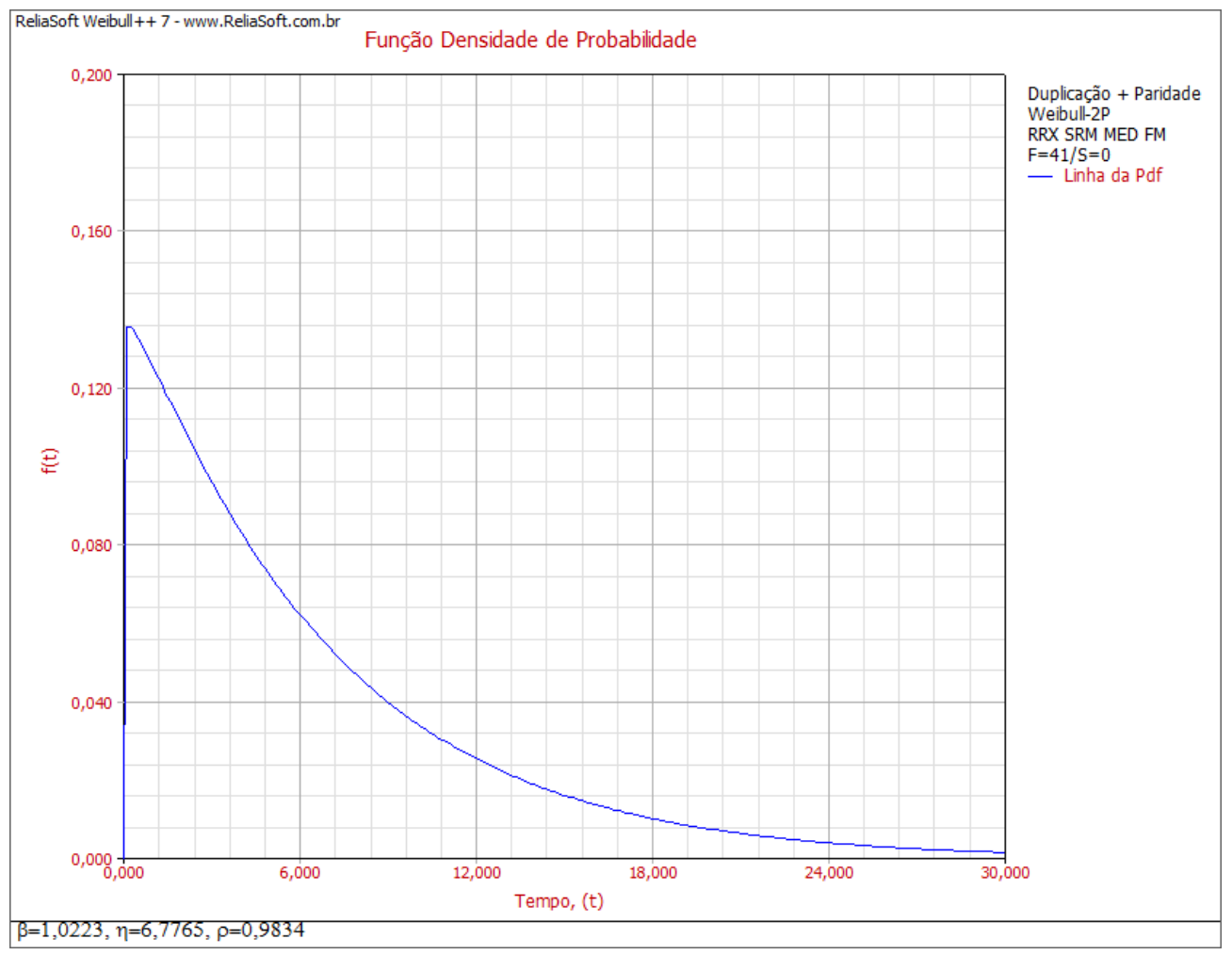

Figura 96 - Função de densidade de probabilidade para falhas inseguras: técnica de programação defensiva duplicação de variáveis e paridade combinadas 


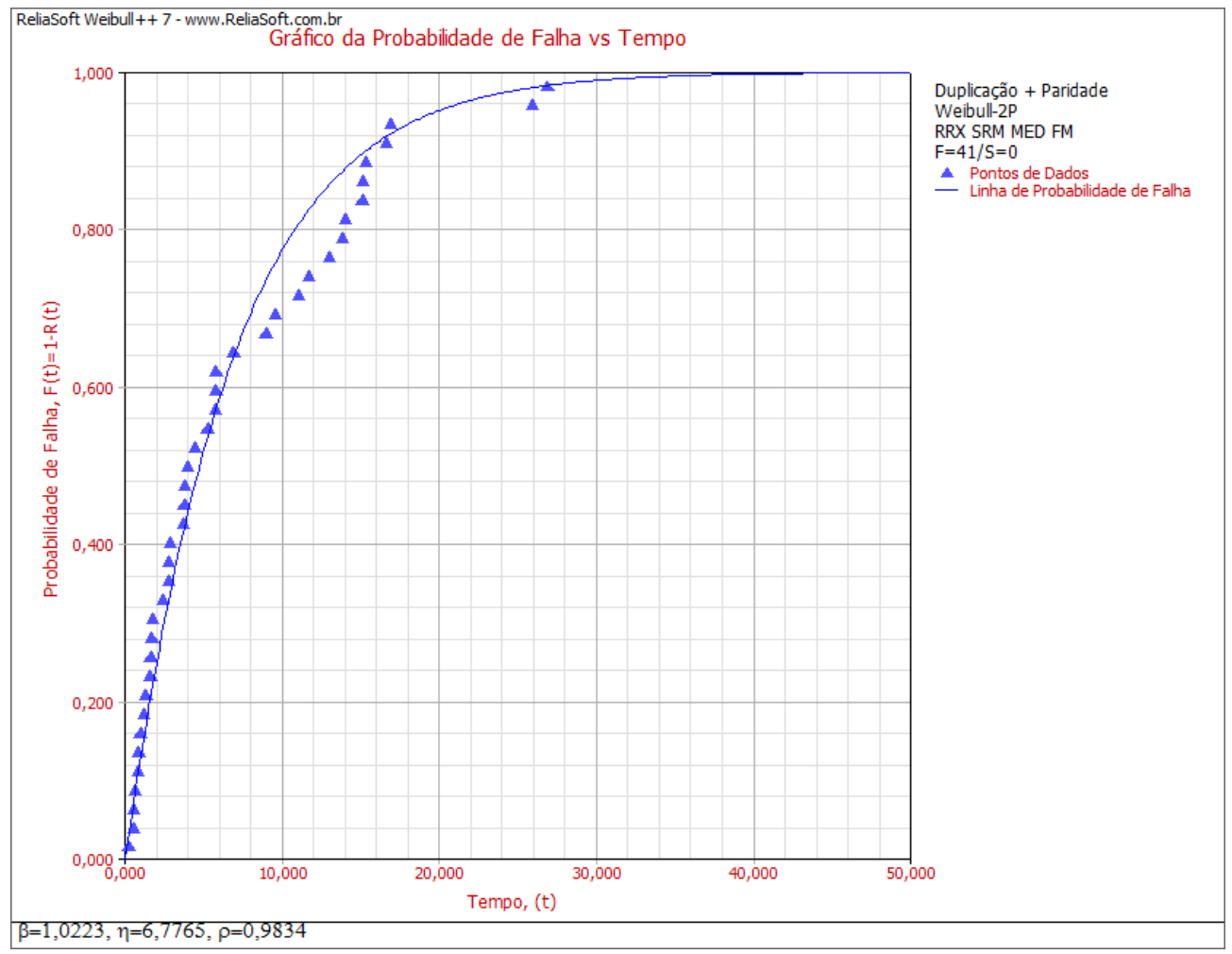

Figura 97 - Gráfico de probabilidade de falha insegura: Técnica duplicação de variáveis e paridade combinadas

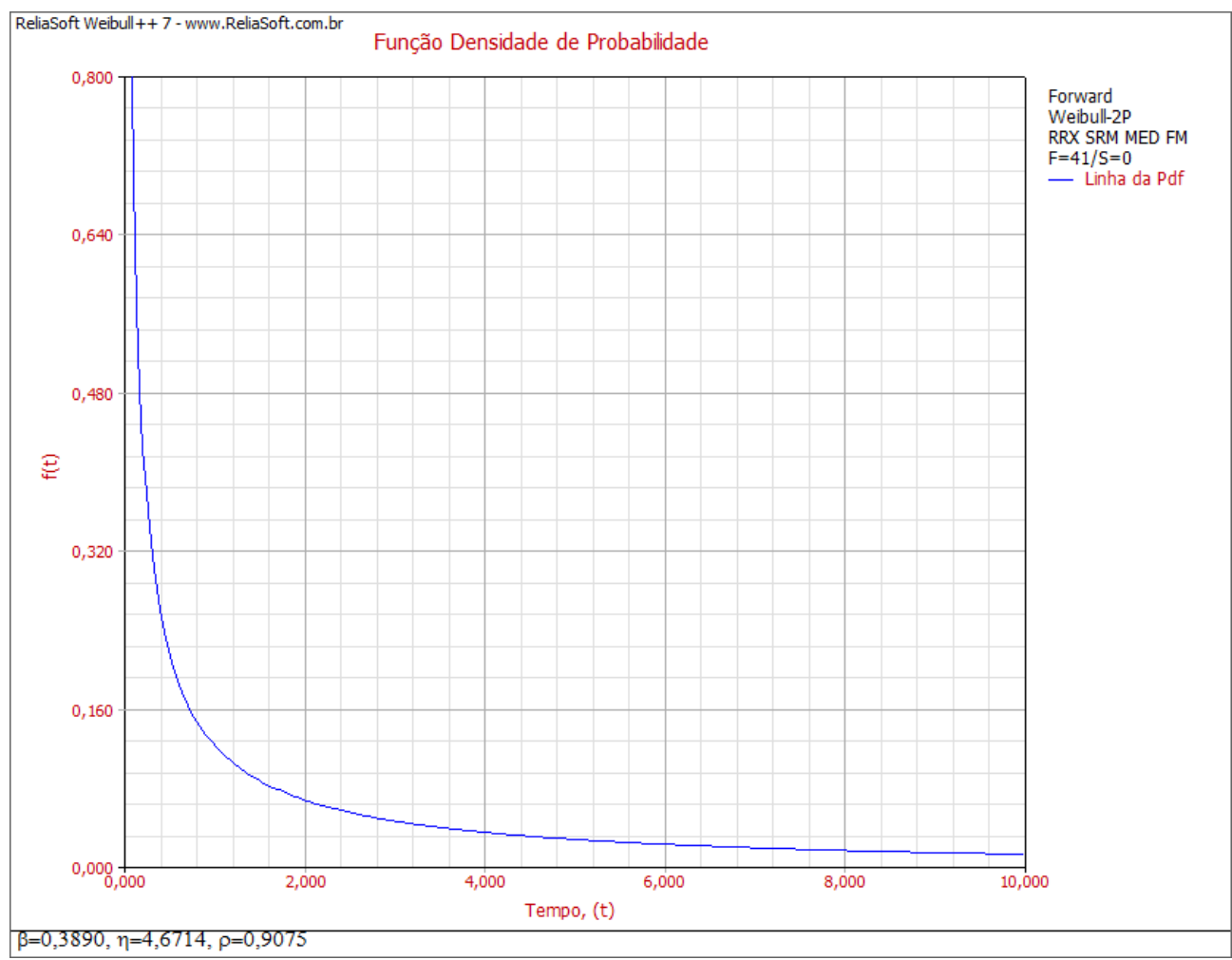

Figura 98 - Função de densidade de probabilidade para falhas inseguras: técnica de programação defensiva forward 


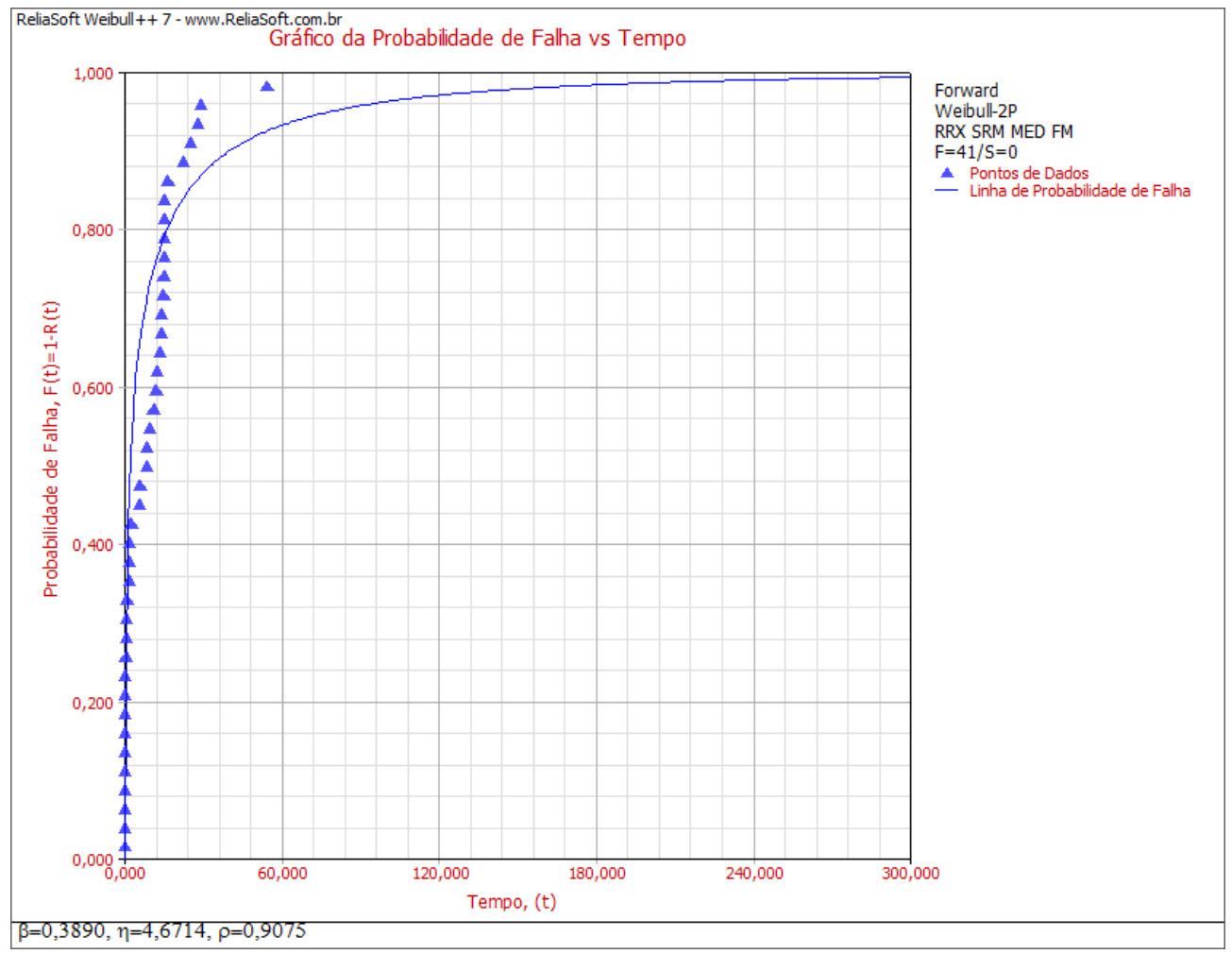

Figura 99 - Gráfico de probabilidade de falha insegura: Técnica forward

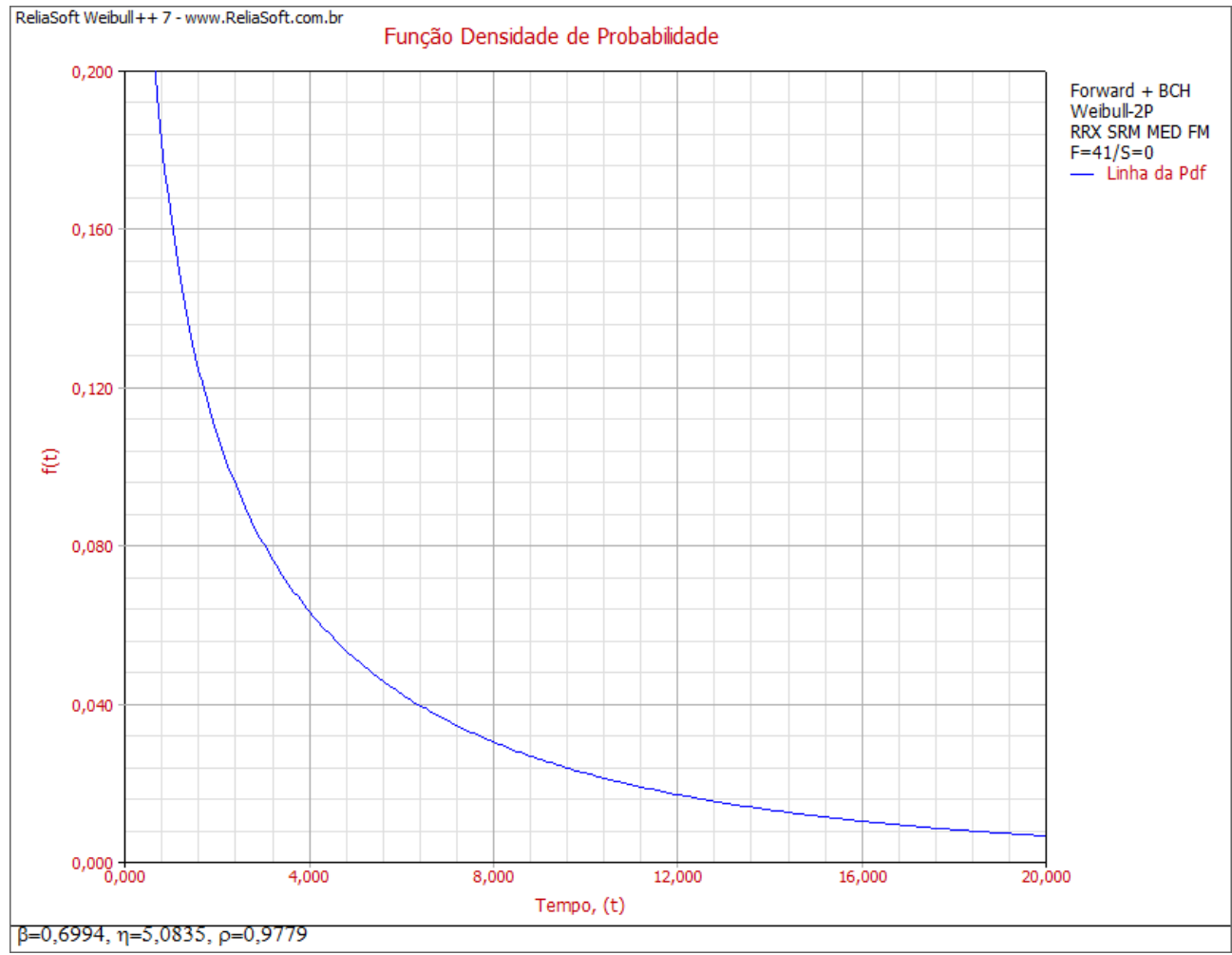

Figura 100 - Função de densidade de probabilidade para falhas inseguras: técnica de programação defensiva forward e $\mathrm{BCH}$ combinadas 


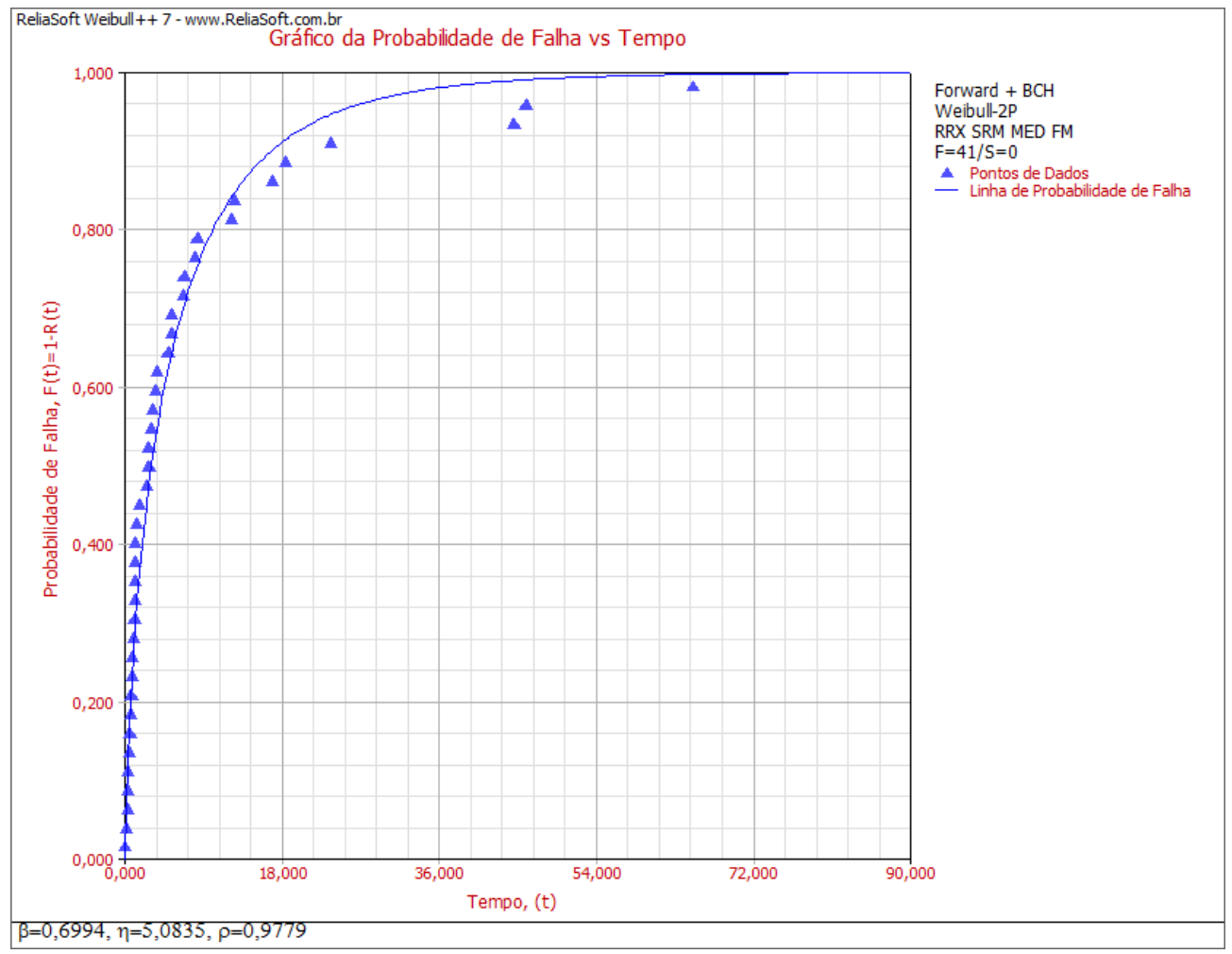

Figura 101 - Gráfico de probabilidade de falha insegura: Técnica forward e BCH combinadas

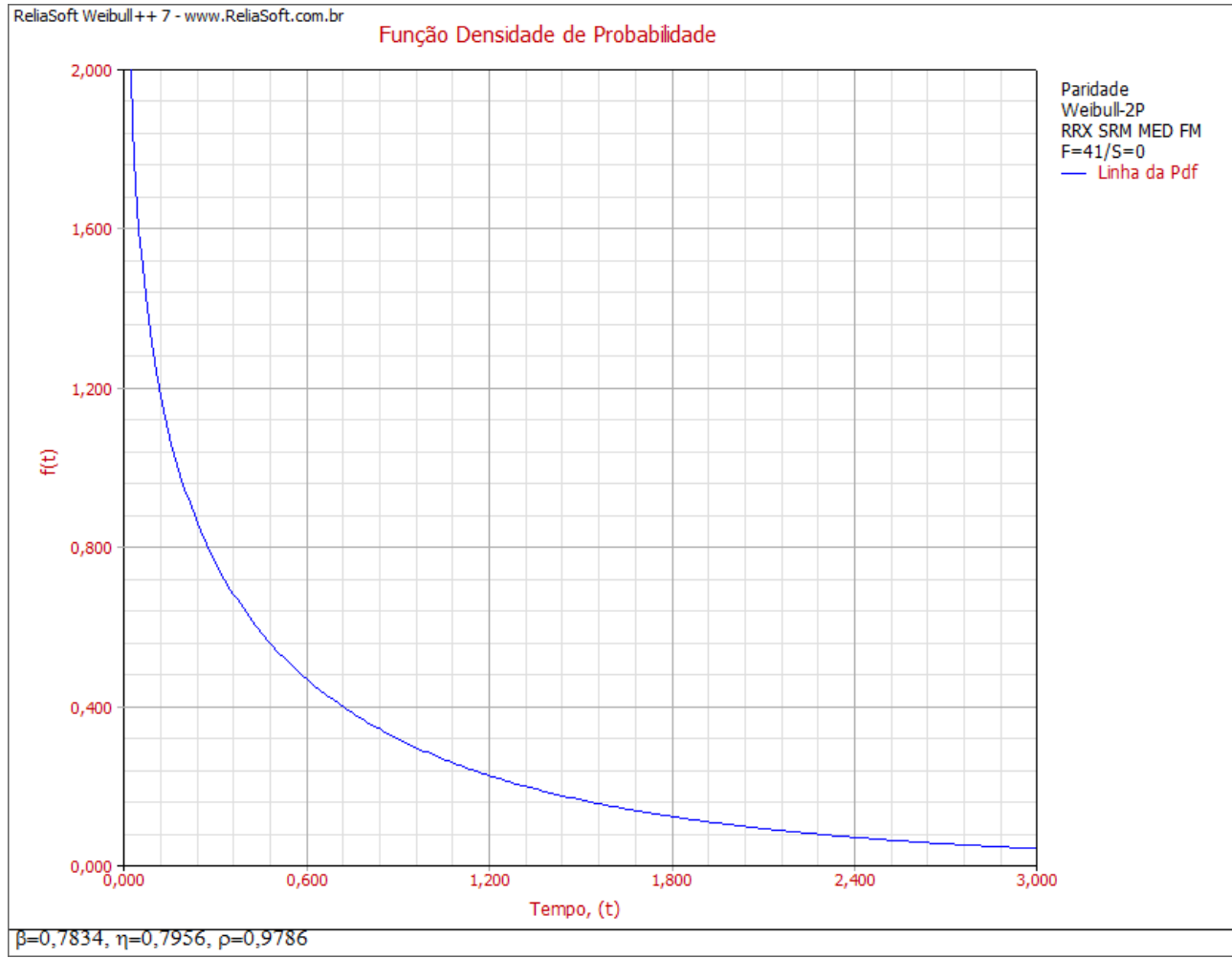

Figura 102 - Função de densidade de probabilidade para falhas inseguras: técnica de programação defensiva paridade 


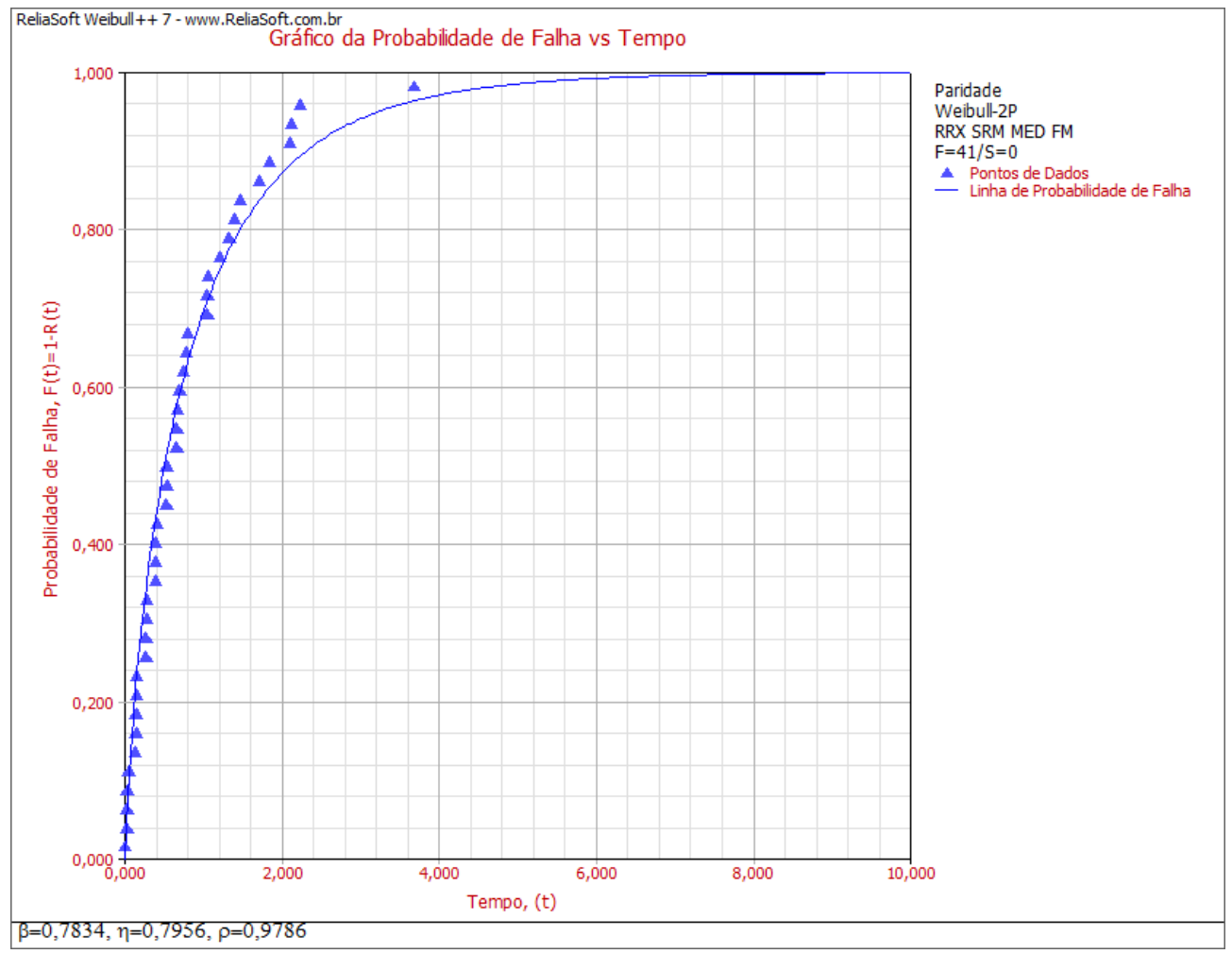

Figura 103 - Gráfico de probabilidade de falha insegura: Técnica paridade

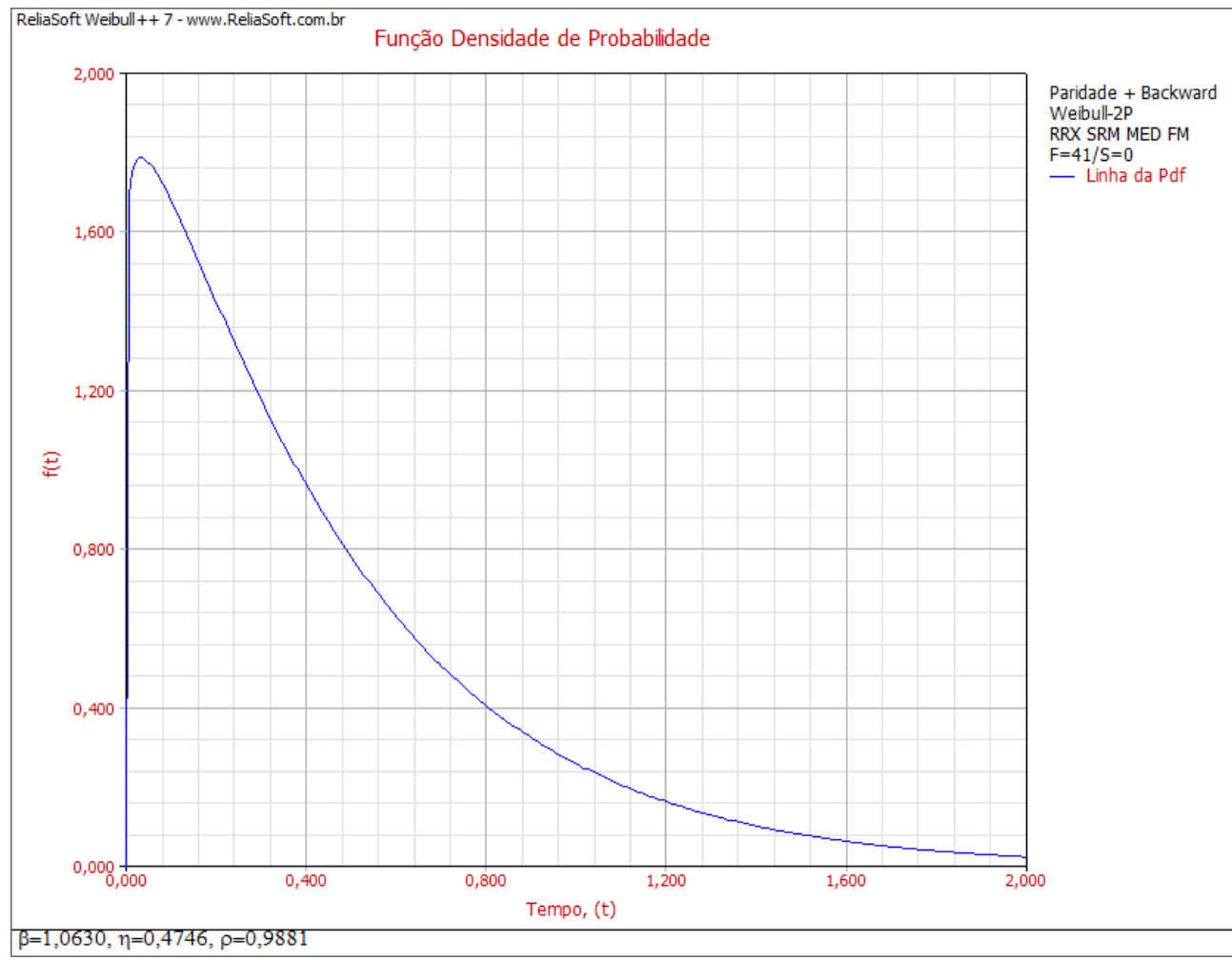

Figura 104 - Função de densidade de probabilidade para falhas inseguras: técnica de programação defensiva paridade e backward combinadas 


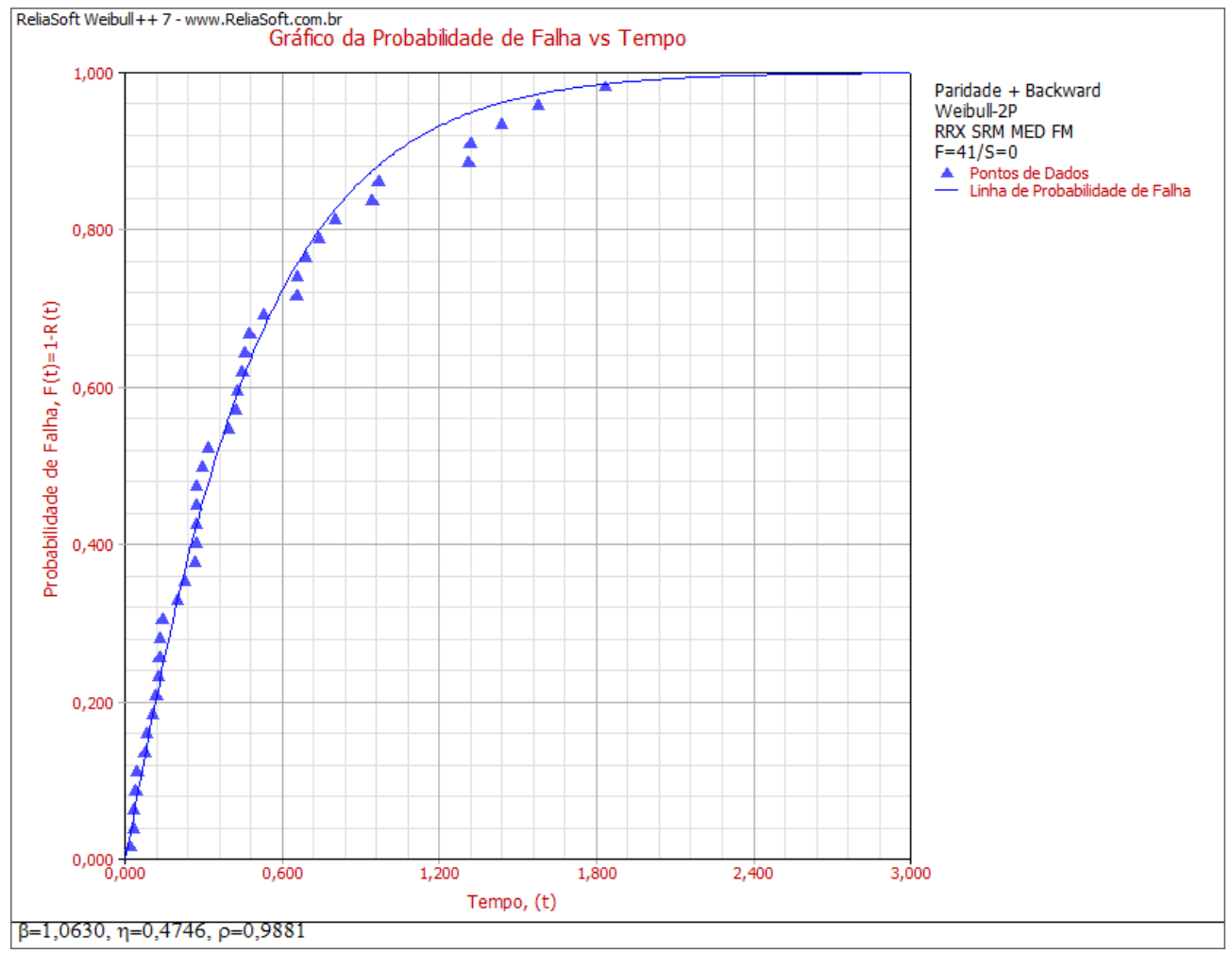

Figura 105 - Gráfico de probabilidade de falha insegura: Técnica paridade e backward combinadas

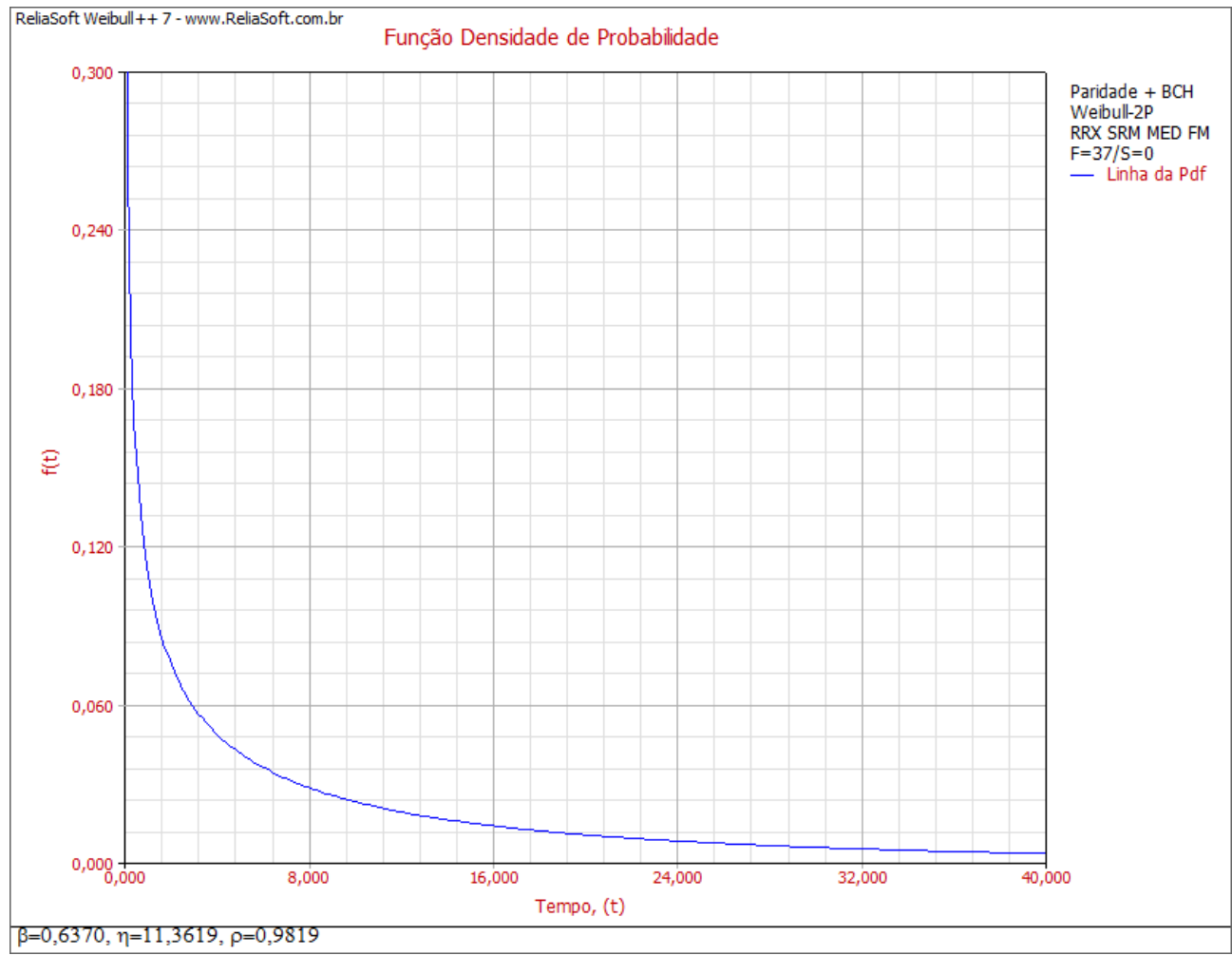

Figura 106 - Função de densidade de probabilidade para falhas inseguras: técnica de programação defensiva paridade e $\mathrm{BCH}$ combinadas 


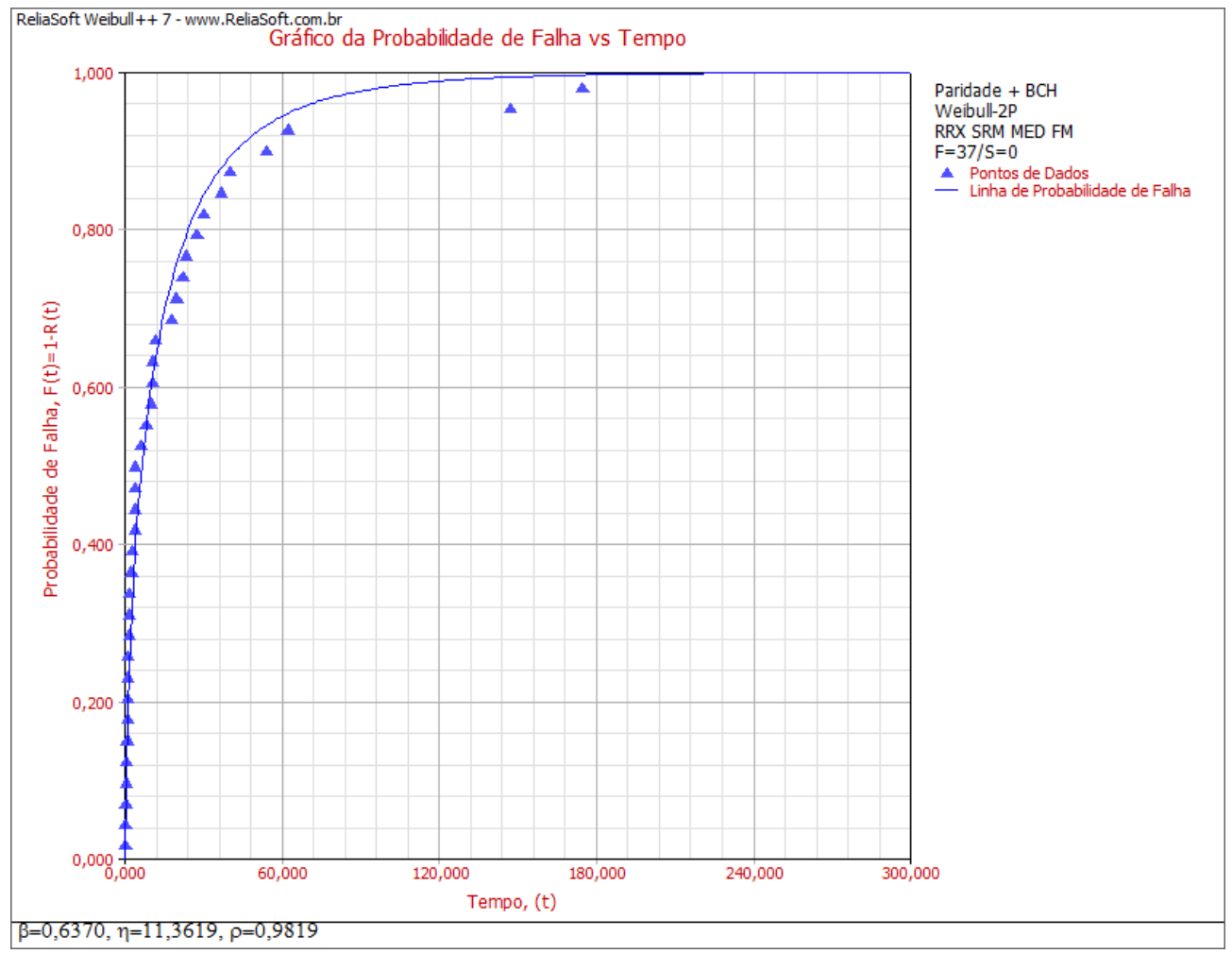

Figura 107 - Gráfico de probabilidade de falha insegura: Técnica paridade e BCH combinadas

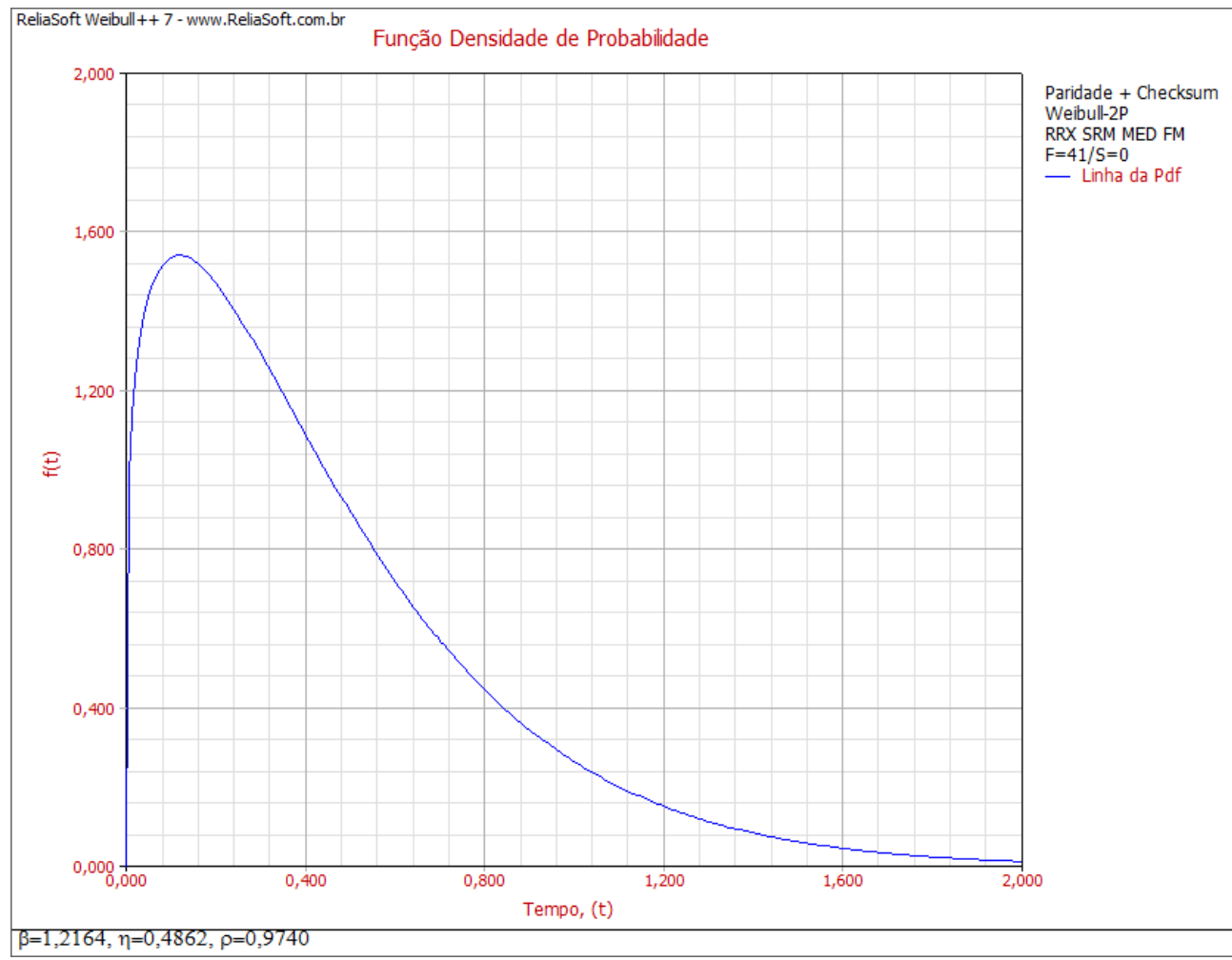

Figura 108 - Função de densidade de probabilidade para falhas inseguras: técnica de programação defensiva paridade e checksum combinadas 


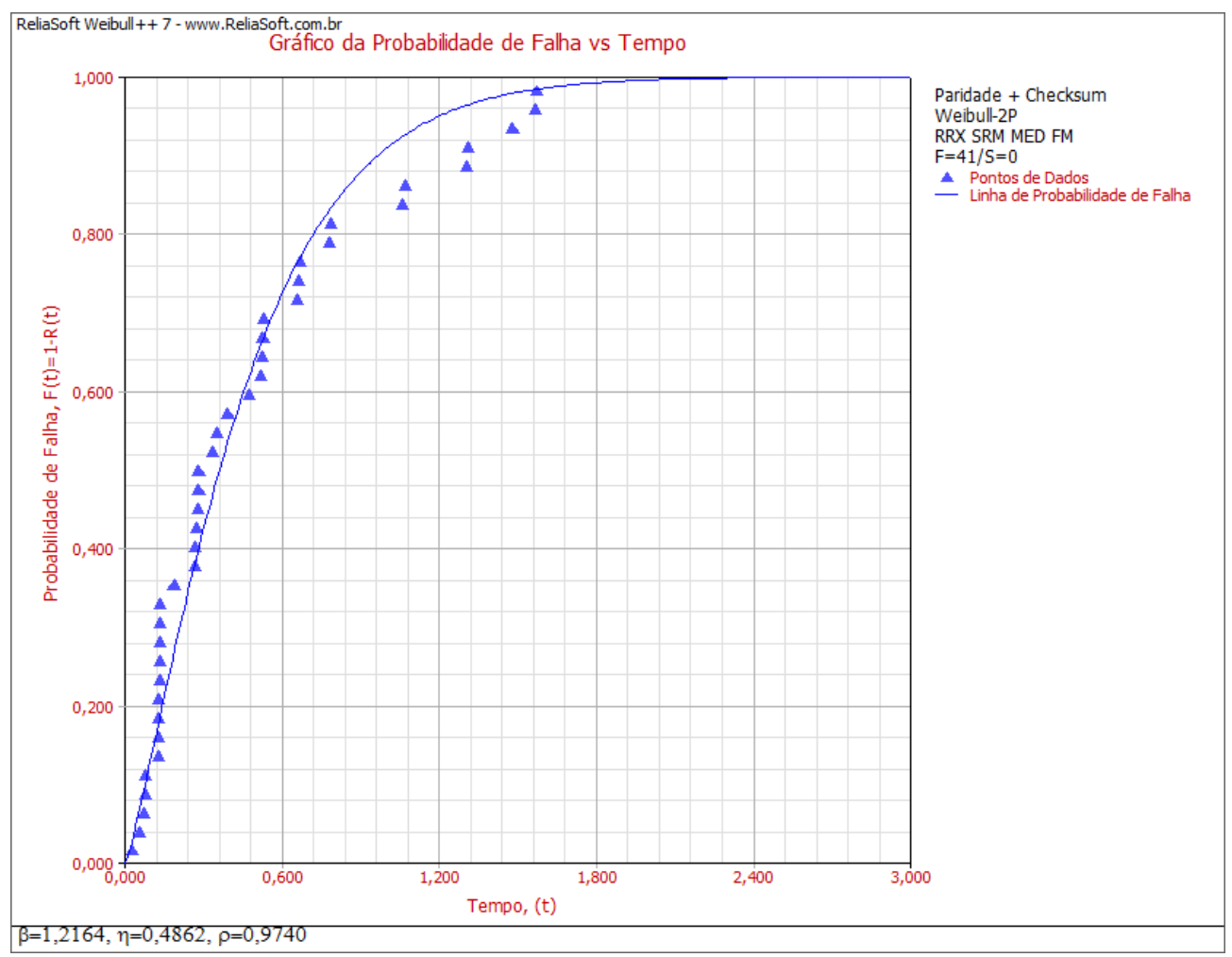

Figura 109 - Gráfico de probabilidade de falha insegura: Técnica paridade e checksum combinadas

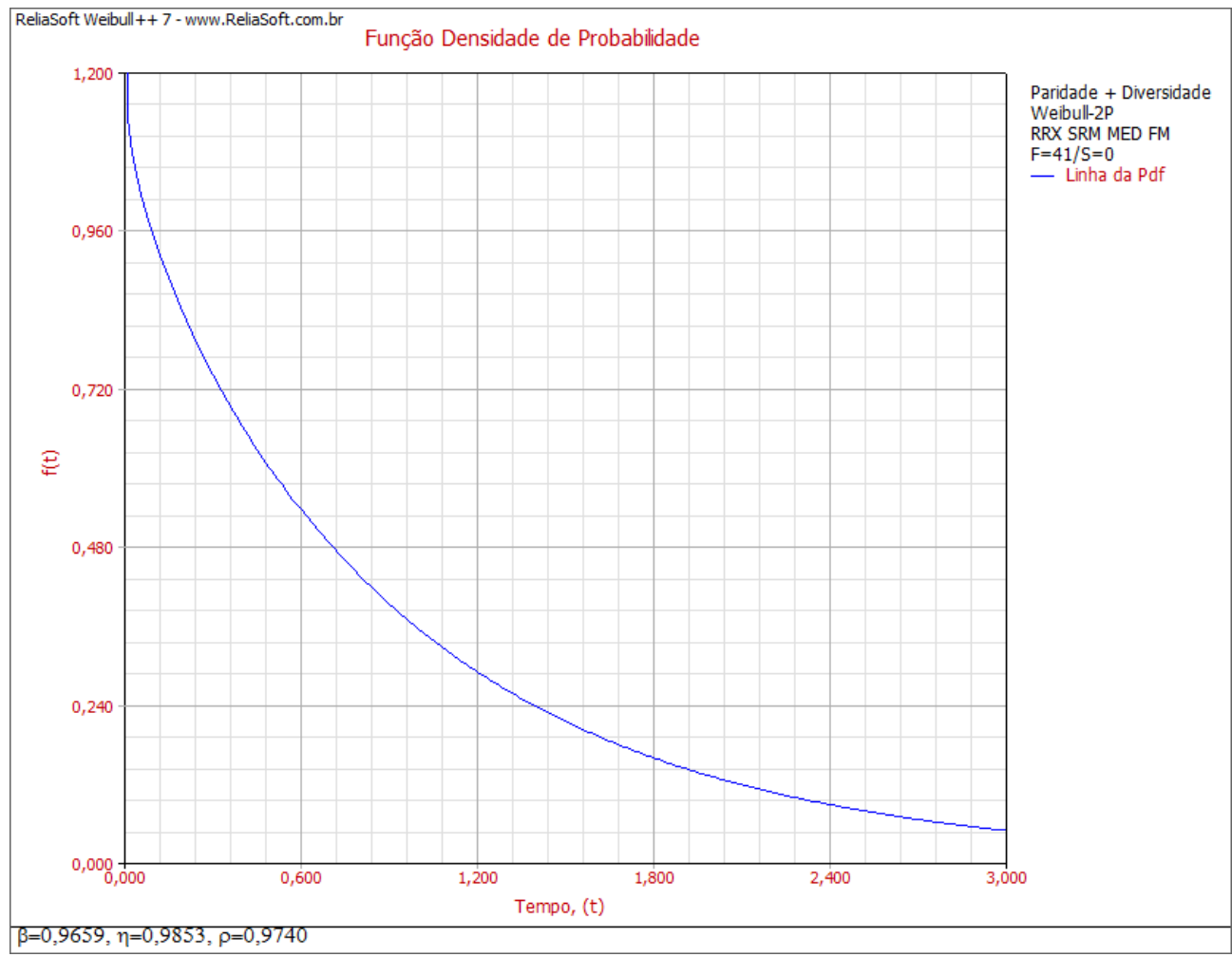

Figura 110 - Função de densidade de probabilidade para falhas inseguras: técnica de programação defensiva paridade e diversidade combinadas 


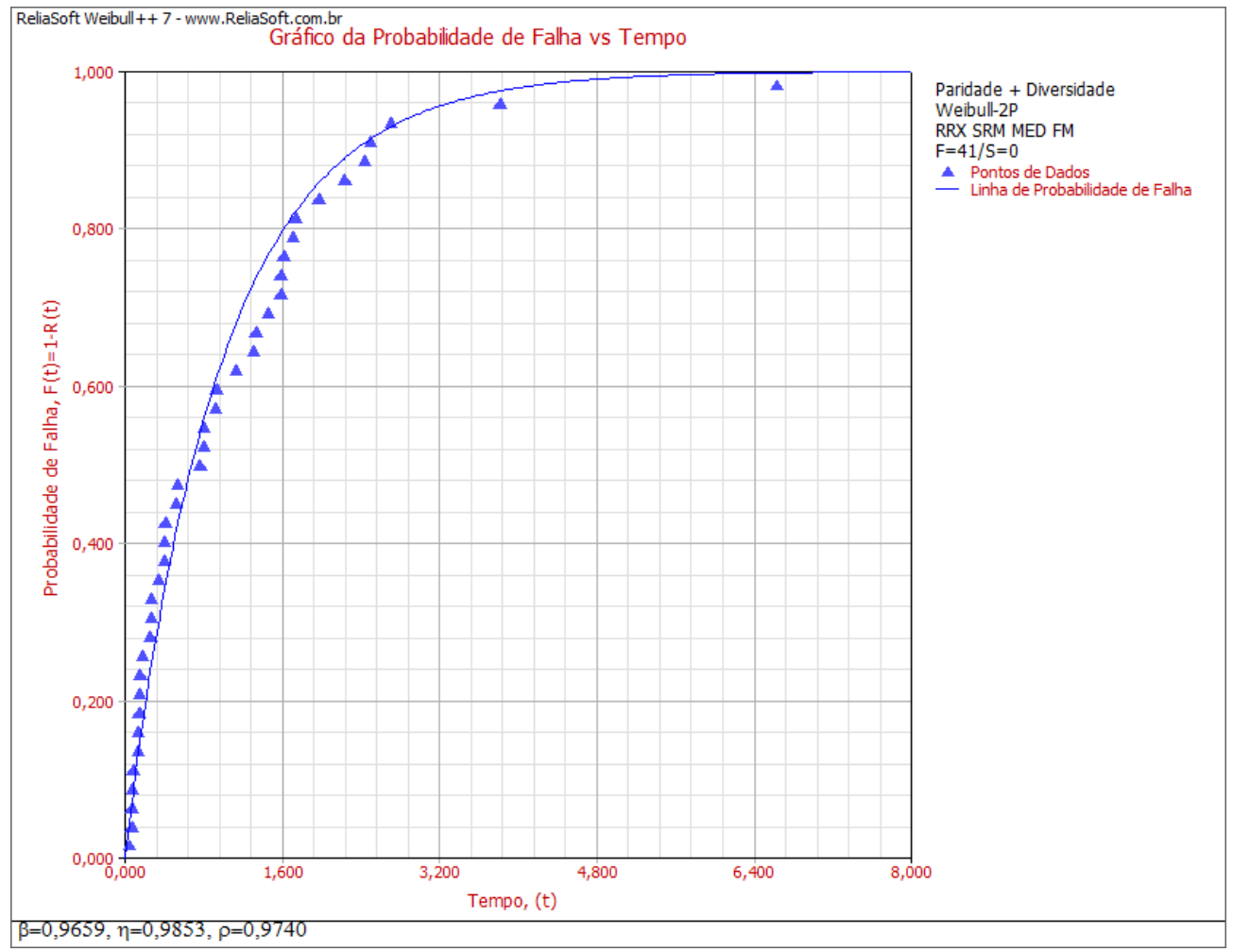

Figura 111 - Gráfico de probabilidade de falha insegura: Técnica paridade e diversidade combinadas

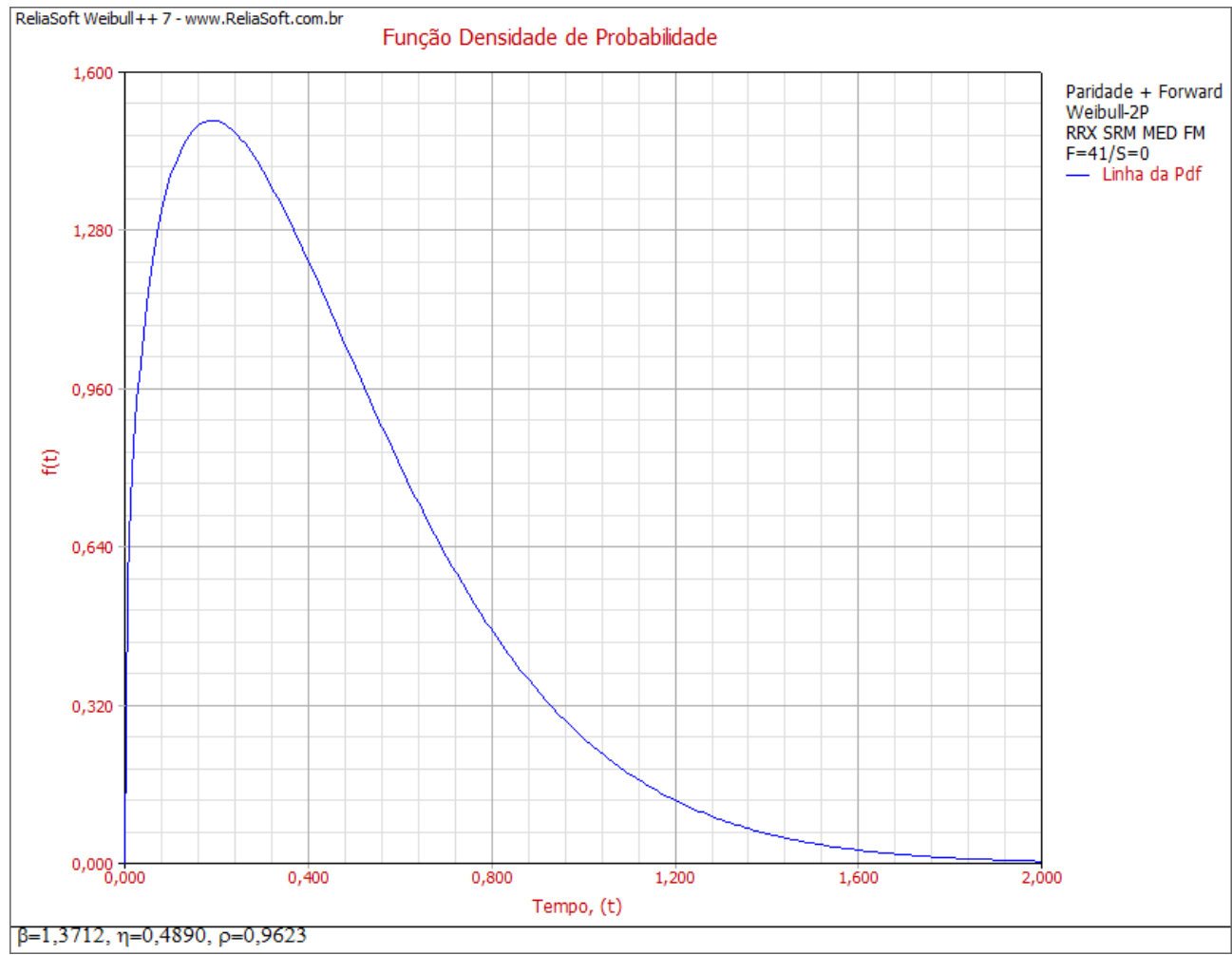

Figura 112 - Função de densidade de probabilidade para falhas inseguras: técnica de programação defensiva paridade e forward combinadas 


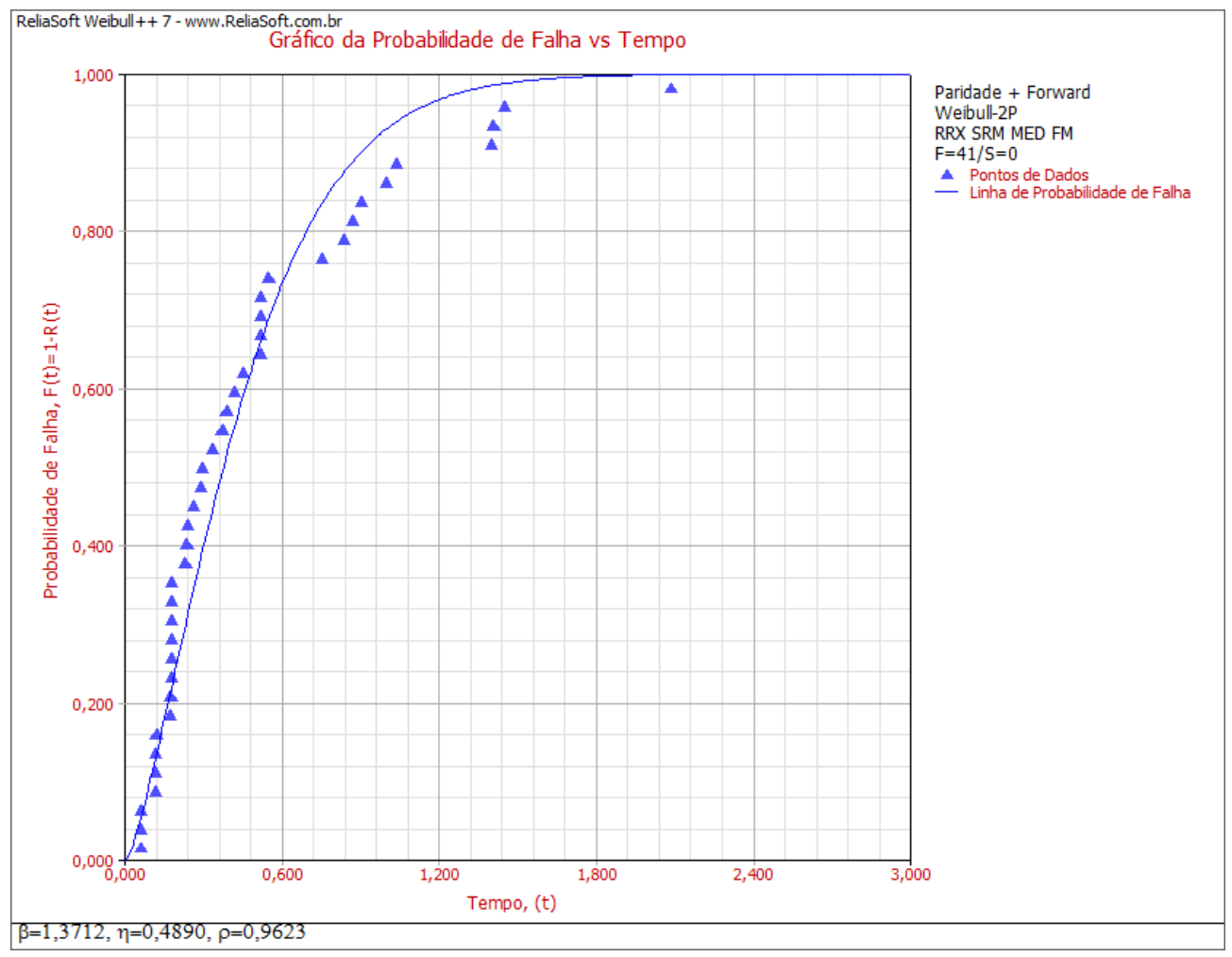

Figura 113 - Gráfico de probabilidade de falha insegura: Técnica paridade e forward combinadas

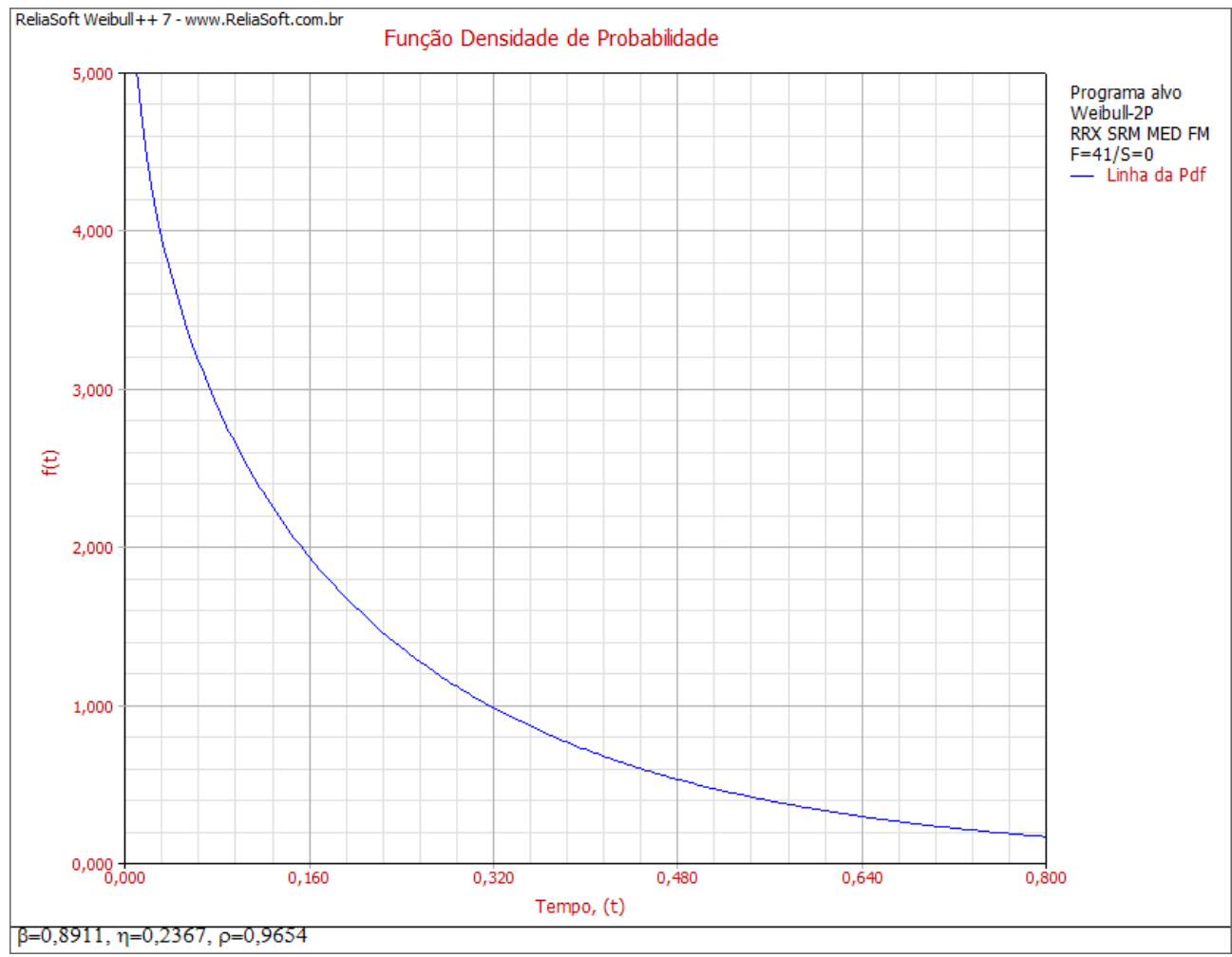

Figura 114 - Função de densidade de probabilidade para falhas inseguras : programa alvo (ausência de técnicas de programação defensiva) 


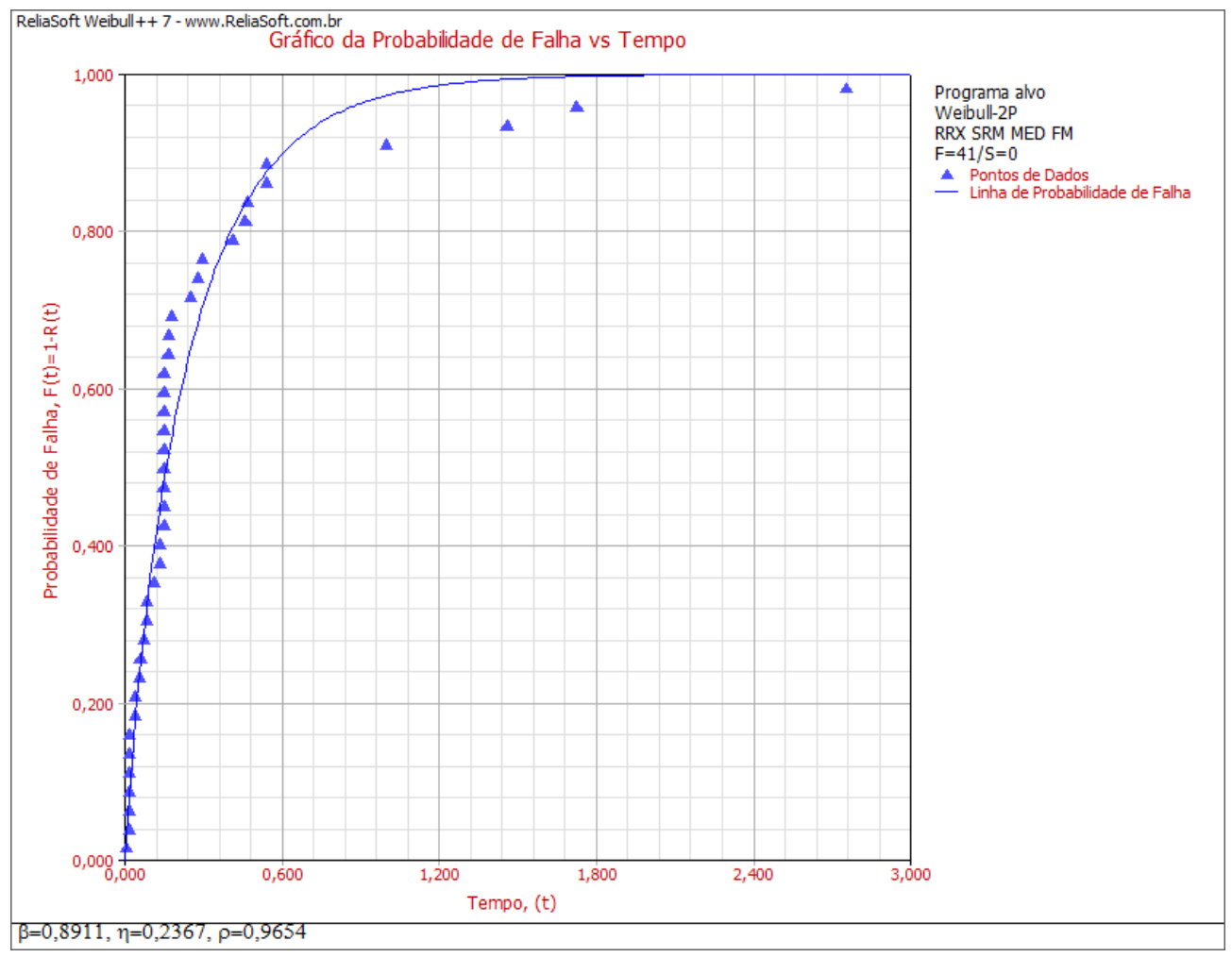

Figura 115 - Gráfico de probabilidade de falha insegura: programa alvo (ausência de técnicas de programação defensiva) 


\section{APÊNDICE B}

Nas figuras a seguir são descritas as combinações de técnicas de programação defensiva mencionadas no tópico 5.1

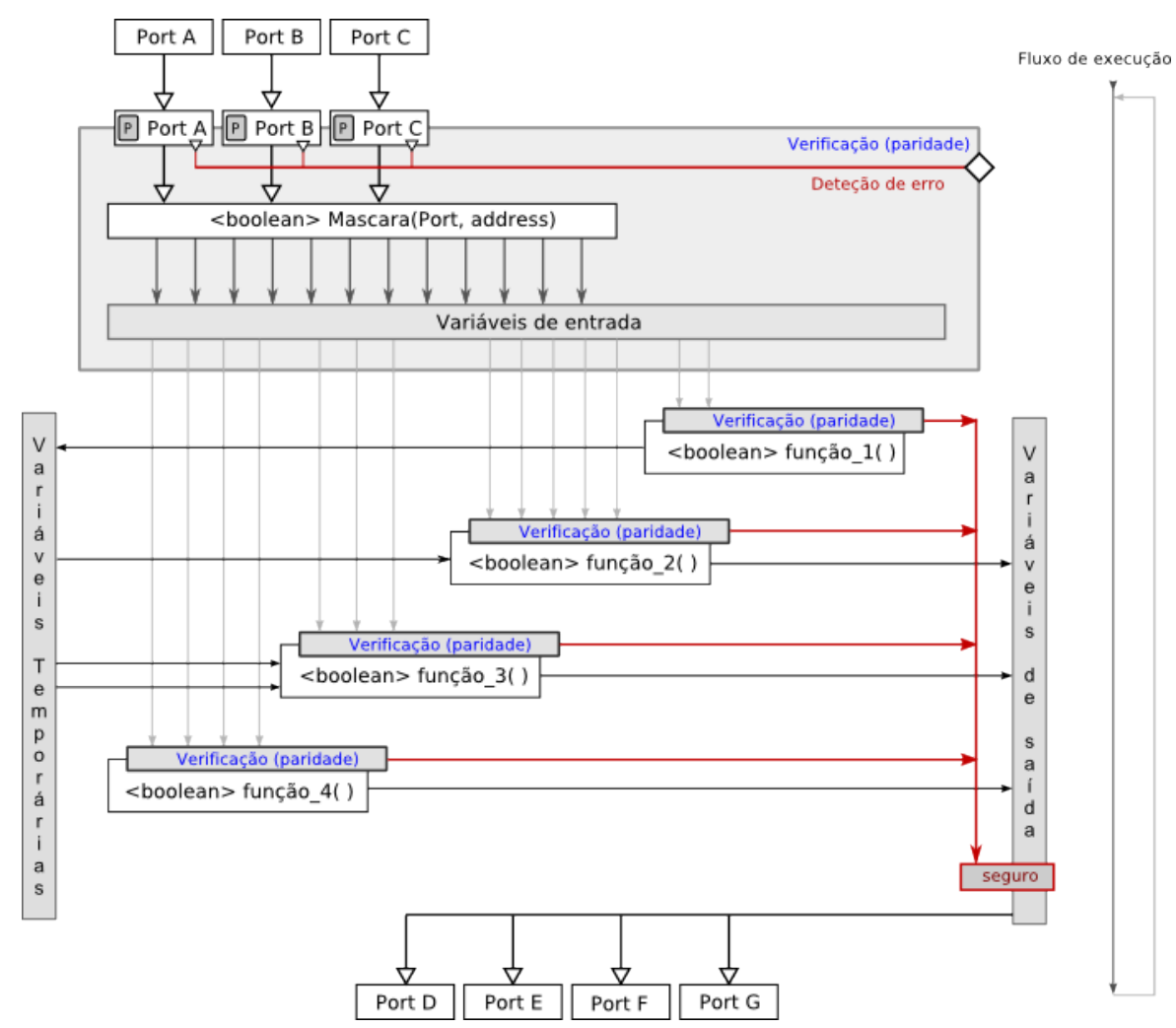

Figura 116 - Aplicação das técnicas forward recovery e paridade combinadas 


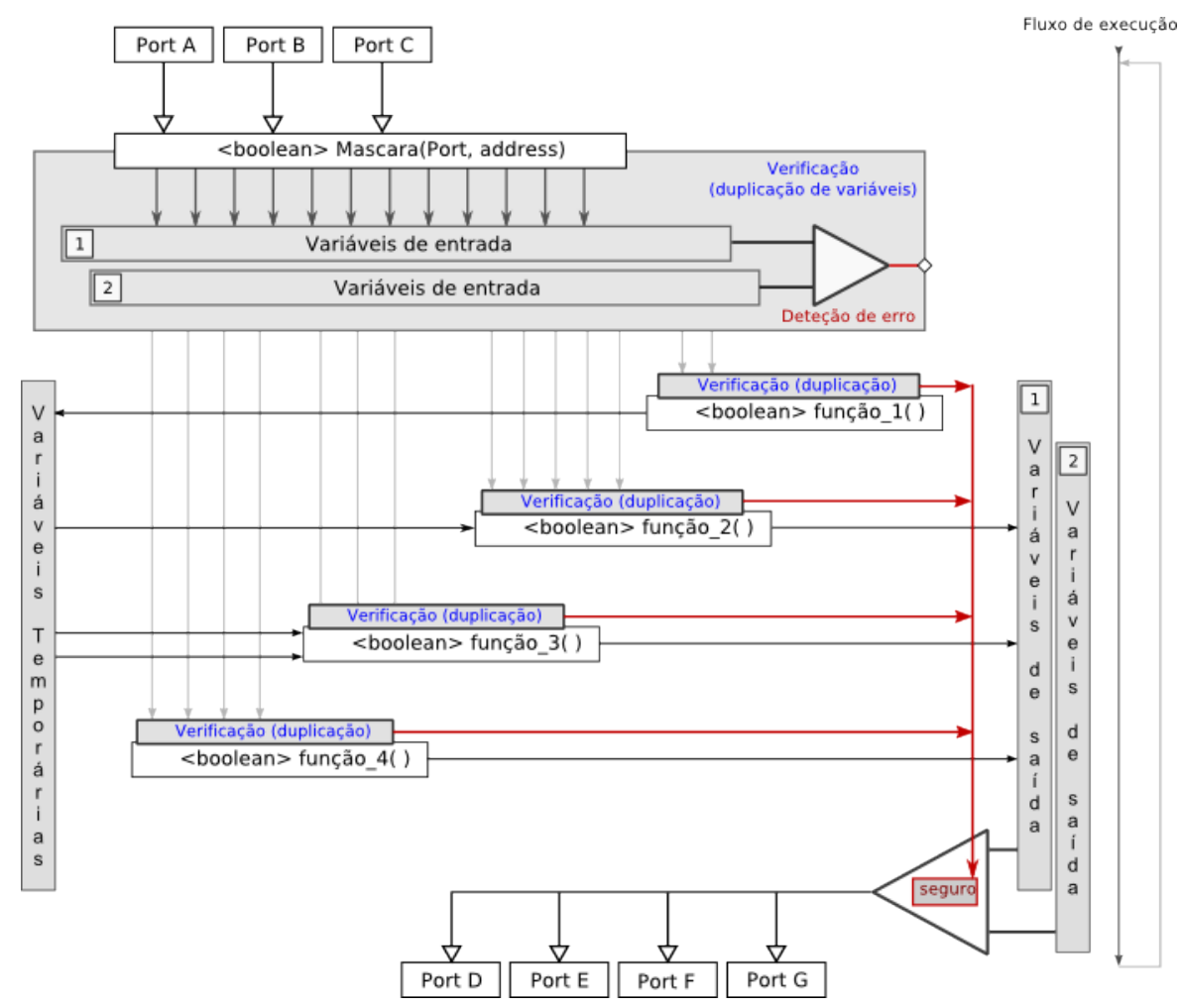

Figura 117 - Aplicação das técnicas forward recovery e duplicação de variáveis combinadas

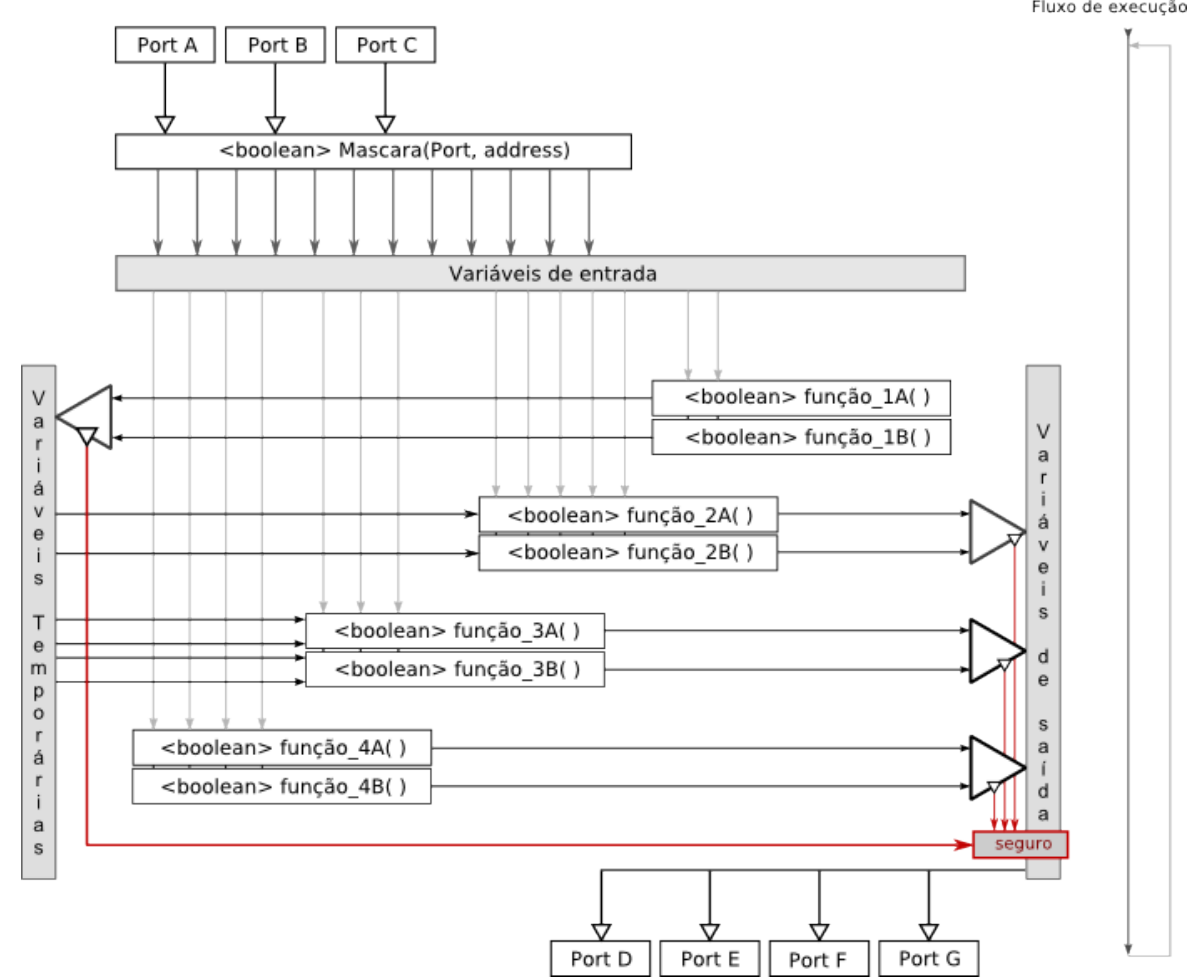

Figura 118 - Aplicação das técnicas forward recovery e diversidade combinadas 


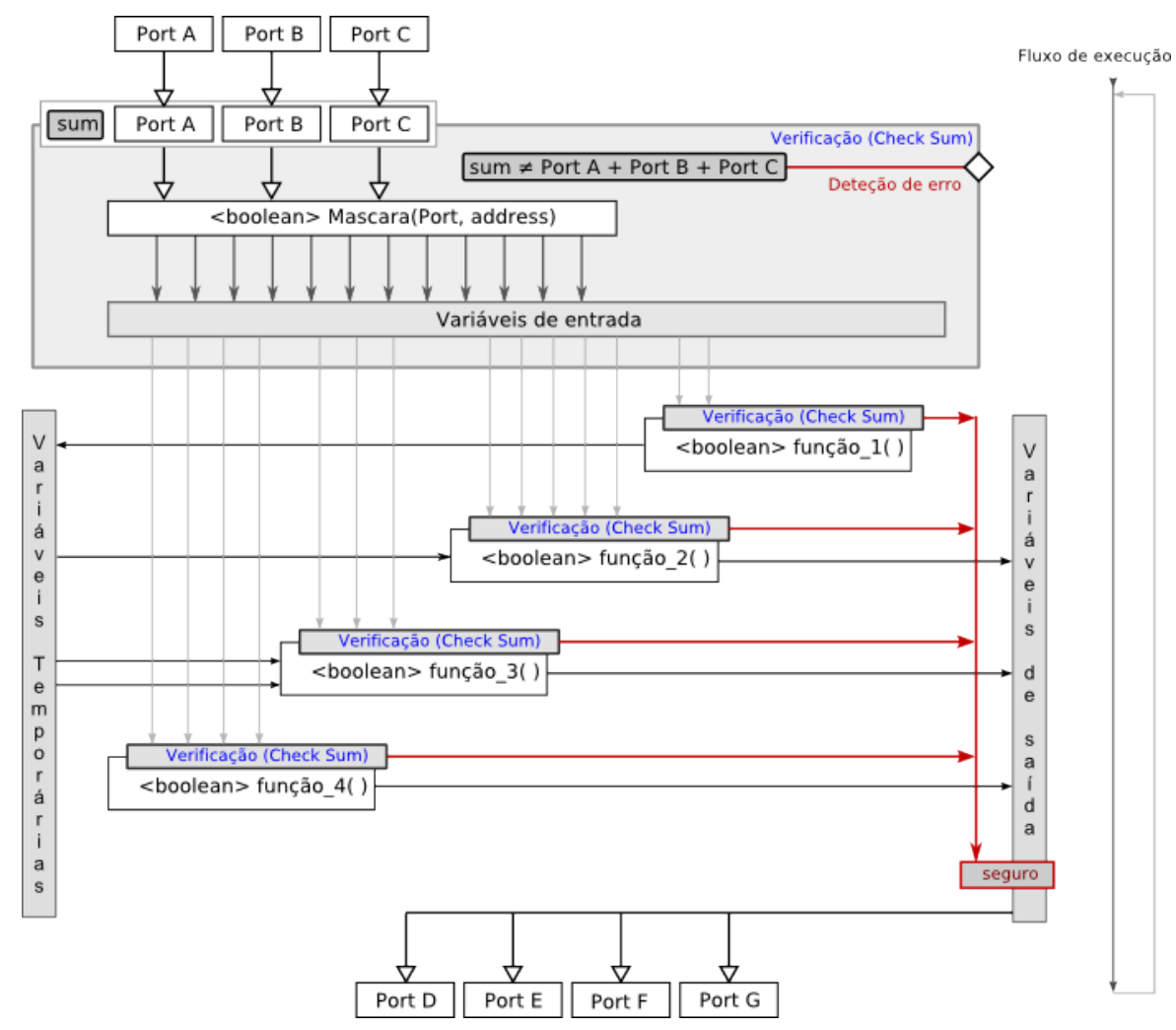

Figura 119 - Aplicação das técnicas forward recovery e checksum combinadas 


\section{APÊNDICE C}

Nas tabelas seguintes estão os valores tempo para falha insegura, obtidas a partir da simulação desenvolvida no estudo apresentado.

\begin{tabular}{|c|c|c|c|}
\hline Programa alvo & Paridade & Checksum & Diversidade \\
\hline 0,03644900 & 0,04331375 & 0,03250425 & 0,03611750 \\
\hline 0,16370300 & 1,32385975 & 0,13332600 & 0,01548175 \\
\hline 0,14689200 & 0,27138525 & 1,58677050 & 0,01547875 \\
\hline 1,45767075 & 1,83239575 & 0,53824500 & 0,26200775 \\
\hline 0,17611975 & 0,52608275 & 0,41250075 & 0,98240750 \\
\hline 0,14715350 & 0,52634275 & 0,01374025 & 0,13149750 \\
\hline 0,13083125 & 0,39201225 & 1,19256050 & 0,31118025 \\
\hline 0,54032800 & 1,05862700 & 1,19256050 & 0,01546675 \\
\hline 0,01620025 & 0,14135750 & 0,01374625 & 0,40889650 \\
\hline 0,14690825 & 0,13554900 & 0,27525525 & 0,01546525 \\
\hline 1,72415675 & 2,10174025 & 1,19214925 & 0,36814825 \\
\hline 0,06916650 & 0,00106725 & 0,03246925 & 0,03610550 \\
\hline 0,14694925 & 1,20473975 & 0,01375525 & 0,01547875 \\
\hline 0,14697050 & 0,02093375 & 1,71673925 & 0,82213675 \\
\hline 0,24970325 & 0,27610750 & 0,66988600 & 0,67108450 \\
\hline 0,01620950 & 0,02094225 & 0,01372975 & 0,13153325 \\
\hline 0,13121700 & 0,39200200 & 0,17970325 & 0,22412375 \\
\hline 0,40912375 & 0,66064925 & 0,14626550 & 0,01546675 \\
\hline 0,29482875 & 0,13706250 & 0,40792275 & 0,01546075 \\
\hline 0,46645975 & 1,38928925 & 1,58595950 & 1,32637825 \\
\hline 0,14695325 & 1,45818250 & 0,27536650 & 0,12239925 \\
\hline 0,99494725 & 0,40280725 & 0,78897575 & 0,78608925 \\
\hline 0,00430675 & 0,69069700 & 0,06769050 & 0,16715450 \\
\hline 0,01632550 & 2,11009175 & 0,33261575 & 0,01631150 \\
\hline 0,01631800 & 1,04512300 & 1,06263975 & 0,14650225 \\
\hline 0,14699150 & 0,12937850 & 0,01421650 & 0,27833125 \\
\hline 0,08181400 & 3,67594450 & 0,93216925 & 0,65589500 \\
\hline 0,08181400 & 0,65487375 & 0,53941100 & 0,14684275 \\
\hline 2,75238850 & 0,79712375 & 0,01422250 & 0,54014225 \\
\hline 0,14696225 & 0,52303000 & 0,53650575 & 0,14683050 \\
\hline 0,05265800 & 2,22502925 & 1,19351950 & 0,40873950 \\
\hline 0,27808375 & 0,78121650 & 0,14565425 & 0,14664125 \\
\hline 0,01585025 & 0,26281750 & 0,01456075 & 0,39672750 \\
\hline 0,03654275 & 0,39201125 & 0,13138400 & 0,00370375 \\
\hline 0,01586700 & 1,04549600 & 0,91852400 & 0,40936950 \\
\hline 0,11055025 & 0,74379100 & 1,01490200 & 0,13115000 \\
\hline 0,45854650 & 1,69941950 & 0,80112650 & 0,78599375 \\
\hline 0,05712050 & 0,65557425 & 0,14384500 & 0,01585025 \\
\hline 0,14691825 & 0,26326675 & 0,40783550 & 0,40915875 \\
\hline 0,54036225 & 0,02499250 & 0,94562400 & 0,01584875 \\
\hline 0,16747575 & 0,13789025 & 0,09841200 & 0,03588500 \\
\hline
\end{tabular}

Tabela 4 - Valores de tempo para falha insegura do programa alvo e das técnicas de programação defensiva: paridade, checksum e diversidade 


\begin{tabular}{|c|c|c|c|}
\hline $\begin{array}{l}\text { Duplicação } \\
\text { TUF (seg) }\end{array}$ & $\begin{array}{c}\text { Backward + Forward } \\
\text { TUF (seg) }\end{array}$ & $\begin{array}{c}\text { Checksum + Backward } \\
\text { TUF (seg) }\end{array}$ & $\begin{array}{c}\text { Diversidade + Backward } \\
\text { TUF (seg) }\end{array}$ \\
\hline 1,41029150 & 1,74454650 & 1,04825925 & 0,06882000 \\
\hline 1,59095650 & 1,73661400 & 0,14432075 & 0,40882550 \\
\hline 11,41970850 & 3,20538550 & 0,01408300 & 0,23702450 \\
\hline 6,56920250 & 3,22270600 & 1,06487600 & 0,53962525 \\
\hline 4,34072450 & 2,46391125 & 0,01408900 & 0,62643100 \\
\hline 2,11353225 & 0,72893500 & 0,13403475 & 0,08128450 \\
\hline 1,06494750 & 0,03705225 & 1,45572075 & 0,76990975 \\
\hline 0,26411425 & 1,75460100 & 0,40824700 & 0,01551350 \\
\hline 0,27824675 & 6,36913775 & 0,14430600 & 0,02236725 \\
\hline 4,08095800 & 2,49187975 & 0,14429400 & 1,08786450 \\
\hline 3,17028275 & 0,01799900 & 0,53775775 & 0,03585875 \\
\hline 3,09679400 & 0,42151725 & 0,13208300 & 0,03620750 \\
\hline 1,71733800 & 1,78979925 & 1,71834550 & 0,01552550 \\
\hline 0,49252600 & 8,36573675 & 0,51544975 & 0,08083550 \\
\hline 5,78424000 & 0,12459450 & 0,40924050 & 0,67111800 \\
\hline 0,97176050 & 0,40387100 & 0,13401725 & 0,52437600 \\
\hline 0,24676775 & 0,74991525 & 1,19287100 & 0,06459600 \\
\hline 0,26232100 & 6,06568025 & 0,14416100 & 0,01551350 \\
\hline 15,26209400 & 1,58683800 & 0,14416250 & 0,02237125 \\
\hline 8,42240000 & 8,60720925 & 0,07029575 & 1,09663300 \\
\hline 3,40677525 & 0,69001200 & 1,33580175 & 0,80228075 \\
\hline 1,17919700 & 2,39361275 & 0,39343750 & 0,43305600 \\
\hline 1,05281900 & 0,32386175 & 0,59321525 & 0,10152250 \\
\hline 1,98230975 & 0,50557375 & 1,04590500 & 0,54017825 \\
\hline 0,99123100 & 2,49010750 & 1,24583375 & 0,14728050 \\
\hline 6,55206950 & 2,29125825 & 0,27669750 & 0,52522375 \\
\hline 0,93373675 & 0,44228550 & 1,18029575 & 0,84727625 \\
\hline 0,84260300 & 3,04930775 & 0,27599425 & 1,04020075 \\
\hline 1,24541275 & 0,17806525 & 0,66936875 & 0,02636400 \\
\hline 3,72952350 & 4,00742650 & 0,27598550 & 0,53984650 \\
\hline 13,36854950 & 1,75525375 & 0,27502475 & 1,85057625 \\
\hline 0,61119400 & 5,10949350 & 0,22172925 & 0,93310525 \\
\hline 13,23631200 & 2,23202575 & 0,14396325 & 0,40911725 \\
\hline 0,03371700 & 1,84030000 & 0,16793075 & 0,72102375 \\
\hline 0,65451725 & 2,45524200 & 0,40654600 & 1,83483825 \\
\hline 4,73302550 & 0,30082275 & 0,13404125 & 0,01590325 \\
\hline 2,49074400 & 2,96057800 & 1,18428375 & 0,51562025 \\
\hline 0,26355450 & 0,28234900 & 0,14438725 & 0,01528725 \\
\hline 7,73213725 & 2,14798525 & 0,40907150 & 0,01563350 \\
\hline 5,63408075 & 2,59916975 & 0,16755075 & 1,12126575 \\
\hline 1,34668425 & 3,72905800 & 0,00333575 & 0,20045675 \\
\hline
\end{tabular}

Tabela 5 - Valores de tempo para falha insegura das técnicas de programação defensiva: duplicação de variáveis, backward e forward, checksum e backward, diversidade e backward 


\begin{tabular}{|c|c|c|c|}
\hline $\begin{array}{c}\text { Diversidade + Checksum } \\
\text { TUF (seg) }\end{array}$ & $\begin{array}{c}\text { Paridade + Backward } \\
\text { TUF (seg) }\end{array}$ & $\begin{array}{c}\text { Paridade + Checksum } \\
\text { TUF (seg) }\end{array}$ & $\begin{array}{c}\text { Paridade + diversidade } \\
\text { TUF (seg) }\end{array}$ \\
\hline 0,29619875 & 0,73931150 & 0,07585925 & 0,06515600 \\
\hline 0,13274700 & 0,02094750 & 0,39162525 & 3,81270175 \\
\hline 0,144466625 & 0,52852300 & 0,33476500 & 2,69964375 \\
\hline 0,24149825 & 1,43802400 & 0,13205850 & 1,44987500 \\
\hline 0,01600500 & 0,44704750 & 0,27096025 & 0,39554925 \\
\hline 0,01596600 & 0,94383075 & 0,66391100 & 0,40698750 \\
\hline 0,18011675 & 0,65557925 & 0,27926500 & 0,51631175 \\
\hline 0,01597050 & 1,83500325 & 0,78421375 & 0,92226975 \\
\hline 0,14412750 & 0,27106300 & 0,12522375 & 0,15165900 \\
\hline 0,14412450 & 0,80275375 & 0,12521200 & 0,14499325 \\
\hline 1,32324150 & 1,31791325 & 1,30787825 & 6,62913275 \\
\hline 0,10109425 & 0,10545750 & 0,07587325 & 0,06512850 \\
\hline 0,14414225 & 0,96675750 & 0,65605275 & 1,12301075 \\
\hline 1,30973000 & 0,08199550 & 0,13207350 & 0,04165675 \\
\hline 0,65564175 & 0,45841400 & 0,02642300 & 0,26665825 \\
\hline 0,01596600 & 0,14097650 & 0,27667100 & 0,79445075 \\
\hline 1,06290825 & 0,26908750 & 0,27923750 & 0,17354500 \\
\hline 0,14491700 & 1,31105800 & 0,52402750 & 0,92645450 \\
\hline 0,14432550 & 0,27189475 & 0,12520675 & 2,43452725 \\
\hline 1,58681625 & 1,57904950 & 0,12519600 & 1,58157900 \\
\hline 0,27593500 & 0,12671825 & 0,78090950 & 1,61177300 \\
\hline 0,78617650 & 0,20087475 & 0,26661225 & 0,52859425 \\
\hline 0,10203150 & 0,29528150 & 0,18564475 & 0,34125150 \\
\hline 0,66821400 & 0,07371475 & 0,13171975 & 1,72909925 \\
\hline 0,01257225 & 0,42191400 & 0,52696800 & 0,79793175 \\
\hline 0,01253325 & 0,26637025 & 1,07011600 & 0,40203150 \\
\hline 1,06189375 & 0,47529175 & 1,56528375 & 2,49385175 \\
\hline 0,01253775 & 0,04515175 & 0,52515850 & 1,30499700 \\
\hline 0,01254825 & 0,39487475 & 0,66623450 & 0,26231725 \\
\hline 0,14629175 & 0,69206475 & 1,47894100 & 0,13453600 \\
\hline 1,19214075 & 0,42919875 & 1,30516225 & 2,23250975 \\
\hline 0,14603975 & 0,27101000 & 0,26582725 & 1,96724725 \\
\hline 0,01289850 & 0,13015600 & 0,13292000 & 0,13345375 \\
\hline 0,16427575 & 0,03246450 & 0,05435975 & 0,07910375 \\
\hline 0,01291200 & 0,04010450 & 0,47414550 & 1,58146175 \\
\hline 0,91769500 & 0,22631725 & 0,35084325 & 1,32781200 \\
\hline 1,15301925 & 0,11792575 & 1,57039300 & 0,76163600 \\
\hline 0,14603075 & 0,65433000 & 0,51821175 & 1,70758825 \\
\hline 0,01288800 & 0,03162150 & 1,05926425 & 0,25451675 \\
\hline 0,01288350 & 0,31443525 & 0,13290350 & 0,13915900 \\
\hline 0,00381275 & 0,13142725 & 0,07263275 & 0,07452925 \\
\hline
\end{tabular}

Tabela 6 - Valores de tempo para falha insegura das técnicas de programação defensiva: diversidade e checksum, paridade e backward, paridade e checksum, paridade e diversidade 


\begin{tabular}{|c|c|c|c|}
\hline $\begin{array}{c}\text { Duplicação + Backward } \\
\text { TUF (seg) }\end{array}$ & $\begin{array}{c}\text { Duplicação + Cheksum } \\
\text { TUF (seg) }\end{array}$ & $\begin{array}{c}\text { Duplicação + Diversidade } \\
\text { TUF (seg) }\end{array}$ & $\begin{array}{c}\text { Duplicação + Paridade } \\
\text { TUF (seg) }\end{array}$ \\
\hline 0,02563950 & 0,06369725 & 3,11518675 & 0,22221050 \\
\hline 2,24543550 & 10,15933525 & 5,01575175 & 11,01647475 \\
\hline 0,82226375 & 9,45373400 & 10,63326600 & 25,89196000 \\
\hline 3,94833250 & 5,37644575 & 5,78297475 & 5,76428400 \\
\hline 0,11191075 & 1,28874425 & 3,55385450 & 3,74571450 \\
\hline 1,84831150 & 1,66927325 & 1,32771025 & 1,60873625 \\
\hline 1,92301425 & 6,02819600 & 1,42515725 & 0,85570550 \\
\hline 1,45648800 & 0,81382875 & 11,16626225 & 4,46539425 \\
\hline 0,01581150 & 4,60288800 & 9,58682650 & 2,40607750 \\
\hline 0,01603225 & 2,90081725 & 7,50642050 & 1,32202300 \\
\hline 1,19301675 & 4,32581850 & 12,58408700 & 0,53829925 \\
\hline 0,56029475 & 0,30349275 & 3,21386650 & 2,76568900 \\
\hline 0,27567900 & 17,16693700 & 10,61904125 & 26,88582725 \\
\hline 0,32870300 & 1,45450850 & 6,80253700 & 5,77606375 \\
\hline 4,66297850 & 2,35446050 & 1,06217900 & 3,67292900 \\
\hline 4,17796575 & 2,35446050 & 0,34532800 & 1,59043525 \\
\hline 2,76624150 & 0,53714475 & 1,70555675 & 0,65321475 \\
\hline 1,31080050 & 3,69487475 & 1,38571175 & 3,97785200 \\
\hline 0,01581150 & 6,45569275 & 20,18258650 & 5,23553575 \\
\hline 0,40676625 & 2,71314250 & 3,65489725 & 0,80468600 \\
\hline 2,89758150 & 2,22691575 & 3,40737825 & 15,08718575 \\
\hline 1,45704625 & 11,54817175 & 1,17660600 & 12,98906275 \\
\hline 0,00311600 & 0,36058000 & 0,69102800 & 2,73947575 \\
\hline 0,67165700 & 3,12537325 & 0,57332375 & 8,95727125 \\
\hline 6,43728225 & 1,02407125 & 6,68621550 & 6,89697000 \\
\hline 4,73280325 & 3,68519300 & 3,04407650 & 3,79373475 \\
\hline 0,97025625 & 1,70504175 & 1,19595850 & 1,69574950 \\
\hline 1,85029950 & 0,80819300 & 1,76146300 & 0,55389575 \\
\hline 0,40707375 & 4,19083000 & 9,58321150 & 16,64193050 \\
\hline 1,06218225 & 1,11071750 & 7,50277550 & 15,34289425 \\
\hline 1,84820900 & 0,70857600 & 1,42580675 & 13,79990850 \\
\hline 1,72002025 & 2,60502325 & 12,84484925 & 11,67026725 \\
\hline 0,27745825 & 4,20670575 & 0,26618250 & 9,56861650 \\
\hline 0,16524350 & 0,62259500 & 2,09893900 & 1,72785650 \\
\hline 1,44772100 & 0,14340575 & 1,09354750 & 5,77190950 \\
\hline 1,34046500 & 2,34213625 & 3,93449875 & 2,89192675 \\
\hline 2,76589550 & 1,05092175 & 1,70351975 & 0,95227550 \\
\hline 1,32503275 & 3,04738950 & 6,14439875 & 16,92294275 \\
\hline 0,01334950 & 1,73982100 & 3,35911900 & 15,15160825 \\
\hline 0,40674575 & 13,10754975 & 1,03259075 & 14,03788150 \\
\hline 1,38203600 & 0,75481100 & 1,41228350 & 1,18231425 \\
\hline
\end{tabular}

Tabela 7 - Valores de tempo para falha insegura das técnicas de programação defensiva: duplicação de variáveis e backward, duplicação de variáveis e checksum, duplicação de variáveis e diversidade, duplicação de variáveis e paridade 


\begin{tabular}{|c|c|c|c|}
\hline $\begin{array}{c}\text { Backward + BCH } \\
\text { TUF (seg) }\end{array}$ & $\begin{array}{c}\text { Checksum + BCH } \\
\text { TUF (seg) }\end{array}$ & $\begin{array}{c}\text { Diversidade + BCH } \\
\text { TUF (seg) }\end{array}$ & $\begin{array}{c}\text { BCH + Forward } \\
\text { TUF (seg) }\end{array}$ \\
\hline 2,24477375 & 0,06719950 & 0,06673625 & 18,39593000 \\
\hline 1,81695025 & 2,59941850 & 4,81237450 & 1,04689300 \\
\hline 8,59195275 & 31,22268325 & 0,06602775 & 0,26068900 \\
\hline 0,04783325 & 3,35307925 & 1,67919450 & 3,66814375 \\
\hline 4,98867300 & 4,76860675 & 1,19515200 & 1,15097525 \\
\hline 2,91296225 & 61,22268325 & 8,79639550 & 64,98546425 \\
\hline 4,03727825 & 20,28979125 & 17,62421825 & 0,29276450 \\
\hline 9,12158250 & 5,18141975 & 2,01904950 & 6,62664650 \\
\hline 4,06988350 & 0,00005375 & 1,88226900 & 1,07540125 \\
\hline 0,01801975 & 11,44684775 & 0,76425775 & 12,53590375 \\
\hline 6,45120200 & 1,19279550 & 1,32382150 & 7,99794175 \\
\hline 0,55971100 & 1,01173075 & 2,30687750 & 2,71467950 \\
\hline 1,02774625 & 4,05914900 & 0,25373275 & 23,56936425 \\
\hline 13,12182675 & 2,38797725 & 3,44491425 & 2,72282750 \\
\hline 8,65502950 & 4,64896750 & 2,16918850 & 6,76078550 \\
\hline 0,33445375 & 4,64896750 & 4,30092550 & 44,54231725 \\
\hline 4,15156225 & 222,98347550 & 0,96835150 & 3,46337500 \\
\hline 6,02955475 & 89,30017025 & 0,85419450 & 16,84902400 \\
\hline 0,66333625 & 0,00005375 & 5,80069975 & 45,89056300 \\
\hline 0,05415800 & 9,17096025 & 19,49833025 & 0,12075025 \\
\hline 0,84621125 & 1,44070425 & 0,27468000 & 1,15323100 \\
\hline 0,38914875 & 15,35234850 & 1,88425775 & 5,32879925 \\
\hline 5,70383150 & 0,00005525 & 8,93349950 & 0,00667850 \\
\hline 6,93754525 & 57,90444650 & 1,76935275 & 4,90277625 \\
\hline 1,21079225 & 123,48625925 & 1,64259625 & 0,76000050 \\
\hline 0,82769125 & 3,94908450 & 1,85953300 & 0,69445825 \\
\hline 0,31506925 & 2,26153075 & 1,54429575 & 0,59613825 \\
\hline 0,82769300 & 0,94549025 & 1,75329725 & 0,53059375 \\
\hline 0,06179950 & 0,00005525 & 0,47535375 & 0,46504100 \\
\hline 0,03141425 & 57,52440950 & 0,05280225 & 5,29603175 \\
\hline 4,86411075 & 0,56577600 & 1,32219575 & 1,60315175 \\
\hline 0,51230475 & 0,47976175 & 1,18794075 & 8,23713725 \\
\hline 0,17083600 & 0,38971425 & 1,04316275 & 0,31528900 \\
\hline 0,75542725 & 0,97953200 & 3,24456325 & 3,02403225 \\
\hline 6,60304750 & 3,23227350 & 3,02969825 & 1,26345600 \\
\hline 1,44845375 & 0,75016225 & 0,81929750 & 2,46159500 \\
\hline 3,61145375 & 6,29552800 & 0,56747725 & 12,19973225 \\
\hline 0,49975475 & 1,18236700 & 6,46356200 & 1,12013200 \\
\hline 1,72667100 & 0,27479000 & 1,56893300 & 0,97265825 \\
\hline 0,95170725 & 34,83651725 & 2,00152725 & 0,77813175 \\
\hline 1,77040550 & 8,89662925 & 3,67944900 & 3,19412050 \\
\hline
\end{tabular}

Tabela 8 - Valores de tempo para falha insegura das técnicas de programação defensiva: backward e $\mathrm{BCH}$, checksum e $\mathrm{BCH}$, diversidade e $\mathrm{BCH}$, forward e $\mathrm{BCH}$ 


\begin{tabular}{|c|c|c|c|}
\hline $\begin{array}{l}\text { Paridade + BCH } \\
\text { TUF (seg) }\end{array}$ & $\begin{array}{c}\text { Duplicação + BCH } \\
\text { TUF (seg) }\end{array}$ & $\begin{array}{l}\text { Backward } \\
\text { TUF (seg) }\end{array}$ & $\begin{array}{c}\text { BCH } \\
\text { TUF (seg) }\end{array}$ \\
\hline 0,07041450 & 0,26714875 & 3,29176400 & 0,01188300 \\
\hline 53,90102325 & 2,57070400 & 2,37523625 & 9,77130850 \\
\hline 29,81520525 & 1,42875150 & 0,30708375 & 1,03622800 \\
\hline 36,74461650 & 0,12286325 & 0,67014325 & 6,49036275 \\
\hline 81,18872775 & 0,44980850 & 0,53982850 & 4,47660400 \\
\hline 27,41800075 & 0,02465650 & 0,67014675 & 1,03622950 \\
\hline 62,05913375 & 0,64267025 & 0,01489600 & 3,00216425 \\
\hline 2,57295950 & 6,81388300 & 5,78183525 & 10,26330325 \\
\hline 69,98728675 & 0,55408550 & 1,46868425 & 7,57352675 \\
\hline 78,72663875 & 1,16172375 & 1,74030450 & 1,94819500 \\
\hline 0,55064100 & 0,53769500 & 2,52275900 & 1,58415500 \\
\hline 2,34029850 & 13,33602800 & 1,29665475 & 0,03019875 \\
\hline 23,37761325 & 4,12929550 & 1,34496000 & 0,66875475 \\
\hline 3,57246775 & 2,93326525 & 0,22473900 & 0,02964500 \\
\hline 17,60369125 & 9,96199975 & 0,86006650 & 4,77573950 \\
\hline 39,91069925 & 4,32465525 & 0,14675500 & 2,04765875 \\
\hline 11,70224775 & 3,49441825 & 0,44213500 & 0,31369025 \\
\hline 0,98444200 & 0,60673275 & 4,09996050 & 2,15415650 \\
\hline 5,94389775 & 7,08432425 & 0,56101725 & 2,03577850 \\
\hline 19,66138125 & 2,87952400 & 2,06015775 & 2,04765625 \\
\hline 1,57799375 & 111,16471100 & 2,89954400 & 0,27532175 \\
\hline 21,97687200 & 9,44536725 & 3,68572175 & 0,69123650 \\
\hline 172,10178300 & 25,89006750 & 1,19427675 & 0,48323150 \\
\hline 3,71123350 & 4,02222800 & 0,27705150 & 4,20240300 \\
\hline 0,48211300 & 4,02222800 & 0,71502325 & 2,29388175 \\
\hline 10,44262350 & 4,02230150 & 8,01069050 & 2,31829300 \\
\hline 0,10732075 & 5,03040800 & 0,14601225 & 0,95427375 \\
\hline 174,67829625 & 1,85604175 & 0,01497950 & 1,35185850 \\
\hline 10,40672050 & 5,24749100 & 0,09012075 & 10,25203725 \\
\hline 7,98188850 & 5,16485100 & 0,05973550 & 0,89922300 \\
\hline 1,45118450 & 1,87030725 & 3,29200175 & 1,58385150 \\
\hline 0,20925850 & 3,47232800 & 2,35511350 & 0,16278125 \\
\hline 0,89739275 & 2,07546450 & 0,77377450 & 2,20980050 \\
\hline 0,79908300 & 0,52758400 & 0,67076425 & 1,96597650 \\
\hline 0,73357925 & 1,50788375 & 0,13112125 & 1,76534775 \\
\hline 3,81375050 & 0,65835625 & 0,14614775 & 3,53690225 \\
\hline 1,35617875 & 7,44899225 & 0,01499200 & 2,92336250 \\
\hline 146,92249375 & 8,72330175 & 0,15921275 & 2,81698050 \\
\hline 9,87581475 & 2,36800450 & 5,61525525 & 5,41482775 \\
\hline 1,15953650 & 1,50791150 & 2,24833700 & 0,88269425 \\
\hline 3,72840225 & 34,54977350 & 1,19436900 & 16,79161675 \\
\hline
\end{tabular}

Tabela 9 - Valores de tempo para falha insegura das técnicas de programação defensiva: paridade e $\mathrm{BCH}$, duplicação e $\mathrm{BCH}$, backward, $\mathrm{BCH}$ 


\begin{tabular}{|c|c|c|c|c|}
\hline $\begin{array}{c}\text { Checksum + Forward } \\
\text { TUF (seg) }\end{array}$ & $\begin{array}{c}\text { Diversidade + Forward } \\
\text { TUF (seg) }\end{array}$ & $\begin{array}{c}\text { Forward } \\
\text { TUF (seg) }\end{array}$ & $\begin{array}{c}\text { Paridade + Forward } \\
\text { TUF (seg) }\end{array}$ & $\begin{array}{c}\text { Duplicação + Forward } \\
\text { TUF (seg) }\end{array}$ \\
\hline 0,21338225 & 0,26265525 & 1,37017175 & 1,03631550 & 0,00104000 \\
\hline 0,11980200 & 0,17673450 & 28,75543075 & 0,51471225 & 1,17897150 \\
\hline 0,04603050 & 0,52908950 & 10,80727900 & 0,26220325 & 1,71940800 \\
\hline 0,01904675 & 0,56166500 & 0,51001075 & 1,39977175 & 3,94833550 \\
\hline 0,02498300 & 0,01614900 & 14,77228425 & 0,54782350 & 0,53984525 \\
\hline 0,02498175 & 0,13138100 & 27,82217350 & 1,40617975 & 0,14681900 \\
\hline 0,80168850 & 0,40916250 & 25,13925725 & 0,05827975 & 0,20006425 \\
\hline 0,39768075 & 0,27778300 & 54,16760975 & 0,22973425 & 2,24438350 \\
\hline 0,14638350 & 0,27778575 & 9,34098550 & 0,11489550 & 0,01640300 \\
\hline 0,01581875 & 0,27780050 & 16,21211375 & 0,17371825 & 0,99939575 \\
\hline 0,15625025 & 0,05327650 & 0,00410950 & 0,11484400 & 3,68668200 \\
\hline 0,11949300 & 0,14691350 & 0,00410950 & 0,05874000 & 0,00102350 \\
\hline 0,08666475 & 0,13588100 & 0,00410950 & 0,23504950 & 0,14707175 \\
\hline 0,00918125 & 0,53694850 & 0,00410950 & 2,08301325 & 1,10899375 \\
\hline 0,04200450 & 0,04526625 & 0,00410950 & 0,17701000 & 0,67087325 \\
\hline 0,01571250 & 0,13103800 & 0,00410950 & 0,28780175 & 0,14682475 \\
\hline 0,00918125 & 0,36534625 & 0,00410950 & 0,51912625 & 0,54010750 \\
\hline 0,36112750 & 0,14690500 & 0,00410950 & 0,17224575 & 0,14687750 \\
\hline 0,30332250 & 0,01610425 & 0,00410950 & 0,17527300 & 0,67084000 \\
\hline 0,14731625 & 0,72823575 & 0,00410950 & 0,11484425 & 1,04366450 \\
\hline 0,03602300 & 0,63153875 & 1,36197125 & 0,38641725 & 0,09825400 \\
\hline 0,10278050 & 0,68818625 & 13,90809175 & 0,99551475 & 1,96584525 \\
\hline 0,09474050 & 0,57832200 & 8,42346150 & 0,41496850 & 0,40878625 \\
\hline 0,01983825 & 0,10642050 & 12,30244000 & 0,23909800 & 0,67085250 \\
\hline 0,07472300 & 0,06551825 & 0,36254500 & 0,33161575 & 2,22723500 \\
\hline 0,05337950 & 0,54058675 & 2,29553200 & 0,83362000 & 1,19521050 \\
\hline 0,01330200 & 0,52365050 & 0,21489700 & 0,29616200 & 0,67101375 \\
\hline 0,34041825 & 0,80249650 & 5,67915425 & 0,17545550 & 2,24374400 \\
\hline 0,14682800 & 0,75854525 & 13,29361950 & 0,45071125 & 1,62146575 \\
\hline 0,10310850 & 0,70934550 & 1,37016425 & 0,90200275 & 2,46694425 \\
\hline 0,13581600 & 0,27765875 & 0,69022075 & 0,75002500 & 0,03246550 \\
\hline 0,13581600 & 1,81951000 & 14,56343475 & 0,86882125 & 0,81447650 \\
\hline 0,06590550 & 0,13985550 & 11,81093275 & 0,11897625 & 0,14665250 \\
\hline 0,02044575 & 0,01542550 & 22,20839025 & 1,45000425 & 0,14652825 \\
\hline 0,02150850 & 0,31057400 & 14,78049600 & 0,17689575 & 0,10995150 \\
\hline 0,02150850 & 0,39286375 & 5,40673075 & 0,51671950 & 0,14665075 \\
\hline 0,23800425 & 0,34456775 & 14,64938875 & 0,51809875 & 0,16325550 \\
\hline 0,14656000 & 0,14702800 & 14,85009325 & 0,17796175 & 0,52426425 \\
\hline 0,17073450 & 0,27765625 & 15,08773275 & 0,05917825 & 0,14652550 \\
\hline 0,13072500 & 0,53990675 & 13,69703425 & 0,17792750 & 0,01567225 \\
\hline 0,01547100 & 0,01190800 & 8,22687850 & 0,36978425 & 0,00099100 \\
\hline
\end{tabular}

Tabela 10 - Valores de tempo para falha insegura das técnicas de programação defensiva: checksum e forward, diversidade e forward, forward, paridade e forward, duplicação de variáveis e forward 


\section{GLOSSÁRIO}

Bit-Flip: Termo em inglês atribuído ao efeito de se alterar o valor de um bit pelo seu complementar - de um para zero e de zero para um.

Códigos cíclicos: Em teoria da codificação, os códigos cíclicos são códigos de blocos lineares que possuem estruturas algébricas convenientes para a deteç̧ão e correção de erro.

Código convolucional: Código convolucional é um tipo de código corretor de erro em que cada conjunto de $m$ símbolos é transformado em um conjunto de $n$ símbolos, onde $n \geq m$.

Diafônia induzida: Tradução atribuída ao efeito crosstalk, fenômeno que produz interferência indesejável de um circuito eletrônico sobre outro, causado por meio de capacitância, indutância ou acoplamento condutivo (resistência) de um circuito para o outro.

Efeito spilling: O efeito spilling é basicamente a transferência (leitura e escrita) de valores de variáveis entre a memória e registradores. Esse efeito tem menor impacto sobre o desempenho do processador em casos em que o número de registradores é maior.

Elemento Latch: Elemento básico que permite armazenar um bit de informação. 
Mecanismos convolucionais de codificação: Tipo de ECC - Códigos de correção de Erro - em que cada conjunto de $m$ símbolos é transformado em um conjunto de $n$ símbolos, onde $\mathrm{n}>=\mathrm{m}$. São caracterizados pelo uso de elementos de memória. Assim os bits codificados dependem não só dos bits de informação como também da informação em memória. O processo de codificação convolucional é realizado passando a informação a transmitir por $\mathrm{K}$ registros deslizantes em que cada um contém $\mathrm{K}$ bits em que $\mathrm{n}$ equações algébricas geradoras, baseadas no polinômio gerador, descrevem a saída codificada.

Radar de abertura sintética: Os radares SAR (Sinthetic Aperture Radar) são tipicamente acoplados a uma aeronave ou a um satélite. Tais radares usam o movimento da aeronave, ou satélite, para simular uma antena com dimensões maiores. O movimento da antena permite que o radar faça leituras consecutivas de diversos pontos. O sinal recebido é então processado, gerando um resultado próximo ao que seria obtido caso fosse utilizada uma antena maior.

Redundância por verificação cíclica: é um código detector de erros que gera um valor expresso em poucos bits em função de um bloco maior de dados, como um pacote de dados, de forma a detectar erros de transmissão ou armazenamento. $\mathrm{O}$ CRC - Cyclic redundancy check - é calculado e anexado à informação a transmitir (ou armazenar) e verificada após a recepção ou acesso, para confirmar se não ocorreram alterações. 
Refetch seletivo: o termo refetch é associado ao processo de reforço dos dados em cachês que trabalham como SRAM. Tais memórias precisam constantemente ser recarregadas uma vez que são compostas por capacitores. O refetch seletivo leva em consideração a vulnerabilidade de regiões de memória a partir da frequência de utilização delas.

Registradores sombra: Registradores sombra são usados tipicamente em casos onde se pretende aumentar o desempenho em processos de interrupção. Durante a interrupção, se faz necessário que uma cópia dos registradores seja criada para ser posteriormente recuperada. Com o uso de registradores adicionais, evita-se o acesso à memória RAM, uma vez que a cópia do valor de cada registrador é armazenada em seu registrador sombra correspondente. 